\title{
Advancement of the Brown Norway rat as a model for food allergy : route of exposure - immunomodulation - allergogenomics
}

Citation for published version (APA):

de Jonge, J. D. (2009). Advancement of the Brown Norway rat as a model for food allergy : route of exposure - immunomodulation - allergogenomics. [Doctoral Thesis, Maastricht University]. Universiteit Maastricht. https://doi.org/10.26481/dis.20091127jj

Document status and date:

Published: 01/01/2009

DOI:

10.26481/dis.20091127jj

Document Version:

Publisher's PDF, also known as Version of record

\section{Please check the document version of this publication:}

- A submitted manuscript is the version of the article upon submission and before peer-review. There can be important differences between the submitted version and the official published version of record.

People interested in the research are advised to contact the author for the final version of the publication, or visit the DOI to the publisher's website.

- The final author version and the galley proof are versions of the publication after peer review.

- The final published version features the final layout of the paper including the volume, issue and page numbers.

Link to publication

\footnotetext{
General rights rights.

- You may freely distribute the URL identifying the publication in the public portal. please follow below link for the End User Agreement:

www.umlib.nl/taverne-license

Take down policy

If you believe that this document breaches copyright please contact us at:

repository@maastrichtuniversity.nl

providing details and we will investigate your claim.
}

Copyright and moral rights for the publications made accessible in the public portal are retained by the authors and/or other copyright owners and it is a condition of accessing publications that users recognise and abide by the legal requirements associated with these

- Users may download and print one copy of any publication from the public portal for the purpose of private study or research.

- You may not further distribute the material or use it for any profit-making activity or commercial gain

If the publication is distributed under the terms of Article $25 \mathrm{fa}$ of the Dutch Copyright Act, indicated by the "Taverne" license above, 
Advancement of the Brown Norway rat as a model for food allergy Route of exposure - Immunomodulation - Allergogenomics

Jonathan Dennis de Jonge 
C copyright Jonathan Dennis de Jonge, Maastricht 2009

$\begin{array}{ll}\text { Cover design and Artwork } & \text { J.D. de Jonge } \\ \text { Layout } & \text { J.D. de Jonge } \\ \text { Production } & \text { Datawyse Boekproducties, Maastricht }\end{array}$

Financial support for the publication of this thesis was provided by BioMedbooster

RIVM

Universiteitsfonds Limburg/SWOL 


\section{Advancement of the Brown Norway rat as a model for food allergy Route of exposure - Immunomodulation - Allergogenomics}

\section{PROEFSCHRIFT}

Ter verkrijging van de graad van doctor

Aan de Universiteit Maastricht,

Op gezag van de Rector Magnificus,

Prof. mr. G.P.M.F. Mols

volgens het besluit van het College van Decanen,

in het openbaar te verdedigen op

vrijdag 27 november 2009 om 10.00 uur

door

Jonathan Dennis de Jonge

27 februari 1979, Rotterdam (NL) 


\section{Promotores}

Prof. dr. H. van Loveren

\section{Copromotores}

Dr. L.M.J. Knippels (Danone)

Dr. J. Ezendam (RIVM)

\section{Beoordelingscommissie}

Prof. dr. W.A. Buurman (voorzitter)

Prof. dr. J. Garssen (UMC Utrecht)

Dr. D.M. Jonkers

Prof. dr. J.C.S. Kleinjans

Dr. H.P.J.M. Noteborn (VWA)

Prof. dr. P.W.J. Peters (UMC Utrecht) 


\section{Contents}

Chapter

Chapter 1

Chapter 2

Chapter 3

Chapter 4

Chapter 5

Chapter 6

Chapter 7

Dankwoord
Title

Page

General introduction

7

- Food Allergy

- Risk assessment in food allergy

- Factors influencing food allergy

- Immunomodulatory food components

- Animal models for food allergy

- Approaches for prediction of the allergenicity of novel foods

- Outline of this thesis

The importance of dietary control in the

33 development of a peanut allergy model in Brown Norway rats

Bis(tributyltin)oxide (TBTO) decreases the food 63 allergic response against peanut and ovalbumin in Brown Norway rats

Lactobacillus casei Shirota does not decrease the 83 food allergic response to peanut extract in Brown Norway rats

Gene expression changes in the mesenteric lymph nodes of rats after oral peanut extract exposure

Summary and general discussion

Samenvatting en algemene discussie

Curriculum vitae Including list of publications 



\section{Chapter 1 General introduction}

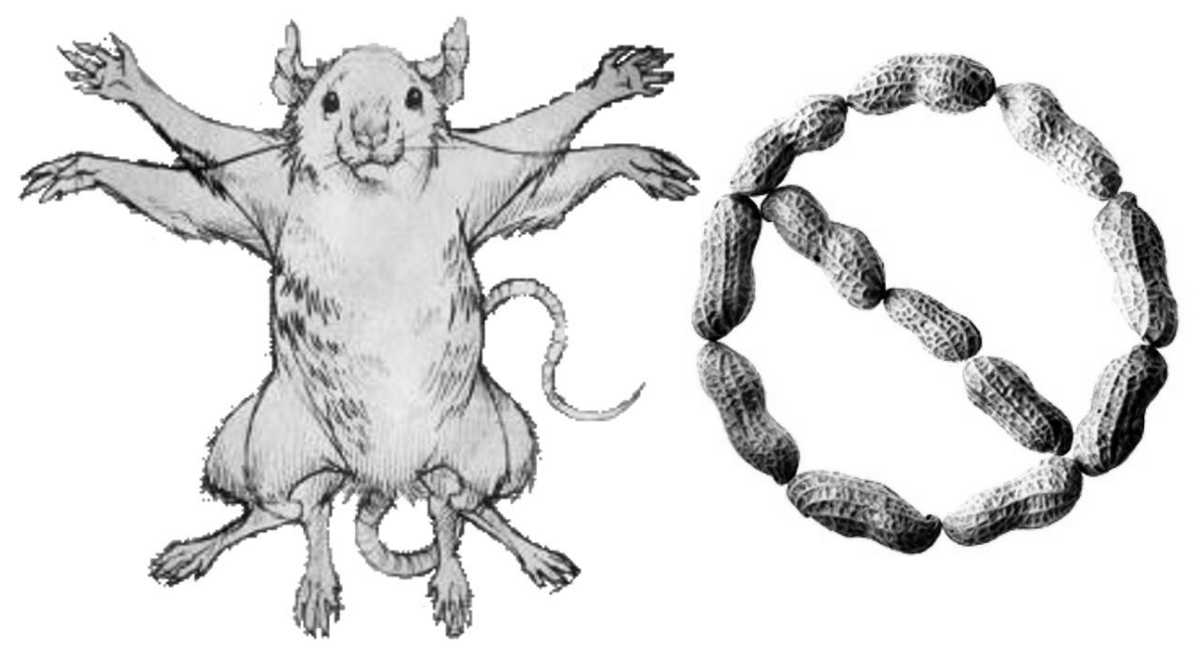

Part of this chapter will be published in Advanced Food Toxicology (de Jonge et al., 2009). 


\section{Preface}

The studies described in this thesis have been performed to gain more insight in the factors and mechanisms that determine the outcome of immune responses to orally administered food allergens.

More specifically, the aims of this thesis are:

Development of an oral sensitization model in the rat to investigate immune responses to the food allergen peanut as a model compound.

Comparing the effect of different routes of exposure to peanut on peanut specificallergen recognition patterns.

Investigating the influence of the probiotic Lactobacillus casei Shirota (LCS) in the rat peanut allergy model and comparing it's effect with the effects of immunotoxic (bis(tributyltin)oxide (TBTO)) and immunostimulating (cholera toxin (CT)) compounds.

Elucidation of changes at the gene expression level in the rat peanut allergy model

\section{Food allergy}

\subsection{Definitions}

Adverse reactions to food can either be of toxic or non-toxic nature (reviewed by Sampson (Sampson, 2003)). Toxic reactions are due to factors inherent to a food and will thus occur in any exposed individual given an appropriate dose. Non-toxic food reactions affect only those individuals that are susceptible and can be divided in non-immune-mediated (food intolerance) or immune-mediated (food allergy). Food intolerances are adverse physiologic responses caused by unique characteristics of the host, such as a direct pharmacologic effect of a chemical present in food (e.g. tyramine induced nausea, emesis, headache) or metabolic disorders (e.g. lactase or disaccharidase deficiency). Food allergy can be further classified into immunoglobulin E (IgE)-mediated and non-IgE-mediated reactions. Non-IgE-mediated reactions to food are caused by aberrant immune reactions to proteins in food without inducing IgE, e.g. celiac disease induced by gluten. IgE-mediated food allergy accounts for the majority of food allergic reactions and is characterized by the presence of antigen (Ag)-specific serum IgE antibodies. This chapter will only focus on IgE-mediated food allergy.

IgE-mediated food allergy is an adverse reaction to an otherwise harmless food or food component that involves an abnormal response of the immune system to specific protein(s) in foods. Food allergy can be caused by foods that are ingested; this is called class 1 food allergy. In addition, allergic responses to food can occur in 
individuals that are sensitized by allergens to which they are exposed via the respiratory tract, this is called class 2 food allergy. For example, in birch-pollen sensitized individuals allergic reactions can occur after ingestion of apple, pear, cherries and hazelnuts. Certain epitopes in these foods are structurally related to epitopes in birch-pollen.

\subsection{Clinical manifestations and diagnosis}

The clinical manifestations of food allergy can vary from mild to fatal anaphylactic reactions. Symptoms can manifest themselves in the oropharyngeal region (mouth itching, lip swelling), the gastrointestinal tract (nausea, vomiting, abdominal pain, diarrhea), skin (atopic dermatitis, urticaria, angioedema, contact dermatitis), the respiratory apparatus (wheeze, cough, asthma, stridor, rhinoconjunctivitis) and cardiovascular system (anaphylaxis caused by collapse due to hypotension).

One of the first steps in the diagnosis of food allergy is a medical history in order to find out if the complaints are associated with a certain food. It is not always possible to identify the implicated food. Sensitization to food allergens can be measured with a skin prick test or by measuring specific IgE in serum. Although those assays can confirm sensitization, they do not always predict clinical reactivity. Only approximately $50 \%$ of the sensitized individuals react with clinical symptoms. The double-blind, placebo-controlled food challenge (DBPCFC) remains the golden standard to confirm symptomatic food allergy (Sampson, 1999b). At present there is no therapy to treat food allergy and patients can only prevent allergic reactions by avoiding the consumption of the food responsible for the allergy.

\subsection{Prevalence of food allergy}

The prevalence of food allergy, in the Western world, is estimated to be $2-6 \%$ in infants, and $1-2 \%$ in adults as demonstrated by DBPCFC (Sampson, 2005). Approximately $80 \%$ of early childhood allergies to milk, egg, soy, and wheat usually resolve by school age (Wood, 2003). Although peanut, tree nut, and seafood allergies are generally considered permanent, $20 \%$ of young children with peanut allergy experience resolution by the age of 5 years (recurrence is also possible) (Fleischer et al., 2003).

In the Netherlands, anaphylactic reactions due to food are thought to be responsible for approximately 100-200 hospital admissions every year. Approximately one to at the most a few fatalities occur annually in the Netherlands (Health_Council_of_the_Netherlands, 2007). 


\subsection{Food allergens}

In infants, the most important allergens are milk, egg, peanut, soy and wheat. These allergens account for $90 \%$ of food allergic reactions in children, whereas peanut, tree nuts, fish and shellfish account for $85 \%$ of reactions in adults and adolescents (Sampson, 1992). Considering the wide variety of foods consumed in the average diet, it is remarkable that allergic responses occur to so few foods.

The major food allergens are glycoproteins, 10-70 kd in size, that are abundantly present in the allergic food. Furthermore, food allergens are generally water-soluble and fairly stable to heat, acid, and proteases (Sampson, 1999a). In addition, some physiochemical properties shared by many food allergens such as binding various types of ligands, glycolisation, interaction with lipid structures, and aggregation may additionally enhance stability and promote allergenicity (Breiteneder and Mills, 2005). Importantly, thermal processing as well as other processing events can alter the structure and characteristics of food proteins, causing either an increase or decrease in allergenicity (Maleki, 2004); peanut for example can loose allergenicity by cooking, while roasting can increase it's allergenicity.

Furthermore, the food matrix itself may play a role in the allergenicity of the food allergen. The presence of interactions between different compounds (proteins, lipids, carbohydrates and non-nutrients) may either affect the gut immune response or the digestion process. In general, allergenic foods contain high protein, high lipid, and low carbohydrate concentrations. The high protein content enhances the likelihood to be exposed to substantial amounts of allergenic protein. High levels of fat may be involved in protecting allergenic molecules during the digestive process and may act as immunostimulating agents (oil emulsions and other lipid structures are widely used as adjuvants). Furthermore, colocalized proteins such as certain phytochemicals or lectins, have been shown to act as immunostimulatory and Th2skewing proteins, respectively (Lehrer et al., 2002).

\subsection{Immunological mechanisms}

\subsubsection{Mucosal immune system}

The human gastrointestinal tract comprises of an enormous mucosal surface area (200-400 $\mathrm{m}^{2}$ ), which is exposed daily to vast amounts of food antigens, commensal bacteria and pathogens. The immune system of the intestine is constantly trying to avoid potentially harmful adverse responses to innocent food proteins and commensal flora, while effectively responding to microbes. In order to prevent infection by pathogens, the gut has several lines of defense. The first is called immune exclusion, which attempts to prevent passage of antigens. The mucosal barrier, formed by a single layer of gut epithelium, joined by tight junctions and covered by a mucus layer, is involved in this immune exclusion. Several factors help to strengthen the 
barrier, e.g. enzymes, bile salts and extremes of $\mathrm{pH}$. In addition, antibody-secreting B-cells play a key role in maintaining immunological silence. The most prominent antibody present at mucosal surfaces is $\lg A$; this secretory $\lg A$ serves as a first line of defense by inhibiting adhesion of microorganisms and by preventing absorption of intact proteins. Binding of serum IgA to antigens does not trigger inflammatory responses, thereby preventing the development of chronic intestinal inflammation (MacDonald, 2003).

The gut microflora also plays an important role in the prevention against pathogenic microbes. The numerous commensal bacteria protect the host against colonization of ingested bacteria by a phenomenon called colonization resistance. Several mechanisms are involved, including competition for substrates and adhesion sites (Vollaard and Clasener, 1994).

Despite the mucosal barrier, some proteins of either innocent or pathogenic origin can pass the epithelium and enter the body. These antigens are presented to the mucosal immune system: the gut associated lymphoid tissue (GALT). The GALT consists of immune structures that are involved in the induction of immune responses, the Peyer's Patches (PPs), the mesenteric lymph nodes (MLNs) and isolated immune cells (predominantly lymphocytes) scattered throughout the epithelium (intraepithelial lymphocytes) and lamina propria (LP) (Fig. 1). PPs are raised areas in the intestinal submucosa and consist of groups of large B-cell follicles and intervening Tcell areas. A single layer of columnar epithelial cells separates the lymphoid areas from the gut lumen. In this epithelial layer, microfold cells ( $M$ cells) are present, which are specialized enterocytes that are involved in the uptake of antigens. The MLNs are the largest lymph nodes in the body and drain the intestines. Within a few hours after feeding a protein, antigen recognition takes place in the MLNs and activation and division of active T-cells occurs predominantly in the MLN. Both the PPS and the MLN are involved in the induction phase of intestinal immune responses and are important sites for the priming of lymphocytes by antigen.

Besides PPs and MLNs the GALT consists of IgA-secreting plasma cells and $\mathrm{CD}^{+}$and $\mathrm{CD}^{+}$effector T-cells that are scattered through the lamina propria. Although heterogenous with regard to their phenotype and function, almost all T-cell populations in the lamina propria and overlying epithelium display characteristics of an effector/memory type. Together, these effector cells are the first line of defense cells to encounter invading pathogens. Furthermore, the GALT plays an important role in maintaining immunological tolerance against dietary proteins (MacDonald, 2003). Tolerance is a selective rather than an absolute phenomenon, therefore a more accurate description is immunological hypo-responsiveness. 


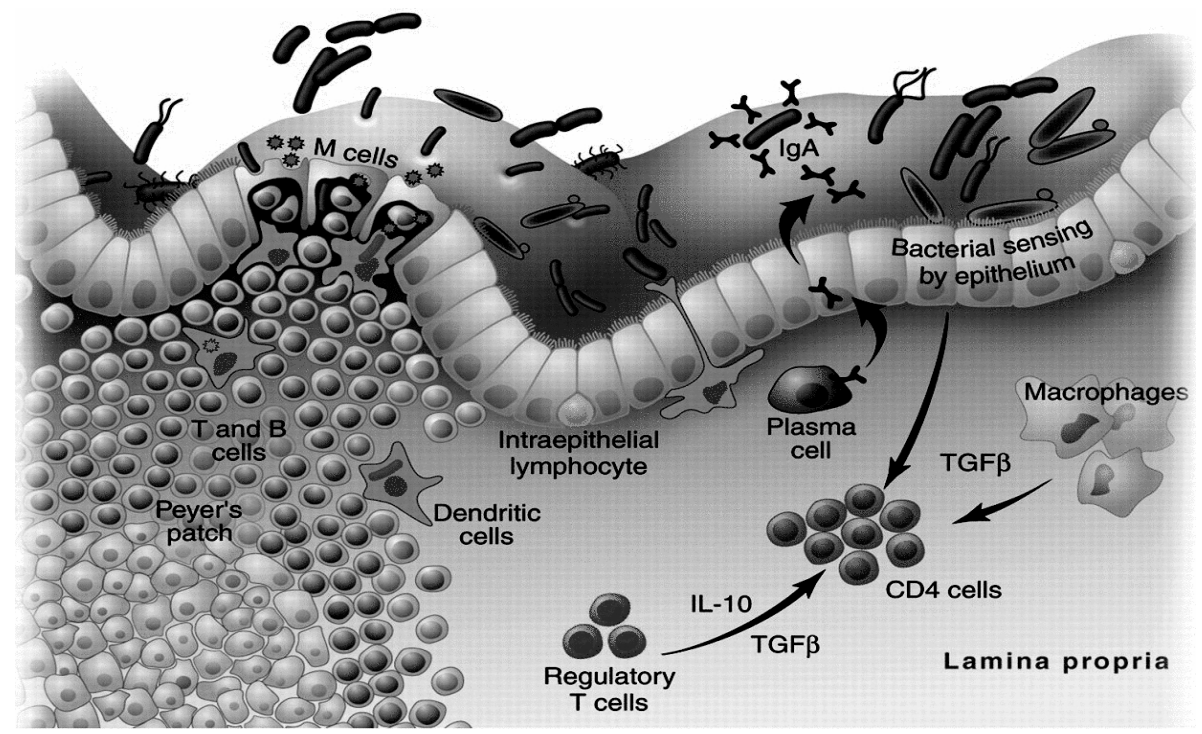

Figure 1. Mucosal immune system of the gut.

The epithelium overlying organized gut-associated lymphoid tissue (GALT) contains specialized microfold cells ( $M$ cells) that constantly transport gut bacteria and antigens from the gut lumen into the lymphoid tissue. Dendritic cells (DC) in the lamina propria (LP) reach through epithelial cells and also sample gut bacteria. The epithelium is filled with $C D 8^{+} T$ cells, and the LP contains many CD4 T cells, macrophages, and IgA antibody-producing plasma cells. Potentially tissue-damaging $T$ cell responses may be inhibited by immunosuppressive cytokines and regulatory T cells. From: (MacDonald and Monteleone, 2005). Reprint with permission of AAS.

\subsubsection{Sensitization and effector phase}

The normal response of the GALT to soluble dietary proteins is the induction of systemic hyporesponsiveness, also known as oral tolerance (Weiner, 2000). Oral tolerance is a state of active inhibition of immune responses to an ingested antigen. Similar suppressive responses are induced towards antigens from the commensal microbial flora. Several mechanisms by which oral tolerance may be mediated have been described, including T-cell deletion and T-cell anergy (a state of nonresponsiveness), and active suppression by regulatory $T$ cells (Tregs) (Chehade and Mayer, 2005). There is convincing evidence that a high dose of antigen induces clonal deletion and anergy, whereas multiple low-dose feeds are more likely to induce active suppression by Tregs (Friedman and Weiner, 1994). Three different subgroups of Tregs are described: Th3 cells, Tr1 cells and CD4+CD25+Foxp3+ T cells (Chehade and Mayer, 2005). Th3 and Tr1 cells regulate suppression mainly via production of the immunosuppressive cytokines, transforming growth factor- $\beta$ (TGF- $\beta$ ) and IL-10, respectively. CD4+CD25+ T Foxp3+ cells are naturally occurring Tregs which mediate suppression via cell surface bound TGF- $\beta$. Failure to induce oral tolerance or abrogation of oral tolerance may result in the development of food allergy. 
The IgE-dependent food allergic reaction is composed of two phases (Fig. 2); (I) sensitization, e.g. the initiation phase in which specific IgE anti-allergen antibodies are produced which are then fixed on mast cells in target organs; and (II) elicitation, e.g. the effector phase, in which the clinical symptoms develop after a second encounter with the allergen (Figure 2).

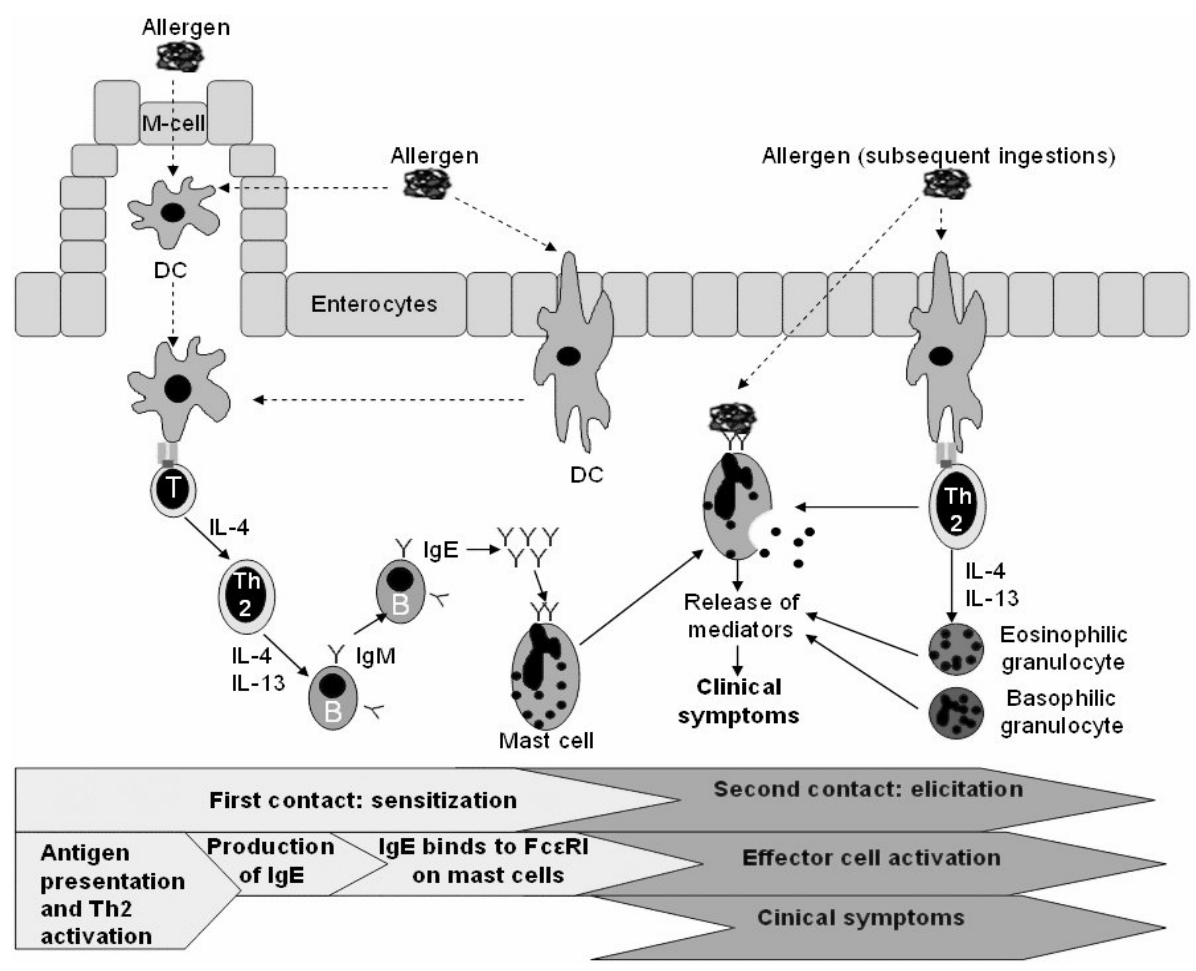

Figure 2. Schematical overview of cellular mechanisms of food allergic responses.

Food proteins are taken up via M-cells of the Peyer's Patches. After recognition and ingestion by DCs the protein is digested and presented to naïve $T$ cells in the mesenteric lymph nodes. Antigen-specific Th2 cells are generated and Th2-derived cytokines, such as IL-4 and IL-13 promote IgE production by B cells. Mast cells bind circulating IgE. Upon subsequent ingestion, antigenic fragments may interact directly with receptor-bound IgE on mast cells and cross-linking of receptors triggers the release of the preformed and newly formed inflammatory mediators responsible for clinical symptoms. Antigen-presentation may also lead to a rapid T-cell activation and the secretion of Th2 cytokines, triggering mediator release by basophilic and eosinophilic granulocytes.

In the sensitization phase, proteins are taken up via $\mathrm{M}$ cells of the PP. After ingestion, APCs process and digest the proteins and migrate to the MLNs, where they present parts of the protein (epitopes) on their major histocompatability complex class II (MHCII) molecules to resting immature T cells. This results in proliferation and activation of $T$ cells into mature effector and memory $T$ cells. $T$ cells can differ- 
entiate into type 1 (e.g. T helper (Th)1) or type 2 (Th2), dependent on the cytokine profile that is induced: interleukin (IL)-4 drives the maturation towards the Th2 direction, whereas interferon- $\gamma$ (IFN- $\gamma$ ) drives the maturation towards the Th1 direction. Typically, Th1 cells are involved in cellular immunity to fight viruses and other intracellular pathogens, eliminate cancerous cells, and stimulate delayed-type hypersensitivity skin reactions whereas Th2 initiate humoral immunity and up-regulate antibody production directed against extracellular organisms. Th2 cells are involved in the development of IgE producing B-cells. Release of cytokines including IL-4, IL-5, IL-10 and IL-13 induces an isotype switch in B cells to become IgE synthesizing plasma cells. In most persons the immunologic response to foreign proteins in food is that of the induction of oral tolerance. However, some proteins are able to breach the state known as oral tolerance, such proteins are allergens and can induce food allergic reactions in persons that are susceptible to such allergens. One of the alterations in the case of food allergy is that of reciprocal T(h)1-T(h)2 control of DCs' function within the inductive site of the gut immune system (Temblay et al., 2007), which results in altered antigen presentation in combination with Th2-prone immunological reactivity that will ultimately lead to the clinical symptoms as seen with food allergy.

In the sensitization phase, antigen-specific IgE binds to IgE receptors (Fc receptors) on the cell surface of the mast cells. Mast cells play a key role in the development of clinical symptoms that are elicited during renewed exposure to the food. In this elicitation phase, allergen-specific IgE becomes cross-linked on the surface of the mast cell, and this initiates intracellular signaling events that activate the cell. When activated, a mast cell rapidly releases its granules with preformed mediators such as histamine and various other mediators are synthesized and secreted (such as chemokines, cytokines, prostaglandins and leukotrienes) into the immediate extracellular environment. These mediators attract circulating basophils, eosinophils, neutrophils and Th2 lymphocytes to the site of mast cell activation, where they amplify the immune reaction and mediate the symptoms of food allergy.

\section{Risk assessment in food allergy}

In toxicology risk assessment is used to estimate the risk of adverse health effects from exposure of a population to a certain substance. In food allergy, this approach can be used to assess the risk from food allergens to allergic individuals (Crevel et al., 2007). For proper risk assessment, data on the amount of (hidden) allergens present in food products and the total intake of these products is necessary. However, at the moment it is unknown what kinds of foodstuffs allergic individuals consume. Risk assessment in food allergy is still in its infancy. However, data that is needed for this approach is emerging and this will lead to more insight in the risks of 
unintended contamination of allergens in foodstuffs. Valid information on the risks will lead to more awareness of the problems that food allergic individuals encounter and this will hopefully improve the labeling of products. In addition to the allergen, other factors have been shown to influence the induction of food allergy and as such might have an impact on risk assessment.

\section{Factors influencing food allergy}

Several factors that affect the development of IgE-mediated food allergy have been identified, the most important being genetic and environmental factors.

Genetic predisposition plays an important role in the development of allergic diseases. An atopic phenotype (e.g. predisposition to mount IgE responses per se) in one or both parents substantially increases the chances of atopy in the offspring. However, the majority of infants, even those genetically predisposed to atopy, are still spared from allergic diseases. Therefore, it is generally assumed that against a genetic background of increased susceptibility, environmental factors also affect the outcome of allergic disease. These factors include, among others, the age at which food antigen is introduced, formula versus breastfeeding, diet, composition of the gut microflora, gastrointestinal infection status and pre- and postnatal exposures such as smoking (Halken and Host, 2001).

One environmental factor that is thought to play an important role in allergic, but also other immune mediated disorders, is the change into a more hygienic lifestyle that has occurred in Westernized countries during the last decades. The so-called 'hygiene hypothesis' has been proposed about 19 years ago by Strachan (Strachan, 1989) to explain the rise in allergic diseases. The hygiene hypothesis is based on circumstantial evidence and there is a lot of debate on the underlying mechanisms that can explain the effects on the immune system. At the moment three different hypotheses exists, which will be shortly outlined. At first, it was proposed that a reduction in infections in early infancy predisposes to allergic responses. The immune response to microbial antigens is accompanied by preferential expression of Th1 cytokines that counterbalance the Th2-polarized cytokine production of neonates and protect against the development of allergy, which is predominantly a Th2 response (Shah and Walker, 2002). However, the Th1/Th2 paradigm of the original hygiene hypothesis cannot explain the rise in Th1-mediated diseases (e.g. multiple sclerosis, diabetes) in Westernized countries. The original Th1/Th2 hypothesis is being replaced by newer data which indicate that reduced microbial exposure, affects the maturation of the immune system, thereby reducing the development of immunoregulatory mechanisms, for instance the functioning of Tregs, which regulate both Th1 and Th2 mediated immune responses. An alternative interpretation of the hygiene hypothesis has been postulated recently, which suggests that perturba- 
tions in gut microflora composition early in life caused by lifestyle changes result in disruption of mechanisms that are involved in maintaining mucosal barrier function, immune regulation, and the development of tolerance (Halken and Host, 2001; Kalliomaki et al., 2001). The status of the microflora can have a strong influence on the development of food allergy, as for example investigated by the group of Bjorksten et al. (Bjorksten et al., 1999; Bjorksten et al., 2001). At the moment there is however no direct scientific evidence that microbial factors influence the prevalence of food allergy.

\section{Immunomodulatory food components}

\subsection{Immunomodulators}

The induction of food allergy is not only dependent on the allergen itself, other factors play a role as well (Ilback and Friman, 2007). Such factors include the food matrix in which the allergen is presented to the gastrointestinal immune system and also immunomodulatory food components.

The presence of immunomodulatory components that are present in food as additives or contaminants might also influence the food allergic response. In which way these immunomodulators affect food allergy is dependent on the type of immunomodulation they exert, e.g. immunosuppression or immunostimulation.

Immunosuppressants are capable of preventing or inhibiting immunological activity. Since the majority of immunosuppressants act non-selectively, the immune system loses or is hampered in its ability to successfully resist infections and spreading of malignant cells. Immunostimulators are capable of stimulating the immune system by either inducing activation or increasing activity of any of its components. There are two main categories of immunostimulators: (I) specific immunostimulators, which provide antigenic specificity in an immune response, such as vaccines or any antigen and (II) non-specific immunostimulators, which act irrespective of antigenic specifity to augment immune responses of other antigens or stimulate components of the immune system without antigenic specificity, such as adjuvants and nonspecific immunostimulators.

Immunomodulating agents can be present in the environment and/or (as contaminants of) our food, and those immunomodulators are therefore of particular importance in the case of food allergy. Diet is one of the major exogenous factors modulating individual immunocompetence (Albers et al., 2005). Examples of such immunomodulating food constituents are: probiotics (see chapter 3.4), prebiotics (Moro et al., 2006), polyunsaturaded fatty acids (Shaikh and Edidin, 2006), vitamin D (Kalueff and Tuohimaa, 2007) and CpG motifs in plant DNA (Wang et al., 2007). 
Examples of immunomodulating food contaminants are: polychlorinated biphenyls (PCBs) (Mori et al., 2008; Tryphonas et al., 1991), 2,3,7,8-Tetrachlorodibenzo-pdioxin (TCDD, or dioxin) and dioxin-like compounds (DLCS) (Yoshizawa et al., 2007), TBTO (see chapter 3.33), and CT (see chapter 3.2).

Our aim was to study effects of CT, TBTO and the probiotic strain LCS, on the food allergic response. These immunomodulatory compounds are chosen because they are all present in food as additives or contaminants and therefore of relevance for food allergic responses. In addition, one of the aims of this thesis is to investigate and position the effect of LCS on the food allergic respons and to compare this with two model compounds that are expected to suppress (TBTO) or stimulate (CT) food allergic response.

\subsection{Lactobacillus casei Shirota}

Probiotics are defined as 'live microorganisms which when administered in adequate amounts confer a health benefit on the host ' (FAO/WHO, 2001a, 2002; Kalliomaki and Isolauri, 2002; Tannock, 2004). Many of the probiotics that are currently used are lactobacilli or bifidobacteria, which are widely used in the production of fermented foods and beverages and contribute both to the sensory qualities of the food and to the prevention of spoilage. Moreover, they are present in large numbers in the normal human and animal gastrointestinal flora. In recent decades, much attention has been paid to the health-promoting (probiotic) properties of lactic acid bacteria. In order to exert health benefits, probiotic microorganisms not only should be capable of surviving passage through the digestive tract but also should have the capability to proliferate in the gut (FAO/WHO, 2001a). Another factor for proper and healthy functioning of the intestinal microflora is that the resulting intestinal microflora after probiotic intake should be balanced (homeostasis). Several probiotics have been shown to survive transit through the human gastrointestinal tract and to maintain a balanced intestinal microflora (FAO/WHO, 2001a; Tannock, 2004).

Lactobacillus casei strain Shirota (LCS) is contained in the commercial fermented milk product Yakult (Yakult Ltd., Tokyo, Japan) and is widely studied for its immune effects, especially in rodent models (Baken et al., 2006a; de Waard et al., 2002; de Waard et al., 2001; Ezendam and van Loveren, 2008; Matsuzaki and Chin, 2000; Matsuzaki et al., 1998; Sgouras et al., 2004; Yasui et al., 1999). One of the mechanisms by which LCS can influence the immune response is by stimulating Th1 responses (Kato et al., 1999; Shida et al., 2002). This could beneficially affect allergic (Th2-mediated) responses. Shida et al. (Shida et al., 2002) have shown that LcS reduced serum ovalbumin (OVA)-specific IgE and IgG1 responses and diminished systemic anaphylaxis in a mouse model for food allergy. In this model, LcS skewed the immune response towards Th1 immunity, thereby reducing the Th2-mediated allergic responses. In another study, LCS stimulated IFN- $\gamma$ production by mouse spleno- 
cytes in vivo and in vitro, possibly via macrophage-activation and IL-12 production and subsequent enhancement of Th1 cell functions (Kato et al., 1999). Effects of LCS have also been studied in a rat model for Th1-mediated autoimmunity (experimental autoimmune encephalomyelitis (EAE) and LCS aggravated clinical symptoms indicating that stimulation of Th1 immunity can also induce unwanted effects (Baken et al., 2006a; Ezendam and van Loveren, 2008). Taken together these data suggest that immunomodulatory effects of LcS can lead to both beneficial and adverse effects.

Besides stimulating Th1 immunity, other mechanisms are proposed to explain the beneficial effects of probiotics on allergic responses. These are summarized in Table 1. The precise mechanisms by which probiotics may influence allergic responses are still unknown and are highly strain-dependent. Data on efficacy in human studies are limited. Effects of LcS have been studied in humans, but these studies focused predominantly on natural killer (NK) cell activity (Nagao et al., 2000; Spanhaak et al., 1998; Takeda and Okumura, 2007). One randomized double-blind, placebocontrolled study assessed the effect of LCS in patients with allergic rhinitis directed against Japanese cedar pollen and found that LCS does not prevent allergic symptoms in patients sensitive to Japanese cedar pollen, but might delay the occurrence of allergic symptoms in moderate to severe patients (Tamura et al., 2007).

Table 1: Mechanisms by which probiotics could beneficially affect allergies

\begin{tabular}{|l|l|}
\hline Mechanism & References \\
\hline $\begin{array}{l}\text { Stabilizing intestinal barrier function, thereby also reducing } \\
\text { antigen load in the gut }\end{array}$ & $\begin{array}{l}\text { (Bongaerts and Severijnen, 2005; } \\
\text { Isolauri et al., 1993; Kalliomaki and } \\
\text { Isolauri, 2002; Rosenfeldt et al., 2004) }\end{array}$ \\
\hline Stimulation of IgA response & $\begin{array}{l}\text { (Malin et al., 1996; Marschan et al., } \\
\text { 2008; Rautava et al., 2006; Viljanen et } \\
\text { al., 2005) }\end{array}$ \\
\hline $\begin{array}{l}\text { Activation of immunomodulatory genes via Toll-like receptors } \\
\text { through two structural components of bacteria, the lipopoly- } \\
\text { saccharide portion of Gram-negative bacteria and specified } \\
\text { CpG motif in bacterial DNA }\end{array}$ & (Kalliomaki and Isolauri, 2002). \\
\hline Stimulation of IL-10 production & (Frossard et al., 2007) \\
\hline $\begin{array}{l}\text { Effect on DC maturation and differentiation } \\
\text { (Christensen et al., 2002; Niers et al., } \\
\text { 2007) }\end{array}$ \\
\hline $\begin{array}{l}\text { Th1-stimulating and Th2-inhibiting properties } \\
\text { Th1- and Th2-associated responses }\end{array}$ & (Kim et al., 2008; Shida et al., 2002) \\
\hline
\end{tabular}

Effects of probiotics on allergy in humans have been studied mostly in children suffering in atopic eczema. In addition, prevention of atopic diseases has been extensively studied in atopic children that received probiotics in the first period of their lives. Recently, a meta-analysis, including twelve randomized trials, has demon- 
strated that probiotics significantly reduce infant eczema. However, when the analysis was restricted to studies on IgE-dependent atopic eczema the reduction in eczema was no longer significant. In addition, it was shown that no benefits were reported for any other allergic disease or (food) hypersensitivity outcome (Osborn and Sinn, 2007). Savilathi et al. (Savilahti et al., 2008) recently reviewed the effect of pre- and probiotics on food allergy and concluded that recent studies using probiotics in the prevention and treatment of food allergy and other allergic diseases show at best a modest effect. Hence, effects of probiotics are mainly studied in infants with atopic eczema. To further explore the effects of probiotics on food allergic responses, we have studied the effects of LCS in the Brown Norway rat model for peanut allergy.

\subsection{Cholera toxin}

Cholera is the illness caused by eating food or drinking water that is contaminated with a bacterium called Vibrio Cholerae ( $V$. Cholerae). It infects people's intestines, causing diarrhea, vomiting and leg cramps.

$V$. Cholerae exports its major virulence factor, the enterotoxin cholera toxin (CT), from its periplasm into the lumen of the gastro-intestinal tract of the host (Abendroth et al., 2004). Here CT intrudes the mucosal layer of the intestines, leading to increased mucosal wall permeability, which results in a more efficient immune response if an allergen is applied as well (Kroghsbo et al., 2003). The result is an increased allergic response with lower dosage of the allergen needed. For this reason CT is often used as a mucosal adjuvant (Kaper et al., 1995; Keusch et al., 1967; Lange et al., 1998; Sack et al., 2004; Sasmal et al., 1995; Yardley and Brown, 1973). Furthermore, CT has been shown to stimulate strong responses to mucosally delivered antigens, by inducing an antigen-specific type 2 response (Bashir et al., 2002; Christensen et al., 2003; Helm et al., 2002; Li et al., 1999; Li et al., 2000; Li et al., 2001; Williams et al., 1999) or a mixed Th1 + Th2 response (Hornquist and Lycke, 1993; Marinaro et al., 1995), with a bias toward Th2 (Marinaro et al., 1995; Wilson et al., 1991; Xu-Amano et al., 1993). We included CT as an immunostimulating compound and investigated its effect on the food allergic response in our BN rat model of food allergy.

\subsection{Bis(tributyltin)oxide}

Organotin contamination of harbours and marinas has been a significant environmental concern, because they disrupt endocrine and reproductive functions and have immunotoxic properties at very low concentrations (Fent, 1996; Vos et al., 2000). Bis(tributyltin)oxide (TBTO; $\mathrm{C}_{24} \mathrm{H}_{54} \mathrm{OSn}_{2}$ ) is used as a biocidal preservative for wood, cotton textiles, paper and paints and stains for residential homes and is also 
added as an anti-fouling agent in numerous formulations of marine paints (WHO, 1999). As a result of its low water solubility and liphophilic character, tributyltin (TBT) adsorbs readily onto particles. Its half-life in the water column ranges from a few days to weeks and TBT may persist in sediments for several years (WHO, 1999). It bioaccumulates in organisms, with the highest concentrations found in liver and kidney (WHO, 1999).

TBTO is present as a contaminant in the food chain (Aluoch and Whalen, 2005; Ikeda et al., 2001; Sekizawa, 1998; WHO-IPCS, 1999). Uptake from food is more important than uptake directly from water (WHO, 1999). TBTO has been detected in human foods as well as in human blood (Aluoch and Whalen, 2005). Some studies have related human exposure to TBT to the dietary uptake of TBT in Japan (Ikeda et al., 2001; Sekizawa, 1998). No information is available on the toxicity of TBTO in humans following long-term exposure. Although some data and case reports indicate that TBTO is a severe dermal and respiratory irritant in humans, these data are not adequate to characterize the exposure-response relationships (WHO, 1999).

In several studies with laboratory animals, both short term and long term, it has been demonstrated that TBTO is an immunotoxic chemical (Aluoch and Whalen, 2005; Ikeda et al., 2001; Sekizawa, 1998; WHO-IPCS, 1999). Immunosuppression by TBTO in rats is characterized by a direct action of TBTO on cortical thymocytes, resulting in suppressed T-cell dependent immune responses. Vos et al. (Vos et al., 1984; Vos et al., 1990) found TBTO to reduce OVA-induced Delayed Type Hypersensitivity (DTH) reactions in rats. TBTO also decreased innate immune responses, such as Natural Killer (NK) cell (Aluoch and Whalen, 2005; Dudimah et al., 2006) and macrophage activity (Vandebriel et al., 1998; Vos et al., 1984). In host resistance models TBTO suppressed resistance to the infectious agents Listeria monocytogenes (Vos et al., 1990) and Trichinella (T.) spiralis (Vos et al., 1984). In the T. spiralis model TBTO suppressed serum T. Spiralis-specific IgE titres (Vos et al., 1984).

Food allergic processes are highly T-cell dependent, and regulation of T-cell responses play an important role in IgE-synthesis, further substantiating a possible effect of TBTO on food allergy. From its effects on specific IgE responses to parasites and its effect on T-cells, one may speculate that TBTO could also influence the food allergic reaction to food proteins, which is largely dependent on IgE responses. For this reason, research of the immunosuppressive effect of TBTO in our BN rat model for food allergy are included in the present studies.

\section{Animal models for food allergy}

In food allergy research, animal models are mainly being used for elucidating mechanisms. In the past decade, several food allergy models in rodents have been developed. It has been demonstrated that rodents can be sensitized to food proteins with or without the use of an adjuvant and that allergic responses upon re- 
exposure to the offending food reflected the human situation (Knippels et al., 1999; Li et al., 2000).

A validated animal model for food allergy should meet several criteria (Dearman and Kimber, 2009; Penninks and Knippels, 2001), which include the induction of allergic parameters that are clinically relevant for humans and of antibody responses that are directed to similar proteins/epitopes as found in patient sera. One important issue in the development of a food allergy model is the route of exposure. Sensitization can be induced either via intraperitoneal injection or oral exposure. The latter is preferred, because it involves the normal route of exposure in humans and several factors, such as gastro-intestinal acid denaturation, enzymatic digestion and mucosal/epithelial layers might influence the allergenicity of proteins. In addition, several animal models use adjuvants in order to achieve sensitization. The use of adjuvants is controversial, because it is not clear how adjuvants affect the immune response in the sensitization process and therefore it is impossible to determine the inherent potential of a given protein to induce allergic sensitization. A predictive model without adjuvant is therefore desirable, because it would reduce the risk of false positives.

A complete recapitulation of the human experience should not be the goal of animal model development. Rather, the objective is to provide a model that will provide useful and reliable information that when used in tandem with other relevant data will allow sound judgements to be made about the nature of likely hazards (Dearman and Kimber, 2009). For an animal model to be truly of value in this context there is a need to understand performance characteristics and to acknowledge limitations, particularly with respect to reliability under different circumstances.

Food allergy is a complex disease, with genetic predisposition, environmental factors and exposure conditions all contributing to inter-individual differences in susceptibility (Boulay et al., 2008; Kimber and Dearman, 2002). Another commonly held opinion is that the usefulness of animal models is limited due to the wide variation among different animal strains and species with respect to immune responsiveness to particular proteins (Goodman et al., 2005; Holt et al., 1981; McClain and Bannon, 2006; Spok et al., 2005; Vaz et al., 1971; Vaz et al., 1970). It is therefore very unlikely that a single method using experimental animals will be developed that is capable of predicting accurately all aspects of the likely prevalence, persistence and severity of food allergy among human populations exposed to a novel allergen in the diet. However, the first step of any safety assessment process is to identify accurately intrinsic hazard, or lack of it, and it is for this purpose that current approaches to the development of animal models of food allergy are directed (Dearman and Kimber, 2009). Once intrinsic hazard has been identified, the next steps in the risk assessment process are to determine the characteristics of that 
hazard and to define the likely conditions and extent of exposure, and on those bases assess likely risks to human health.

In conclusion, animal models for food allergy are useful to study mechanisms, but before these can be used as predictive models, a lot of validation studies remain to be done.

\section{Approaches for prediction of the allergenicity of novel foods}

Animal models can not only be used to investigate the influence of immunomodulatory food constituents or food contaminants on the food allergic response, they are also needed to solve many questions of a more mechanistic nature. Furthermore, a validated animal model for food allergy could be useful in the screening of novel foods for potential allergenicity. Novel foods are products that have never been used as food, and include foods that are modified by genetic manipulation. One of the major issues in the safety assessment of these genetically modified foods is the assessment of the potential allergenicity of the newly expressed proteins.

Theoretically there are three scenarios in which a novel protein may be a risk for allergenicity: identity/crossreactivity with a known allergen, the potential to increase the endogenous allergenicity of the target (commonly allergenic) food due to unintended effects on plant metabolism (that impact on the level of expression of endogenous allergens), or the novel protein may be a de novo allergen that has not previously been experienced by the

human population (Goodman et al., 2008; Lehrer and Bannon, 2005). It has been suggested that the primary risk is the introduction of a known allergen, or a crossreactive allergen, into a food crop. One example that is relevant to recall in this context is the halt of the development of a transgenic (genetically modified (GM)) soybean, when it was discovered that the methionine-rich Brazil nut protein introduced to improve the nutritional quality of the crop was an important allergen (Nordlee et al., 1996). In addition, animal models may also play a part in the assessment of foods modified for reduction of allergenicity (del Val et al., 1999; Niggemann et al., 2001) and in the characterization of the modulating effects of food processing and the influence of the food matrix on allergenic potential (Mills and Mackie, 2008; Orlandi et al., 2004; Rupa et al., 2007).

Therefore, approaches to assess the safety of novel foods have been formulated, such as the decision tree of the Food and Agriculture Organization and the World Health Organization (FAO/WHO) (FAO/WHO, 2001b). More recently, it has been suggested that instead of using a step-wise decision tree approach, more factors should be taken into account, especially since there is neither a single factor recognized as an identifier for protein allergenicity, nor a single test available to assess this. The weight of evidence approach, suggested by the Codex takes into account a 
variety of factors and approaches for an overall assessment of allergenic potential (CAC, 2003). This weight-of-evidence approach is summarized in Table 2.

The guidelines of the Codex will be briefly placed into context. Independent of the source, e.g. allergenic or non-allergenic, determination of amino acid sequence homology can be done by using several databases. However, it is important to realize that homology of 6-8 amino acids, might lead to many false-positves because not all sequence homologues will be clinically relevant (Ladics, 2008). Of greater scientific merit is consideration of the degree of identity over the length of the whole protein, with high identity matches with one or more known allergens (470\%) indicating a high potential for crossreactivity. Lower degrees of homology (435\%) will be associated with a lower potential for cross-reactivity (Goodman et al., 2005; Goodman et al., 2008). In addition, protein digestibility is used, since most food allergens are resistant to digestive degradation. Again, this endpoint has value in a weight of evidence approach but cannot be used as a standalone assay. For proteins from an allergenic source, assessment of binding to specific IgE present in sera from patients allergic to this specific protein can be used. In addition to these endpoints, Codex considers several other methods, including animal models, that might be useful. However, these approaches are only applicable when they are thoroughly evaluated or validated for predicting protein allergenicity (Ladics, 2008).

Table 2: Codex Guidance (2003)

\begin{tabular}{|c|c|}
\hline \multicolumn{2}{|c|}{$\begin{array}{l}\text { If protein is introduced from a non-allergenic source } \\
\text { - } \quad \text { Assess amino acid sequence similarity to known allergens } \\
\text { - } \quad \text { Assess in vitro pepsin resistance } \\
\text { If protein is introduced from an allergenic source } \\
\text { - } \quad \text { Assess amino acid sequence similarity to known allergens } \\
\text { - } \quad \text { Assess in vitro pepsin resistance } \\
\text { - } \quad \text { Assess specific lgE binding } \\
\text { - } \quad \text { Assess skin prick testing on appropriate individuals }\end{array}$} \\
\hline $\begin{array}{r}\text { Other conside } \\
-\quad \text { Ex } \\
\text { As } \\
\text { ○ } \\
\end{array}$ & $\begin{array}{l}\text { tions such as scientific knowledge and technology evolve } \\
\text { sure level of the introduced protein } \\
\text { lence and technology evolve other methods may be considered } \\
\text { Targeted serum screens } \\
\text { Animal models } \\
\text { Examination of newly expressed proteins for T-cell epitopes and structural motifs as- } \\
\text { sociated with allergens }\end{array}$ \\
\hline
\end{tabular}

Adapted from (Ladics, 2008).

Despite many efforts that have been made in the last years, the only approach that currently can be used is a weight of evidence approach. A validated and reliable animal model that can predict allergenicity of novel proteins would be very useful in this approach. In such a model, conventional parameters, e.g. measurement of 
allergen-specific IgE, release of mast cell mediators, cytokine respones, are normally used to study the food allergic response.

Additionally, studying transcriptome profiles could also proof to be useful in this area. Genomics is the study of an organism's entire genome. The publication of the sequence of the human genome has resulted in a dramatic increase in knowledge in the field of genomics (Gatzidou et al., 2007) and as a consequence, during the past two decades great advances have been achieved in molecular biology. One of the most recent techniques accountable for these advances is the microarray technique. DNA microarrays permit the quantitative measurement of the expression levels of thousands of individual genes in different biological samples at the same time. Another benefit of this technique is that it allows the investigation of early parameters of biological effect. Several studies have shown that it is possible to detect changes in the gene expression profile after exposure to immunomodulating agents, both in vivo (Ezendam et al., 2004) and in vitro (Schoeters et al., 2007). So far no studies have been performed that assessed the expression profile in food allergy.

Seen in this light, genomics might have the potential to advance our knowledge of food allergy. Allergogenomics would herein be defined as a form of analysis by which the activity of a particular allergen on living tissue can be identified upon a profiling of its known effect on genetic material. Our study was the first published that described the effect of food allergic sensitization on the level of gene expression profiles.

\section{Outline of this thesis}

In order to gain more insight in both the factors and the mechanisms that determine the outcome of immune responses to orally administered food allergens the studies described in this thesis have been performed.

Chapter 2 describes a rat model of peanut hypersensitivity in which peanutspecific responses are measured following oral exposure to the aqueous fraction of peanut. Data from this study compare the allergic response in an oral model for food allergy of animals that were bred and kept naïve for the allergen of interest with that of animals that were bred for multiple generations and kept naive for the allergen of interest as well as cross-reactive proteins. Furthermore, in this chapter effects of route of exposure and the mucosal adjuvant CT on the food allergic response are investigated.

In Chapter 3 the effect of the immunotoxic compound TBTO on the food allergic process against peanut or ovalbumin is investigated.

In the next part of the thesis the emphasis lies on the potential immunomodulating capacities of the probiotic LCS on the food allergic process. 
Chapter 4 investigates whether the probiotic LCS could influence the food allergic response against peanut, suppression of the Th2-dependent response and thus a reduced allergic response was expected.

One factor that was apparent in all the previous chapters is that in experimental models for food allergy parameters of multiple levels of the food allergic process should be investigated. One new tool that could play an important role is the microarray technique, which offers the possibility to look at thousands of genes similarly. Therefore, the emphasis of the last part of the thesis lies on food allergy on the gene expression level. Chapter 5 describes the effect of sensitization to the food allergen peanut on the level of gene expression as analyzed with the microarray technique.

Finally, the results and significance of our findings are discussed in Chapter 6.

\section{References}

Abendroth, J., Bagdasarian, M., Sandkvist, M., Hol, W.G., 2004, The structure of the cytoplasmic domain of EpsL, an inner membrane component of the type II secretion system of Vibrio cholerae: an unusual member of the actin-like ATPase superfamily. J Mol Biol 344, 619-633.

Albers, R., Antoine, J.M., Bourdet-Sicard, R., Calder, P.C., Gleeson, M., Lesourd, B., Samartin, S., Sanderson, I.R., Van Loo, J., Vas Dias, F.W., Watzl, B., 2005, Markers to measure immunomodulation in human nutrition intervention studies. Br J Nutr 94, 452-481.

Aluoch, A.O., Whalen, M.M., 2005, Effects of interleukins 2 and 12 on TBT-induced alterations of MAP kinases p38 and p44/42 in human natural killer cells. J Appl Toxicol.

Baken, K.A., Ezendam, J., Gremmer, E.R., de Klerk, A., Pennings, J.L., Matthee, B., Peijnenburg, A.A., van Loveren, H., 2006a, Evaluation of immunomodulation by Lactobacillus casei Shirota: Immune function, autoimmunity and gene expression. Int J Food Microbiol 112, 8-18.

Baken, K.A., van Loveren, H., Pennings, J.L.A., de Vries, A., Breit, T.M., van Steeg, H., 2006b, Gene Expression Profiling of Bis(tri-n-butyltin)oxide (TBTO)-Induced Immunotoxicity in Mice and Rats. Journal of Immunotoxicology 3, 227-244.

Baken, K.A., Vandebriel, R.J., Pennings, J.L., Kleinjans, J.C., van Loveren, H., 2007, Toxicogenomics in the assessment of immunotoxicity. Methods 41, 132-141.

Bashir, M.E., Andersen, P., Fuss, I.J., Shi, H.N., Nagler-Anderson, C., 2002, An enteric helminth infection protects against an allergic response to dietary antigen. J Immunol 169, 3284-3292.

Bjorksten, B., Naaber, P., Sepp, E., Mikelsaar, M., 1999, The intestinal microflora in allergic Estonian and Swedish 2-year-old children. Clin Exp Allergy 29, 342-346.

Bjorksten, B., Sepp, E., Julge, K., Voor, T., Mikelsaar, M., 2001, Allergy development and the intestinal microflora during the first year of life. J Allergy Clin Immunol 108, 516-520.

Bongaerts, G.P., Severijnen, R.S., 2005, Preventive and curative effects of probiotics in atopic patients. Med Hypotheses 64, 1089-1092.

Boulay, A., Houghton, J., Gancheva, V., Sterk, Y., Strada, A., Schlegel-Zawadzka, M., Sora, B., Sala, R., van Ree, R., Rowe, G., 2008, A EuroPrevall review of factors affecting incidence of peanut allergy: priorities for research and policy. Allergy 63, 797-809.

Breiteneder, H., Mills, E.N., 2005, Plant food allergens--structural and functional aspects of allergenicity. Biotechnol Adv 23, 395-399.

CAC, C.A.C., 2003, Alinorm 03/34: Joint FAO/WHO Food Standard Programme, Codex Alimentarius Commission, Twenty-Fifth Session, Rome, Italy, 30 June-5 July, 2003. Appendix III, Guideline for the conduct of food safety assessment of foods derived from recombinant-DNA plants, and Appendix IV, Annex on the assessment of possible allergenicity. 
Chehade, M., Mayer, L., 2005, Oral tolerance and its relation to food hypersensitivities. J Allergy Clin Immunol 115, 3-12; quiz 13.

Christensen, H.R., Frokiaer, H., Pestka, J.J., 2002, Lactobacilli differentially modulate expression of cytokines and maturation surface markers in murine dendritic cells. J Immunol 168, 171-178.

Christensen, H.R., Kjaer, T.M., Frokiaer, H., 2003, Low-dose oral tolerance due to antigen in the diet suppresses differentially the cholera toxin-adjuvantized IgE, IgA and IgG response. Int Arch Allergy Immunol. 132, 248-257.

Crevel, R.W., Briggs, D., Hefle, S.L., Knulst, A.C., Taylor, S.L., 2007, Hazard characterisation in food allergen risk assessment: the application of statistical approaches and the use of clinical data. Food Chem Toxicol 45, 691-701.

de Jonge, J.D., Ezendam, J., Van Loveren, H., 2009, Chapter 21: Food Allergy. In: Advanced Food Toxicology. Wageningen Academic Publishers, Wageningen, The Netherlands.

de Waard, R., Garssen, J., Bokken, G.C., Vos, J.G., 2002, Antagonistic activity of Lactobacillus casei strain shirota against gastrointestinal Listeria monocytogenes infection in rats. Int.J.Food Microbiol. 73, 93100.

de Waard, R., Garssen, J., Snel, J., Bokken, G.C., Sako, T., Veld, J.H., Vos, J.G., 2001, Enhanced antigenspecific delayed-type hypersensitivity and immunoglobulin $\mathrm{G} 2 \mathrm{~b}$ responses after oral administration of viable Lactobacillus casei YIT9029 in Wistar and Brown Norway rats. Clin Diagn Lab Immunol 8, 762-767.

Dearman, R.J., Kimber, I., 2009, Animal models of protein allergenicity: potential benefits, pitfalls and challenges. Clin Exp Allergy 39, 458-468.

del Val, G., Yee, B.C., Lozano, R.M., Buchanan, B.B., Ermel, R.W., Lee, Y.M., Frick, O.L., 1999, Thioredoxin treatment increases digestibility and lowers allergenicity of milk. J Allergy Clin Immunol 103, 690697.

Dudimah, F.D., Odman-Ghazi, S.O., Hatcher, F., Whalen, M.M., 2006, Effect of tributyltin (TBT) on ATP levels in human natural killer (NK) cells: Relationship to TBT-induced decreases in NK function. J Appl Toxicol.

Ezendam, J., Staedtler, F., Pennings, J., Vandebriel, R.J., Pieters, R., Harleman, J.H., Vos, J.G., 2004, Toxicogenomics of subchronic hexachlorobenzene exposure in Brown Norway rats. Environ Health Perspect 112, 782-791.

Ezendam, J., van Loveren, H., 2008, Lactobacillus casei Shirota administered during lactation increased the duration of autoimmunity in rats and enhanced lung inflammation in mice. BrJ Nutr 99, 83-90.

FAO/WHO, 2001a, Health and nutritional properties of probiotics in food including powder milk with live lactic acid bacteria, a joint FAO/WHO expert consultation. 1 - 4 October. Cordoba, Argentina, 2001. website: http://www.who.int/foodsafety/publications/fs_management/en/probiotics.pdf; visited December 2, 2004, 1-34.

FAO/WHO, 2002, Guidelines for the Evaluation of Probiotics in Food: Joint FAO/WHO Working Group meeting, London Ontario, Canada, 30 April-1 May 2002. website: http://www.who.int/foodsafety/fs_management/en/probiotic_guidelines.pdf; visited December 2, 2004, 1-11.

FAO/WHO, F.a.A.O.W.H.O., 2001b, FAO/WHO Expert Consultation on Foods Derived from Biotechnology. Evaluation of Allergenicity of Genetically Modified Foods. Rome: FAO.

Fent, K., 1996, Ecotoxicology of organotin compounds. Crit Rev Toxicol 26, 1-117.

Fleischer, D.M., Conover-Walker, M.K., Christie, L., Burks, A.W., Wood, R.A., 2003, The natural progression of peanut allergy: Resolution and the possibility of recurrence. J Allergy Clin Immunol 112, 183189.

Friedman, A., Weiner, H.L., 1994, Induction of anergy or active suppression following oral tolerance is determined by antigen dosage. Proc.Natl.Acad.Sci.U.S.A 91, 6688-6692.

Frossard, C.P., Steidler, L., Eigenmann, P.A., 2007, Oral administration of an IL-10-secreting Lactococcus lactis strain prevents food-induced IgE sensitization. J Allergy Clin Immunol 119, 952-959.

Gatzidou, E.T., Zira, A.N., Theocharis, S.E., 2007, Toxicogenomics: a pivotal piece in the puzzle of toxicological research. J Appl Toxicol 27, 302-309. 
Goodman, R.E., Hefle, S.L., Taylor, S.L., van Ree, R., 2005, Assessing genetically modified crops to minimize the risk of increased food allergy: a review. Int Arch Allergy Immunol 137, 153-166.

Goodman, R.E., Vieths, S., Sampson, H.A., Hill, D., Ebisawa, M., Taylor, S.L., van Ree, R., 2008, Allergenicity assessment of genetically modified crops--what makes sense? Nat Biotechnol 26, 73-81.

Halken, S., Host, A., 2001, Prevention. Curr Opin Allergy Clin Immunol 1, 229-236.

Health_Council_of_the_Netherlands, 2007, Food allergy. The Hague: Health council of the Netherlands publication no. 2007/07.

Helm, R.M., Furuta, G.T., Stanley, J.S., Ye, J., Cockrell, G., Connaughton, C., Simpson, P., Bannon, G.A., Burks, A.W., 2002, A neonatal swine model for peanut allergy. J Allergy Clin Immunol 109, 136-142.

Holt, P.G., Rose, A.H., Batty, J.E., Turner, K.J., 1981, Induction of adjuvant-independent IgE responses in inbred mice: primary, secondary, and persistent IgE responses to ovalbumin and ovomucoid. Int Arch Allergy Appl Immunol 65, 42-50.

Hornquist, E., Lycke, N., 1993, Cholera toxin adjuvant greatly promotes antigen priming of T cells. Eur J Immunol 23, 2136-2143.

Ikeda, M., Takatsuki, M., Yakabe, Y., Arimoto, Y., Fukuma, T., Higashikawa, K., 2001, Experiences on persistent organic pollutants under the Law concerning the Examination and Regulation of Manufacture, etc. of Chemical Substances, Japan, with references to biodegradation and bioaccumulation. Int Arch Occup Environ Health 74, 295-301.

Ilback, N.G., Friman, G., 2007, Interactions among infections, nutrients and xenobiotics. Crit Rev Food Sci Nutr 47, 499-519.

Isolauri, E., Majamaa, H., Arvola, T., Rantala, I., Virtanen, E., Arvilommi, H., 1993, Lactobacillus casei strain GG reverses increased intestinal permeability induced by cow milk in suckling rats. Gastroenterology 105, 1643-1650.

Kalliomaki, M., Isolauri, E., 2002, Pandemic of atopic diseases--a lack of microbial exposure in early infancy? Curr Drug Targets Infect Disord 2, 193-199.

Kalliomaki, M., Salminen, S., Arvilommi, H., Kero, P., Koskinen, P., Isolauri, E., 2001, Probiotics in primary prevention of atopic disease: a randomised placebo-controlled trial. Lancet 357, 1076-1079.

Kalueff, A.V., Tuohimaa, P., 2007, Neurosteroid hormone vitamin D and its utility in clinical nutrition. Curr Opin Clin Nutr Metab Care 10, 12-19.

Kaper, J.B., Morris, J.G.J., Levine, M.M., 1995, Cholera. Clin Microbiol Rev 8, 48-86.

Kato, I., Tanaka, K., Yokokura, T., 1999, Lactic acid bacterium potently induces the production of interleukin-12 and interferon-gamma by mouse splenocytes. Int J Immunopharmacol 21, 121-131.

Keusch, G.T., Atthasampunna, P., Finkelstein, R.A., 1967, A vascular permeability defect in experimental cholera. Proc Soc Exp Biol Med 124, 822-825.

Kim, J.Y., Choi, Y.O., Ji, G.E., 2008, Effect of Oral Probiotics (Bifidobacterium lactis AD011 and Lactobacillus acidophilus AD031) Administration on Ovalbumin-Induced Food Allergy Mouse Model. J Microbiol Biotechnol 18, 1393-1400.

Kimber, I., Dearman, R.J., 2002, Factors affecting the development of food allergy. Proc.Nutr.Soc. 61, 435439.

Knippels, L.M., Penninks, A.H., Smit, J.J., Houben, G.F., 1999, Immune-mediated effects upon oral challenge of ovalbumin-sensitized Brown Norway rats: further characterization of a rat food allergy model. Toxicol. Appl. Pharmacol. 156, 161-169.

Kroghsbo, S., Christensen, H.R., Frokiaer, H., 2003, Experimental parameters differentially affect the humoral response of the cholera-toxin-based murine model of food allergy. Int.Arch.Allergy Immunol. 131, 256-263.

Ladics, G.S., 2008, Current codex guidelines for assessment of potential protein allergenicity. Food Chem Toxicol 46, S20-S23.

Lange, S., Delbro, D.S., Jennische, E., Johansson, E., Lonnroth, I., 1998, Recombinant or plasma-derived antisecretory factor inhibits cholera toxin-induced increase in Evans blue permeation of rat intestinal capillaries. Dig Dis Sci 43, 2061-2070. 
Lehrer, S.B., Ayuso, R., Reese, G., 2002, Current understanding of food allergens. Ann N Y Acad Sci 964, 69-85.

Lehrer, S.B., Bannon, G.A., 2005, Risks of allergic reactions to biotech proteins in foods: perception and reality. Allergy 60, 559-564.

Li, X.M., Schofield, B.H., Huang, C.K., Kleiner, G.I., Sampson, H.A., 1999, A murine model of IgE-mediated cow's milk hypersensitivity. J Allergy Clin Immunol 103, 206-214.

Li, X.M., Serebrisky, D., Lee, S.Y., Huang, C.K., Bardina, L., Schofield, B.H., Stanley, J.S., Burks, A.W., Bannon, G.A., Sampson, H.A., 2000, A murine model of peanut anaphylaxis: T- and B-cell responses to a major peanut allergen mimic human responses. J Allergy Clin Immunol 106, 150-158.

Li, X.M., Zhang, T.F., Huang, C.K., Srivastava, K., Teper, A.A., Zhang, L., Schofield, B.H., Sampson, H.A., 2001, Food Allergy Herbal Formula-1 (FAHF-1) blocks peanut-induced anaphylaxis in a murine model. J Allergy Clin Immunoll 108, 639-646.

MacDonald, Monteleone, 2005, Fig 1. SCIENCE 307, 1920.

MacDonald, T.T., 2003, The mucosal immune system. Parasite Immunol 25, 235-246.

Maleki, S.J., 2004, Food processing: effects on allergenicity. Curr Opin Allergy Clin Immunol 4, 241-245.

Malin, M., Suomalainen, H., Saxelin, M., Isolauri, E., 1996, Promotion of IgA immune response in patients with Crohn's disease by oral bacteriotherapy with Lactobacillus GG. Ann Nutr Metab 40, 137-145.

Marinaro, M., Staats, H.F., Hiroi, T., Jackson, R.J., Coste, M., Boyaka, P.N., Okahashi, N., Yamamoto, M., Kiyono, H., Bluethmann, H., al., e., 1995, Mucosal adjuvant effect of cholera toxin in mice results from induction of T helper 2 (Th2) cells and IL-4. J Immunol 155, 4621-4629.

Marschan, E., Kuitunen, M., Kukkonen, K., Poussa, T., Sarnesto, A., Haahtela, T., Korpela, R., Savilahti, E., Vaarala, O., 2008, Probiotics in infancy induce protective immune profiles that are characteristic for chronic low-grade inflammation. Clin Exp Allergy 38, 611-618.

Matsuzaki, T., Chin, J., 2000, Modulating immune responses with probiotic bacteria. Immunol.Cell Biol. 78, 67-73.

Matsuzaki, T., Yamazaki, R., Hashimoto, S., Yokokura, T., 1998, The effect of oral feeding of Lactobacillus casei strain Shirota on immunoglobulin E production in mice. J Dairy Sci. 81, 48-53.

McClain, S., Bannon, G.A., 2006, Animal models of food allergy: opportunities and barriers. Curr Allergy Asthma Rep 6, 141-144.

Mills, E.N., Mackie, A.R., 2008, The impact of processing on allergenicity of food. Curr Opin Allergy Clin Immunol 8, 249-253.

Mori, C., Morsey, B., Levin, M., Gorton, T.S., De Guise, S., 2008, Effects of organochlorines, individually and in mixtures, on B-cell proliferation in marine mammals and mice. J Toxicol Environ Health A 71, 266-275.

Moro, G., Arslanoglu, S., Stahl, B., Jelinek, J., Wahn, U., Boehm, G., 2006, A mixture of prebiotic oligosaccharides reduces the incidence of atopic dermatitis during the first six months of age. Arch Dis Child 91, 814-819.

Nagao, F., Nakayama, M., Muto, T., Okumura, K., 2000, Effects of a fermented milk drink containing Lactobacillus casei strain Shirota on the immune system in healthy human subjects. Biosci Biotechnol Biochem 64, 2706-2708.

Niers, L.E., Hoekstra, M.O., Timmerman, H.M., van Uden, N.O., de Graaf, P.M., Smits, H.H., Kimpen, J.L., Rijkers, G.T., 2007, Selection of probiotic bacteria for prevention of allergic diseases: immunomodulation of neonatal dendritic cells. Clin Exp Immunol 149, 344-352.

Niggemann, B., Nies, H., Renz, H., Herz, U., Wahn, U., 2001, Sensitizing capacity and residual allergenicity of hydrolyzed cow's milk formulae: results from a murine model. Int Arch Allergy Immunol 125, 316321.

Nordlee, J.A., Taylor, S.L., Townsend, J.A., Thomas, L.A., Bush, R.K., 1996, Identification of a Brazil-nut allergen in transgenic soybeans. N Engl J Med 334, 688-692.

Orlandi, A., Grasso, F., Corinti, S., Marinaro, M., Bonura, A., Boirivant, M., Colombo, P., Di Felice, G., 2004, The recombinant major allergen of Parietaria judaica and its hypoallergenic variant: in vivo evaluation in a murine model of allergic sensitization. Clin Exp Allergy 34, 470-477. 
Osborn, D.A., Sinn, J.K., 2007, Probiotics in infants for prevention of allergic disease and food hypersensitivity. Cochrane Database Syst Rev, CD006475.

Penninks, A.H., Knippels, L.M., 2001, Determination of protein allergenicity: studies in rats. Toxicol.Lett. 120, 171-180.

Prioult, G., Pecquet, S., Fliss, I., 2004, Stimulation of interleukin-10 production by acidic betalactoglobulin-derived peptides hydrolyzed with Lactobacillus paracasei NCC2461 peptidases. Clin Diagn Lab Immunol 11, 266-271.

Rautava, S., Arvilommi, H., Isolauri, E., 2006, Specific probiotics in enhancing maturation of IgA responses in formula-fed infants. Pediatr Res 60, 221-224.

Rook, G.A., Adams, V., Hunt, J., Palmer, R., Martinelli, R., Brunet, L.R., 2004, Mycobacteria and other environmental organisms as immunomodulators for immunoregulatory disorders. Springer Semin Immunopathol 25, 237-255.

Rosenfeldt, V., Benfeldt, E., Valerius, N.H., Paerregaard, A., Michaelsen, K.F., 2004, Effect of probiotics on gastrointestinal symptoms and small intestinal permeability in children with atopic dermatitis. J Pediatr 145, 612-616.

Rupa, P., Nakamura, S., Mine, Y., 2007, Genetically glycosylated ovomucoid third domain can modulate Immunoglobulin E antibody production and cytokine response in BALB/c mice. Clin Exp Allergy 37, 918-928.

Sack, D.A., Sack, R.B., Nair, G.B., Siddique, A.K., 2004, Cholera. Lancet 363, 223-233.

Salminen, S., Isolauri, E., Salminen, E., 1996, Clinical uses of probiotics for stabilizing the gut mucosal barrier: successful strains and future challenges. Antonie Van Leeuwenhoek 70, 347-358.

Sampson, H.A., 1992, The immunopathogenic role of food hypersensitivity in atopic dermatitis. Acta Derm Venereol Suppl (Stockh) 176, 34-37.

Sampson, H.A., 1999a, Food allergy. Part 1: immunopathogenesis and clinical disorders. J Allergy Clin Immunol 103, 717-728.

Sampson, H.A., 1999b, Food allergy. Part 2: diagnosis and management. J Allergy Clin Immunol 103, 981989.

Sampson, H.A., 2003, 9. Food allergy. J.Allergy Clin.Immunol. 111, 540-547.

Sampson, H.A., 2005, Food allergy--accurately identifying clinical reactivity. Allergy 60 Suppl 79, 19-24.

Sasmal, D., Guhathakurta, B., Ghosh, A.N., Pal, C.R., Datta, A., 1995, Studies on adhesion, haemagglutination and other biological properties of Vibrio cholerae O139. FEMS Immunol Med Microbiol 10, 199205.

Savilahti, E., Kuitunen, M., Vaarala, O., 2008, Pre and probiotics in the prevention and treatment of food allergy. Curr Opin Allergy Clin Immunol 8, 243-248.

Schoeters, E., Verheyen, G.R., Nelissen, I., Van Rompay, A.R., Hooyberghs, J., Van Den Heuvel, R.L., Witters, H., Schoeters, G.E., Van Tendeloo, V.F., Berneman, Z.N., 2007, Microarray analyses in dendritic cells reveal potential biomarkers for chemical-induced skin sensitization. Mol Immunol.

Sekizawa, J., 1998, [Health and environmental risk assessment of organotin pollution in Japan] [Article in Japanese]. Kokuritsu lyakuhin Shokuhin Eisei Kenkyusho Hokoku, 126-131.

Sgouras, D., Maragkoudakis, P., Petraki, K., Martinez-Gonzalez, B., Eriotou, E., Michopoulos, S., Kalantzopoulos, G., Tsakalidou, E., Mentis, A., 2004, In vitro and in vivo inhibition of Helicobacter pylori by Lactobacillus casei strain Shirota. Appl Environ Microbiol 70, 518-526.

Shah, U., Walker, W.A., 2002, Pathophysiology of intestinal food allergy. Adv Pediatr 49, 299-316.

Shaikh, S.R., Edidin, M., 2006, Polyunsaturated fatty acids, membrane organization, T cells, and antigen presentation. Am J Clin Nutr 84, 1277-1289.

Shida, K., Takahashi, R., Iwadate, E., Takamizawa, K., Yasui, H., Sato, T., Habu, S., Hachimura, S., Kaminogawa, S., 2002, Lactobacillus casei strain Shirota suppresses serum immunoglobulin $E$ and immunoglobulin G1 responses and systemic anaphylaxis in a food allergy model. Clin Exp Allergy 32, 563570 . 
Spanhaak, S., Havenaar, R., Schaafsma, G., 1998, The effect of consumption of milk fermented by Lactobacillus casei strain Shirota on the intestinal microflora and immune parameters in humans. Eur J Clin Nutr 52, 899-907.

Spok, A., Gaugitsch, H., Laffer, S., Pauli, G., Saito, H., Sampson, H., Sibanda, E., Thomas, W., van Hage, M., Valenta, R., 2005, Suggestions for the assessment of the allergenic potential of genetically modified organisms. Int Arch Allergy Immunol. 137, 167-180.

Strachan, D.P., 1989, Hay fever, hygiene, and household size. BMJ 299, 1259-1260.

Takeda, K., Okumura, K., 2007, Effects of a fermented milk drink containing Lactobacillus casei strain Shirota on the human NK-cell activity. J Nutr 137, 791S-793S.

Tamura, M., Shikina, T., Morihana, T., Hayama, M., Kajimoto, O., Sakamoto, A., Kajimoto, Y., Watanabe, O., Nonaka, C., Shida, K., Nanno, M., 2007, Effects of probiotics on allergic rhinitis induced by Japanese cedar pollen: randomized double-blind, placebo-controlled clinical trial. Int Arch Allergy Immunol 143, 75-82.

Tannock, G.W., 2004, A special fondness for lactobacilli. Appl Environ Microbiol 70, 3189-3194.

Temblay, J.N., Bertelli, E., Arques, J.L., Regoli, M., Nicoletti, C., 2007, Production of IL-12 by Peyer patchdendritic cells is critical for the resistance to food allergy. J Allergy Clin Immunol 120, 659-665.

Tryphonas, H., Luster, M.I., Schiffman, G., Dawson, L.L., Hodgen, M., Germolec, D., Hayward, S., Bryce, F., Loo, J.C., Mandy, F., et al., 1991, Effect of chronic exposure of PCB (Aroclor 1254) on specific and nonspecific immune parameters in the rhesus (Macaca mulatta) monkey. Fundam Appl Toxicol 16, 773-786.

Vandebriel, R.J., Meredith, C., Scott, M.P., Roholl, P.J., Van Loveren, H., 1998, Effects of in vivo exposure to bis(tri-n-butyltin)oxide, hexachlorobenzene, and benzo(a)pyrene on cytokine (receptor) mRNA levels in cultured rat splenocytes and on IL-2 receptor protein levels. Toxicol Appl Pharmacol 148, 126-136.

Vaz, N.M., Phillips-Quagliata, J.M., Levine, B.B., Vaz, E.M., 1971, H-2-linked genetic control of immune responsiveness to ovalbumin and ovomucoid. J Exp Med 134, 1335-1348.

Vaz, N.M., Vaz, E.M., Levine, B.B., 1970, Relationship between histocompatibility (H-2) genotype and immune responsiveness to low doses of ovalbumin in the mouse. J Immunol 104, 1572-1574.

Viljanen, M., Kuitunen, M., Haahtela, T., Juntunen-Backman, K., Korpela, R., Savilahti, E., 2005, Probiotic effects on faecal inflammatory markers and on faecal IgA in food allergic atopic eczema/dermatitis syndrome infants. Pediatr Allergy Immunol 16, 65-71.

Vollaard, E.J., Clasener, H.A., 1994, Colonization resistance. Antimicrob Agents Chemother 38, 409-414.

Vos, J.G., de Klerk, A., Krajnc, E.I., Kruizinga, W., van Ommen, B., Rozing, J., 1984, Toxicity of bis(tri-nbutyltin)oxide in the rat. II. Suppression of thymus-dependent immune responses and of parameters of nonspecific resistance after short-term exposure. Toxicol Appl Pharmacol 75, 387-408.

Vos, J.G., De Klerk, A., Krajnc, E.I., Van Loveren, H., Rozing, J., 1990, Immunotoxicity of bis(tri-nbutyltin)oxide in the rat: effects on thymus-dependent immunity and on nonspecific resistance following long-term exposure in young versus aged rats. Toxicol Appl Pharmacol 105(144-155.

Vos, J.G., Dybing, E., Greim, H.A., Ladefoged, O., Lambre, C., Tarazona, J.V., Brandt, I., Vethaak, A.D., 2000, Health effects of endocrine-disrupting chemicals on wildlife, with special reference to the European situation. Crit Rev Toxicol 30, 71-133.

Wang, Y., Zhou, J., Liu, B., 2007, Decreased suppression of immune stimulatory CpG motifs in plant DNA. Immunol Lett 114, 73-80.

Weiner, H.L., 2000, Oral tolerance, an active immunologic process mediated by multiple mechanisms. J Clin Invest 106, 935-937.

WHO, 1999, Concise International Chemical Assesment Document 14: Tributyltinoxide. website: http://www.who.int/ipcs/publications/cicad/en/cicad14.pdf; visited at December 7, 2004 Geneva 1999, Switzerland, 1-29.

WHO-IPCS, 1999, Concise International Chemical Assesment Document 14: Tributyltinoxide. website: http://www.who.int/ipcs/publications/cicad/en/cicad14.pdf; visited at December 7, 2004 Geneva 1999, Switzerland, 1-29. 
Williams, N.A., Hirst, T.R., Nashar, T.O., 1999, Immune modulation by the cholera-like enterotoxins: from adjuvant to therapeutic. Immunol Today 20, 95-101.

Wilson, A.D., Bailey, M., Williams, N.A., Stokes, C.R., 1991, The in vitro production of cytokines by mucosal lymphocytes immunized by oral administration of keyhole limpet hemocyanin using cholera toxin as an adjuvant. Eur J Immunol 21, 2333-2339.

Wood, R.A., 2003, The natural history of food allergy. Pediatrics 111, 1631-1637.

Xu-Amano, J., Kiyono, H., Jackson, R.J., Staats, H.F., Fujihashi, K., Burrows, P.D., Elson, C.O., Pillai, S., McGhee, J.R., 1993, Helper T cell subsets for immunoglobulin A responses: oral immunization with tetanus toxoid and cholera toxin as adjuvant selectively induces Th2 cells in mucosa associated tissues. J Exp Med 178, 1309-1320.

Yardley, J.H., Brown, G.D., 1973, Horseradish peroxidase tracer studies in the intestine in experimental cholera. Lab Invest 28, 482-493.

Yasui, H., Shida, K., Matsuzaki, T., Yokokura, T., 1999, Immunomodulatory function of lactic acid bacteria. Antonie Van Leeuwenhoek 76, 383-389.

Yoshizawa, K., Heatherly, A., Malarkey, D.E., Walker, N.J., Nyska, A., 2007, A Critical Comparison of Murine Pathology and Epidemiological Data of TCDD, PCB126, and PeCDF. Toxicol Pathol 35, 865-879. 



\section{Chapter 2}

\section{The importance of dietary control in the development of a peanut allergy model in Brown Norway rats}

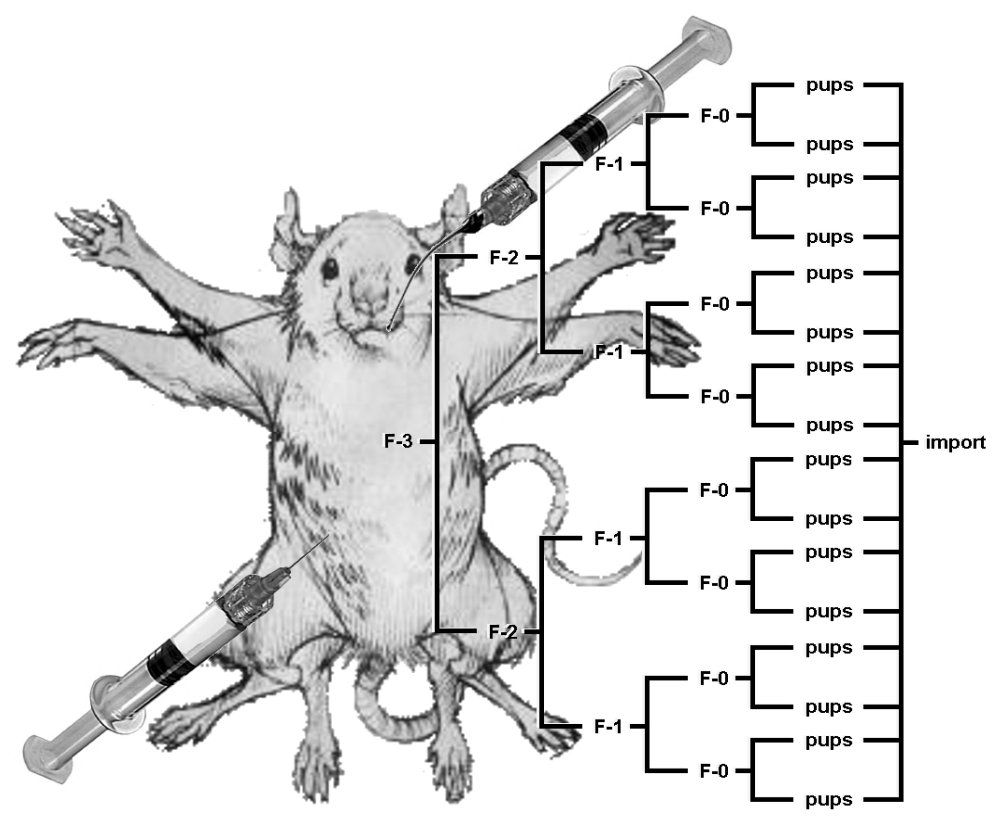

Published in Methods 41, 99-111 (2007). 


\section{ABSTRACT}

This report describes the further development of a peanut allergy model in Brown Norway (BN) rats and in particular the importance of allergen-free breeding of the laboratory animals for the allergen to be used. For this purpose $\mathrm{BN}$ rats were bred for 3 generations on soy- and peanut-free feed since it is known that the legumes peanut and soy are cross-reactive. In addition, the effect of cholera toxin (CT), an oral adjuvant often used to increase the sensitivity of food allergy models, was investigated in the $\mathrm{BN}$ rat model. $\mathrm{BN}$ rats that were bred on both soy- and peanut-free feed could be sensitized orally to peanut (all exposed rats developed peanut-specific IgE, IgG2a and IgG1) and the adjuvant CT could only enhance this sensitization to a limited extent. We also found different protein recognition patterns against purified peanut allergens (Ara h1, Ara h2 and Ara h3) between intraperitoneally (i.p.) and orally sensitized $\mathrm{BN}$ rats. Orally sensitized rats recognized all tested allergens whereas i.p. sensitized rats only recognized Ara $h 1$ and Ara h2. Our conclusion is that a model for food allergy should preferably be (A) oral and (B) if possible without the use of adjuvantia. Our model in BN rats unites these preferred characteristics. In addition, we show the importance of dietary control when conducting oral sensitization studies. Special attention must be paid to unscheduled dietary preexposure of the animals to the protein under investigation to obtain optimal oral sensitization.

\section{INTRODUCTION}

The incidence of adult food allergy is estimated at approximately $3 \%$, but in young children it is thought to be as high as 6\% [1]. Although food allergic children often outgrow their food allergy, once established in adults food allergy is rarely cured [2]. There are indications that the prevalence of food allergy has risen substantially over the past decade $[1,3]$. Food allergic individuals often have difficulties in determining which food products they can safely consume. Recently, the European Union, the USA, and other countries have released new regulations to ensure that major allergenic foods and products derived from them, or composed ingredients, are labelled on pre-packaged foods when present based on recipe [4]. It should be noted, however, that contamination of pre-packaged food with allergens is not covered by this Directive. The major allergenic foods that are concerned in the new EU directive [5] on labelling of foods (Directive 2003/89/EC) include peanuts, cereals containing gluten, crustaceans, eggs, fish, soybeans, milk, nuts, celery, mustard, and sesame seeds. Peanut allergy deserves special attention for several reasons. Peanut dominates the list of food allergens implicated in fatal and near-fatal allergic reactions and as many as one third of peanut-sensitive patients have severe challenge reactions [6]. Unlike most food allergies peanut allergy tends to be a lifelong problem for approximately $80 \%$ of the peanut allergic population $[7,8]$. Several peanut pro- 
teins belonging to different families of seed storage proteins have been identified by immunoblotting as major or minor allergens for humans and seven of them have been characterized and officially termed Ara h1-7 [9]. Although the allergens listed in the EU-Directive are responsible for the majority of allergic reactions, many other allergenic proteins are not covered by this labelling directive. An issue that received much attention during the past years is the possible introduction of new allergens by genetic modification of foods. Such techniques may be associated with the potential risks of allergic reactions to proteins expressed by the newly introduced genes. The need for a widely accepted and validated animal model to test the potential allergenicity and potency of (novel) proteins has therefore become an important issue for their safety evaluation.

Animal models have been suggested as a tool that could help to evaluate the potential allergenicity of such foods. In addition to identifying new food allergens, such models may also be helpful in investigating the influence of the food matrix, including food additives and contaminants, on dose-response relationships of allergens and food allergic responses. This is of importance since some food constituents have the potential to modulate allergic responses to allergens.

\section{An oral food allergy model in the Brown Norway rat}

Food allergy is a type I (IgE-mediated) hypersensitivity reaction to an offending food. This IgE-dependent allergic reaction is composed of two phases; a sensitization and a challenge phase. During the sensitization phase the immune system of the host is sensitized by the allergen, resulting in production of specific anti-allergen IgE antibodies. These antibodies are fixed by mast cells in various organs and tissues. In the challenge phase, the renewed exposure to the allergen will result in binding of the allergens to these fixed IgE antibodies and the release of various mediators from these mast cells which are responsible for the subsequent clinical reactions. For evaluating the allergenicity of food antigens, both phases should be examined by appropriate tests in in vivo animal models [10]. An important aspect for these food allergy models is that attention must be given to the unscheduled dietary pre-exposure of the test animals and their parental generations to the allergen under investigation as this may result in tolerance induction. In addition, sensitization and challenge should preferably be orally, because natural barriers (for instance gastro-intestinal acid denaturation, enzymatic digestion and mucosal/epithelial layers) and intestinal flora might influence the allergenicity of proteins. If possible, adjuvants should not be used as these may add to the complexity of the model. Test animals must be capable of producing significant amounts of IgEand/or other Th2-specific antibody (sub)classes, and these antibody responses should be directed to similar proteins (and allergenic epitopes) as found in patient sera. Ideally, test animals should show clinical reactions with respect to organ sensitivities that reflect responses seen in humans upon a challenge with the allergen. 
Finally, the model should be relatively easy to conduct and reproducible in time and different laboratories [11]. Although all these criteria are difficult to attain in one model, an oral food allergy model developed in Brown Norway (BN) rats might provide a suitable model to study the allergenicity of food proteins in humans [12-23]. This high-immunoglobulin (particularly IgE) responder rat strain resembles, to a certain degree, atopic humans in their genetic predisposition to react with an overproduction of IgE to antigens. In addition, clinical reactions, like an increased gut permeability and changes in blood pressure and respiratory function, were observed in BN rats after an oral challenge [23] and the profile of allergens recognized by the immune system of the BN rat appeared comparable with the profile of allergens recognized by allergic patients [24]. An important advantage of the BN rat model above other animal models [25-28] is the oral application of proteins without the use of an adjuvant, which mimics the relevant route of exposure in humans.

The standard protocol for sensitizing BN rats is based on the results of various studies with mainly ovalbumin (OVA) as allergen [12-15]. These studies revealed that the best results were obtained from daily intragastric dosing with allergen during 42 days. The sensitizing effects of allergens were determined by measurements of allergen-specific IgE and IgG antibodies in sera. In rats, IgE and IgG2a are considered to be controlled by Th2 cytokines, whereas IgG1 is known to be controlled by Th1 cytokines. For evaluation of the in vivo challenge reactions by an allergen, sensitized rats can be orally challenged with a high dose of the allergen followed by e.g. determination of the level of rat mast cell protease II (RMCP-II) in the serum. This protease is selectively expressed by intestinal mucosal mast cells in the rat and is a specific marker for mast cell activation that can be measured in serum [29].

Soybean and peanut are members of the legume family and share several common antigenic fractions. Patients allergic to one of these foods have serum IgE antibodies that immunologically cross-react with other legumes [30,31]. Because exposure of the parental generation to the antigen under investigation influences the outcome of oral sensitization studies with the offspring, at least two generations of animals should be bred on a diet free of the antigen under investigation or of antigens that can cross-react with this antigen for animals to be immunologically naïve. Knippels et al. [32] described that soy-specific IgG antibodies could not be detected after two generations bred on soy-free diet.

We describe herein the further development of the food allergy model in the BN rat as earlier presented by Knippels et al. [15], and in particular the importance of allergen-free breeding of the laboratory animals used for this model [32,33], for this purpose we used $\mathrm{BN}$ rats that were bred 3 generations on soy- and peanut-free feed. As in our original efforts to use the BN model to study allergenicity of peanuts often animals did not respond, we also investigated the effect of cholera toxin (CT), an oral adjuvant [34-38] often used in food allergy models to increase the sensitivity of the model $[27,39-45]$. CT is a major enterotoxin produced by the bacterium Vibrio 
Cholerae. It is known for its properties to increase gut permeability [46-51], thereby enhancing allergen uptake. Adjuvation with $\mathrm{CT}$ is often used in food allergy models because oral administration of $\mathrm{Ag}$ with $\mathrm{CT}$ stimulates strong responses to mucosally delivered antigens, by inducing an antigen-specific type 2 response [26,27,34,39$41,52]$ or a mixed Th1 + Th2 response [53,54], including IgE, but with a bias toward Th2 [54-56].

The use of adjuvantia is controversial especially for the development of predictive animal models, because it is not clear how adjuvants affect the immune response in the sensitization process and therefore it is impossible to determine the inherent potential of a given protein to induce allergic sensitization (IgE antibody responses). A predictive model without adjuvant is therefore desirable, because it would reduce the risk of false positives.

\section{DESCRIPTION OF METHODS}

\section{Animals}

Oral sensitization was studied in young Brown Norway (BN) rats. In the first study (experiment A) Brown Norway (BN Rij:Hsd) rats obtained from Harlan Netherlands B.V. (Horst, the Netherlands) were used. These rats were bred and raised on a peanut and soy protein-free diet obtained from Harlan Netherlands B.V (2016S Teklad Global 16\% Protein Rodent Diet) at our institute. In this experiment, female rats of the third generation (F3) and onwards were used and fed the peanut and soy protein-free diet during the experiments. At study initiation rats were 3-4 weeks old.

In the second study (experiment B) male BN rats directly obtained from Charles River (Sulzfeld, Germany) were used. These rats were raised on a commercially available peanut- and whey-protein-free diet (LAD1, Special Diet Services, Witham, England).

The rats were housed in an animal room maintained at $23 \pm 3^{\circ} \mathrm{C}$, with a light/dark cycle of $14 \mathrm{~h} / 10 \mathrm{~h}$, and a relative humidity of 30-70\% during the experiment and for at least 7 days prior to study initiation. The animals were housed in stainless-steel wire (Macrolon III) cages in groups of two (experiment A) or five (experiment B) and had free access to food and tap-water. Approval from the Institutional Animal Ethics Committee was obtained for all experimental procedures involving animals.

\section{Preparation of peanut extract}

Lightly blanched $\left(100^{\circ} \mathrm{C}\right.$ ) peanuts (Arachis Hypogaea) from the USA Runner cultivar were kindly provided by IMKO Gelria (Doetinchem, The Netherlands) and were stored at $4^{\circ} \mathrm{C}$ until use. Peanut extract was prepared according to the method described by Koppelman et al. [57] with some minor modifications. Peanuts were ground using a food mixing machine equipped with shredding knifes and stored at $20^{\circ} \mathrm{C}$. Extracts for sensitization were prepared by mixing $1 \mathrm{~kg}$ ground peanut with 4 
L PBS and for the oral challenge by mixing $750 \mathrm{~g}$ ground peanut with $500 \mathrm{ml}$ PBS at room temperature. After stirring the mixture overnight at $4^{\circ} \mathrm{C}$, the aqueous fraction was collected by centrifugation for 30 minutes at $3000 \mathrm{G}$ at room temperature. The aqueous fraction was subsequently centrifuged for 30 minutes at $8000 \mathrm{G}$ at room temperature, to remove residual traces of fat and insoluble particles. The remaining aqueous fraction was homogenized and is further referred to as peanut extract (PE) and protein concentrations were determined using a bicinchoninic acid (BCA) protein assay obtained from Pierce (Rockford, USA) according to the manufacturer's instructions. Separate portions of 1 and $10 \mathrm{mg} / \mathrm{ml} \mathrm{PE}$ for sensitizing and $50 \mathrm{mg} / \mathrm{ml}$ $\mathrm{PE}$ for the oral challenge were stored at $-20^{\circ} \mathrm{C}$ in aliquoted portions until use.

\section{Endotoxin content}

The endotoxin content of the PE $(33.6 \mathrm{mg} / \mathrm{ml}$ in PBS) was assessed chromatographically by quantitative limulus amebocyte ( $L A L)$ assay according to the manufacturer's instructions in a microtitre 96 flat-bottomed well plate format (Cambrex BioSciences, Wokingham, UK). Serial dilutions of proteins were generated using endotoxin-free water (Cambrex) in endotoxin free test tubes, and all solutions were vortexed for $1 \mathrm{~min}$ prior to diluting or plating. Protein solution $(100 \mathrm{l})$ or endotoxin standard (Escherica coli 055:B5 endotoxin; range 0.005 to $50 \mathrm{EU} / \mathrm{ml}$ ) was incubated (10 $\mathrm{min}$ at $37^{\circ} \mathrm{C}$ in an incubating plate reader) prior to addition of the Kinetic-QCL reagent (a co-lyophilized mixture of lysate prepared from the circulating amoebocytes of the horse shoe crab Limulus polyphemus and chromogenic substrate; 100 $\mu$ l per well (Cambrex)). Samples were monitored automatically over time in an incubating plate reader for the appearance of a yellow color. The reaction time is inversely proportional to the amount of endotoxin present; that is, the higher the concentration of endotoxin, the shorter the reaction time. Samples were tested in quadruplicate, with two of these containing the test protein alone and two of these containing test protein which is spiked with $0.5 \mathrm{EU}$ endotoxin, as a quality control to check the recovery of endotoxin by the assay. Endotoxin standards were tested in duplicate. PBS was used as negative control sample. All the PE samples had endotoxin levels $<0.01 \mathrm{EU} / \mathrm{ml}$ and since levels of endotoxin of $100 \mathrm{EU} / \mathrm{mg}$ of protein appear to be without marked effect on IgE anti-protein responses, these endotoxin levels were considered very low.

\section{Purification of Ara h1, Ara h2 and Ara h3}

Ara $h 1$ and Ara h2 were purified as described by de Jong et al. [58] and Ara h3 was purified as described by Koppelman et al. [57].

All steps were performed at room temperature. Lyophilized crude peanut extract was dissolved in $20 \mathrm{mM}$ Tris-bis-propane (TBP), pH 7.2 to a final concentration of 1 $\mathrm{mg} / \mathrm{ml}$. Undissolved particles were removed by centrifugation (15 $\mathrm{min}$. at $3000 \mathrm{G}$ ) and the solution was applied on a $8 \mathrm{ml}$ source $Q$ column $(1 \times 10 \mathrm{~cm})$, equilibrated 
with TBP. After rinsing the column with $80 \mathrm{ml}$ of TBP, a linear gradient of $200 \mathrm{ml}$ (0$1 \mathrm{M} \mathrm{NaCl}$ in TBP) was applied to elute the bound proteins $(2 \mathrm{ml} / \mathrm{min}$.) Fractions of 4 $\mathrm{ml}$ were collected and analyzed by SDS-PAGE using $8-25 \%$ gels essentially as described under header SDS-PAGE. To remove traces of peanut lectin from Ara $h 2$ (less than 1\%), Ara $h 2$ was dialyzed against $50 \mathrm{mM} \mathrm{NaAc}, \mathrm{pH} 5.0$ and loaded on a $1 \mathrm{ml}$ Source $S$ column $(0.5 \times 5 \mathrm{~cm})$ equilibarated with $50 \mathrm{mM} \mathrm{NaAc}, \mathrm{pH}$ 5.0. After washing with $10 \mathrm{ml}$ of $50 \mathrm{mM} \mathrm{NaAc}$, pH 5.0, the column was eluted using a $25 \mathrm{ml}$ linear gradient $(0-500 \mathrm{mM} \mathrm{NaCl}$ in $50 \mathrm{mM} \mathrm{NaAc}, \mathrm{pH} 5.0$ ) with a flow velocity of $0.25 \mathrm{ml} / \mathrm{min}$. Fractions of $0.5 \mathrm{ml}$ were collected and analyzed by SDS-PAGE. Peanut allergens were stored at $-30^{\circ} \mathrm{C}$ until use. Purified Ara $h 1$ and Ara $h 2$ blotted on PVDF membranes and blot fragments were $\mathrm{N}$-terminal sequenced using a gas-phase sequenator (performed at SECU, Utrecht, the Netherlands). Ara $h 3$ was purified essentially in the same way.

\section{SDS-PAGE}

To verify whether the peanut extract contained the major allergens (Ara h1, Ara h2 and Ara h3) SDS-PAGE was performed essentially according to Laemlli [59] using a BioRad Mini Protean II system (BioRad, Hercules, CA) with 15\% acrylamide gels $(15 \mathrm{~cm} \times 10 \mathrm{~cm})$. Pre-stained molecular weight markers (BioRad) with molecular weights of $6.4,21.3,29.2,35.8,49.8,93,115$ and $198 \mathrm{kDa}$ were used as reference. Undiluted sample, $2 x$ diluted sample and 10x diluted sample were mixed in a $1: 1$ ratio with $2 x$ concentrated SDS-PAGE extraction buffer (130 mM Tris with $4.6 \%$ $(\mathrm{w} / \mathrm{v})$ SDS, $20 \%(\mathrm{v} / \mathrm{v})$ glycerol and $0.02 \%$ bromophenol blue, $\mathrm{pH}$ 8.0) containing $0.5 \%$ dithiotreitol (DDT) and were subsequently boiled for $5 \mathrm{~min}$. The electrophoresis was performed in electrophoresis buffer ( $25 \mathrm{mM}$ Tris, $192 \mathrm{mM}$ glycine, $0.1 \% \mathrm{SDS}$ ) at $80 \mathrm{~V}$ for approximately $20 \mathrm{~min}$. and hereafter at $200 \mathrm{~V}$ until the samples were reaching the end of the gel. The stacking gel part was cut-off after which the staining steps were started. Gels were stained with Coomassie Brilliant Blue R-250 solution $(0.25 \%$ (w/v) Coomassie Brilliant Blue R-250 in methanol-water-glacial acetic acid (5-5-1)) overnight. The gels were destained with decoloration fluid (volume ratios of acetic acid:ethanol:distilled water as follows: 1:3:6). After destaining, gels were scanned with a Hewlett-Packard ScanJet IIC/ADF obtained from Hewlett-Packard France (Paris, France).

The protein composition profile of peanut extract as used for experiment $A$ can be found in Figure 1 and was comparable to that described by de Jong et al. [58]. In addition, the protein composition for experiment B as prepared by TNO Quality of Life (Zeist, The Netherlands) was also similar to the composition as used for experiment A. Furthermore, the protein composition profiles displayed the Ara h1, Ara h2 and Ara $h 3$ bands as described by Koppelman et al. [57]. 


\section{Figure 1}

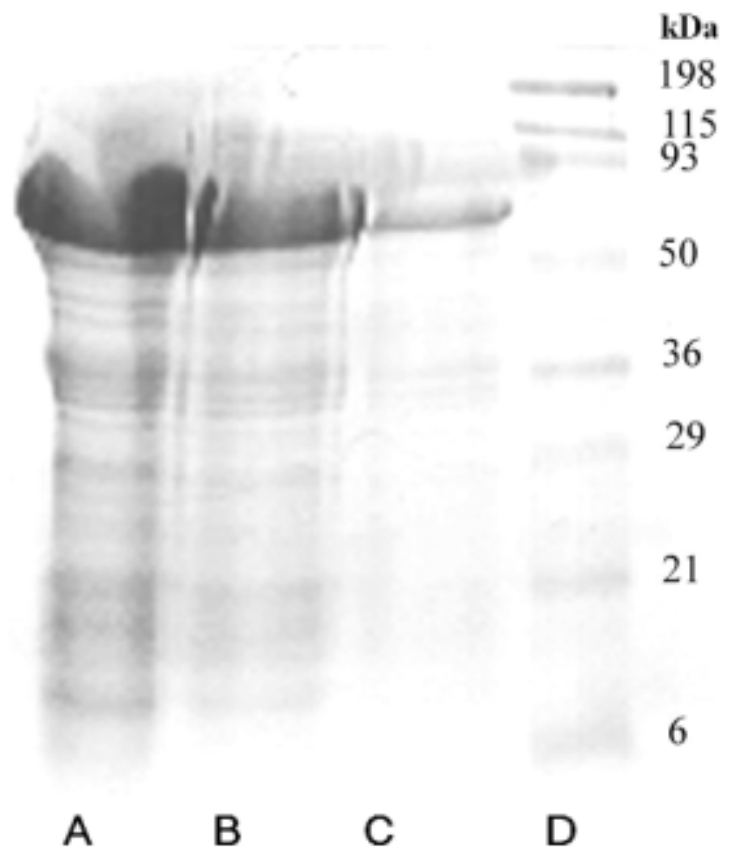

FIGURE 1. Peanut extract protein composition by SDS-PAGE

Peanut extract $(\mathrm{PE})$ was isolated as an aqueous fraction from ground peanut in PBS by centrifugation steps and this extract's protein composition was analyzed by SDS-PAGE. Column A was loaded with 74.27 $\mu \mathrm{g}$ PE/slot, column B was loaded with $37.14 \mu \mathrm{g}$ PE/slot, column C was loaded with $7.43 \mu \mathrm{g}$ PE/slot and column $\mathrm{D}$ was loaded with molecular weight markers with their weights mentioned in the figure.

\section{Experimental design oral sensitization}

To ensure the use of immunologically naive animals with respect to peanut, pre-study blood samples were always tested for peanut protein specific antibodies. Then, rats were randomly allocated to their dosing regimens $(n=8$ per dosing regimen for experiment A), some reallocation was performed to ensure even starting weight distribution in all dosing regimens. For experiment $A$ rats were exposed to 0 , 1 or $10 \mathrm{mg} / \mathrm{ml}$ PE in PBS by daily gavage, using a 18-gauge stainless steel animal feeding needle ( $1 \mathrm{ml} /$ animal) during 6 weeks, with and without the use of the adjuvant cholera toxin (CT; $1 \mu \mathrm{g} / \mathrm{rat} /$ day). In rats that were coexposed to $\mathrm{CT}$ daily $\mathrm{CT}$ gavage dosing started one week prior (day -7) to exposure to the allergen.

CT (azide free) was obtained from List Biological Laboratories, Inc. (Campbell, CA, USA). For experiment $B$ the same sensitization procedure was used, without administration of an adjuvant. For experiment $B$ dosing regimens 0 and $10 \mathrm{mg} P E /$ day/rat consisted of 10 rats/ dosing regimen, while 20 rats were used for dosing regimen 1 $\mathrm{mg} \mathrm{PE} / \mathrm{rat} /$ day. Blood samples were obtained from the tail vein at two-weekly inter- 
vals (day 14, 28 and 42 after start sensitization to PE). After coagulation for $1 \mathrm{~h}$ at room temperature, the blood samples were centrifuged (Heraeus Sepatech Biofuge 13 , Osterode, Germany) for $15 \mathrm{~min}$. at $3000 \mathrm{G}$ and $4^{\circ} \mathrm{C}$ to obtain sera. The sera were stored at $-80^{\circ} \mathrm{C}$ until analyses for PE-specific IgE and IgG titres and RMCP-II levels by Enzyme Linked Immunosorbent Assay (ELISA).

After the sensitization period (day 42), animals were not exposed for one week and were deprived of their food one day prior to sacrifice (day 49). At day 49, all rats were orally challenged by intragastric intubation with PE $(2 \mathrm{~mL}$ of a $50 \mathrm{mg} / \mathrm{mL}$ solution). Thirty minutes after the oral challenge, the animals were sacrificed by exsanguination from the aorta under $\mathrm{CO}_{2} / \mathrm{O}_{2}$ anesthesia. Blood samples from the orbital plexus $(0.5 \mathrm{ml} / \mathrm{rat})$ collected in K3-EDTA tubes obtained from Terumo Europe N.V. (Leuven, Belgium) were used for the determination of differential cell types in blood. Also blood was taken by exsanguinations from the abdominal aorta and from this blood serum samples were prepared as described above. Spleens were removed aseptically, weighed and single cell suspensions were prepared for cytokine analysis after ex-vivo re-stimulation with antigen.

\section{Experimental design intraperitoneal sensitization}

$\mathrm{BN}$ rats bred on a commercially available whey- and peanut-free rodent diet (LAD1; Special Diet Services, Witham, England) were sensitized by intraperitoneal (i.p.) injection of $0.5 \mathrm{ml}$ of a $0.2 \mathrm{mg} \mathrm{PE} / \mathrm{ml}$ solution in sterile PBS on days $0,2,4,7,9$ and 11. To potentiate the immune response, $0.2 \mathrm{ml}$ of a $25 \mathrm{mg} / \mathrm{ml}$ alum adjuvant suspension (Pierce) in sterile saline mixed with the $0.5 \mathrm{ml}$ of PE-solution was injected on day 0 . The animals were bled on day 28 by exsanguation from the abdominal aorta and serum was prepared as described above. Sera were used to determine IgG2a against Ara h1, Ara h2 and Ara h3.

\section{PE-DIG coupling}

Peanut protein-Digoxigenin (PE-DIG) coupling was established using a DIG-protein labeling kit obtained from Roche Diagnostics $\mathrm{GmbH}$ (Mannheim, Germany) according to manufacturer's instructions except for the following changes: $50 \mu \mathrm{L}$ of a 20 $\mathrm{mg} / \mathrm{mL}$ digoxigenin-3-0-succinyl- $\varepsilon$-aminocaproic acid- $\mathrm{N}$-hydroxy-succinimide ester (DIG-NHS) solution in DMSO was added to $1 \mathrm{~mL}$ of a $6 \mathrm{mg} / \mathrm{mL}$ solution of crude PE extract in PBS, from this point on the manufacturer's instructions were followed. A 1:2000 dilution of PE-DIG was used in the assay.

\section{Negative and positive control sera for Ig ELISAs}

Pooled serum, obtained from male F3 BN rats which were not exposed to peanut allergens, was used as negative control. Positive control sera were obtained by i.p. injections of female $\mathrm{F} 3 \mathrm{BN}$ rats with $0.5 \mathrm{ml}$ of a $0.2 \mathrm{mg} \mathrm{PE} / \mathrm{ml}$ solution in sterile PBS on days $0,2,4,7,9$ and 11 . To potentiate the immune response, $0.2 \mathrm{ml}$ of a 40 
$\mathrm{mg} / \mathrm{ml}$ alum adjuvant suspension (Pierce) in sterile saline mixed with the $0.5 \mathrm{ml}$ of PE-solution was injected on day 0 . The animals were bled on day 28 by exsanguation from the abdominal aorta. Sera were prepared and stored as described above. These sera were pooled and used as positive control sera in the PE-specific Ig ELISAs.

\section{PE-specific Ig ELISAs}

Positive and negative controls were incorporated in each plate of all Ig-ELISAs. After each incubation plates were washed six times with $300 \mu \mathrm{L}$ PBS containing $0.1 \%$ Tween 20 using an ELISA washer (Auto plate washer ELX405R, Biotek Instruments Inc., Winooski, VT, USA).

PE-specific IgE ELISA

For detection of PE-specific IgE, a sandwich ELISA was performed. Microtitre plates (for all ELISAs: F96 Cert.Maxisorp no. 439454 Nunc-Immuno Plate, Nunc A/S, Roskilde, Denmark) were coated overnight at $4{ }^{\circ} \mathrm{C}$ with $100 \mu \mathrm{L} /$ well of a $1.5 \mu \mathrm{g} / \mathrm{mL}$ dilution of mouse anti-rat IgE (MARE; Zymed, San Francisco, USA) in carbonatebicarbonate buffer ( $\mathrm{pH}$ 9.6). Then, $200 \mu \mathrm{L} /$ well of a postcoat solution (Tris Buffered Saline containing $1 \%$ bovine serum albumin (TBS-BSA, Sigma-Aldrich, St Louis, USA) was added and incubated 30 minutes at room temperature. Serial dilutions (starting at a 1:4 dilution) of rat serum (test sera and control sera) in standard diluent (postcoat solution with $0.5 \%$ Tween 20 ) were added to the wells and incubated for $1 \mathrm{~h}$ at room temperature. Next, $100 \mu \mathrm{L} /$ well PE-DIG conjugate was added and incubated for $1 \mathrm{~h}$ at $37^{\circ} \mathrm{C}$. Followed by the addition of $100 \mu \mathrm{L} /$ well of a $625 \mathrm{x}$ dilution of $50 \mathrm{U} / \mathrm{mL}$ anti-diogoxigenin-POD (poly) Fab Fragments (anti-DIG-POD) obtained from Roche Diagnostics $\mathrm{GmbH}$ in standard diluent. After incubation for $2 \mathrm{~h}$ at $37^{\circ} \mathrm{C}$, the plates were incubated with $\mathrm{TMB}$ substrate and the enzyme reaction was stopped with $2 \mathrm{M}$ $\mathrm{H}_{2} \mathrm{SO}_{4}$ and absorbance was read at $450 \mathrm{~nm}$ with an ELISA plate reader (Fluostar Galaxy, BMG Labtechnologies GmbH, Offenburg, Germany). The ${ }^{2}$ log titre in the samples was determined by using the average extinction in the plates' negative control wells, to which three times the standard deviation was added as a cutoff.

PE-specific IgG1 and IgG2a ELISA

For detection of peanut-specific $\operatorname{lgG1}$ and $\operatorname{lgG} 2 \mathrm{a}, 96$-wells microtitre plates were coated with $100 \mathrm{~L} /$ well of a $100 \mu \mathrm{g} / \mathrm{mL}$ solution of PE-extract in PBS. The plates were washed and blocked by addition of $200 \mu \mathrm{L} /$ well postcoat solution. After 30 minutes incubation at room temperature, the plates were washed and serial dilutions (starting at a 1:128 dilution) of rat serum (test sera and control sera) in standard diluent were added to the wells and incubated for $1 \mathrm{~h}$ at room temperature. After washing, $100 \mu \mathrm{L} /$ well of an anti-lgG1 or anti-lgG2a horse radish peroxidase conjugate (Research Diagnostics Inc., Flanders, USA) in standard diluent was added (20000x diluted) and incubated for $1 \mathrm{~h}$ at room temperature. Plates were washed again and $100 \mu \mathrm{L}$ of TMB substrate solution was added. The color reaction was 
stopped by adding $100 \mu \mathrm{L} /$ well $2 \mathrm{M} \mathrm{H}_{2} \mathrm{SO}_{4}$ and optical densities were read at $450 \mathrm{~nm}$. Calculation of PE-specific IgG1 and IgG2a titres was the same as described for IgE ELISAs.

To determine specific IgG2a antibodies against the purified allergens, plates were coated with $5 \mu \mathrm{g} / \mathrm{ml}$ Ara h1, Ara h2 or Ara h3 solution in carbonate buffer. After coating the protocol was similar as described above for the PE-specific IgG2a ELISA, with exception of the start dilution of the sera (1:8). The absorbance of 1:8 sera dilutions from control animals typically would not exceed an optic density (OD) at $450 \mathrm{~nm}$ of 0.2 ; this was the case for all three purified peanut allergens. In order to discriminate between IgG2a high and low responders for the specific purified allergens we set an arbitrary cut-off point for IgG2a high responders at an OD at $450 \mathrm{~nm}$ of at least 0.6 for $1: 8$ sera dilutions.

\section{Measurement of Rat mast cell protease II}

Rat mast cell protease II (RMCPII) concentrations were determined in day 42 and 49 sera with a RMPCII ELISA kit (Moredun Scientific Limited, Penicuik, Midlothian, Scotland, UK) according to manufacturer's instructions.

\section{Differential cell counting}

Blood samples, obtained on day 49 were diluted 1:1 in a solution of Bovine Serum Albumin (Fraction V, purity $\geq 96 \%$; Sigma-Aldrich) in saline (40 g/L). The number of white blood cells (WBC), lymphocytes, eosinophils and basophils in the blood were counted with Bayer Advia 120 Hematology System (Bayer HealthCare, Diagnostics division, Tarrytown, NY, USA).

\section{Cell culture}

For in vitro restimulation of spleen cells, $50 \mathrm{mg} / \mathrm{mL}$ PE was filtrated using a syringe driven filter unit (Millipore Millex-HA $0.45 \mu \mathrm{m}$, Millipore, Billerica, USA) and diluted in RPMI $1640+25$ mM Hepes + L-Glutamine obtained from Gibco BRL (Breda, the Netherlands) supplemented with $10 \%$ heat inactivated fetal calf serum (FCS) obtained from Integro B.V. (Zaandam, The Netherlands) and $1 \%$ penicillinstreptomycin (Gibco). This medium will be referred to as standard medium. Spleens were dissected at day 49 and collected in standard medium with 5\% FCS. Single cell suspensions were prepared by pressing spleens through a $70 \mu \mathrm{m}$ nylon cell strainer (Falcon, BD Biosciences, Franklin Lakes, USA) using a $5 \mathrm{~mL}$ Falcon syringe plunger. Cells were washed twice in $30 \mathrm{~mL}$ standard medium (1500 rpm, 10 minutes, $4{ }^{\circ} \mathrm{C}$ ) and resuspended in $5 \mathrm{~mL}$ (spleen) or $2 \mathrm{~mL}$ (MLN) standard medium with 10\% FCS and $7.5 \times 10^{-5} \mathrm{M}$ 2-mercaptoethanol (2-ME) obtained from SERVA (Heidelberg, Germany). The concentration of the cell suspensions was adjusted to $4 \times 10^{6}$ cells $/ \mathrm{mL}$ in standard medium with $10 \%$ FCS and 2-ME. Cell suspensions, were incubated with PE $(0,0.5$ and $1 \mathrm{mg} / \mathrm{ml})$ in cell cultures $\left(4 \times 10^{5}\right.$ cells/well) for $96 \mathrm{~h}$. Cell cultures incu- 
bated for $48 \mathrm{~h}$ with $3.33 \mu \mathrm{g} / \mathrm{mL}$ of the mitogen Concanavalin A (ConA; ICN Biomedicals Inc., Irvine, USA) were used as positive controls. In the supernatants IFN- $\gamma$ and IL-4 were determined by ELISA.

\section{Cytokine ELISAs}

IFN- $\gamma$

A rat IFN- $\gamma$ ELISA set (Rat IFN- $\gamma$ BD OptEIA ELISA set; BD Biosciences, Erembodegem, Belgium) and Reagent set (IFN- $\gamma$ BD OptEIA Reagent Set B, BD Biosciences) were used for detection of IFN- $\gamma$ according to manufacturer's instructions. Briefly: plates were coated overnight at $4{ }^{\circ} \mathrm{C}$ with anti-rat IFN- $\gamma$ monoclonal antibody diluted 1:250 in coating buffer ( $0.1 \mathrm{M}$ Sodium Carbonate). The following day, plates were washed with $300 \mu \mathrm{L} /$ repeat PBS containing 0.1\% Tween 20 (Sigma-Aldrich) and blocked with $200 \mu \mathrm{L} /$ well assay diluent (PBS with 10\% fetal bovine serum) for $1 \mathrm{~h}$ at room temperature. After washing, samples and IFN- $\gamma$ standards were added and incubated for $2 \mathrm{~h}$ at room temperature. IFN- $\gamma$ standards were added in duplo (start concentration $=2000 \mathrm{pg} / \mathrm{mL}$ ) and diluted in assay diluent to a concentration of $7.81 \mathrm{pg} / \mathrm{mL}$. Six wells per plate contained only assay diluent and were used as blanks. Plates were washed and incubated with $100 \mu \mathrm{L} /$ well of a 1:250 dilution of biotinylated anti-rat IFN- $\gamma$ monoclonal antibody in assay diluent for $1 \mathrm{~h}$ at room temperature. After washing, $100 \mu \mathrm{L} /$ well of a 1:250 dilution of avidin-horseradish peroxidase conjugate in assay diluent was added and plates were incubated for 30 minutes at room temperature. Plates were washed again and incubated with $100 \mu \mathrm{L} /$ well of a substrate solution (containing TMB and hydrogen peroxide) for 30 minutes at room temperature. Then, the color reaction was stopped with stop solution $\left(\mathrm{H}_{2} \mathrm{SO}_{4}\right)$ and absorbance was measured at $450 \mathrm{~nm}$ using an ELISA plate reader (Fluostar Galaxy, BMG Labtechnologies $\mathrm{GmbH}$ ). IFN- $\gamma$ concentrations in samples were determined using the standard curve, corrected for deducted average absorbance of the blanks.

IL-4

IL-4 was measured using a rat IL-4 cytosets kit obtained from BioSource (Camarillo, CA, USA) according to the manufacturer's instructions. Briefly: plates were coated overnight at $4{ }^{\circ} \mathrm{C}$ with $100 \mu \mathrm{L} /$ well of a $1.25 \mu \mathrm{g} / \mathrm{mL}$ solution of rat IL-4 antibody in coating buffer $\left(8.0 \mathrm{~g} \mathrm{NaCl}, 1.42 \mathrm{~g} \mathrm{Na}_{2} \mathrm{HPO}_{4} \quad 2 \mathrm{H}_{2} \mathrm{O}, 0.2 \mathrm{~g} \mathrm{KH}_{2} \mathrm{PO}_{4}\right.$ and $0.2 \mathrm{~g} \mathrm{KCl}$ in $1 \mathrm{~L}$ distilled water; all chemicals from Merck, Darmstadt, Germany). The plates were washed six times with $300 \mu \mathrm{L} /$ repeat PBS containing 0.1\% Tween 20 (Sigma-Aldrich). This was followed by the addition of $200 \mu \mathrm{L} /$ well of TBS-BSA (Sigma-Aldrich). After 2 $\mathrm{h}$ incubation at room temperature, the plates were washed six times. IL-4 standards were added in duplo at a start concentration of $1000 \mathrm{pg} / \mathrm{mL}$ and diluted in TBS-BSA containing $0.05 \%$ Tween 20 until a concentration of $3.7 \mathrm{pg} / \mathrm{mL}$ was reached. Supernatants were added to the wells and were incubated for 90 minutes at room temperature. After washing, $100 \mu \mathrm{L}$ of a $0.05 \mu \mathrm{g} / \mathrm{mL}$ solution of rat IL-4 biotinylated antibody in TBS-BSA with $0.05 \%$ Tween 20 was added and incubated for $1 \mathrm{~h}$ at room 
temperature. Then, plates were washed again and $100 \mu \mathrm{L} /$ well of a $0.15 \mu \mathrm{g} / \mathrm{mL}$ solution of streptavidin-horseradish peroxidase conjugate (in TBS-BSA with $0.05 \%$ Tween 20) was added. After incubation (45 minutes at room temperature), plates were washed and $100 \mu \mathrm{L}$ of an enzyme substrate solution (see Ig ELISAs) was added. The plates were developed at room temperature for 30 minutes. Finally, 100 $\mu \mathrm{L} /$ well $2 \mathrm{M} \mathrm{H}_{2} \mathrm{SO}_{4}$ (Merck) was added and absorbance was measured at $450 \mathrm{~nm}$ using an ELISA plate reader (Fluostar Galaxy, BMG Labtechnologies GmbH). IL-4 concentrations in samples were determined using the standard curve, corrected for deducted average absorbance of the blanks.

\section{Statistics}

Differences between peanut dosage groups in ${ }^{2} \log$ IgE and IgG titres, RMCPII concentrations, and cytokine levels were analyzed using one-way ANOVA, with Bonferroni as a post hoc test. The number of immune cells in blood was log-transformed prior to analysis, because these data did not meet the prerequisite of ANOVA that data should be normally distributed.

In order to investigate the effect of the usage of CT the above mentioned one-way ANOVA was also performed in the CT-modulated group. Furthermore, the influence of an adjuvant on dose-response relationships between $\mathrm{PE}$-exposure groups was analyzed by comparing data of the CT-coexposed group with data of the nonadjuvated group. Differences between these two groups were analyzed using twoway Analysis Of Variance (ANOVA) with Bonferroni for pairwise comparisons as post hoc test. Finally, the effect of the adjuvant was analyzed separately for each of the three PE dose levels (by splitting on PE-exposure) using a one-way ANOVA. This additional test was performed to investigate if CT influenced the outcome of an immunological parameter within a certain PE-exposure group.

In all analyses, data were considered significantly different if $p<0.05$.

\section{RESULTS}

To determine if the BN rats bred on a peanut- and soy-free diet for 3 generations could be orally sensitized to peanut without the use of an adjuvant we determined peanut protein-specific Ig responses, mast cell degranulation, number of eosinophilic and basophilic granulocytes and cytokine production.

\section{PE-specific $\lg E$, $\lg G 1$ and $\lg G 2 a$ titres}

Daily intragastric administration of 1 or $10 \mathrm{mg}$ PE for 42 days, without the use of an adjuvant, resulted in antigen-specific antibody responses in all rats. No IgE titres were detected in samples taken before sensitization. PE-specific IgE responses of rats orally exposed to PE increased with time. In the $10 \mathrm{mg} / \mathrm{rat} /$ day group they were found to increase at an earlier time point, and reached higher levels than in the $1 \mathrm{mg}$ group (Fig. 2). 


\section{Figure 2}

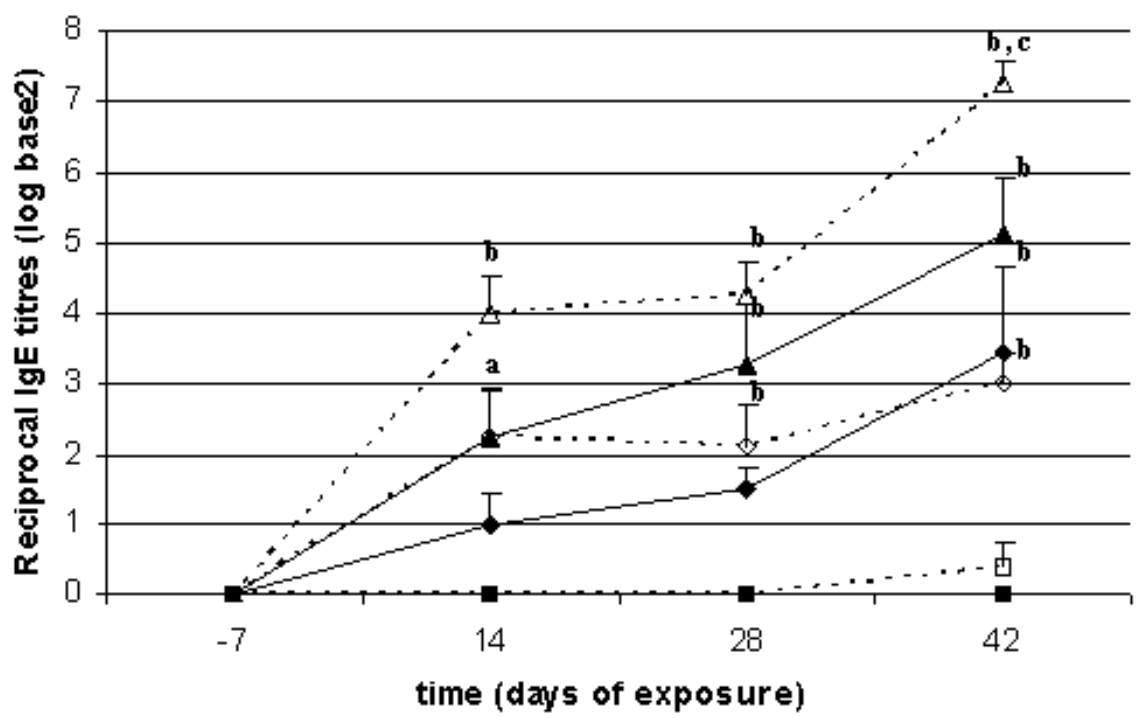

FIGURE 2. PE-specific IgE titres in time following oral exposure to peanut extract

Groups of female rats ( $n=8$ for each dosing regiment) bred for 3 generations on peanut- and soy-free feed received 0 (square), 1 (diamond) or 10 (triangle) $\mathrm{mg} / \mathrm{rat} /$ day of peanut extract (PE) by daily oral gavage. Data are displayed as serum reciprocal IgE titres (average + S.E.M) in time. Day -7 is the predosing punction that has been tested to verify if the animals were naïve for PE. Closed lines represent the non-adjuvated groups, while interrupted lines represent CT-adjuvated groups (oral $1 \mu \mathrm{g} C \mathrm{CT} / \mathrm{rat} / \mathrm{day}$ ).

${ }^{a}$ denotes the significant differences compared to the control group $(0 \mathrm{mg} P E$ and $0 \mathrm{mg} P E+C T$, respectively) with $p<0.02$ for the $10 \mathrm{mg} \mathrm{PE}$ group and $p<0.01$ for $1 \mathrm{mg} \mathrm{PE}+\mathrm{CT}$ group; ${ }^{\mathrm{b}}$ significantly different from the control group ( $0 \mathrm{mg} \mathrm{PE}$ and $0 \mathrm{mg} \mathrm{PE}+\mathrm{CT}$, respectively) with $p<0.01 ;{ }^{\mathrm{c}}$ significantly different from the $\mathrm{CT}$ adjuvated group with $p<0.03$. 


\section{Figure 3}

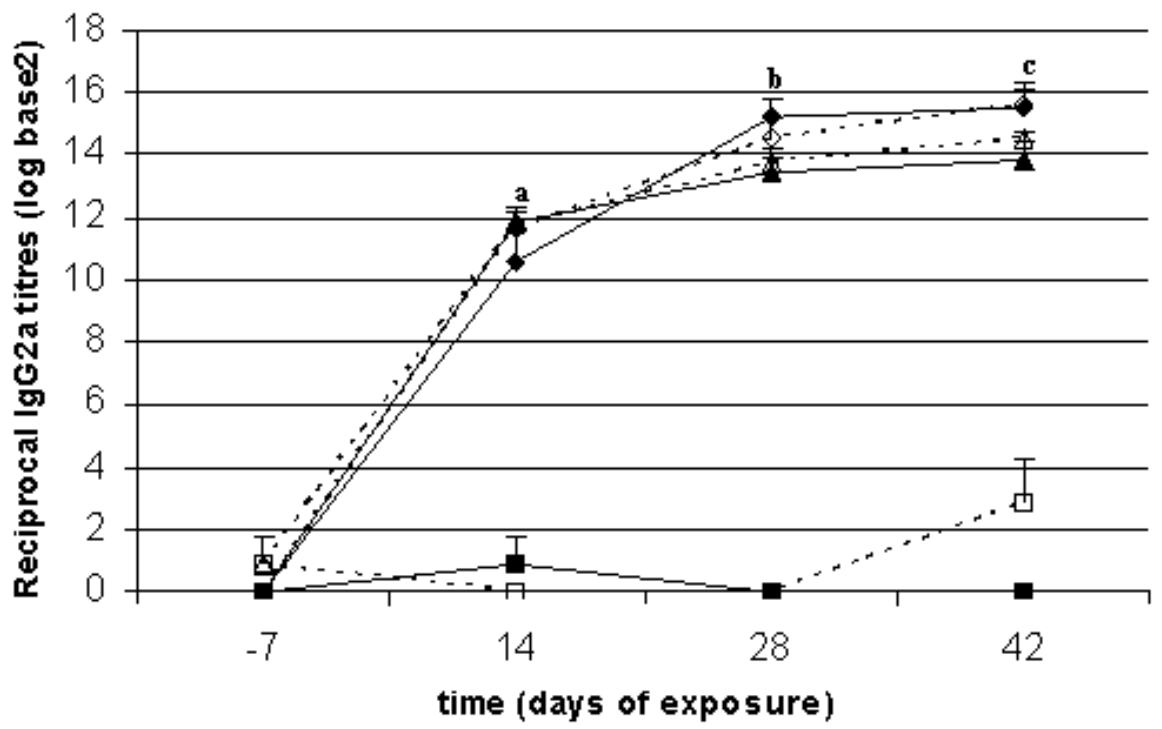

FIGURE 3. PE-specific IgG2a titres in time following oral exposure to peanut extract

Groups of female rats ( $n=8$ for each dosing regiment) bred for 3 generations on peanut- and soy-free feed received 0 (square), 1 (diamond) or 10 (triangle) $\mathrm{mg} / \mathrm{rat} /$ day of peanut extract (PE) by daily oral gavage. Data are displayed as serum reciprocal IgG2a titres (average + S.E.M) in time. Day -7 is the predosing punction that has been tested to verify if the animals were naïve for PE. Closed lines represent the non-adjuvated groups, while interrupted lines represent CT-adjuvated groups (oral $1 \mu \mathrm{g} C T / \mathrm{rat} / \mathrm{day}$ ).

${ }^{a}$ on day 14 all PE exposed groups with and without CT adjuvation are significantly different $(p<0.01)$ compared to the control group ( $0 \mathrm{mg} P \mathrm{PE}$ and $0 \mathrm{mg} \mathrm{PE}+\mathrm{CT}$, respectively); ${ }^{\mathrm{b}}$ on day 28 all PE exposed groups with and without CT adjuvation are significantly different $(p<0.01)$ compared to the control group ( $0 \mathrm{mg} P E$ and $0 \mathrm{mg} P E+C T$, respectively), titres are also significantly higher in the $1 \mathrm{mg} P E$ group compared to the $10 \mathrm{mg} \mathrm{PE}$ group with $p<0.03$; ${ }^{\mathrm{C}}$ on day 42 all $\mathrm{PE}$ exposed groups with and without CT adjuvation are significantly different $(p<0.01)$ compared to the control group $(0 \mathrm{mg} \mathrm{PE}$ and $0 \mathrm{mg} \mathrm{PE}+\mathrm{CT}$, respectively), titres are also significantly higher in the $1 \mathrm{mg} P E$ group compared to the $10 \mathrm{mg} P E$ group with $p<0.04$.

All animals that were sensitized to peanut for 42 days developed PE-specific IgG2a responses. Figure 3 shows that starting from day 14 significant differences in IgG2a titres between controls and both orally sensitized groups were seen. On day 28 and 42, IgG2a titres were significantly higher in $1 \mathrm{mg}$ group than in animals exposed to $10 \mathrm{mg}$ PE/day.

Daily administration of PE resulted in the production PE-specific IgG1 antibodies in all rats. Figure 4 shows that from day 14 and onwards significant differences in IgG1 titres between controls and both sensitized groups were seen. No differences in IgG1 were detected between animals in the $1 \mathrm{mg}$ and $10 \mathrm{mg}$ dose group. 


\section{Figure 4}

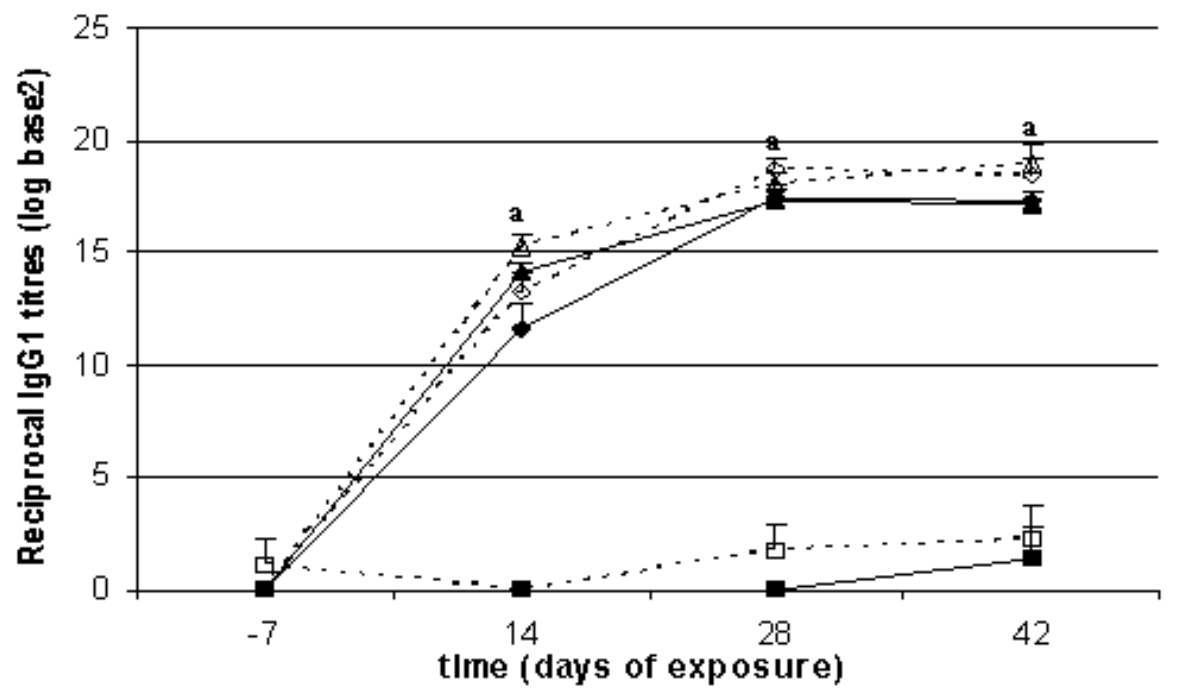

FIGURE 4. PE-specific IgG1 titres in time following oral exposure to peanut extract

Groups of female rats ( $n=8$ for each dosing regiment) bred for 3 generations on peanut- and soy-free feed received 0 (square), 1 (diamond) or 10 (triangle) $\mathrm{mg} / \mathrm{rat} /$ day of peanut extract (PE) by daily oral gavage. Data are displayed as serum reciprocal IgG1 titres (average + S.E.M) in time. Day -7 is the predosing punction that has been tested to verify if the animals were naïve for PE. Closed lines represent the non-adjuvated groups, while interrupted lines represent CT-adjuvated groups (oral $1 \mu \mathrm{g} \mathrm{CT} / \mathrm{rat} / \mathrm{day}$ ).

${ }^{a}$ titres are significantly higher $(p<0.01)$ than their control groups $(0 \mathrm{mg} \mathrm{PE}$ and $0 \mathrm{mg} \mathrm{PE}+\mathrm{CT}$, respectively) for all PE exposed groups with and without CT adjuvation.

\section{Rat mast cell protease-II}

To illustrate the clinical consequences of the PE-specific IgE antibody production, the mast cell product RMCP-II was also monitored. The RMCP-II responses before oral challenge (day 42) did not differ between PE-dosage groups. However, after oral challenge on day 49 all peanut-exposed groups had higher RMCP-Il levels compared to the $0 \mathrm{mg} \mathrm{PE} / \mathrm{rat} / \mathrm{day}$ group. This increase was significant for the $10 \mathrm{mg}$ $\mathrm{PE} /$ rat/day group (Fig. 5). 


\section{Figure 5}

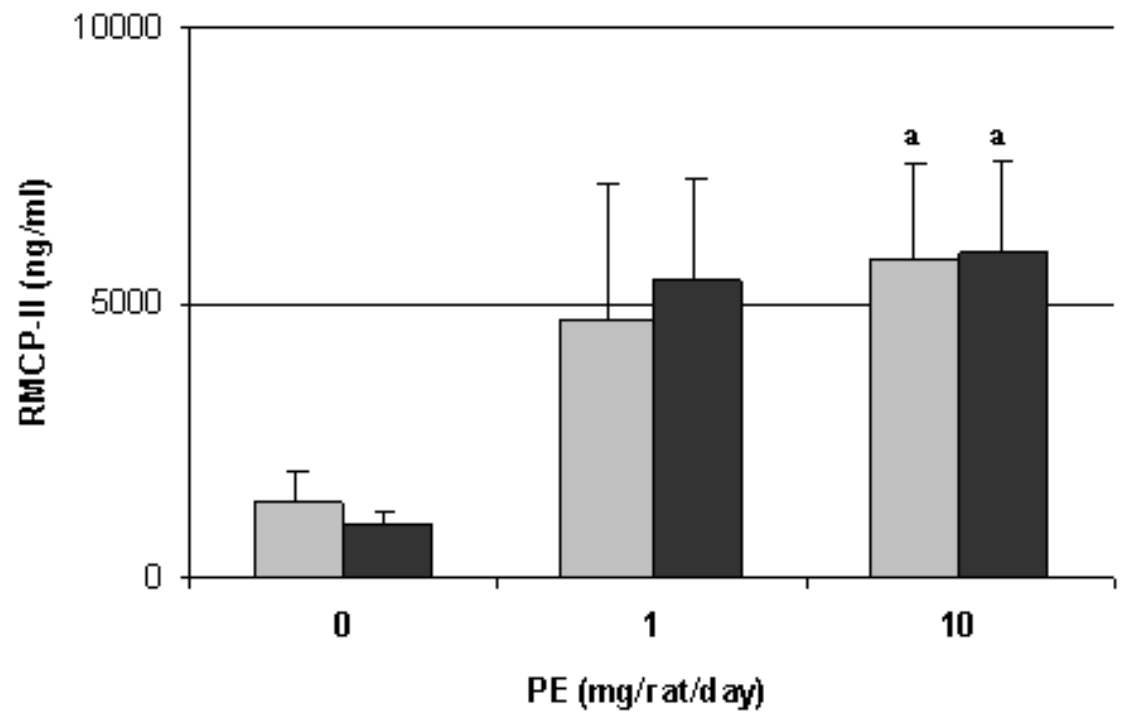

FIGURE 5. RMCP-II release after oral challenge with peanut extract

Groups of female rats ( $n=8$ for each dosing regiment) bred for 3 generations on peanut- and soy-free feed received 0,1 or $10 \mathrm{mg} / \mathrm{rat} /$ day of peanut extract (PE) by daily oral gavage. Data are displayed as serum RMCP-II levels (average + S.E.M) on day 49, 30 minutes after oral challenge with $100 \mathrm{mg} \mathrm{PE} / \mathrm{rat}$. Grey bars represent the non-adjuvated groups, while black bars represent the CT-adjuvated groups (oral $1 \mu \mathrm{g} \mathrm{CT/rat/day).}$

a denotes significance $(p<0.02)$ compared to the $0 \mathrm{mg}$ PE group control.

\section{Number of eosinophils and basophilic granulocytes in blood}

Another marker of the induction of allergy is the increase of eosinophilic and basophilic granulocytes in the blood collected at day 49 (Fig. 6). In rats that were exposed to $10 \mathrm{mg}$ PE daily, both basophils and eosinophils were increased. Exposure to $1 \mathrm{mg}$ PE did not influence the number of basophils and eosinophils. 


\section{Figure 6}

(a)

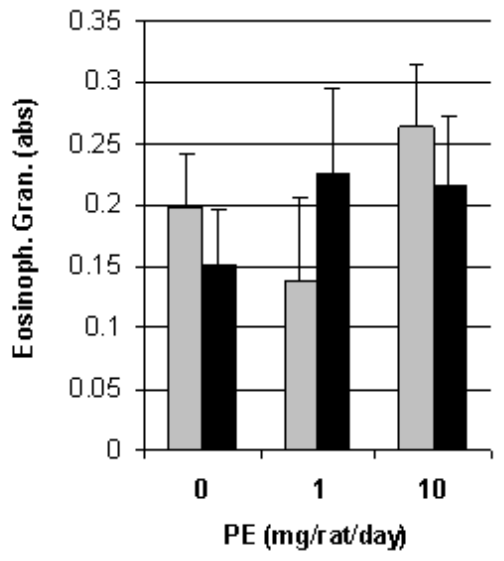

(b)

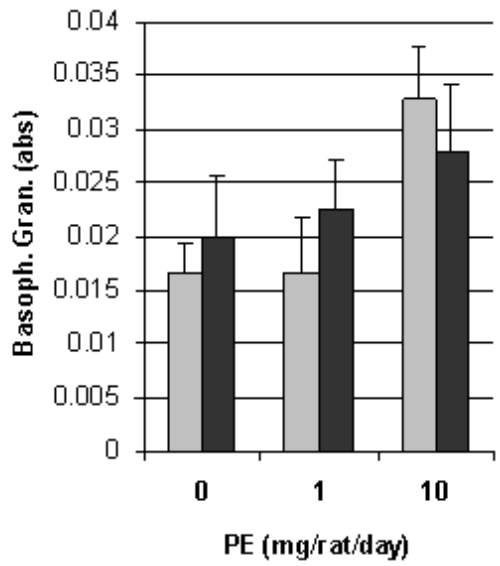

FIGURE 6. Numbers of eosinophilic and basophilic granulocytes

Groups of female rats ( $n=8$ for each dosing regiment) bred for 3 generations on peanut- and soy-free feed received 0,1 or $10 \mathrm{mg} / \mathrm{rat} /$ day of peanut extract (PE) by daily oral gavage. Data are displayed as numbers of eosinophilic (A) or basophilic (B) granulocytes (average + S.E.M) in blood of day 49 ( $\times 10^{9} /$ L). Grey bars represent the non-adjuvated groups, while black bars represent the CT-adjuvated groups (oral $1 \mu \mathrm{g} \mathrm{CT/rat/day).}$

\section{Th2 and Th1 cytokines}

To gain insight in the Th2 and Th1 cytokines involved we determined IL-4 (Th2) and IFN- $\gamma$ (Th1) in spleen cells stimulated ex vivo with PE. In many samples, IL-4 levels were below the detection limit $(3.7 \mathrm{pg} / \mathrm{mL})$ or only low concentrations were detectable (Fig. 7A). In the $1 \mathrm{mg}$ PE/rat/day exposed group a non-significant increase in IL4 was seen. A significantly increased IFN- $\gamma$ release (Fig. 7B) was detected in animals that were in vivo exposed to $1 \mathrm{mg} \mathrm{PE} / \mathrm{rat} /$ day and $10 \mathrm{mg} \mathrm{PE} / \mathrm{rat} /$ day. 


\section{Figure 7}

(a)

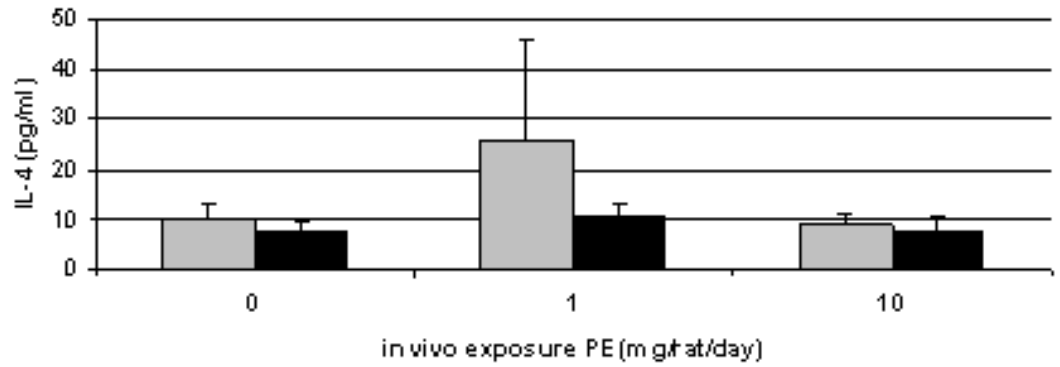

(b)

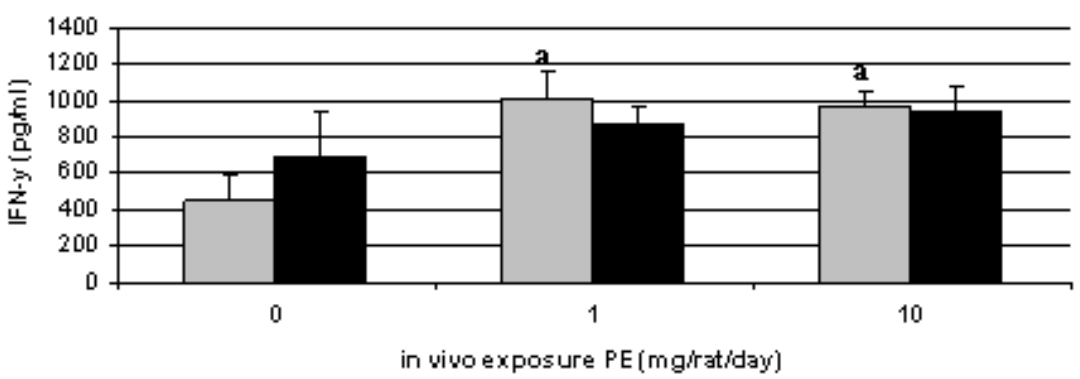

FIGURE 7. IL-4 and IFN- $p$ levels in PE-restimulated spleen cells

Groups of female rats ( $n=8$ for each dosing regiment) bred for 3 generations on peanut- and soy-free feed received 0,1 or $10 \mathrm{mg} / \mathrm{rat} /$ day of peanut extract $(\mathrm{PE})$ by daily oral gavage. Spleens were dissected at day 49 , single cell suspensions were prepared and these cells were incubated with PE in cell cultures $\left(4 \times 10^{5}\right.$ cells/culture) for $96 \mathrm{~h}$. Data are displayed as supernatant IL-4 (A) or IFN- $\gamma$ (B) levels (average + S.E.M). Grey bars represent the non-adjuvated groups, while black bars represent the CT-adjuvated groups (oral $1 \mu \mathrm{g} \mathrm{CT} / \mathrm{rat} / \mathrm{day}$ ). Data of optimal PE-specific restimulation concentrations (1 $\mathrm{mg} \mathrm{PE} / \mathrm{ml}$ for IL-4 and $0.5 \mathrm{mg} \mathrm{PE} / \mathrm{ml}$ for IFN- $\gamma$ ) for each cytokine are presented.

${ }^{a}$ significantly different $(p<0.02)$ from the $0 \mathrm{mg}$ PE group.

\section{The effect of extensive diet control}

We investigated the effect of the extensive diet intervention. Therefore, PE-specific IgE, IgG2a and IgG1 titres and RMCP-II responses in rats bred for 3 generations on peanut- and soy-free ( $3 \mathrm{G} P E+$ soy-free) feed were compared to that of rats directly obtained from an animal supplier that were bred and raised on a commercially available whey- and peanut-free (PE-free) diet.

First we compared PE-specific IgE titres after 42 days of exposure to PE. The IgE titres of $3 G \mathrm{PE}+$ soy-free fed rats were higher than those of the PE-free fed rats. In the $3 G$ PE+soy-free fed group 100\% IgE responders were found after sensitization to both 1 and $10 \mathrm{mg}$ PE. In contrast, in the PE-free fed group only 2/20 IgE responders were observed in the rats sensitized to $1 \mathrm{mg} P E$ and no PE-specific IgE levels could be detected in the $10 \mathrm{mg}$ group (Fig. 8). Next, we compared PE-specific IgG2a titres after 42 days of exposure to PE. In the rats fed $3 G$ PE+soy-free all sensitized groups 
showed $100 \%$ IgG2a responders, whereas in the rats fed PE-free, 17/20 of rats sensitized to $1 \mathrm{mg} \mathrm{PE}$, and 9/10 of rats sensitized to $10 \mathrm{mg} P E$ showed positive reactions. Additionally, IgG2a titres were also higher in the 3G PE+soy-free fed rats than those in the PE-free fed rats (Fig. 9).

\section{Figure 8}

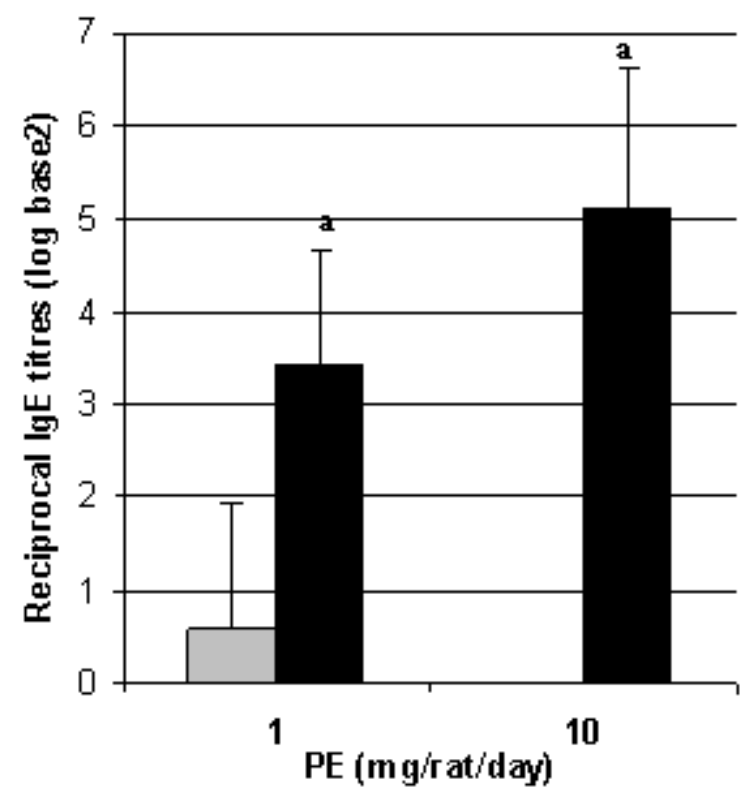

FIGURE 8. PE-specific IgE titres in both diet groups

Comparison of rats bred and raised on peanut-free food with rats bred on peanut- and soy-free food for 3 generations. Data are displayed as serum reciprocal IgE titres (average + S.E.M) on day 42. Grey bars represent the peanut-free bred group, while black bars represent the 3 generation peanut-and soy-free bred group.

a statistically significant $(p<0.001)$ compared to the PE-free bred group exposed to the same amount of peanut. 


\section{Figure 9}

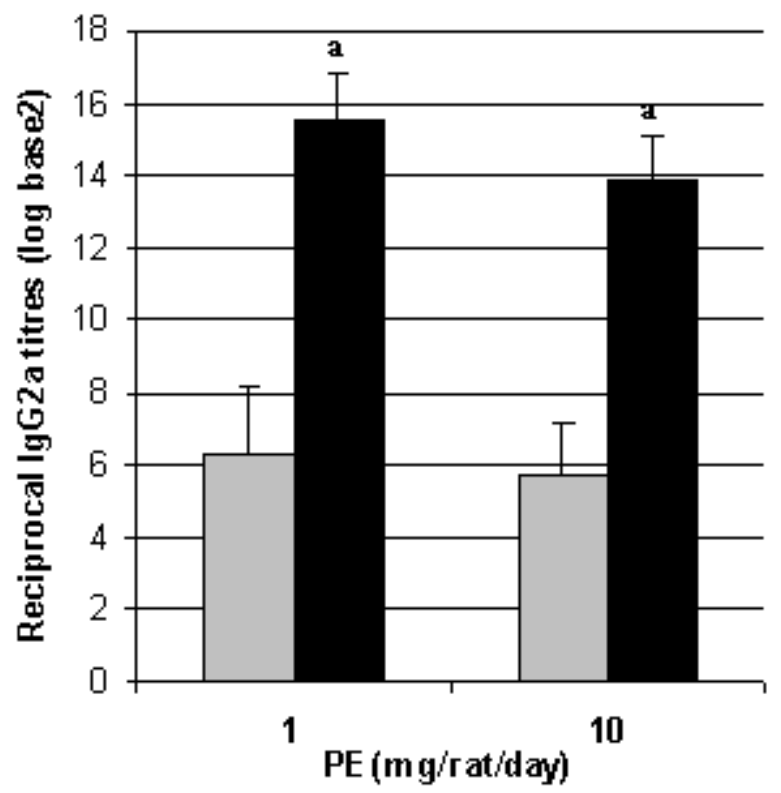

FIGURE 9. PE-specific IgG2a titres in both diet groups

Comparison of rats bred and raised on peanut-free food with rats bred on peanut- and soy-free food for 3 generations. Data are displayed as serum reciprocal IgG2a titres (average + S.E.M) on day 42 . Grey bars represent the peanut-free bred group, while black bars represent the 3 generation peanut-and soy-free bred group.

${ }^{a}$ statistically significant $(p<0.001)$ compared to the PE-free bred group exposed to the same amount of peanut.

Subsequently, we compared PE-specific IgG1 titres after 42 days of exposure to PE. All rats fed $3 G$ PE+soy-free showed positive IgG1 titres while in the PE-free group 19/20 rats reacted positively after sensitization to $1 \mathrm{mg} P E$, and 9/10 after sensitization to $10 \mathrm{mg} P E$. In addition, the PE-specific IgG1 responses were higher in the $3 \mathrm{G}$ $\mathrm{PE}+$ soy-free group than those in the PE-free group (Fig. 10). 


\section{Figure 10}

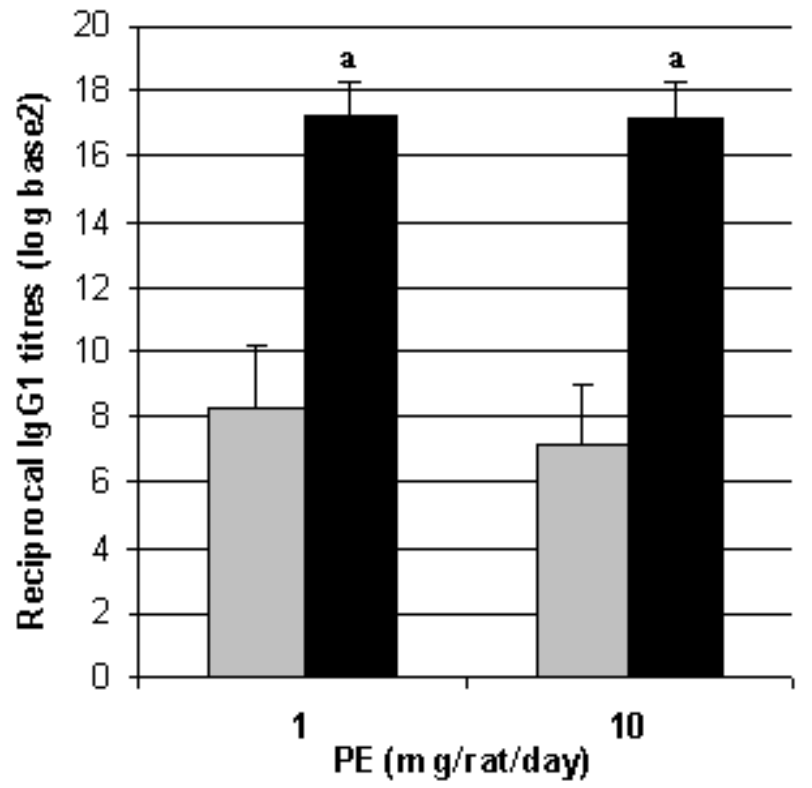

FIGURE 10. PE-specific IgG1 titres in both diet groups

Comparison of rats bred and raised on peanut-free food with rats bred on peanut- and soy-free food for 3 generations. Data are displayed as serum reciprocal IgG1 titres (average + S.E.M) on day 42. Grey bars represent the peanut-free bred group, while black bars represent the 3 generation peanut-and soy-free bred group.

${ }^{a}$ statistically significant $(p<0.001)$ compared to the PE-free bred group exposed to the same amount of peanut.

Finally, we studied the effect of diet on the RMCP-II responses 30 minutes after an oral PE challenge. An animal was considered a RMCP-II responder if the RMCP-II level after oral challenge exceeded 3 times the level prior to oral challenge. The percentage of animals of $3 \mathrm{G} \mathrm{PE+soy-free} \mathrm{fed} \mathrm{rats} \mathrm{that} \mathrm{showed} \mathrm{a} \mathrm{RMCP-II} \mathrm{response}$ was considerably higher than that of PE-free fed rats. Moreover, no RMCP-II responders could be detected in the $10 \mathrm{mg}$ PE-free group (Fig. 11). 


\section{Figure 11}

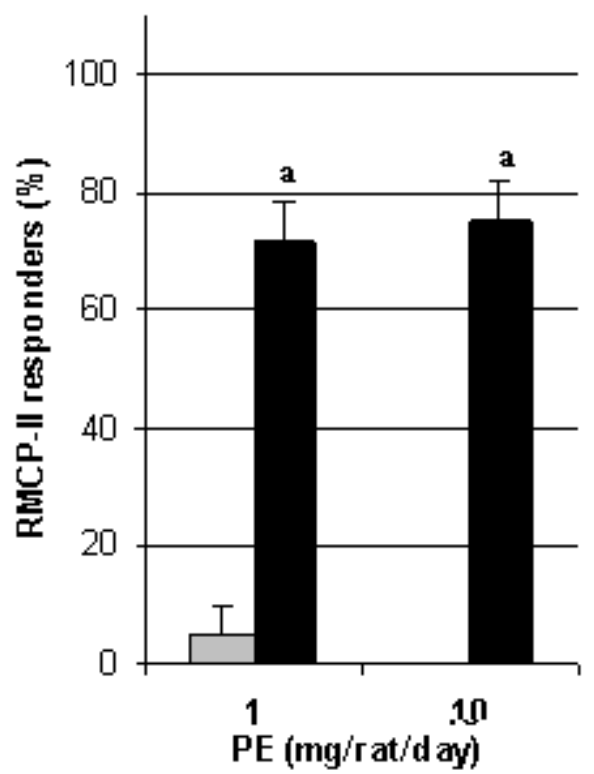

FIGURE 11. RMCP-II responders after oral challenge in both diet groups

Comparison of rats bred and raised on peanut-free food with rats bred on peanut- and soy-free food for 3 generations. Data are displayed as percentage of RMCP-II responders (average + S.E.M) 30 minutes after oral challenge with $100 \mathrm{mg}$ of PE/rat. An animal is a RMCP-II responder if the RMCP-II level after oral challenge exceeds 3 times the level prior to oral challenge. Grey bars represent the peanut-free bred group, while black bars represent the 3 generation peanut-and soy-free bred group.

a statistically significant $(p<0.001)$ compared to the PE-free bred group exposed to the same amount of peanut.

The effect of the oral adjuvant cholera toxin

Many animal models for food allergy apply an adjuvant to boost allergic responses. We investigated the effect of cholera toxin (CT) as an oral adjuvant in our model. In rats fed for 3 generations with peanut-and soy-free feed, daily adjuvation with cholera toxin resulted in higher PE-specific IgE titres in time compared to nonadjuvated rats (Fig. 2). This difference was significant at day 14. Furthermore, IgE titres also occurred at an earlier time point in the adjuvated group.

CT-adjuvation did not influence the development of PE-specific IgG2a titres as can be seen in Figure 3. A small but significant increase in IgG1 titres in CT exposed animals on day 28 was observed (Fig. 4). No influence of CT on RMCP-II levels was seen after oral challenge with $100 \mathrm{mg}$ PE as is shown in Figure 5. We found CT to neither significantly influence the number of eosinophilic basophilic granulocytes in blood (Fig. 6) nor have an influence on cytokine levels (Fig. 7). 
The effect of route of exposure on allergen recognition

In order to compare the allergen recognition of different routes of exposure the purified peanut allergens Ara h1, Ara $h 2$ and Ara $h 3$ were used to determine IgG2a responses against these specific allergens in rats bred on peanut-free feed. From these allergen-specific responses we calculated the percentage of animals that gave high responses (at least 3 times that of a control) to these purified allergens.

First, we looked at the IgG2a response against Ara $h 3$ in i.p. or orally sensitized animals ( 1 and $10 \mathrm{mg} / \mathrm{rat} /$ day). We found no high responders against Ara h3 in i.p. sensitized animals whereas the animals sensitized orally with $1 \mathrm{mg}$ or $10 \mathrm{mg}$ showed $50 \%$ and $30 \%$ Ara $h 3$ specific IgG2a high responders, respectively.

Next, we compared Ara $h 1$ and Ara h2-specific IgG2a responses in the i.p. sensitized group with the highest responding orally sensitized group ( $1 \mathrm{mg} / \mathrm{rat} / \mathrm{day})$. From Table 1 it is clear that the i.p. and the orally sensitized groups show a similar percentage of IgG2a high responders against Ara h1, while the i.p. group shows a higher percentage of IgG2a high responders to Ara $h 2$ (70\%) as compared to the oral group (37.5\%).

TABLE 1. Specific IgG2a responses against Ara $h 1, \operatorname{Ara} h 2$ and $A r a h 3$

\section{Table 1}

\begin{tabular}{|c|c|c|c|c|}
\hline Group & $\mathrm{n}$ & $\begin{array}{l}\text { Ara h3 high } \\
\text { responders } \%)\end{array}$ & $\begin{array}{l}\text { Ara h2 high } \\
\text { responders }(\%)\end{array}$ & $\begin{array}{l}\text { Ara hl high } \\
\text { responders }(\%)\end{array}$ \\
\hline i.p. group & 10 & 0.0 & 70.0 & 60.0 \\
\hline oral group & 8 & $50.0^{4}$ & 37.5 & 50.0 \\
\hline
\end{tabular}

Rats bred on peanut-free feed received $1 \mathrm{mg} / \mathrm{rat} /$ day of peanut extract $(\mathrm{PE}$ ) by daily oral gavage (sera from day 42$)$ and were compared with rats sensitized i.p. $(0.5 \mathrm{ml}$ of a $0.2 \mathrm{mg} \mathrm{PE} / \mathrm{ml}$ solution in sterile PBS on days 0 (on this day potentiated with $0.2 \mathrm{ml}$ of a $25 \mathrm{mg} / \mathrm{ml}$ alum), 2, 4, 7, 9 and 11; sera from day 28). Data are displayed as percentage of IgG2a high responders against the purified peanut proteins Ara $h 1$, Ara h2 and Ara h3. Cut-off point for Ara h1, Ara h2 and Ara h3 high responders: optic density (O.D.) at $450 \mathrm{~nm}>0.6$ for $1: 8$ sera dilutions.

${ }^{a} p<0.01$ vs i.p. sensitized group.

\section{DISCUSSION}

There is increasing interest in the development and evaluation of approaches for the safety assessment of novel foods, and in particular in methods for characterization of allergenic potential. It is evident that considerable progress has been made in developing rodent models for the assessment of the allergenic potential of novel proteins but a lot of research remains to be done. Animal models have been suggested for the identification of intrinsic hazard that is the inherent potential of a protein to cause allergic sensitization [60]. Since there are no validated animal 
models available yet, further efforts are needed to evaluate and validate the sensitivity, specificity, and reproducibility of these models. The approach described herein comprises systemic oral exposure of BN strain rats to protein allergens (in this experiment the peanut matrix) with responses measured as a function of allergen-specific IgE, IgG1 and IgG2a antibody expression, allergen-specific degranulation analyzed by RMCP-II levels in sera, enumeration of peripheral granulocytes and measurement of T-helper 1 (Th1) and T-helper 2 (Th2) cytokines after restimulation with the antigen in vitro.

The herein described non-adjuvated BN model for food allergy shows $100 \%$ PEspecific IgE, IgG2a and IgG1 responders in both oral dosing groups (1 and $10 \mathrm{mg}$ $\mathrm{PE} / \mathrm{rat} / \mathrm{day})$. Furthermore, the magnitude of the PE-specific IgE responses and the onset of positive responses were dose-related. Other allergy related parameters, such as RMCP-II, blood eosinophils and basophils were also increased in both dosing groups. Furthermore, Th1 (IFN- - ) cytokines were increased. Previous studies [61-66] have shown that food allergy in experimental animals is not strictly mediated by Th2 responses, but that a mixed Th1/Th2 response is involved. Recent studies on airway hypersensitivity $[67,68]$ suggest that the Th2 hypothesis is too simplistic and also in food allergy research the concept of an antigen-specific mixed Th1/Th2 response has gained ground [61-66]. Important to note is that it is not always possible in these models for food allergy to discriminate between the roles of the allergen and the adjuvant. A mixed Th1/Th2 response has also been demonstrated in humans. A polyisotypic peanut-specific humoral response was observed in peanut-allergic individuals, including elevated levels of serum $\lg G 1, \lg G 4$, and $\lg A$ [69]. Our data on peanut-specific immunoglobulins in $\mathrm{BN}$ rats are in accordance with these human data: both Th1 (IgG1) and Th2 (IgE and IgG2a) Igs were found after exposure to peanut.

These data indicate that $\mathrm{BN}$ rats that were bred for 3 generations on a soy- and peanut-free diet could be orally sensitized to peanut without the use of an adjuvant. In addition, the measured specific antibodies were shown to be bioactive since clear challenge reactions could be observed in these animals, as demonstrated by elevated levels of RMCP-II. In contrast, in rats that were bred on a peanut-free diet only a few rats responded with IgE. Thus, exposure to soy can render the animals tolerant for subsequent oral peanut exposure. This underlines that with proper diet restrictions oral models for food allergy can be a sensitive tool which is in accordance with previous studies [32,33,40,70].

The adjuvant CT had only limited effects in this model. Adjuvation with CT enhanced the magnitude of IgE and to a lesser extent IgG1 but not of IgG2a, RMCP-II levels, numbers of granulocytes and cytokine levels. This indicates that in rats bred on a soy- and peanut-free diet, oral sensitization may already have been optimal or nearly optimal and CT could not increase the sensitivity of the model. 
Since one of the most contentious issues regarding the development of various animal models of food allergy is that of the preferred route of exposure, we examined whether BN rats orally or i.p. exposed to peanut proteins would develop specific antibodies against the purified major allergens (Ara h1, Ara h2 and Ara h3). When comparing the allergen recognition of different routes of exposure we found that the response of i.p. and orally sensitized animals were comparable against one of the three tested purified allergens (Ara h1) but differed for the remaining two purified allergens (Ara h2 and Ara h3). The specific IgG2a response (Th2-mediated in rat) against $A r a h 2$ in i.p. sensitized animals was twice that of orally sensitized animals. Moreover, the specific IgG2a response against Ara $h 3$ was not found in the i.p. sensitized group but was found in $50 \%$ of the orally sensitized group. We could thus conclude that the route of exposure has an influence on the allergen recognition pattern: i.p. sensitization leads to the recognition of Ara $h 1$ and Ara $h 2$ and not Ara $h 3$, while oral sensitization leads to the recognition of all three purified major allergens. After oral exposure, proteins can be digested in the gastrointestinal tract, which may lead to presentation of different antigenic structures compared to i.p. exposure, without digestion. In contrast to i.p. dosing, oral dosing involves both oral mucosa and gut [71] and the accompanying mucosal immune systems, which may lead to induction of IgE responses to different allergens in orally compared to i.p. exposed rats.

We showed that the profile of peanut allergens recognized by the immune system of the $\mathrm{BN}$ rat could be more comparable to the profile of allergens recognized by peanut allergic humans after oral compared to i.p. exposure of the $\mathrm{BN}$ rats to peanut. These data support the preference for an oral model when dealing with food allergy since oral administration represents the most appropriate route of exposure for a method designed to identify potential food allergens. Furthermore, BN rats could discriminate between strong- (ovalbumin) weak- (bovine serum albumin) and non-allergenic (potato acid phophatase) proteins after oral exposure without the use of any adjuvants [16].

Other factors, including gender and age of animals, are also known to contribute to the sensitivity of oral allergy induction. Pilegaard and Madsen [14] demonstrated that sensitization of female BN rats to egg allergens offered a higher amount of IgEresponders (38-75\%) than did males (13-38\%). Therefore we used female rats from the third generation of peanut- and soy-free bred rats (study $A$ ), while for study $B$ male rats were used. This difference in sex, could to some extent contribute to the increased sensitivity of our extensive diet-controlled model. Another factor of importance is age. With age the immune system matures which makes sensitization harder $[72,73]$. BN rats become less Th2-prone with age $[74,75]$ and consequently less apt to sensitization. For this reason we used young rats (3-4 weeks at study initiation). 


\section{CONCLUSION}

Our study shows that extensive diet control can greatly increase sensitivity of BN rats to oral sensitization to peanut. The non-adjuvated oral model as described displayed maximum PE-specific IgE, IgG2a and IgG1 responders. The extensive diet control enhanced the sensitivity by such extent that even the potent oral adjuvant CT could enhance the allergic response to a limited extent. Furthermore, we demonstrated by comparing the specific IgG2a response against several purified peanut allergens of i.p. and orally sensitized animals that the allergen recognition patterns differ between different routes of exposure with only oral exposed animals recognizing all tested major allergens. Taken together, these data demonstrate that for food allergy the preferred model would be (A) oral and (B) if possible without the use of an adjuvant. Our model in BN rats unites these preferred characteristics.

\section{ACKNOWLEDGEMENTS}

The author likes to thank the following people for their generous assistance: Femke van Wijk, Stef J. Koppelman, Raymond Pieters, Arja de Klerk, Bert Verlaan, Eric R. Gremmer, Yvonne C. Wallbrink, Liset J.J. de la Fonteyne, Piet J. van Schaaik and Hans C. Strootman. This study was financed by a grant from the Netherlands Food and Consumer Products Authority (VWA, Den Haag, the Netherlands).

\section{REFERENCES}

[1] H.A. Sampson, J Allergy Clin Immunol 113 (2004) 805-819

[2] D.A. Moneret-Vautrin, M. Morisset, Curr Allergy Asthma Rep 5 (2005) 80-85.

[3] R.S. Kagan, Environ. Health Perspect. 111 (2003) 223-225.

[4] E.N. Mills, H. Breiteneder, Biotechnol Adv 23 (2005) 409-414.

[5] EU, website: http://europa.eu.int/eur-lex/pri/en/oj/dat/2003/I_308/I_30820031125en00150018.pdf (2003).

[6] S.A. Bock, A. Munoz-Furlong, H.A. Sampson, J Allergy Clin Immunol 107 (2001) 191-193.

[7] L. Pons, K. Palmer, W. Burks, Curr Opin Allergy Clin Immunol 5 (2005) 558-562.

[8] H.S. Skolnick, M.K. Conover-Walker, C.B. Koerner, H.A. Sampson, W. Burks, R.A. Wood, J Allergy Clin Immunol 107 (2001) 367-374.

[9] T. Kleber-Janke, R. Crameri, U. Appenzeller, M. Schlaak, W.M. Becker, Int Arch Allergy Immunol 119 (1999) 265-274.

[10] R. Fritsche, Toxicol.Lett. 140-141 (2003) 303-309.

[11] A.H. Penninks, L.M. Knippels, Toxicol.Lett. 120 (2001) 171-180.

[12] H.A. Atkinson, I.T. Johnson, J.M. Gee, F. Grigoriadou, K. Miller, Food Chem.Toxicol. 34 (1996) 27-32.

[13] H.A. Atkinson, K. Miller, Toxicology 91 (1994) 281-288.

[14] K. Pilegaard, C. Madsen, Toxicology 196 (2004) 247-257.

[15] L.M. Knippels, A.H. Penninks, S. Spanhaak, G.F. Houben, Clin. Exp. Allergy 28 (1998) 368-375.

[16] X.D. Jia, N. Li, Y.N. Wu, X.G. Yang, World J Gastroenterol 11 (2005) 5381-5384.

[17] X. Jia, L. N., W. Wang, Y. Wu, Wei Sheng Yan Jiu 33 (2004) 63-65.

[18] T. Ogawa, S. Miura, Y. Tsuzuki, T. Ogino, K. Teramoto, T. Inamura, C. Watanabe, R. Hokari, H. Nagata, H. Ishii, AJP - Gastrointestinal and Liver Physiology (2003) 00183.

[19] L.M. Knippels, A.H. Penninks, Ann.N.Y.Acad.Sci. 964 (2002) 151-161. 
[20] L.M. Knippels, H.P. van der Kleij, S.J. Koppelman, G.F. Houben, A.H. Penninks, Allergy 55 (2000) 251258.

[21] L.M. Knippels, G.F. Houben, S. Spanhaak, A.H. Penninks, Methods 19 (1999) 78-82.

[22] L.M. Knippels, A.H. Penninks, M. van Meeteren, G.F. Houben, Food Chem. Toxicol. 37 (1999) 881888.

[23] L.M. Knippels, A.H. Penninks, J.J. Smit, G.F. Houben, Toxicol. Appl. Pharmacol. 156 (1999) 161-169.

[24] L.M. Knippels, A.H. Penninks, Environ.Health Perspect. 111 (2003) 233-238.

[25] I. Kimber, S. Stone, R.J. Dearman, Environ. Health Perspect. 111 (2003) 227-231.

[26] X.M. Li, D. Serebrisky, S.Y. Lee, C.K. Huang, L. Bardina, B.H. Schofield, J.S. Stanley, A.W. Burks, G.A. Bannon, H.A. Sampson, J Allergy Clin Immunol 106 (2000) 150-158.

[27] X.M. Li, B.H. Schofield, C.K. Huang, G.I. Kleiner, H.A. Sampson, J Allergy Clin Immunol 103 (1999) 206-214.

[28] X.M. Li, G. Kleiner, C.K. Huang, S.Y. Lee, B. Schofield, N.A. Soter, H.A. Sampson, J Allergy Clin Immunol 107 (2001) 693-702.

[29] G.R. Stenton, H. Vliagoftis, A.D. Befus, Ann Allergy Asthma Immunol 81 (1998) 1-11.

[30] T.A. Beardslee, M.G. Zeece, G. Sarath, J.P. Markwell, Int Arch Allergy Immunol 123 (2000) 299-307.

[31] P.A. Eigenmann, A.W. Burks, G.A. Bannon, H.A. Sampson, J Allergy Clin Immunol 98 (1996) 969-978.

[32] L.M. Knippels, A.H. Penninks, G.F. Houben, J. Allergy Clin. Immunol. 101 (1998) 815-820.

[33] S. Brix, H.R. Christensen, V. Barkholt, H. Frokiaer, Int Arch Allergy Immunol 136 (2005) 250-257.

[34] N.A. Williams, T.R. Hirst, T.O. Nashar, Immunol Today 20 (1999) 95-101.

[35] C.O. Elson, W. Ealding, J Immunol 133 (1984) 2892-2897.

[36] J. Holmgren, N. Lycke, C. Czerkinsky, Vaccine 11 (1993) 1179-1184.

[37] N. Lycke, Res Immunol 148 (1997) 504-520.

[38] C.P. Simmons, M. Ghaem-Magami, L. Petrovska, L. Lopes, B.M. Chain, N.A. Williams, G. Dougan, Scand J Immunol 53 (2001) 218-226.

[39] M.E. Bashir, P. Andersen, I.J. Fuss, H.N. Shi, C. Nagler-Anderson, J Immunol 169 (2002) 3284-3292.

[40] H.R. Christensen, T.M. Kjaer, H. Frokiaer, Int Arch Allergy Immunol. 132 (2003) 248-257.

[41] R.M. Helm, G.T. Furuta, J.S. Stanley, J. Ye, G. Cockrell, C. Connaughton, P. Simpson, G.A. Bannon, A.W. Burks, J Allergy Clin Immunol 109 (2002) 136-142.

[42] S. Kroghsbo, H.R. Christensen, H. Frokiaer, Int.Arch.Allergy Immunol. 131 (2003) 256-263.

[43] N. Foss, M. Duranti, C. Magni, H. Frokiaer, Int Arch Allergy Immunol 141 (2006) 141-150.

[44] K. Adel-Patient, H. Bernard, S. Ah-Leung, C. Creminon, J.M. Wal, Allergy 60 (2005) 658-664.

[45] F. van Wijk, S. Nierkens, I. Hassing, M. Feijen, S.J. Koppelman, G.A. de Jong, R. Pieters, L.M. Knippels, Toxicol Sci 86 (2005) 333-341.

[46] J.H. Yardley, G.D. Brown, Lab Invest 28 (1973) 482-493.

[47] G.T. Keusch, P. Atthasampunna, R.A. Finkelstein, Proc Soc Exp Biol Med 124 (1967) 822-825.

[48] D. Sasmal, B. Guhathakurta, A.N. Ghosh, C.R. Pal, A. Datta, FEMS Immunol Med Microbiol 10 (1995) 199-205.

[49] S. Lange, D.S. Delbro, E. Jennische, E. Johansson, I. Lonnroth, Dig Dis Sci 43 (1998) 2061-2070.

[50] D.A. Sack, R.B. Sack, G.B. Nair, A.K. Siddique, Lancet 363 (2004) 223-233.

[51] J.B. Kaper, J.G.J. Morris, M.M. Levine, Clin Microbiol Rev 8 (1995) 48-86.

[52] X.M. Li, T.F. Zhang, C.K. Huang, K. Srivastava, A.A. Teper, L. Zhang, B.H. Schofield, H.A. Sampson, J Allergy Clin Immunoll 108 (2001) 639-646.

[53] E. Hornquist, N. Lycke, Eur J Immunol 23 (1993) 2136-2143.

[54] M. Marinaro, H.F. Staats, T. Hiroi, R.J. Jackson, M. Coste, P.N. Boyaka, N. Okahashi, M. Yamamoto, H. Kiyono, H. Bluethmann, e. al., J Immunol 155 (1995) 4621-4629.

[55] A.D. Wilson, M. Bailey, N.A. Williams, C.R. Stokes, Eur J Immunol 21 (1991) 2333-2339.

[56] J. Xu-Amano, H. Kiyono, R.J. Jackson, H.F. Staats, K. Fujihashi, P.D. Burrows, C.O. Elson, S. Pillai, J.R. McGhee, J Exp Med 178 (1993) 1309-1320.

[57] S.J. Koppelman, E.F. Knol, R.A. Vlooswijk, M. Wensing, A.C. Knulst, S.L. Hefle, H. Gruppen, S. Piersma, Allergy 58 (2003) 1144-1151. 
[58] E.C. de Jong, M. Van Zijverden, S. Spanhaak, S.J. Koppelman, H. Pellegrom, A.H. Penninks, Clin Exp Allergy 28 (1998) 743-751.

[59] U.K. Laemmli, Nature 227 (1970) 680-685.

[60] I. Kimber, R.J. Dearman, A.H. Penninks, L.M. Knippels, R.B. Buchanan, B. Hammerberg, H.A. Jackson, R.M. Helm, Environ. Health Perspect. 111 (2003) 1125-1130.

[61] F. van Wijk, S. Hartgring, S.J. Koppelman, R. Pieters, L.M. Knippels, Clin Exp Allergy 34 (2004) 14221428.

[62] K. Palmer, W. Burks, Curr Opin Allergy Clin Immunol 6 (2006) 202-206.

[63] T.W. Ng, P.G. Holt, S.L. Prescott, Allergy 57 (2002) 207-214.

[64] E. Holen, B. Bolann, S. Elsayed, Clin Exp Allergy 31 (2001) 952-964.

[65] J.M. Smart, A.S. Kemp, Clin Exp Allergy 32 (2002) 796-802.

[66] P.A. Eigenmann, C.P. Frossard, Curr. Opin. Allergy Clin. Immunol. 3 (2003) 199-203.

[67] H.A. Boushey, J.V. Fahy, Lancet 356 (2000) 2114-2116.

[68] S.S. Salvi, K.S. Babu, S.T. Holgate, Am J Respir Crit Care Med 164 (2001) 1343-1346.

[69] M.N. Kolopp-Sarda, D.A. Moneret-Vautrin, B. Gobert, G. Kanny, L. Guerin, G.C. Faure, M.C. Bene, Clin Exp Allergy 31 (2001) 47-53.

[70] H.R. Christensen, S. Brix, H. Frokiaer, Br J Nutr 91 (2004) 725-732.

[71] C. Madsen, K. Pilegaard, Int.Arch.Allergy Immunol. 130 (2003) 66-72.

[72] R. Pauwels, H. Bazin, B. Platteau, M. van der Straeten, Immunology 36 (1979) 145-149.

[73] S. Strobel, A. Ferguson, Pediatr Res 18 (1984) 588-594.

[74] K. Ide, H. Hayakawa, T. Yagi, A. Sato, Y. Koide, A. Yoshida, M. Uchijima, T. Suda, K. Chida, H. Nakamura, J Immunol 163 (1999) 396-402.

[75] P.H. van der Meide, R.J. Groenestein, M.C. de Labie, J. Aten, J.J. Weening, Cell Immunol 162 (1995) 131-137. 



\section{Chapter 3}

\section{Bis(tributyltin)oxide (TBTO) decreases}

the food allergic response against peanut and ovalbumin in Brown Norway rats

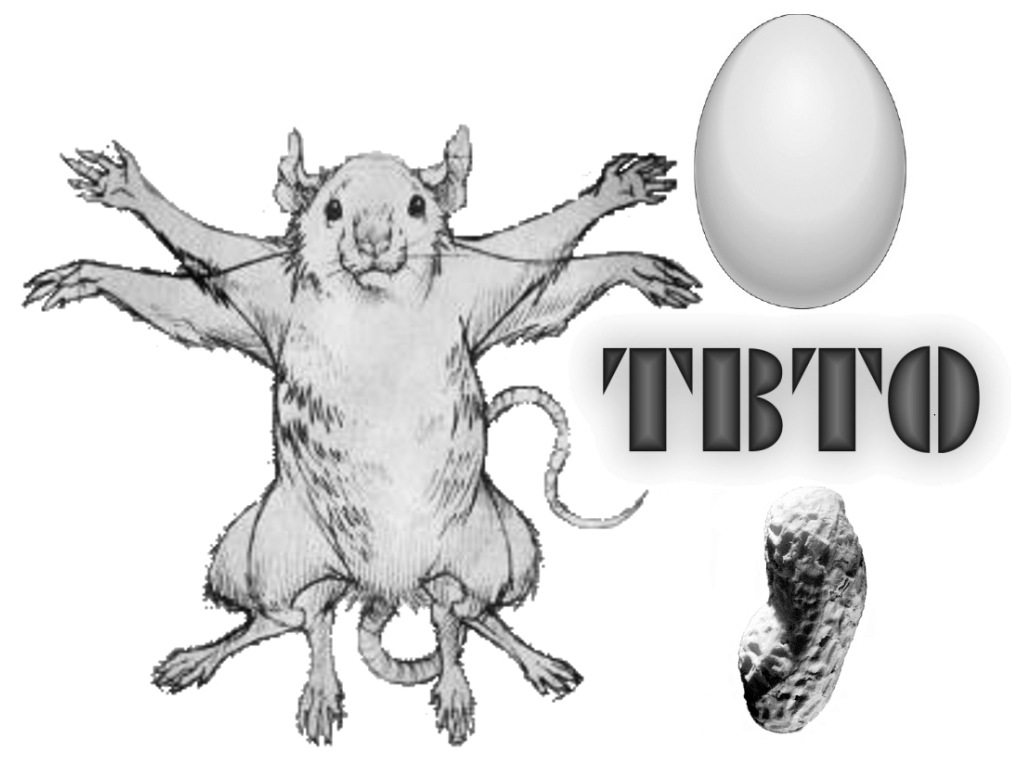

Published in Toxicology 239, 68-76 (2007). 


\section{ABSTRACT}

Other factors than the allergen itself may be of importance in the development of food allergy. This report describes the influence of the immunosuppressive compound bis(tributyltin)oxide (TBTO), present in the food chain, on the development of food allergy to peanut or ovalbumin in Brown Norway (BN) rats. To study these effects $B N$ rats were sensitized to either 1 or $10 \mathrm{mg}$ peanut or ovalbumin by daily oral gavage and the TBTO-groups were fed a diet containing $80 \mathrm{mg}$ TBTO per $\mathrm{kg}$ diet.

Co-exposure to TBTO not only resulted in decreased general immunologic parameters such as weights of mesenteric lymph nodes and Peyer's patches, lymphocyte proliferation rates in splenocytes, but also on allergic parameters. In the peanut allergen-model TBTO decreased allergen-specific Th2 cytokine production by spleen cells, number of eosinophilic and basophilic granulocytes in the blood and production of mast cell protease II after oral food challenge. In the ovalbumin allergenmodel TBTO decreased the number of eosinophilic and basophilic granulocytes, allergen-specific IgE and production of mast cell protease II after oral food challenge.

The data imply that in the process of risk assessment of food allergy attention should be given to immunomodulating compounds present in the diet.

\section{INTRODUCTION}

Considerable progress has been made in the development of rodent models for the assessment of allergenic potential of food proteins (de Jonge et al. 2007; Dearman et al. 2000; Dearman and Kimber 2001; Knippels et al. 1998). So far, animal models are being proposed for hazard identification of potential allergenicity of (novel) foods. A next step may be to use animal models for risk assessment of allergens. This manuscript describes the effect of immunomodulating compounds in food on the development of allergic responses, as such influences may possibly be needed to incorporate in the eventual process of risk assessment.

As an example of an immunomodulatory compound that could influence the food allergic response we studied bis(tributyltin)oxide (TBTO; $\mathrm{C}_{24} \mathrm{H}_{54} \mathrm{OSn}_{2}$ ). TBTO is present in the food chain (Aluoch and Whalen 2005; Ikeda et al. 2001; Sekizawa 1998; WHO-IPCS 1999). In several studies with laboratory animals, both short term and long term, it has been demonstrated that TBTO is an immunotoxic chemical (Aluoch and Whalen 2005; Ikeda et al. 2001; Sekizawa 1998; WHO-IPCS 1999). Immunosuppression by TBTO in rats is characterized by a direct action of TBTO on cortical thymocytes, resulting in suppressed T-cell dependent immune responses. Vos et al. (Vos et al. 1984; Vos et al. 1990) found TBTO to reduce ovalbumin (OVA)-induced Delayed Type Hypersensitivity (DTH) reactions in rats. TBTO also decreased innate immune responses, such as Natural Killer (NK) cell (Aluoch and Whalen 2005; Dudi- 
mah et al. 2006) and macrophage activity (Vandebriel et al. 1998; Vos et al. 1984). In host resistance models TBTO suppressed resistance to the infectious agents Listeria monocytogenes (Vos et al. 1990) and Trichinella (T.) spiralis (Vos et al. 1984). In the $T$. spiralis model TBTO suppressed serum $T$. Spiralis-specific IgE titres (Vos et al. 1984).

TBTO has not only immunosuppressive effects as has been shown in a study in rats. In a study by Smialowicz et al. (1990) TBTO exposure enhanced the plaque forming cell (PFC) responses to sheep erythrocytes, which was attributed to effects on the suppressor (OX8-positive) T-lymphocyte population. In contrast, in a study by Van Loveren et al. (1991) it was found that TBTO decreased IgM-responses to sheep erythrocytes. These opposite results may relate to the different study design and the use of different dosages of TBTO, however both studies clearly show that TBTO has an influence on humoral responses to T-cell dependent antigens.

Food allergic processes are highly T-cell dependent, and regulation of T-cell responses play an important role in IgE-synthesis, further substantiating a possible effect of TBTO on food allergy. From its effects on specific IgE responses to parasites and its effect on T-cells, one may speculate that TBTO could also influence the food allergic reaction to food proteins, which is largely dependent on IgE responses. We have addressed this hypothesis in a Brown Norway (BN) rat model for food allergy, sensitized with ovalbumin (Knippels et al. 1998) or peanut allergen (de Jonge et al. 2007).

\section{MATERIALS AND METHODS}

Animals

Oral sensitization was studied in young Brown Norway (BN) rats. In the first study (experiment A) Brown Norway (BN Rij:Hsd) rats obtained from Harlan Netherlands B.V. (Horst, the Netherlands) were used. These rats were bred and raised on a peanut and soy protein-free diet (since soy and peanut are cross-reactive legumes (Beardslee et al. 2000; Eigenmann et al. 1996)) obtained from Harlan Netherlands B.V (2016S Teklad Global 16\% Protein Rodent Diet) at our institute (de Jonge et al. 2007). In this experiment, female rats of the third generation (F3) and onwards were used and fed the peanut and soy protein-free diet during the experiments.

In the second study (experiment B) female BN rats obtained from Harlan Netherlands B.V. (Horst, the Netherlands) were directly used. These rats were kept on a hen's egg white-free diet obtained from Harlan Netherlands B.V (2018S Teklad Global 18\% Protein Rodent Diet) at our institute and were bred by Harlan on the same diet.

At study initiation rats were 3-4 weeks old. The rats were housed in an animal room maintained at $23 \pm 3^{\circ} \mathrm{C}$, with a light/dark cycle of $14 \mathrm{~h} / 10 \mathrm{~h}$, and a relative humidity of $30-70 \%$ during the experiment and for at least 7 days prior to study initiation. The 
animals were housed in stainless-steel wire (Macrolon III) cages in groups of two and had free access to food and tap-water. Approval from the Institutional Animal Ethics Committee was obtained for all experimental procedures involving animals.

\section{Preparation of peanut extract}

Lightly blanched $\left(100^{\circ} \mathrm{C}\right.$ ) peanuts (Arachis Hypogaea) from the USA Runner cultivar were kindly provided by IMKO Gelria (Doetinchem, The Netherlands) and were stored at $4^{\circ} \mathrm{C}$ until use. Peanut extract (PE) was prepared according to the method described by Koppelman et al. (Koppelman et al. 2003) with some minor modifications that are described in our previous publication (de Jonge et al. 2007). To verify whether the PE contained the major allergens (Ara h1, Ara h2 and Ara h3) SDS-PAGE was performed essentially according to Laemlli (Laemmli 1970) using a BioRad Mini Protean II system (BioRad, Hercules, CA) with 15\% acrylamide gels $(15 \mathrm{~cm} \times 10 \mathrm{~cm}$ ) and the method applied has been described in detail previously (de Jonge et al. 2007).

\section{Preparation of TBTO diet}

Bis(tributyltin)oxide (TBTO) was purchased from Sigma-Aldrich Chemie GmbH (Steinheim, Germany). Prior to mixing the diets and TBTO, the diets were ground, in order to allow even distribution of $80 \mathrm{mg}$ TВTO/kg in the diet. The TBTO-diets were prepared at the facilities of the Toxicology and Applied Pharmacology Department of TNO Quality of Life (Zeist, The Netherlands).

\section{Endotoxin content}

The endotoxin content of the PE $(33.6 \mathrm{mg} / \mathrm{ml}$ in PBS) and OVA (10 mg/ml in PBS) was assessed chromatographically by quantitative limulus amebocyte (LAL) assay according to the manufacturer's instructions (Cambrex BioSciences, Wokingham, UK). The applied method has been described in detail in our previous publication (de Jonge et al. 2007). All the PE samples had endotoxin levels $<0.01 \mathrm{EU} / \mathrm{ml}$. These endotoxin levels are considered very low. All the OVA samples had endotoxin levels of $640 \mathrm{EU} / \mathrm{ml}(6.4 \mathrm{ng} / \mathrm{mg})$. These endotoxin levels for OVA were considered acceptable.

\section{Experimental design oral sensitization}

To ensure that animals were immunologically naive with respect to peanut (experiment A) or OVA (experiment B), pre-study blood samples were always tested for allergen specific antibodies. Rats were randomly allocated to their dosing regimens ( $n=8$ per dosing regimen). Some reallocation was performed to ensure even starting weight distribution in all dosing regimens. Rats were exposed to $1 \mathrm{ml}$ of 0,1 or 10 $\mathrm{mg} / \mathrm{ml} \mathrm{PE}$ in PBS (experiment A) or to $0.5 \mathrm{ml}$ of 0,2 or $20 \mathrm{mg} / \mathrm{ml}$ OVA in milliQ (experiment $B$ ) by daily oral gavage, using a 18-gauge stainless steel animal feeding 
needle for the duration of 6 weeks. The TBTO-groups were also exposed to the immunosuppressant (TBTO; $80 \mathrm{mg} / \mathrm{kg}$ diet) in their diets. Feeding with TBTO-diet started one week prior (day -7) to exposure to the allergen.

Blood samples were obtained from the tail vein at two-weekly intervals (day 14, 28 and 42 after start sensitization to PE or OVA). After coagulation for $1 \mathrm{~h}$ at room temperature, the blood samples were centrifuged (Heraeus Sepatech Biofuge 13, Osterode, Germany) for $15 \mathrm{~min}$. at $3000 \mathrm{G}$ and $4^{\circ} \mathrm{C}$ to obtain sera. The sera were stored at $-80^{\circ} \mathrm{C}$ until analyses for allergen-specific IgE and IgG antibodies and RMCPII levels by Enzyme Linked Immunosorbent Assay (ELISA).

Sensitized rats were orally challenged with a high dose of allergen followed by the determination of the level of rat mast cell protease II (RMCPII) in the serum. This protease is selectively expressed by intestinal mucosal mast cells in the rat and is a specific marker for mast cell activation that can be measured in serum (Stenton et al. 1998). After 42 days of daily oral exposure to the PE-dosages, rats did not receive allergen and TBTO for one week and were deprived of their food one day prior to sacrifice (day 49). At day 49, all rats were orally challenged by intragastric intubation with PE ( $2 \mathrm{~mL}$ of a $50 \mathrm{mg} / \mathrm{mL}$ solution) or OVA ( $1 \mathrm{~mL}$ of $100 \mathrm{mg} / \mathrm{ml}$ solution). Blood samples for hematology were taken from the orbital plexus $(0.5 \mathrm{ml} / \mathrm{rat})$ directly after oral challenge and were collected in K3-EDTA tubes obtained from Terumo Europe N.V. (Leuven, Belgium) to prevent clotting. Thirty minutes after the oral challenge, the animals were sacrificed by exsanguination from the aorta under $\mathrm{CO}_{2} / \mathrm{O}_{2}$ anesthesia. Serum samples were prepared as described above. Spleens, mesenteric lymph nodes (MLNs) and Peyer's patches (PP) were removed aseptically and weighed. A total of $10 \mathrm{PP} /$ rat were removed from the ileum (starting from the cecum).

Ex vivo stimulation of spleen cells: allergen-specific cell proliferation and cytokine production

Single cell suspensions were prepared under aseptic conditions by pressing the spleen through a $70 \mu \mathrm{m}$ nylon cell strainer (Falcon, Franklin Lakes, USA). Cells were washed twice and resuspended in $5 \mathrm{~mL}$ standard medium (RPMI $1640+25 \mathrm{mM}$ Hepes + L-Glutamine) obtained from Gibco BRL (Breda, the Netherlands) supplemented with $10 \%$ heat inactivated fetal calf serum (FCS) obtained from Integro B.V. (Zaandam, The Netherlands) and $1 \%$ penicillin-streptomycin (Gibco) with $7.5 \times 10^{-5} \mathrm{M}$ 2-mercaptoethanol (2-ME) obtained from SERVA (Heidelberg, Germany). Cell number was determined with a Coulter Counter (Z2, Coulter Electronics, Mijdrecht, The Netherlands). Cell viability was determined by the Trypan blue cytotoxicity test. The concentration of the cell suspensions was adjusted to $4 \times 10^{6}$ viable cells $/ \mathrm{ml}$.

For cell proliferation, $100 \mu \mathrm{L}$ of the cell suspension was added per well in triplicate. Cells were incubated for $96 \mathrm{~h}$ with $2 \mathrm{mg} / \mathrm{ml} \mathrm{PE}$ and $\left[{ }^{3} \mathrm{H}\right]$-Thymidine was added for the last 18-20 h. 
For cytokine measurements, $100 \mu \mathrm{l}$ of the cell suspension was added to the well and incubated with $1 \mathrm{mg} / \mathrm{ml}$ PE for $96 \mathrm{~h}$. In the supernatants, IL-2, IL-4, IL-5, IL-10, IL-13 and IFN- $\gamma$ were measured using a rat cytokine LINCOplex kit obtained from NUCLILAB B.V. (Ede, The Netherlands) according to the manufacturer's instructions. Cytokine measurements were performed on a Luminex ${ }^{\circledR}$ (Biorad Life Science, Hercules, CA, USA) and Luminex software was used to calculate the amount of cytokines (in $\mathrm{pg} / \mathrm{ml}$ supernatant).

\section{PE-DIG and OVA-DIG coupling}

Peanut extract-Digoxigenin (PE-DIG) and ovalbumin-Digoxigenin (OVA-DIG) coupling was established using a DIG-protein labeling kit obtained from Roche Diagnostics $\mathrm{GmbH}$ (Mannheim, Germany) according to manufacturer's instructions except for the following changes: $50 \mu \mathrm{L}$ of a $20 \mathrm{mg} / \mathrm{mL}$ digoxigenin-3-0-succinyl- $\varepsilon$-aminocaproic acid-N-hydroxy-succinimide ester (DIG-NHS) solution in DMSO was added to $1 \mathrm{~mL}$ of a $6 \mathrm{mg} / \mathrm{mL}$ solution of crude PE in PBS or OVA in PBS. From this point on the manufacturer's instructions were followed. A 1:2000 dilution of PE-DIG or OVA-DIG was used in the assay.

\section{Negative and positive control sera for Ig ELISAs}

Pooled serum, obtained from male F3 BN rats which were not exposed to peanut allergens, was used as negative control for both experiment $A$ and experiment $B$. Positive control sera were obtained by sensitizing female $B N$ rats i.p. . At day 0 rats were injected with a solution that contained $500 \mu \mathrm{l}$ of $0.2 \mathrm{mg} / \mathrm{ml}$ PE or OVA mixed with $200 \mu$ l alum adjuvant suspension (Pierce) in sterile saline. On day 2, 4, 7, 9 and 11 rats were injected ip with $500 \mu \mathrm{l} 0.2 \mathrm{mg}$ PE or OVA $/ \mathrm{ml}$ solution in sterile PBS. The animals were sacrificed on day 28 by exsanguination from the abdominal aorta. Sera were prepared and stored as described above.

\section{PE- and OVA-specific IgE, IgG1 and IgG2a ELISAs}

PE-specific IgE, IgG1 and IgG2a ELISAs were performed as described earlier (de Jonge et al. 2007). OVA-specific IgE, IgG1 and IgG2a ELISAs were done following the same protocol, but for the IgE ELISA an OVA-DIG conjugate was used.

\section{Measurement of rat mast cell protease II (RMCPII)}

RMCPII concentrations were determined in day 42 and 49 sera with a RMCPII ELISA kit (Moredun Scientific Limited, Penicuik, Midlothian, Scotland, UK) according to manufacturer's instructions.

\section{Differential cell counting}

Blood samples, obtained on day 49 were diluted 1:1 in a solution of Bovine Serum Albumin (Fraction V, purity $\geq 96 \%$; Sigma-Aldrich) in saline (40 g/L). The number of 
white blood cells (WBC), and differential cell counting was performed using Bayer Advia 120 Hematology System (Bayer HealthCare, Diagnostics division, Tarrytown, NY, USA).

\section{Statistics}

We tested the hypothesis that TBTO decreases parameters of food allergy. The overall difference between the control groups and TBTO-treated groups regarding the immune parameters tested were assessed with a two-way analysis of variance (ANOVA) with Bonferroni for pairwise comparisons as post hoc test. The results from the PE and OVA experiments were analyzed separately. To determine if TBTO decreased an allergic parameter within a dosing group of either OVA or PE a one-way ANOVA with Bonferroni as post hoc test was done.

The number of immune cells in blood was log-transformed prior to analysis, because these data did not meet the prerequisite of ANOVA that data should be normally distributed. In all analyses, data were considered significantly different if $p<$ 0.05 (one-sided).

\section{RESULTS}

The effect of TBTO on relative weight of PP and $M L N$

Daily oral exposure to $1 \mathrm{mg} P E$ resulted in a significant increase of the relative weight of the PPs (Figure 1A). TBTO decreased the weight of PPs significantly. If separate allergen dose groups were evaluated, the decrease was significant in the groups exposed to 1 and $10 \mathrm{mg}$ PE. Relative weights of MLNs were not affected by exposure to PE. Overall, TBTO significantly reduced MLN weight, but this difference was not statistically significant when separate allergen dose groups were analyzed (Fig. 1B).

Generally, in the model with OVA similar observations were done (Figure 2). In contrast to the model with PE, TBTO decreased the MLN weight in all separate dose groups (Figure $2 \mathrm{~B}$ ). 
(a)

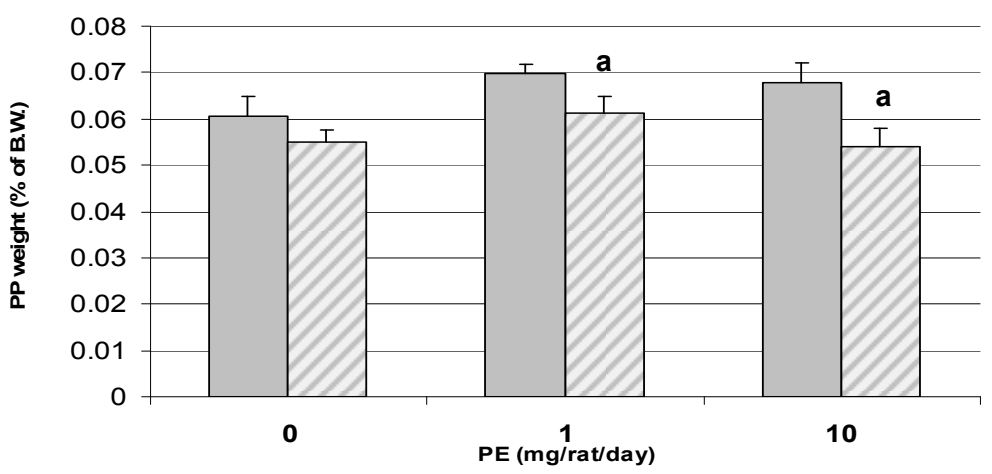

(b)

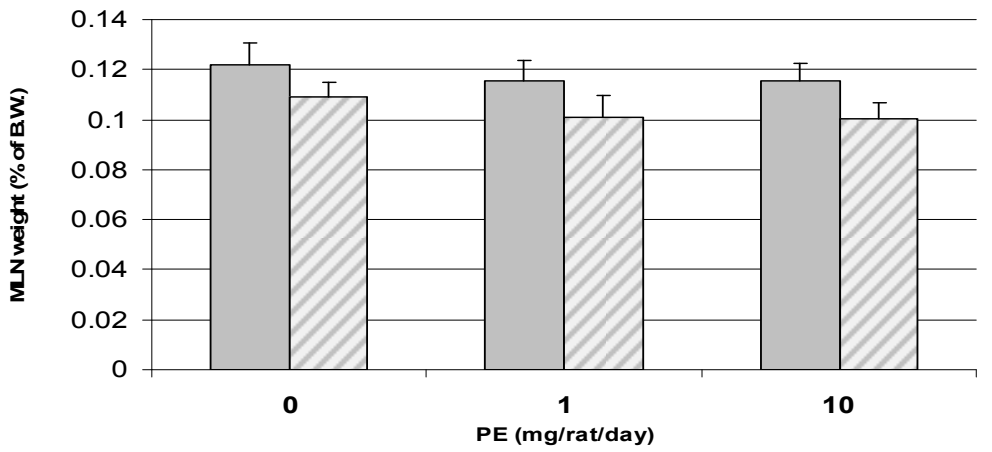

FIGURE 1. Lymph node weights in the PE-model

Groups of female rats ( $n=8$ for each dosing regiment) received 0,1 or $10 \mathrm{mg} / \mathrm{rat} /$ day of PE by daily oral gavage. MLNs and PP were dissected at day 49. Data are displayed as percentages of the body weight (B.W.) for PP (A) and MLN (B) (average + S.E.M). Grey bars represent the groups that received the control diet and striped grey bars represent the groups that received the TBTO diet (80 $\mathrm{mg}$ TBTO/kg diet). TBTO significantly decreased the relative weight of the MLN $(p=0.012)$ and of the PP $(p=0.001)$. ${ }^{a}$ effects of TBTO on relative PP weight were significant when separate allergen dose groups were analyzed: $p=0.023$ ( $1 \mathrm{mg}$ PE + TBTO compared to $1 \mathrm{mg} \mathrm{PE}$ ) and $p=0.016$ (10 mg PE + TBTO compared to 10 $\mathrm{mg} P \mathrm{P})$. 
(a)

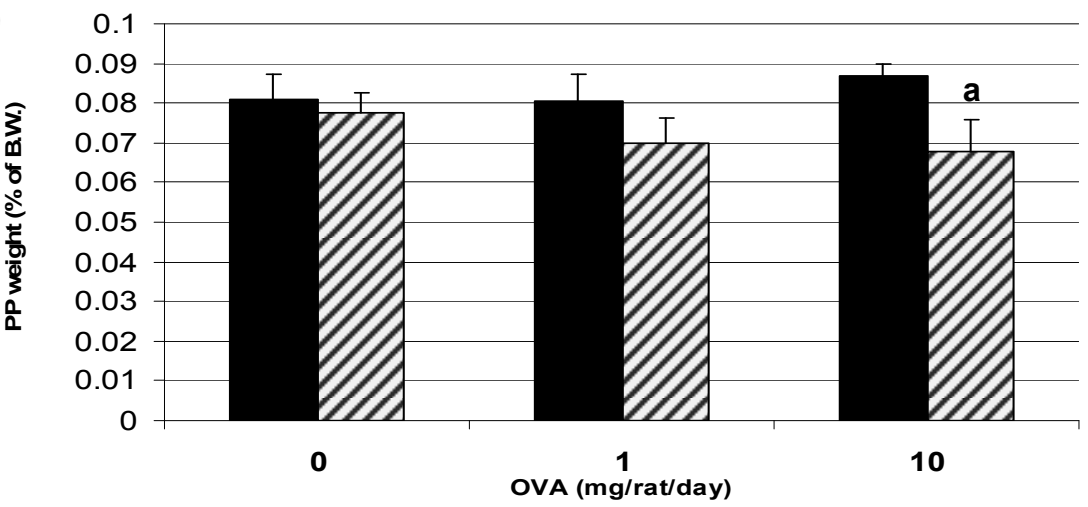

(b)

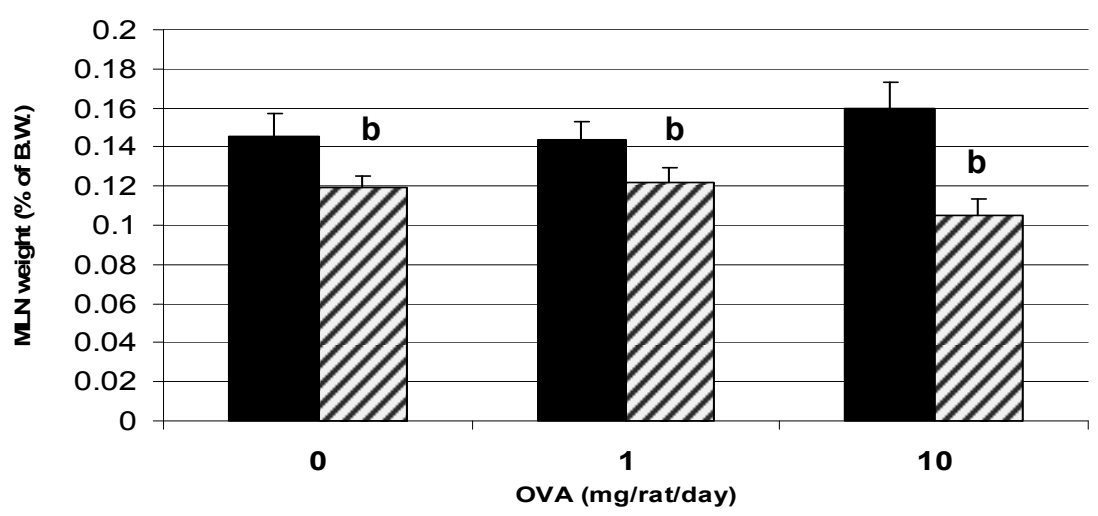

FIGURE 2. Lymph node weights in the OVA-model

Groups of female rats ( $\mathrm{n}=8$ for each dosing regiment) received 0,1 or $10 \mathrm{mg} / \mathrm{rat} /$ day of OVA by daily oral gavage. MLNs and PP were dissected at day 49. Data are displayed as percentages of the body weight (B.W.) for PP (A) and MLN (B) (average + S.E.M). Black bars represent the groups that received the control diet and striped black bars represent the groups that received the TBTO diet (80 $\mathrm{mg}$ TBTO/kg diet).

TBTO significantly decreased the relative weight of the $\operatorname{MLN}(p=0.001)$ and of the $\operatorname{PP}(p=0.011)$.

a effects of TBTO on relative PP weight were significant when separate allergen dose groups were analyzed: $p=0.019$ (10 mg OVA + TBTO compared to $10 \mathrm{mg}$ OVA).

${ }^{b}$ effects of TBTO on relative MLN weight were significant when separate allergen dose groups were analyzed: $p=0.041$ ( 0 mg OVA + TBTO compared to $0 \mathrm{mg}$ OVA), $p=0.044$ ( $1 \mathrm{mg}$ OVA + TBTO compared to $1 \mathrm{mg}$ OVA) and $p=0.002$ (10 mg OVA + TBTO compared to $10 \mathrm{mg}$ OVA).

The effect of TBTO on PE-specific lymphocyte cell proliferation in the spleen

Figure 3 shows that TBTO suppressed PE-specific proliferation of splenocytes. When separate dose groups were evaluated, this decrease was significant only in rats sensitized with $1 \mathrm{mg}$ PE.

The effect of TBTO on PE-specific cytokine levels in spleen supernatant

The production of cytokines by spleen cells cultured ex vivo with PE is shown in Table 1. IL-2 production was not influenced by PE, but IL-2 levels were significantly 
lower in TBTO exposed animals $(p=0.007)$. When evaluating the dose groups separately, this decrease was significant in the 0 and $10 \mathrm{mg}$ PE groups $(p=0.028$ and $p=$ 0.044 respectively). In sensitized rats, IL-4, IL-5, IL-10, IL-13 and IFN- $\gamma$ were increased. Overall, TBTO decreased IL-4 $(p=0.036)$, IL-5 $(p=0.016)$, and IL-13 ( $p=$ $0.014)$. When single dose groups were analyzed IL-13 levels were significantly decreased in rats exposed to $10 \mathrm{mg}$ PE $(p=0.036)$.

TABLE 1. PE-specific cytokine production by spleen cells

$$
\mathrm{PE} \text { (mg/rat/day) }
$$

\begin{tabular}{|c|c|c|c|c|}
\hline All cytokines (pg/ml) & Modulator & 0 & 1 & 10 \\
\hline \multirow[t]{2}{*}{ IL-2 ${ }^{a}$} & None & $131.58 \pm 20.26$ & $103.90 \pm 18.23$ & $109.53 \pm 12.40$ \\
\hline & твто & $82.16 \pm 12.26^{b}$ & $86.41 \pm 16.47$ & $79.66 \pm 10.55^{b}$ \\
\hline \multirow[t]{2}{*}{ IL-4 ${ }^{\mathrm{a}}$} & None & $3.41 \pm 1.88$ & $5.19 \pm 3.38$ & $8.72 \pm 5.46$ \\
\hline & тВTO & $1.75 \pm 0.62$ & $0.00 \pm 0.00$ & $4.44 \pm 2.30$ \\
\hline \multirow[t]{2}{*}{${\mathrm{IL}-5^{\mathrm{a}}}$} & None & $0.00 \pm 0.00$ & $30.40 \pm 18.49$ & $17.16 \pm 11.16$ \\
\hline & ТВTO & $0.87 \pm 0.87$ & $1.61 \pm 1.61$ & $1.09 \pm 1.09$ \\
\hline \multirow[t]{2}{*}{ IL-10 } & None & $275.22 \pm 31.94$ & $422.34 \pm 96.40$ & $393.83 \pm 90.78$ \\
\hline & твто & $285.43 \pm 39.25$ & $305.43 \pm 28.66$ & $330.09 \pm 30.18$ \\
\hline \multirow[t]{2}{*}{ IL-13 ${ }^{\mathrm{a}}$} & None & $285.45 \pm 71.63$ & $1203.59 \pm 616.05$ & $547.16 \pm 137.98$ \\
\hline & ТВTO & $192.53 \pm 62.32$ & $220.75 \pm 60.23$ & $286.20 \pm 31.90^{b}$ \\
\hline \multirow[t]{2}{*}{ IFN- $\nu$} & None & $190.13 \pm 52.36$ & $513.24 \pm 131.02$ & $554.96 \pm 76.70$ \\
\hline & TВTO & $218.01 \pm 39.47$ & $379.00 \pm 63.85$ & $636.40 \pm 121.39$ \\
\hline
\end{tabular}

Groups of female rats ( $n=8$ for each dosing regiment) received 0,1 or $10 \mathrm{mg} / \mathrm{rat} /$ day of peanut extract (PE) by daily oral gavage. Spleens were dissected at day 49 , single cell suspensions were prepared and incubated $\left(4 \times 10^{5}\right.$ cells/well) with PE $(1 \mathrm{mg} / \mathrm{ml})$ for $96 \mathrm{~h}$. IL-2, IL-4, IL-5, IL-10, IL-13 and IFN- $p$ production were measured in supernatants and are expressed as $\mathrm{pg} / \mathrm{ml}$ supernatant (average + S.E.M).

${ }^{\mathrm{a}}$ TBTO decreased cytokine levels of IL-2 $(p=0.007)$, IL-4 $(p=0.036), \mathrm{IL}-5(p=0.016)$ and IL-13 $(p=0.014)$;

${ }^{b}$ significantly different from non-immune-modulated group with $p=0.028$ (IL-2; $0 \mathrm{mg}$ PE + TBTO compared with $0 \mathrm{mg} \mathrm{PE}$ ), $p=0.044$ (IL-2; $10 \mathrm{mg}$ PE + TBTO compared with $10 \mathrm{mg}$ PE), $p=0.036$ (IL-13; $10 \mathrm{mg}$ $\mathrm{PE}+\mathrm{TBTO}$ compared with $10 \mathrm{mg} \mathrm{PE})$. 


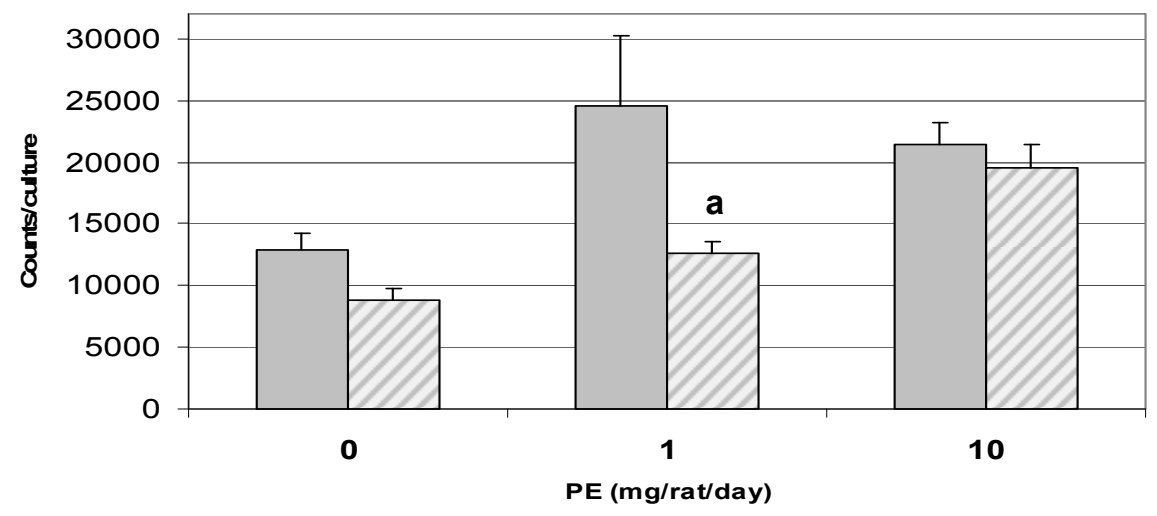

FIGURE 3. PE-specific proliferation of spleen cells

Groups of female rats ( $n=8$ for each dosing regiment) received 0,1 or $10 \mathrm{mg} P E / \mathrm{rat} /$ day by daily oral gavage. Spleens were dissected at day 49 , single cell suspensions were prepared and $4 \times 10^{5}$ cells/well were incubated with $2 \mathrm{mg} / \mathrm{ml}$ PE for $96 \mathrm{~h}$. Lymphocyte proliferation in spleen cells is expressed in cpm (average + S.E.M). Black bars represent the groups that received the control diet and striped black bars represent the groups that received the TBTO diet ( $80 \mathrm{mg}$ TBTO $/ \mathrm{kg}$ diet).

TBTO significantly decreased cell proliferation with $p=0.003$.

a effects of TBTO on cell proliferation were significant when separate allergen dose groups were analyzed: $p=0.001$ (1 mg PE + TBTO compared to $1 \mathrm{mg}$ PE).

\section{The effect of TBTO on allergen-specific antibodies}

TBTO did not affect OVA-specific IgG1 and IgG2a serum levels (data not shown). With the allergen PE no effects of TBTO on these antibodies were observed either, except a small but significant decrease of PE-specific IgG1 serum levels at day 28 ( $p$ $=0.043$; data not shown).

With the allergen PE we observed a rather modest increase of specific IgE antibodies in sensitized rats after 28 days of daily oral exposure, on which TBTO did not have an effect (Figure 4A). With the allergen OVA the specific IgE responses after 28 days of oral exposure were higher and significantly affected by TBTO. When evaluating this in the separate dose groups, the effect of TBTO was significant in the 1 and $10 \mathrm{mg}$ OVA groups (Fig. 4B). 
(a)

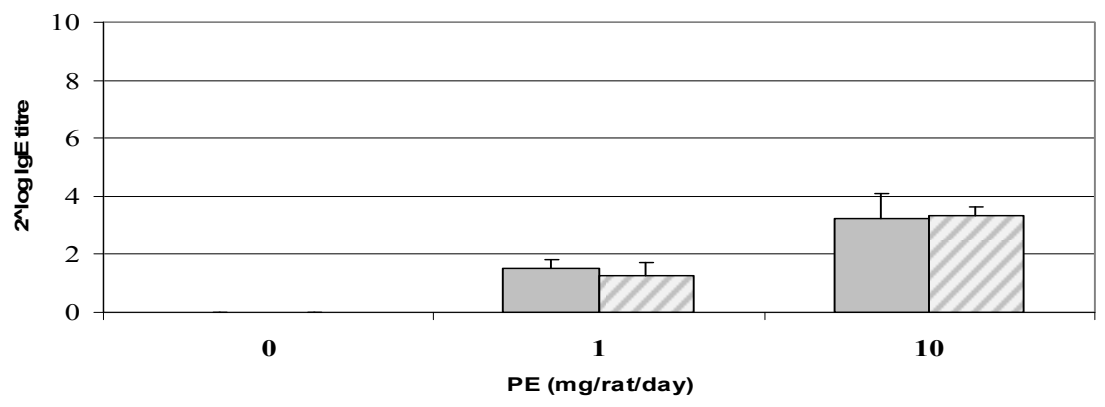

(b)

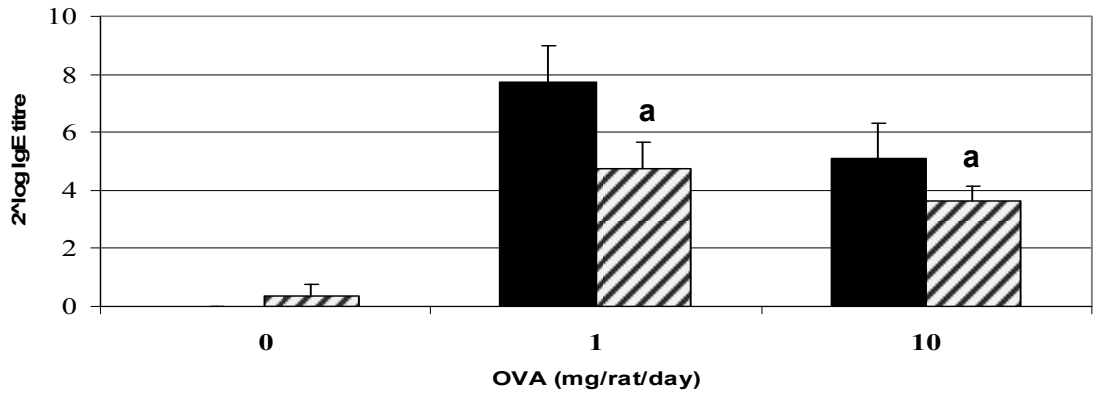

FIGURE 4. PE- and OVA-specific IgE titres following 28 days of oral exposure

Groups of female rats ( $n=8$ for each dosing regiment) received 0,1 or $10 \mathrm{mg} / \mathrm{rat} /$ day of PE or OVA by daily oral gavage. Data are displayed as serum reciprocal antigen-specific IgE titres (average + S.E.M) on day 28 in the PE-model (A) or in the OVA-model (B). Grey bars represent the groups that received the control diet and striped grey bars represent the groups that received the TBTO in the PE allergen-model. For the OVA allergen-model: black bars represent the groups that received the control diet and striped black bars represent the groups that received the TBTO diet (80 mg TBTO/kg diet).

TBTO decreased OVA-specific IgE levels $(p=0.008)$.

a effects of TBTO on OVA-specific IgE levels were significant when separate allergen dose groups were analyzed: $p=0.034$ ( $1 \mathrm{mg}$ OVA + TBTO compared to $1 \mathrm{mg}$ OVA) and $p=0.038$ (10 mg OVA + TBTO compared to $10 \mathrm{mg}$ OVA).

The effect of TBTO on eosinophilic and basophilic granulocytes in the blood

The numbers of white blood cells, lymphocytes, and neutrophilic granulocytes in the circulation were decreased after TBTO exposure in both allergen models (data not shown). Also the number of eosinophilic granulocytes was decreased by TBTO in both allergen-models (Fig. 5). When evaluating the separate dose groups the effect of TBTO was signficant in the 0 en $10 \mathrm{mg}$ PE group. In the OVA model the effect of TBTO on eosinophils was only significant in the $1 \mathrm{mg}$ OVA group, but approached significance $(p=0.052)$ in the $10 \mathrm{mg}$ OVA/rat/day group. 
(a)

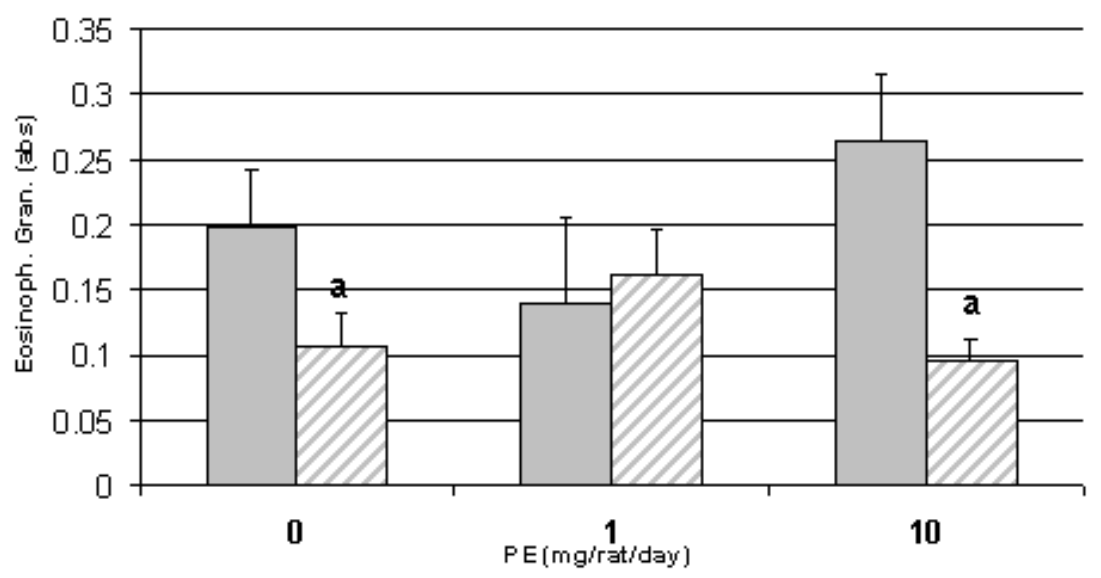

(b)

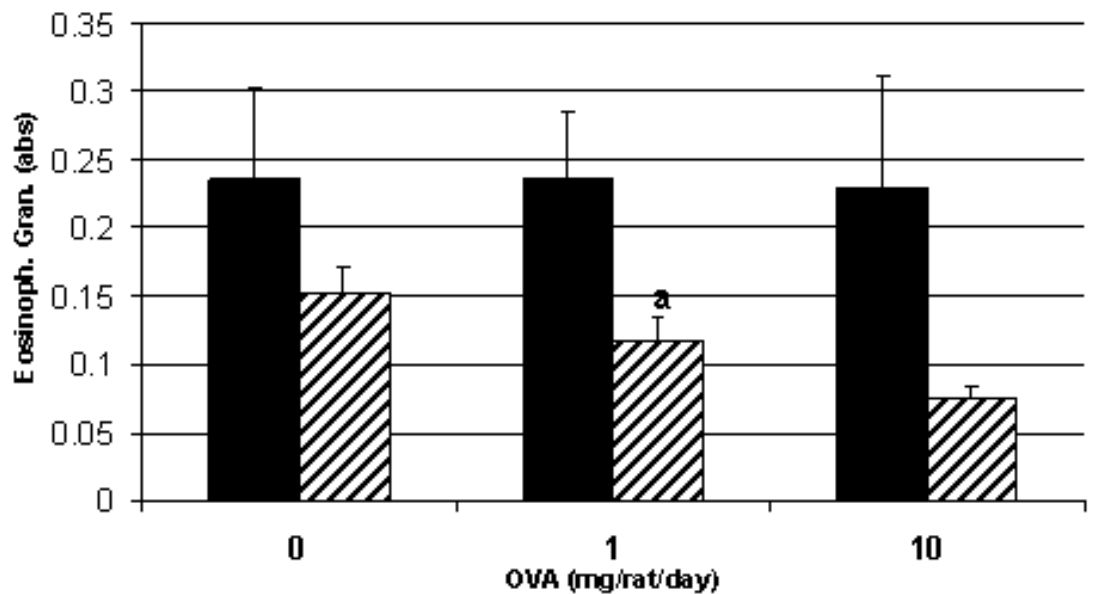

FIGURE 5. Numbers of eosinophilic granulocytes

Groups of female rats ( $n=8$ for each dosing regiment) received 0,1 or $10 \mathrm{mg} / \mathrm{rat} /$ day of PE or OVA by daily oral gavage. Data are displayed for the PE-study (A) and for the OVA-study (B) as numbers of eosinophilic granulocytes (average + S.E.M) in blood of day $49\left(\times 10^{9} / L\right)$. Grey bars represent the groups that received the control diet and striped grey bars represent the groups that received the TBTO in the PE allergen-model. For the OVA allergen-model: black bars represent the groups that received the control diet and striped black bars represent the groups that received the TBTO diet (80 mg TBTO/kg diet).

TBTO decreased number of eosinophilic granulocytes significantly in the the PE allergen-model $(p=$ $0.032)$ and the OVA allergen-model $(p=0.003)$.

a effects of TBTO on eosiniophilic granulocytes were significant when separate allergen dose groups were analyzed: $p=0.049$ (0 mg PE + TBTO compared to $0 \mathrm{mg}$ PE), $p=0.001$ (10 mg PE + TBTO compared to 10 $\mathrm{mg} \mathrm{PE}$ ) and $p=0.015$ ( $1 \mathrm{mg}$ OVA + TBTO compared to $1 \mathrm{mg}$ OVA).

Figure 6 shows that the numbers of basophilic granulocytes in the blood were increased in rats sensitized with $10 \mathrm{mg}$ PE or $1 \mathrm{mg}$ OVA. TBTO significantly decreased the number of basophilic granulocytes only in those two dose groups. 
(a)

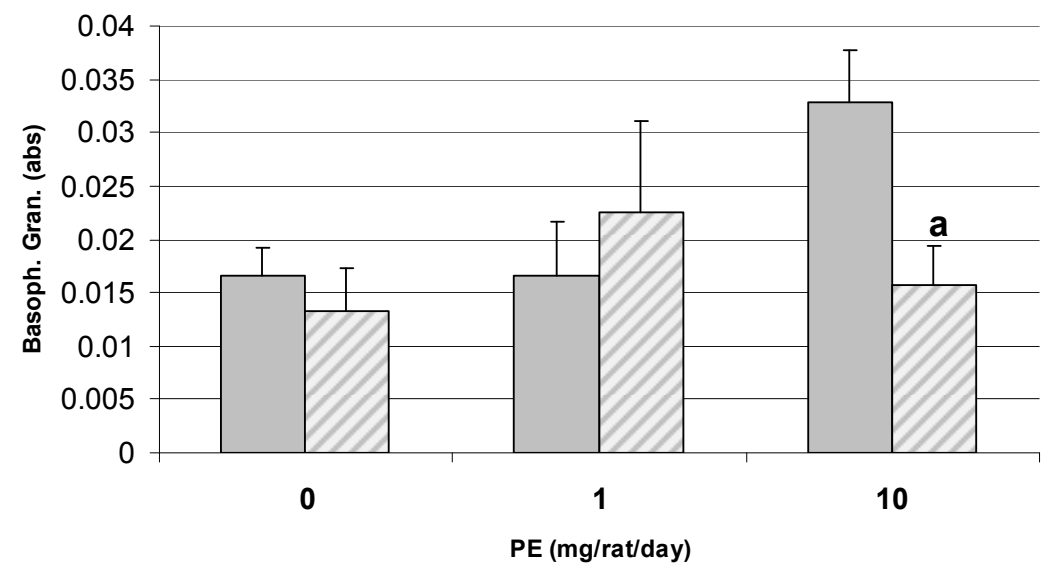

(b)

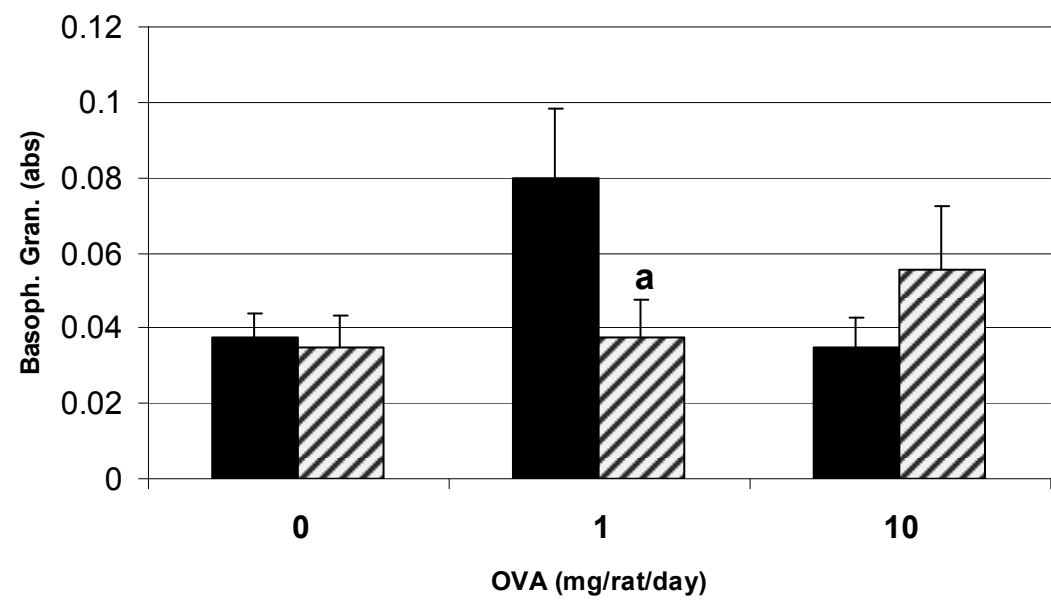

FIGURE 6. Numbers of basophilic granulocytes

Groups of female rats ( $n=8$ for each dosing regiment) received 0,1 or $10 \mathrm{mg} / \mathrm{rat} / \mathrm{day}$ of PE or OVA by daily oral gavage. Data are displayed for the PE-study (A) and for the OVA-study (B) as numbers of basophilic granulocytes (average + S.E.M) in blood of day $49\left(\times 10^{9} /\right.$ L). Grey bars represent the groups that received the control diet and striped grey bars represent the groups that received the TBTO in the PE allergen-model. For the OVA allergen-model: black bars represent the groups that received the control diet and striped black bars represent the groups that received the TBTO diet ( $80 \mathrm{mg}$ TBTO/kg diet).

a effects of TBTO on basophilic granulocytes were significant when separate allergen dose groups were analyzed: $p=0.007$ (10 mg PE + TBTO compared to $10 \mathrm{mg} \mathrm{PE}$ ) and $p=0.030$ (1 mg OVA + TBTO compared to $1 \mathrm{mg}$ OVA).

The effect of TBTO on mast cell degranulation after oral challenge with the allergen RMCPII levels increased after oral challenge with the allergens PE and OVA (Figure 7). Exposure to TBTO significantly decreased the amount of PE-induced RMCPII in serum. These effects were especially evident in the $1 \mathrm{mg}$ PE and OVA group. 
(a)

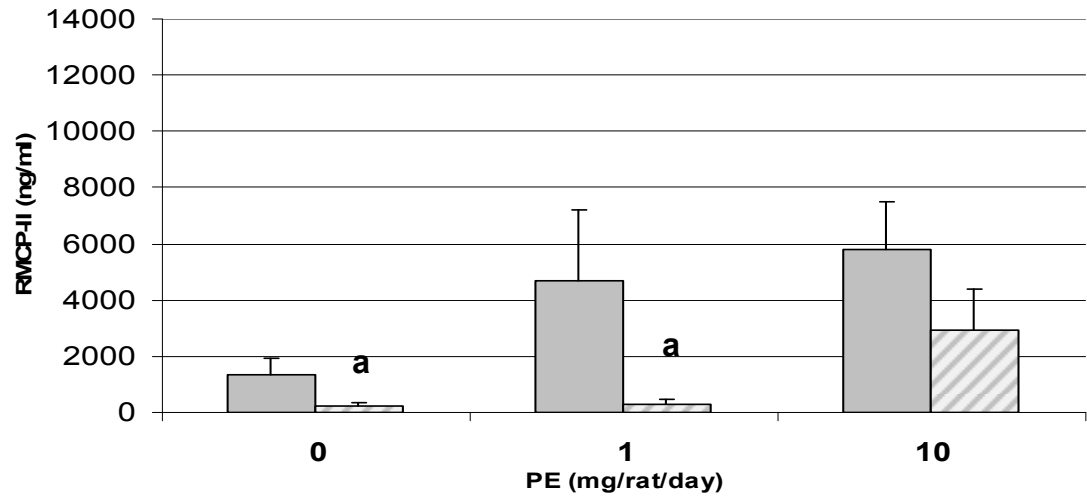

(b)

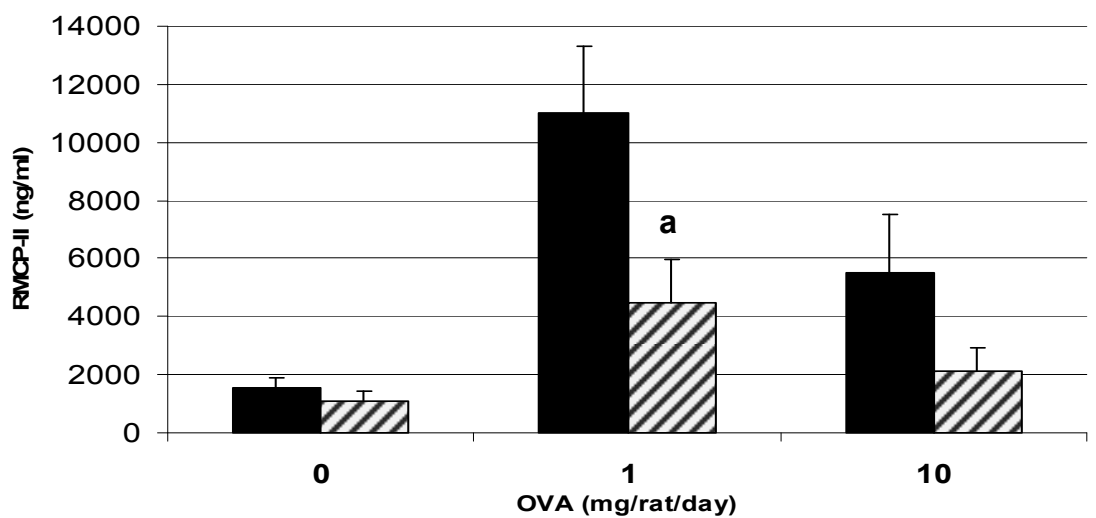

FIGURE 7. RMCPII release after oral challenge

Groups of female rats ( $n=8$ for each dosing regiment) received 0,1 or $10 \mathrm{mg} / \mathrm{rat} /$ day of $P E$ or OVA by daily oral gavage. Data are displayed in the PE allergen-model (A) and in the OVA allergen-model (B) as serum RMCPII levels (average + S.E.M) on day 49, 30 minutes after oral challenge with $100 \mathrm{mg}$ PE or OVA/rat. Grey bars represent the groups that received the control diet and striped grey bars represent the groups that received the TBTO in the PE allergen-model. For the OVA allergen-model: black bars represent the groups that received the control diet and striped black bars represent the groups that received the ТВTO diet ( $80 \mathrm{mg}$ TВTO/kg diet).

TBTO decreased release of RMCPII significantly in the PE allergen-model $(p=0.007)$ and in the OVA allergen-model $(p=0.003)$.

${ }^{\text {a }}$ effects of TBTO on RMCPII were significant when separate allergen dose groups were analyzed: $p=$ 0.031 ( $\mathrm{mg}$ PE + TBTO compared to $0 \mathrm{mg} \mathrm{PE}$ ), $p=0.041$ (1 mg PE + TBTO compared to $1 \mathrm{mg} \mathrm{PE}$ ) and $p=$ 0.016 ( $1 \mathrm{mg}$ OVA + TBTO compared to $1 \mathrm{mg}$ OVA).

\section{DISCUSSION}

The chemical TBTO that is present in the food chain is a known immunosuppressive compound. In several studies in experimental animals it has been demonstrated that the thymus is a target organ of TBTO, and that one of the main immune effects of TBTO is the suppression of $T$ cell dependent immune responses (Raffray and 
Cohen 1991; Vos et al. 1984; WHO-IPCS 1999). In a host resistance model it has been shown that TBTO decreased resistance against $T$. Spiralis and also decreased specific IgE serum levels (Vos et al. 1984). This effect of TBTO has led to the hypothesis that this chemical could also influence food allergic responses which are IgE dependent.

The effects of TBTO were investigated in a model for food allergy in BN rats using two allergens: PE and OVA. TBTO suppressed the weight of PP and MLN, confirming previous reports (Funahashi et al. 1980; Krajnc et al. 1984). In studies investigating the immune effects of TBTO, various dosages of TBTO have been applied. The dose applied in our study is based on earlier research conducted by our igroup (Krajnc et al. 1984; van Loveren et al. 1990; Vandebriel et al. 1998). Immunotoxic effects of TBTO are dose-dependent. In a study in rats (Verdier et al. 1991) no treatmentrelated effects were noted on IgM responses to immunization with sheep erythrocytes and delayed type hypersensitivity responses to bovine serum albumin at dosages of $0,0.5,2,5$, or $50 \mathrm{mg}$ TВTO/kg of diet, whereas thymic atrophy and impaired clearance of $L$. monocytogenes were noted only at a dietary concentration of 50 $\mathrm{mg} / \mathrm{kg}$. Several other studies (Krajnc et al. 1984; Verdier et al. 1991; Vos et al. 1984; Vos et al. 1990) have described effects of TBTO on the T-cell dependent immune response, including IgE-production, at concentrations as low as $5 \mathrm{mg}$ TBTO $/ \mathrm{kg}$ food. In our study we used $80 \mathrm{mg}$ TBTO/kg of feed, a dose that is similar or somewhat higher than the dosages used by Verdier et al. (Verdier et al. 1991), Krajnc et al. (Krajnc et al. 1984) and Vos et al. (Vos et al. 1984; Vos et al. 1990) and our results are therefore in line with these findings of effects on T-cell activity.

Our study shows that TBTO also suppressed allergen specific parameters. In rats sensitized to either peanut or ovalbumin, TBTO decreased the number of eosinophils and basophils and mast cell degranulation was also suppressed. The production of the Th2 cytokines IL-4, IL-5 and IL-13 by spleen cells ex vivo stimulated with PE were suppressed by TBTO. TBTO did not significantly affect IL-10 and IFN- $\gamma$, although these cytokines were slightly decreased in the $1 \mathrm{mg}$ PE group. Hence, TBTO predominantly affected Th2 cytokines and not Th1 and regulatory T cell (Treg) associated cytokines. The effect on IL-5, a cytokine that is important for the influx of eosinophils, is in line with the observed suppression of blood eosinophils. The decrease of IL-4 and IL-13, which play a role in IgE production, contrasts the absence of decreased PE-specific IgE levels after TBTO exposure. In rats sensitized to OVA, specific IgE levels were significantly decreased by TBTO.

In our study we found that TBTO predominantly suppressed Th2-associated cytokines and not Th1- and Treg-associated cytokines. TBTO did not have an effect on DTH in rats exposed to doses of TBTO ranging from $1.25-15 \mathrm{mg}$ TBTO/kg B.W./day (Smialowicz et al. 1990) or $0.5-50 \mathrm{mg}$ TBTO/kg feed/day (Verdier et al. 1991). This is in contrast with the decrease in Th1/Th2 ratio as found in a C56Bl/6 mice model (van den Berg et al. 2005) induced by the maximum tolerated dose of TBTO. This 
difference could be due to dose-dependent effects of TBTO on the immune system and the use of different animal models in their and our study designs.

With OVA we observed specific IgE levels to be significantly decreased. It is difficult to explain the discrepancy between the effect of TBTO on PE- and on OVA-specific IgE levels, especially since other immune parameters in both allergen models were similarly affected by TBTO. Another discrepancy is the fact that in the PE experiment TBTO had no effect on specific IgE levels, yet decreased the mast cell RMCPII release. This latter finding may indicate a direct, IgE-independent effect of TBTO on mast cells. It is important to note that several differences exist between the two allergen models: e.g. different breeding for multiple generations on different diets (Knippels et al. 1999; Pilegaard and Madsen 2004), different allergens and different purity of allergens (OVA is a purified protein, while PE is the aequous extract of the peanut matrix) and different affinities for proteins (de Jonge et al. 2007; Knippels and Penninks 2005; Knippels et al. 1998; Penninks and Knippels 2001). Furthermore the allergic response is not identical in both experiments. Administration of OVA at a dose of $1 \mathrm{mg}$ induces higher IgE levels than at a dose of $10 \mathrm{mg}$, whereas in the case of PE IgE increases dose dependently. Also, the specific IgE response is considerably lower in PE-sensitized rats, than in OVA-sensitized rats. This difference might explain the observed differences in effects of TBTO on IgE. Possibly, TBTO can more easily modulate vigorous IgE responses, than more subtle IgE responses. TBTO suppressed the release of RMCPII by mast cells after an oral challenge with both allergens. This parameter is clinically relevant (Stenton et al. 1998) and this indicates that TBTO directly suppressed the allergic response. These data imply that it is important to investigate multiple parameters at multiple immunological levels in a food allergy model, rather than primarily focusing on a single immune parameter.

In conclusion TBTO suppressed allergy-specific parameters. This complements earlier findings of immunosuppression by TBTO, exemplified by delayed-type hypersensitivity responses, decreased innate immune responses (NK activity and macrophage activity (Aluoch and Whalen 2005; Dudimah et al. 2006; Vandebriel et al. 1998; Vos et al. 1984)) and may be interpreted as a general suppression of immune responsiveness, rather than a selective modulation of Th1 or Th2 mediated immune responses. The data imply that immunomodulatory components present in food may have an impact on the expression of food allergy, and that such components need to be considered if an eventual risk assessment of food allergens is to be made.

\section{ACKNOWLEDGEMENTS}

The author likes to thank the following people for their generous assistance: Arja de Klerk, Bert Verlaan, Eric R. Gremmer, Yvonne C. Wallbrink, and Liset J.J. de la Fonteyne. This study was financed by a grant from the Netherlands Food and Consumer Products Authority (VWA, Den Haag, the Netherlands). 


\section{REFERENCES}

de Jonge, J.D., Knippels, L., Ezendam, J., Odink, J., Penninks, A.H. and van Loveren, H. (2007) The importance of dietary control in the development of a peanut allergy model in Brown Norway rats. Methods 41, 99-111.

Dearman, R.J., Caddick, H., Basketter, D.A. and Kimber, I. (2000) Divergent antibody isotype responses induced in mice by systemic exposure to proteins: a comparison of ovalbumin with bovine serum albumin. Food Chem Toxicol 38, 351-360.

Dearman, R.J. and Kimber, I. (2001) Determination of protein allergenicity: studies in mice. Toxicol Lett 120, 181-186.

Knippels, L.M., Penninks, A.H., Spanhaak, S. and Houben, G.F. (1998) Oral sensitization to food proteins: a Brown Norway rat model. Clin. Exp. Allergy 28, 368-375.

Aluoch, A.O. and Whalen, M.M. (2005) Effects of interleukins 2 and 12 on TBT-induced alterations of MAP kinases p38 and p44/42 in human natural killer cells. J Appl Toxicol.

Ikeda, M., Takatsuki, M., Yakabe, Y., Arimoto, Y., Fukuma, T. and Higashikawa, K. (2001) Experiences on persistent organic pollutants under the Law concerning the Examination and Regulation of Manufacture, etc. of Chemical Substances, Japan, with references to biodegradation and bioaccumulation. Int Arch Occup Environ Health 74, 295-301.

Sekizawa, J. (1998) [Health and environmental risk assessment of organotin pollution in Japan] [Article in Japanese]. Kokuritsu lyakuhin Shokuhin Eisei Kenkyusho Hokoku, 126-131.

WHO-IPCS. (1999) Concise International Chemical Assesment Document 14: Tributyltinoxide. website: http://www.who.int/ipcs/publications/cicad/en/cicad14.pdf; visited at December 7, 2004 Geneva 1999, Switzerland, 1-29.

Vos, J.G., de Klerk, A., Krajnc, E.I., Kruizinga, W., van Ommen, B. and Rozing, J. (1984) Toxicity of bis(tri-nbutyltin)oxide in the rat. II. Suppression of thymus-dependent immune responses and of parameters of nonspecific resistance after short-term exposure. Toxicol Appl Pharmacol 75, 387-408.

Vos, J.G., De Klerk, A., Krajnc, E.I., Van Loveren, H. and Rozing, J. (1990) Immunotoxicity of bis(tri-nbutyltin)oxide in the rat: effects on thymus-dependent immunity and on nonspecific resistance following long-term exposure in young versus aged rats. Toxicol Appl Pharmacol 105(144-155.

Dudimah, F.D., Odman-Ghazi, S.O., Hatcher, F. and Whalen, M.M. (2006) Effect of tributyltin (TBT) on ATP levels in human natural killer (NK) cells: Relationship to TBT-induced decreases in NK function. J Appl Toxicol.

Vandebriel, R.J., Meredith, C., Scott, M.P., Roholl, P.J. and Van Loveren, H. (1998) Effects of in vivo exposure to bis(tri-n-butyltin)oxide, hexachlorobenzene, and benzo(a)pyrene on cytokine (receptor) mRNA levels in cultured rat splenocytes and on IL-2 receptor protein levels. Toxicol Appl Pharmacol 148, 126-136.

Beardslee, T.A., Zeece, M.G., Sarath, G. and Markwell, J.P. (2000) Soybean glycinin G1 acidic chain shares IgE epitopes with peanut allergen Ara h 3. Int Arch Allergy Immunol 123, 299-307.

Eigenmann, P.A., Burks, A.W., Bannon, G.A. and Sampson, H.A. (1996) Identification of unique peanut and soy allergens in sera adsorbed with cross-reacting antibodies. J Allergy Clin Immunol 98, 969978.

Koppelman, S.J., Knol, E.F., Vlooswijk, R.A., Wensing, M., Knulst, A.C., Hefle, S.L., Gruppen, H. and Piersma, S. (2003) Peanut allergen Ara h 3: isolation from peanuts and biochemical characterization. Allergy 58, 1144-1151.

Laemmli, U.K. (1970) Cleavage of structural proteins during the assembly of the head of bacteriophage T4. Nature 227, 680-685.

Stenton, G.R., Vliagoftis, H. and Befus, A.D. (1998) Role of intestinal mast cells in modulating gastrointestinal pathophysiology. Ann Allergy Asthma Immunol 81, 1-11; quiz 12-15.

Raffray, M. and Cohen, G.M. (1991) Bis(tri-n-butyltin)oxide induces programmed cell death (apoptosis) in immature rat thymocytes. Arch Toxicol Suppl 65, 135-139.

Funahashi, N., Iwasaki, I. and Ide, G. (1980) Effects of bis (tri-n-butyltin) oxide on endocrine and lymphoid organs of male rats. Acta Pathol Jpn 30, 955-966. 
Krajnc, E.I., Wester, P.W., Loeber, J.G., van Leeuwen, F.X., Vos, J.G., Vaessen, H.A. and van der Heijden, C.A. (1984) Toxicity of bis(tri-n-butyltin)oxide in the rat. I. Short-term effects on general parameters and on the endocrine and lymphoid systems. Toxicol Appl Pharmacol 75, 363-386.

van Loveren, H., Krajnc, E.I., Rombout, P.J., Blommaert, F.A. and Vos, J.G. (1990) Effects of ozone, hexachlorobenzene, and bis(tri-n-butyltin)oxide on natural killer activity in the rat lung. Toxicol Appl Pharmacol 102, 21-33.

Verdier, F., Virat, M., Schweinfurth, H. and Descotes, J. (1991) Immunotoxicity of bis(tri-n-butyltin) oxide in the rat. J Toxicol Environ Health 32, 307-317.

Smialowicz, R.J., Riddle, M.M., Rogers, R.R., Leubke, R.W., Copeland, C.B. and Ernst, G.G. (1990) Immune alterations in rats following subacute exposure to tributyltin oxide. Toxicology 64, 169-178.

van den Berg, F.A., Baken, K.A., Vermeulen, J.P., Gremmer, E.R., van Steeg, H. and van Loveren, H. (2005) Use of the local lymph node assay in assessment of immune function. Toxicology 211, 107-114.

Knippels, L.M., Penninks, A.H., van Meeteren, M. and Houben, G.F. (1999) Humoral and cellular immune responses in different rat strains on oral exposure to ovalbumin. Food Chem. Toxicol. 37, 881-888.

Pilegaard, K. and Madsen, C. (2004) An oral Brown Norway rat model for food allergy: comparison of age, sex, dosing volume, and allergen preparation. Toxicology 196, 247-257.

Knippels, L.M. and Penninks, A.H. (2005) Recent advances using rodent models for predicting human allergenicity. Toxicol Appl Pharmacol.

Penninks, A.H. and Knippels, L.M. (2001) Determination of protein allergenicity: studies in rats. Toxicol.Lett. 120, 171-180. 



\section{Chapter 4}

\section{Lactobacillus casei Shirota does not decrease the food allergic response to peanut extract in Brown Norway rats}

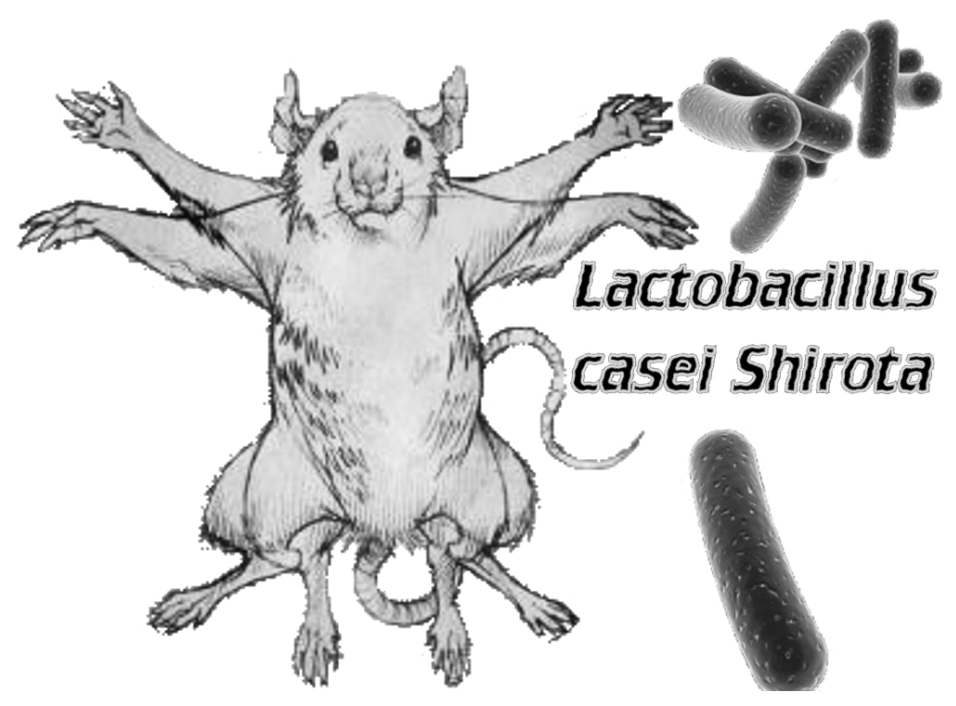

Published in Toxicology 249, 140-5 (2008). 


\section{ABSTRACT}

Probiotics are claimed to beneficially affect the immune system and their involvement in allergy prevention is being investigated extensively. However, the efficacy of probiotics in allergy prevention remains controversial. We investigated whether the probiotic Lactobacillus casei Shirota (LCS) could modulate the food allergic response against peanut extract $(\mathrm{PE})$ in Brown Norway (BN) rats. For this purpose $\mathrm{BN}$ rats were sensitized to PE $(0,1$ and $10 \mathrm{mg} / \mathrm{rat} / \mathrm{d})$ by daily oral gavage and the LCSgroups were additionally orally dosed with $1 * 10^{9}$ Colony Forming Units LcS/rat/d. LcS administration had minor effects in animals that were not sensitized. LcS increased Th1- (PE-specific IgG1), whereas the Th1/Th2 ratio based on PE-specific IgG1/PE-specific IgG2a shifted towards Th2 dominance in rats sensitized to PE in the presence of LCS as compared to rats that were sensitized to PE only. LCS stimulated PE-specific IgG2a; but for PE-specific IgE the effect was less clear; whereas there was no overall effect, 2 rats did not show detectable specific IgE antibodies, whereas the remainder showed significantly increased levels. LcS also resulted in increased numbers of basophilic granulocytes in blood. Furthermore, LcS increased levels of both Th1- (IFN- $\gamma$ ) and Th2- (IL-4) related cytokines in PE stimulated spleen and mesenteric lymph node (MLN) cells, but predominantly IL-4 levels in the supernatants of both spleens and MLNs.

Our study does not support the hypothesis that LCS down-regulates food allergic responses in a $\mathrm{BN}$ rat model for food allergy to peanut.

\section{INTRODUCTION}

The increase of allergies over the last decennia has highlighted the need to develop preventive strategies. Growing concern about the adverse immunological consequences of increasing hygiene in the developed world has fueled the interest in the role of microbial products such as probiotics as tools to prevent and/or treat allergic diseases. The intake of lactic acid bacteria with Th1 stimulating properties is thought to be potentially beneficial in reducing allergic symptoms in atopic individuals.

Immune effects of Lactobacillus casei Shirota (LCS) have been demonstrated in rodent models (Baken et al. 2006; de Waard et al. 2001; Ezendam and van Loveren 2008; Matsuzaki and Chin 2000; Matsuzaki et al. 1998). Shida et al. (Shida et al. 2002) have shown that LcS reduced serum ovalbumin (OVA)-specific IgE and IgG1 responses and diminished systemic anaphylaxis in a mouse model for food allergy. In this model, LcS skewed the immune response towards Th1 immunity, thereby reducing the Th2-mediated allergic responses. LCS stimulated IFN- $\gamma$ production by mouse splenocytes in vivo and in vitro, possibly via macrophage-activation and IL-12 production and subsequent enhancement of Th1 cell functions (Kato et al. 1999). Effects of LcS have also been studied in a rat model for Th1-mediated autoimmunity (experimental autoimmune encephalomyelitis (EAE)) and LcS aggravated clinical 
symptoms indicating that stimulation of Th1 immunity can also induce unwanted effects (Baken et al. 2006; Ezendam and van Loveren 2008). Taken together these data suggest that immunomodulatory effects of LcS can lead to both beneficial as well as adverse effects.

Effects of probiotics on Th1-mediated immunity is only one of the mechanisms that have been proposed to explain the beneficial effects of probiotics on allergic responses. Other mechanisms, such as stimulation of regulatory T cells (Tregs), which suppress both Th1- and Th2-associated responses (Prioult et al. 2004; Rook et al. 2004) and a decrease in intestinal permeability (Bongaerts and Severijnen 2005; Rosenfeldt et al. 2004) have also been suggested. The precise mechanisms by which probiotics may influence allergic responses are still unknown and data on efficacy in human studies are limited. In humans, the effects of probiotics on prevention or alleviation of atopic eczema have been studied most extensively. Administration of probiotics reduced symptoms in infants who suffered from IgE mediated atopic eczema (Rosenfeldt et al. 2003; Sistek et al. 2006; Viljanen et al. 2005). In addition, probiotics reduced the prevalence of atopic eczema in infants that received the probiotic Lactobacillus GG in the first six months of their lives (Kalliomaki et al. 2001; Kalliomaki et al. 2003). However, in other studies (Brouwer et al. 2006; Gruber et al. 2007) no effects on symptoms of atopic eczema were found. Remarkably, in a study with atopic infants that received the probiotic L. acidophilus during the first six months of their lives, no effects on prevalence of atopic eczema was found, but sensitization to several allergens was increased (Taylor et al. 2007).

These studies in humans demonstrate that probiotics can have beneficial effects on atopic eczema, but that some probiotics can also induce unintended immunostimulation. These differences can probably be explained by the strain-dependent effects of probiotics. To investigate the effects of a probiotic with Th1 stimulating properties on allergic responses, the effects of LCS were studied in a rat model for peanut allergy.

\section{EXPERIMENTAL METHODS}

\section{Animals}

Oral sensitization was studied in young Brown Norway (BN) rats. Brown Norway (BN Rij:Hsd) rats obtained from Harlan Netherlands B.V. (Horst, the Netherlands) were used. These rats are bred by Harlan on their basal diet (2018 Teklad Global 18\% Protein Rodent Diet), which does contain soy-products as a protein source. At our institute these rats were bred and raised on a peanut and soy protein-free diet (since soy and peanut are cross-reactive legumes (Beardslee et al. 2000; de Jonge et al. 2007; Eigenmann et al. 1996)) obtained from Harlan Netherlands B.V (2016S Teklad Global 16\% Protein Rodent Diet). In this experiment, female rats of the third 
generation (F3) and onwards were used and fed the peanut and soy protein-free diet during the experiments. At study initiation, rats were 3-4 weeks old.

The rats were housed in an animal room maintai

ned at $23 \pm 3^{\circ} \mathrm{C}$, with a light/dark cycle of $14 \mathrm{~h} / 10 \mathrm{~h}$, and a relative humidity of 30$70 \%$ during the experiment and for at least $7 \mathrm{~d}$ prior to study initiation. The animals were housed in stainless-steel wire (Macrolon III) cages in groups of two and had free access to food and tap-water. Approval from the Institutional Animal Ethics Committee was obtained for all experimental procedures involving animals.

\section{Preparation of peanut extract}

Lightly blanched $\left(100^{\circ} \mathrm{C}\right)$ peanuts (Arachis Hypogaea) from the USA Runner cultivar were kindly provided by IMKO Gelria (Doetinchem, The Netherlands) and were stored at $4^{\circ} \mathrm{C}$ until use. Peanut extract was prepared according to the method described by Koppelman et al. (Koppelman et al. 2003) with some previously described minor modifications (de Jonge et al. 2007). To verify whether the peanut extract contained the major allergens (Ara h1, Ara h2 and Ara h3) SDS-PAGE was performed essentially according to Laemlli (Laemmli 1970) using a BioRad Mini Protean II system (BioRad, Hercules, CA) with $15 \%$ acrylamide gels $(15 \mathrm{~cm} \times 10 \mathrm{~cm})$ using a previously described method (de Jonge et al. 2007).

\section{Probiotic preparation}

Lactobacillus casei Shirota strain (LCS) was cultured for 72 hours at $30^{\circ} \mathrm{C}$ under anaerobic conditions in Man Rogosa Sharpe (MRS) broth (52.5 g MRS (Merck, Darmstadt, Germany)/L distilled water). Thereafter, bacteria were washed twice with saline $(0.9 \% \mathrm{NaCl})$ and resuspended in saline to a final concentration of $10^{*} 10^{9} \mathrm{Col}-$ ony Forming Units (CFU)/ml (allowing doses of $100 \mu \mathrm{l} / \mathrm{rat} / \mathrm{d}$ ) and stored at $4{ }^{\circ} \mathrm{C}$ prior to use. The number and viability of the lactobacilli were determined by aerobic culturing on MRS plates (Tritium Microbiologie B.V., Veldhoven, The Netherlands) for 72 hours. Rats were dosed with LCS averaging between $1-2 * 10^{9} \mathrm{CFU}$ of LCS/rat/d. Every week, $100 \mu \mathrm{l}$ of $10^{-7}, 10^{-8}$ and $10^{-9}$ suspensions of bacteria in saline were plated in duplicate on MRS containing agar plates (Tritium Microbiologie B.V., Veldhoven, The Netherlands). After $72 \mathrm{~h}$ of cultivation, the number of colonies on each plate was counted in order to check the concentration of bacteria in the suspension used for co-exposure of animals. There was some variation between weeks but always 1 to $2 * 10^{9} \mathrm{CFU}$ per daily dose per rat was applied.

\section{Endotoxin content}

The endotoxin content of the PE (33.6 mg PE/ml in PBS) was assessed chromatographically by quantitative limulus amebocyte (LAL) assay according to the manufacturer's instructions (Cambrex BioSciences, Wokingham, UK) using the method de- 
scribed previously (de Jonge et al. 2007). Endotoxin content in all PE samples was 1 pg or 0.01 Endotoxin Units (EU)/ml.

\section{Experimental design oral sensitization}

To ensure the use of immunologically naive animals with respect to peanut, pre-study blood samples were tested for peanut-specific antibodies. Rats (8 per experimental group) were then randomly allocated to their dosing regimens), followed by additional reallocation to ensure even starting weight distribution in all dosing groups. Rats were exposed to $1 \mathrm{ml}$ of 0,1 or $10 \mathrm{mg}$ PE /ml PBS by daily oral gavage, using an 18-gauge stainless steel animal feeding needle during the first $42 \mathrm{~d}$ of the study. In addition, the LcS-groups were also exposed by oral gavage of the probiotic (LCS; $1 * 10^{9} \mathrm{CFU} / \mathrm{rat} / \mathrm{d}$ ) and the groups that were not exposed to LcS were given saline by oral gavage by the same dosing regimen as the LcS-groups.

In rats that received LCS, oral dosing with LcS started one week prior (d -7) to exposure to the allergen and was maintained for $49 \mathrm{~d}$.

After commencement of the sensitization, blood samples were obtained from the tail vein at two-weekly intervals (d 14, 28 and 42 after start sensitization to PE). After coagulation for $1 \mathrm{~h}$ at room temperature, the serum samples were centrifuged (Heraeus Sepatech Biofuge 13, Osterode, Germany) for $15 \mathrm{~min}$. at $3000 \mathrm{G}$ and $4^{\circ} \mathrm{C}$ to obtain sera. The sera were stored at $-80^{\circ} \mathrm{C}$ until analyses for allergen-specific IgE and IgG titers and RMCPII levels by ELISA.

After the sensitization period ( $d 42$ ), animals were no longer exposed to allergen or LcS and one d prior to sacrifice rats were deprived of their food ( $d 49$ ). At $d 49$, all rats were orally challenged by intragastric intubation with PE $(2 \mathrm{ml}$ of a $50 \mathrm{mg} / \mathrm{ml}$ solution). Blood samples for hematology were taken from the orbital plexus ( 0.5 $\mathrm{ml} / \mathrm{rat}$ ) directly after oral challenge and were collected in K3-EDTA tubes (Terumo Europe N.V., Leuven, Belgium) to prevent clotting. Thirty min after the oral challenge, the animals were sacrificed by exsanguination from the abdominal aorta under $\mathrm{CO}_{2} / \mathrm{O}_{2}$ anesthesia and serum samples were prepared from this blood as described above. Spleens and mesenteric lymph nodes (MLNs) were removed aseptically, weighed and single cell suspensions were prepared for cytokine analysis in the supernatant of spleen and MLN cells after ex-vivo re-stimulation with PE.

\section{Ex vivo stimulation of spleen cells: allergen-specific cytokine production}

Single cell suspensions were prepared under aseptic conditions by pressing the spleens or MLNs through a $70 \mu \mathrm{m}$ nylon cell strainer (Falcon, Franklin Lakes, USA). Cells were washed twice and resuspended in $5 \mathrm{~mL}$ standard medium (RPMI 1640, 25 $\mathrm{mM}$ Hepes concentration, L-Glutamine) obtained from Gibco BRL (Breda, the Netherlands) supplemented with $10 \%$ heat inactivated fetal calf serum (FCS) obtained from Integro B.V. (Zaandam, The Netherlands) and $1 \%$ penicillin-streptomycin (Gibco) with $7.5 \times 10^{-5}$ M 2-mercaptoethanol (2-ME) (SERVA, Heidelberg, Germany). 
Cell number was determined using a Coulter Counter (Z2, Coulter Electronics, Mijdrecht, The Netherlands). Cell viability was determined by the Trypan blue cytotoxicity test. The concentration of the cell suspensions was adjusted to $4 \times 10^{6}$ viable cells/ml.

For cytokine measurements, $100 \mu \mathrm{l}$ of the cell suspension was added to the well of 96-wells microtitre plates (Greiner tissue culture plate U-shape, no. 650180; Greiner, Frickenhausen, Germany) and incubated with 1 (for IL-4) and 0.5 (for IFN- $\gamma$ ) $\mathrm{mg} / \mathrm{ml}$ PE for $96 \mathrm{~h}$. IFN- $\gamma$ present in the supernatants was measured by ELISA (Rat IFN- $\gamma$ BD OptEIA ELISA set; BD Biosciences, Erembodegem, Belgium) and Reagent set (IFN- $\gamma$ BD OptEIA Reagent Set B, BD Biosciences) according to the manufacturer's instructions. IL-4 was measured using a rat IL-4 cytoset kit obtained from BioSource (Camarillo, CA, USA) as described previously (de Jonge et al. 2007).

\section{PE-DIG coupling}

Peanut protein-Digoxigenin (PE-DIG) coupling was established using a DIG-protein labeling kit obtained from Roche Diagnostics $\mathrm{GmbH}$ (Mannheim, Germany) according to manufacturer's instructions except for the following changes: $50 \mu \mathrm{l}$ of a 20 $\mathrm{mg} / \mathrm{ml}$ digoxigenin-3-0-succinyl- $\varepsilon$-aminocaproic acid-N-hydroxy-succinimide ester (DIG-NHS) solution in DMSO was added to $1 \mathrm{ml}$ of a $6 \mathrm{mg} / \mathrm{ml}$ solution of crude PE extract in PBS, from this point on the manufacturer's instructions were followed. A 1:2000 dilution of PE-DIG was used in the assay.

Negative and positive control sera for Ig ELISAs

Pooled serum, obtained from male F3 BN rats that were not exposed to peanut allergens, was used as the negative control. Positive control sera were obtained by sensitizing female $\mathrm{F} 3 \mathrm{BN}$ rats i.p. At $\mathrm{d} 0$ rats were injected with a solution containing $0.5 \mathrm{ml}$ of a $0.2 \mathrm{mg} \mathrm{PE} / \mathrm{ml}$ solution in sterile PBS mixed with $0.2 \mathrm{ml}$ of a $40 \mathrm{mg} / \mathrm{ml}$ alum adjuvant suspension (Pierce) in sterile saline. On $d 2,4,7,9$ and 11 rats were injected i.p. with $0.5 \mathrm{ml}$ of a $0.2 \mathrm{mg} \mathrm{PE} / \mathrm{ml}$ solution in sterile PBS. The animals were bled on $\mathrm{d} 28$ by exsanguation from the abdominal aorta. Sera were prepared and stored as described above. These sera were pooled and used as positive control sera in the PE-specific Ig ELISAs.

PE-specific Ig ELISAs

Positive and negative controls were incorporated on each plate of all Ig-ELISA's. After each incubation plates were washed six times with $300 \mu$ PBS containing $0.1 \%$ Tween 20 using an ELISA washer (Auto plate washer ELX405R, Biotek Instruments Inc., Winooski, VT, USA).

PE-specific IgE ELISA

For detection of PE-specific IgE, a sandwich ELISA was performed as described earlier (de Jonge et al. 2007). 


\section{PE specific IgG1 and IgG2a ELISA}

For detection of PE-specific IgG1 and IgG2a, 96-wells microtitre plates were coated with $100 \mu \mathrm{L} /$ well of a $100 \mu \mathrm{g} / \mathrm{ml}$ solution of PE in PBS the remainder of the procedure was similar to that described before (de Jonge et al. 2007).

To determine the effect of LCS on the Th1/Th2 balance, differences (value LCS treated groups divided by the value of the non-treated groups) in IgG1 levels (as fraction of their plate's positive control) of sensitized animals ( $d 42$ ) were divided by the differences in corresponding IgG2a levels (as fraction of their plate's positive control).

\section{Measurement of rat mast cell protease II (RMCPII)}

RMCPII concentrations were determined in $\mathrm{d} 42$ and 49 sera with a RMCPII ELISA kit (Moredun Scientific Limited, Penicuik, Midlothian, Scotland, UK) according to the manufacturer's instructions.

\section{Differential cell counts}

Blood samples, obtained on d 49 were diluted $1: 1$ in a saline solution $(40 \mathrm{~g} / \mathrm{L})$ containing Bovine Serum Albumin (Fraction V, purity $\geq 96 \%$; Sigma-Aldrich). The number of white blood cells (WBC), and differential cell counting was performed using a Bayer Advia 120 Hematology System (Bayer HealthCare, Diagnostics division, Tarrytown, NY, USA).

\section{Statistics}

All experimental groups comprised 8 rats. Statistical treatment of results was processed with SPSS version 13.0 (SPSS Inc., Chicago, Illinois, USA).

The overall difference between the control groups and LCS-treated groups regarding the immune parameters tested were assessed with a two-way ANOVA with Bonferroni for pairwise comparisons as post hoc test. To determine if LCS influenced the outcome of an allergic parameter within a dosing group of PE a one-way ANOVA with Bonferroni as post hoc test was done.

Data for the IgG1/IgG2a ratio's and the number of immune cells in blood were logtransformed prior to analysis, because these data did not meet the prerequisite of ANOVA that data should be normally distributed. In all analyses, data were considered significantly different if $P<0.05$ (two-sided).

\section{RESULTS}

The effect of LCS on PE-specific IgE

In two out of 8 rats that received $10 \mathrm{mg}$ PE together with LCS, PE-specific IgE titres could not be detected at $14 \mathrm{~d}$. However, mean values of PE-specific in this group, calculated after excluding these two rats, showed increased values in both the 1 and 
$10 \mathrm{mg}$ PE group (Fig. 1A). This increase was significant $(P=0.026)$ when all dosing groups were compared with rats that were not treated with LcS. If separate allergen dosages were evaluated, this increase was not significant. On d 42 no significant effect of LCS on the IgE response was found (Fig. 1B).

\section{Figure 1}

(A)

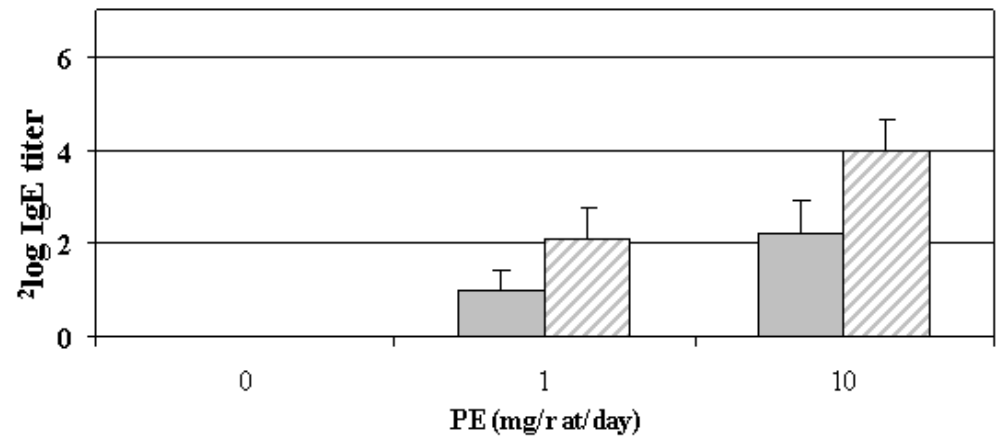

(B)

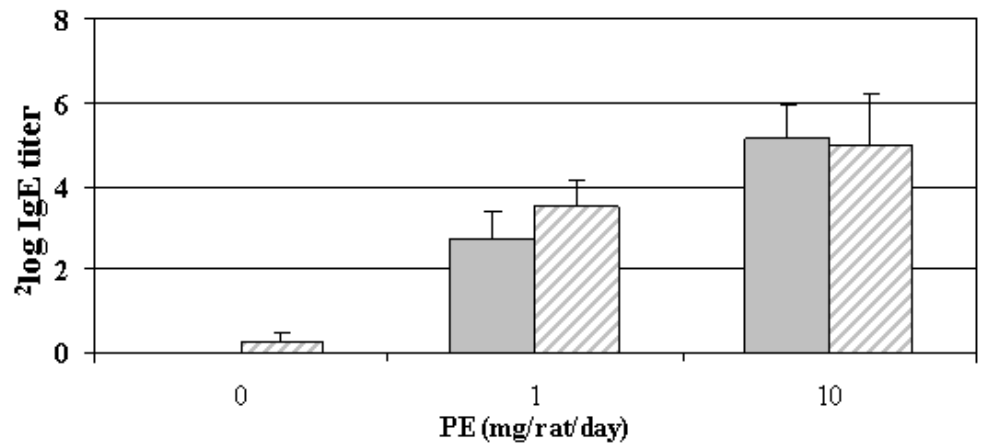

FIGURE 1. PE- specific IgE titers following 14 and $42 \mathrm{~d}$ of oral exposure to peanut

Groups of female rats ( $n=8$ for each dosing regimen) received 0,1 or $10 \mathrm{mg} / \mathrm{rat} / \mathrm{d}$ of peanut extract (PE). Data are displayed as serum reciprocal antigen-specific IgE titers (average + S.E.M) on d 14 (A) or on d 42 (B). Grey bars represent the non-treated groups and striped grey bars represent the Lactobacillus casei Shirota (LCS)-treated groups $\left(1 * 10^{9} \mathrm{CFU}\right.$ of LCS/rat/d).

LcS significantly increased the overall difference in PE-specific lgE levels at $\mathrm{d} 14(P=0.026)$.

The effect of LCS on PE-specific IgG2a and IgG1

Sensitization with 1 or $10 \mathrm{mg}$ PE, resulted in increased PE-specific IgG1 and IgG2a serum levels at d 14, 28,42 and 49. LCS significantly further increased PE-specific IgG1 levels at $d 14(P=0.019)$ and $d 49$ $(P=0.019)$ at the level of overall difference between LCS-treated and non-treated groups. If separate allergen dosages were evaluated, the increase of IgG1 levels was significant in the $10 \mathrm{mg} P E / \mathrm{rat} / \mathrm{d}$ at $\mathrm{d} 14$ $(P=0.030), \mathrm{d} 42(P=0.044)$ and d $49(P=0.044)$ (Table 1A).

LCS also significantly further increased PE-specific IgG2a levels at d $42(P=0.009)$ at the level of overall difference between LCS-treated and non-treated groups. If separate allergen dosages were evaluated, the increase of IgG2a levels was significant in the $10 \mathrm{mg} \mathrm{PE} / \mathrm{rat} / \mathrm{d}$ at $\mathrm{d} 14(P=0.021)$ and $\mathrm{d} 42(P=0.019)$ (Table 1B). 
TABLE 1. PE-specific IgG1 and IgG2a titers in time

TABLE 1A. PE-specific IgG1 titers in time

\begin{tabular}{|l|l|l|l|l|l|l|}
\hline PE (mg/rat/d) & $\mathbf{0}$ & $\mathbf{0}+$ LcS & $\mathbf{1}$ & $\mathbf{1}+$ LcS & $\mathbf{1 0}$ & $\mathbf{1 0}+$ LcS \\
\hline & & & & & & \\
\hline d 14 & $0.00+0.00$ & $0.00+0.00$ & $11.60+1.10$ & $14.00+1.04$ & $14.11+0.46$ & $16.25^{\mathrm{a}}+0.80$ \\
\hline d 28 & $0.00+0.00$ & $0.88+0.88$ & $17.38+0.66$ & $17.00+0.87$ & $17.25+0.53$ & $18.86+0.60$ \\
\hline d 42 & $1.38+1.38$ & $3.50+1.77$ & $17.29+0.36$ & $18.13+0.64$ & $17.13+0.52$ & $19.17^{\mathrm{a}}+0.79$ \\
\hline d 49 & $1.38+1.38$ & $3.38+1.68$ & $17.29+0.84$ & $18.25+0.53$ & $17.25+0.86$ & $20.00^{\mathrm{a}}+0.82$ \\
\hline
\end{tabular}

TABLE 1B. PE-specific lgG2a titers in time

\begin{tabular}{|l|l|l|l|l|l|l|}
\hline PE (mg/rat/d) & $\mathbf{0}$ & $\mathbf{0}+$ LcS & $\mathbf{1}$ & $\mathbf{1}+$ LcS & $\mathbf{1 0}$ & $\mathbf{1 0}+$ LcS \\
\hline & & & & & & \\
\hline d 14 & $0.88+0.88$ & $0.00+0.00$ & $10.60+1.00$ & $11.88+0.64$ & $11.89+0.48$ & $13.63^{\mathrm{a}}+0.46$ \\
\hline d 28 & $0.00+0.00$ & $1.13+1.13$ & $15.25+0.62$ & $15.13+0.44$ & $13.50+0.42$ & $14.86+0.59$ \\
\hline d 42 & $0.00+0.00$ & $2.63+1.72$ & $15.57+0.57$ & $16.50+0.42$ & $13.88+0.52$ & $16.33^{\mathrm{a}}+0.80$ \\
\hline d 49 & $0.00+0.00$ & $3.00+1.97$ & $16.29+0.61$ & $16.63+0.53$ & $15.00+0.50$ & $16.33+0.84$ \\
\hline
\end{tabular}

Groups of female rats ( $n=8$ for each dosing regimen) received 0,1 or $10 \mathrm{mg} / \mathrm{rat} / \mathrm{d}$ of peanut extract (PE). Data are displayed as serum reciprocal antigen-specific IgG1 titers (average + S.E.M) in time (A) and serum reciprocal antigen-specific IgG2a titers (average + S.E.M) in time (B). The tables display the non-treated groups and the Lactobacillus casei Shirota (LCS)-treated groups $\left(1 * 10^{9} \mathrm{CFU}\right.$ of LcS/rat/d) in a direct comparison.

LCS significantly increased the overall difference in PE-specific IgG1 (d 14: $P=0.019 ; \mathrm{d}$ 49: $P=0.046$ ) and IgG2a levels ( $d$ 42: $P=0.009$ ).

${ }^{a}$ effects of LCS on PE-specific IgG1 or IgG2a levels were significant when separate allergen dose groups were analyzed: $P=0.030$ (d 14 lgG1; $10 \mathrm{mg} P \mathrm{PE}+\mathrm{LcS}$ compared to $10 \mathrm{mg} P \mathrm{PE}$ ), $P=0.044$ (d 42 lgG1; $10 \mathrm{mg} P \mathrm{PE}+\mathrm{LcS}$ compared to $10 \mathrm{mg} P \mathrm{PE}$ ), $P=0.044$ (d 49 IgG1; $10 \mathrm{mg} P E+$ LcS compared to $10 \mathrm{mg} P E$ ), $P=0.021$ (d 14 IgG2a; 10 $\mathrm{mg} P \mathrm{PE}+\mathrm{LcS}$ compared to $10 \mathrm{mg} \mathrm{PE}$ ) and $P=0.019$ (d 42 lgG2a; $10 \mathrm{mg} P \mathrm{PE}+\mathrm{LcS}$ compared to $10 \mathrm{mg} \mathrm{PE}$ ).

To determine the effects of LCS on the Th1/Th2 ratio, the ratio of the increase of PEspecific IgG1 over the increase of PE-specific IgG2a on d 42 was calculated. In rats that daily received $10 \mathrm{mg}$ PE a significant shift towards Th2 dominance due to LCS treatment was found on $\mathrm{d} 14$, and in rats that received $1 \mathrm{mg}$ PE such a significant shift was noted at $d$ 28. The greatest shift in this ratio was found on $d 42$, where LcS significantly shifted the Th1/Th2 ratio towards Th2 in both sensitized groups (Figure 2). At d 49 this effect had disappeared.

The effect of LCS on white blood cells, basophilic granulocytes and rat mast cell protease-II

The numbers of basophilic granulocytes were significantly increased $(P=0.017)$ by LCS in the $1 \mathrm{mg}$ PE group as compared to it's untreated control (Fig. 3). The numbers of lymphocytes, neutrophils, monocytes and eosinophilic granulocytes were not affected by LCS compared to the non-treated groups (data not shown).

Sensitization with 1 or $10 \mathrm{mg} P E$, resulted in a dose-dependent increased of PEmediated RMCPII release (Fig. 4). Modulation with LCS did not significantly alter the increase in release of RMCPII. 


\section{Figure 2}

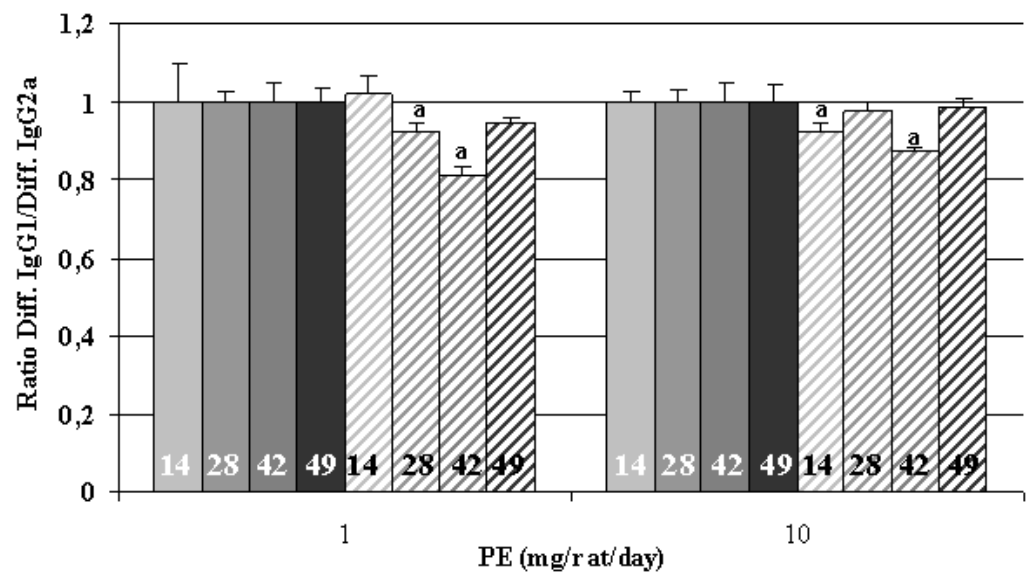

\section{FIGURE 2. PE-specific IgG1/IgG2a ratio's in time}

Groups of female rats ( $n=8$ for each dosing regimen) received 0,1 or $10 \mathrm{mg} / \mathrm{rat} / \mathrm{d}$ of peanut extract (PE). To determine the effect of LCS on the Th1/Th2 balance, differences (value LcS treated groups divided by the value of the non-treated groups) in IgG1 levels of sensitized animals ( $\mathrm{d} 42$ ) were divided by the differences in corresponding IgG2a levels. Data are displayed as IgG1/IgG2a ratio's (average + S.E.M.) in time. Grey bars represent the ratio of the non-treated groups and striped grey bars represent the ratio of the Lactobacillus casei Shirota (LCS)-treated groups $\left(1^{*} 10^{9} \mathrm{CFU}\right.$ of LcS/rat/d), the $\mathrm{d}$ at which the ratio was calculated is displayed within each bar.

LCS significantly increased the overall difference in PE-specific IgG1/IgG2a ratio at d 42 ( $P=0.018$ ); ${ }^{\text {a }}$ effects of LcS on the PE-specific IgG1/IgG2a ratio were significant when separate allergen dose groups were analyzed: $P=0.003$ (d 14; $10 \mathrm{mg} P E+$ LCS compared to $10 \mathrm{mg} \mathrm{PE}$ ), $P=0.039$ (d 28; $1 \mathrm{mg} P E+$ LcS compared to $1 \mathrm{mg} P E$ ), $P=0.003$ (d 42; $1 \mathrm{mg} \mathrm{PE}+\mathrm{LcS}$ compared to $1 \mathrm{mg} \mathrm{PE}$ ) and $P=0.028$ (d 42; $10 \mathrm{mg} P E+\mathrm{LcS}$ compared to $10 \mathrm{mg} P E$ ).

\section{Figure 3}

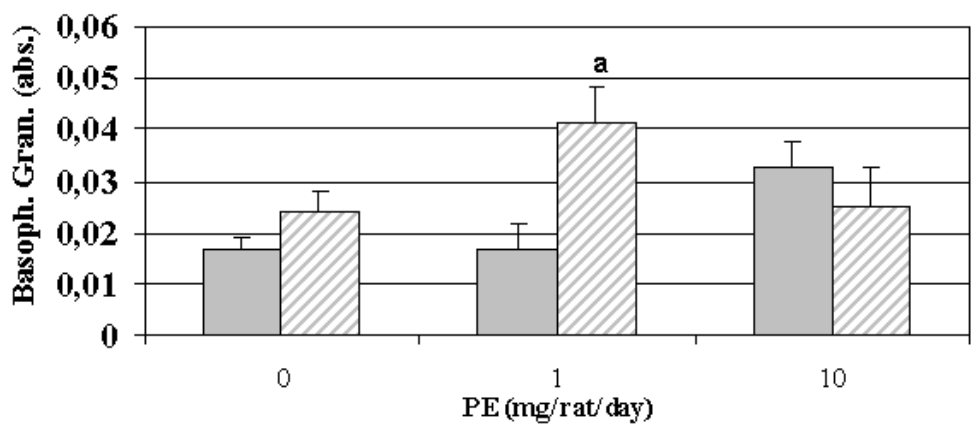

FIGURE 3. Numbers of basophilic granulocytes

Groups of female rats ( $n=8$ for each dosing regimen) received 0,1 or $10 \mathrm{mg} / \mathrm{rat} / \mathrm{d}$ of peanut extract (PE). Data are displayed as numbers of basophilic granulocytes (average + S.E.M) in blood of $d 49\left(\times 10^{9} /\right.$ L). Grey bars represent the non-treated groups and striped grey bars represent the Lactobacillus casei Shirota (LCS)treated groups $\left(1 * 10^{9} \mathrm{CFU}\right.$ of LCS/rat/d); ${ }^{a}$ effects of LCS on basophilic granulocytes were significant when separate allergen dose groups were analyzed: $P=0.017$ ( $1 \mathrm{mg}$ PE + LcS compared to $1 \mathrm{mg} P$ ). 


\section{Figure 4}

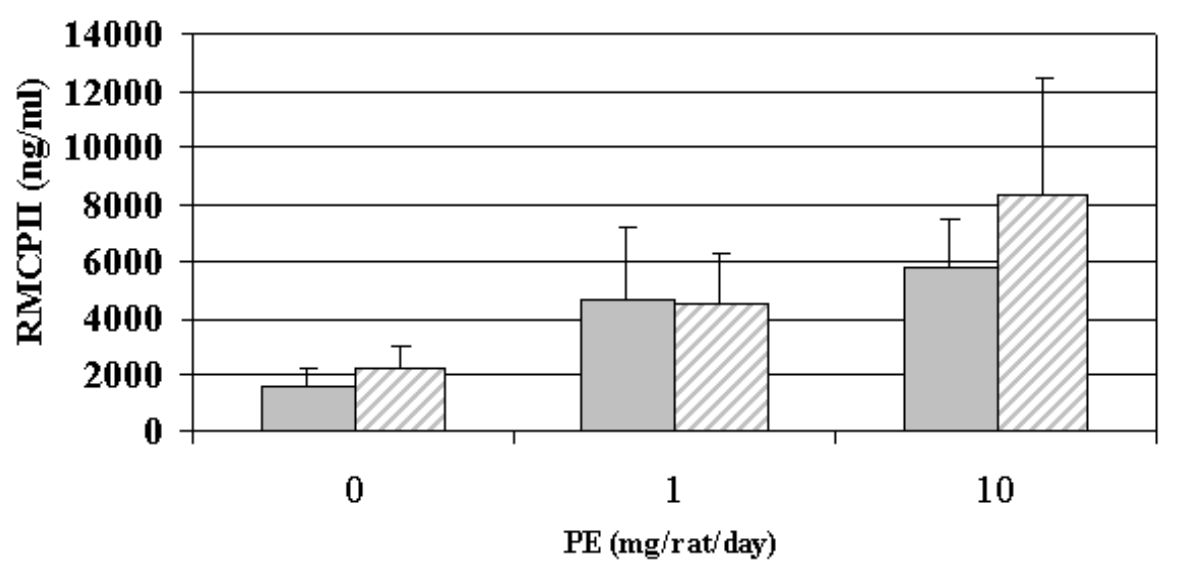

FIGURE 4. RMCPII release after oral challenge

Groups of female rats ( $n=8$ for each dosing regimen) received 0,1 or $10 \mathrm{mg} / \mathrm{rat} / \mathrm{d}$ of peanut extract (PE). Data are displayed as serum rat mast cell protease II (RMCPII) levels (average + S.E.M) on d 49, $30 \mathrm{~min}$ after oral challenge with $100 \mathrm{mg} \mathrm{PE} /$ rat. Grey bars represent the non-treated groups and striped grey bars represent the Lactobacillus casei Shirota (LCS)-treated groups $\left(1 * 10^{9} \mathrm{CFU}\right.$ of LCS/rat/d).

The effect of LCS on cytokine levels in supernatants of PE-stimulated spleen and MLN cells

MLN and spleen cells from PE-sensitized rats showed modest antigen-specific proliferative responses after in vitro culture with PE for $96 \mathrm{hr}$. In addition, restimulation of spleen lymphocytes with PE resulted in increased IFN- $\gamma$ levels in both the $1 \mathrm{mg}$ $(P=0.013)$ and $10 \mathrm{mg} P E(P=0.017)$ groups. LcS did not affect IFN- $\gamma$ levels in either antigen-specific stimulated spleen or MLN cells (data not shown).

Figure 5 shows IL-4 levels in supernatants of cell suspensions of spleen (Fig. 5A) and MLN (Fig 5B) cells that were ex vivo restimulated with PE for 96 hours. LcS significantly increased IL-4 levels further at the level of overall difference between LcStreated and non-treated groups in the supernatants of both spleen and MLN cells. In rats that were dosed with 1 or $10 \mathrm{mg}$ PE, without LCS, IL-4 levels were not significantly affected. In the $1 \mathrm{mg}$ PE group, LcS significantly increased IL-4 levels in cell suspensions of spleen $(P=0.010)$ and MLN cells $(P=0.014)$. In the $10 \mathrm{mg}$ PE group, LcS did not affect IL-4 production. 


\section{Figure 5}

(A)

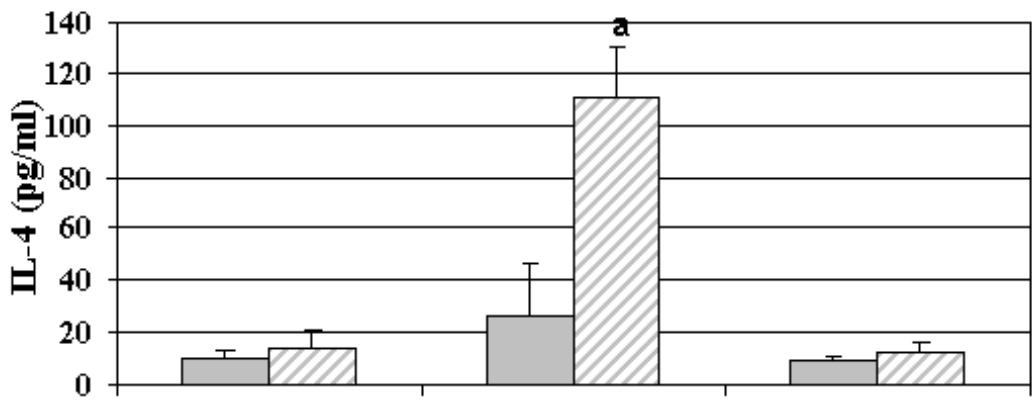

0

1

10

PE (mg/rat/day)

(B)

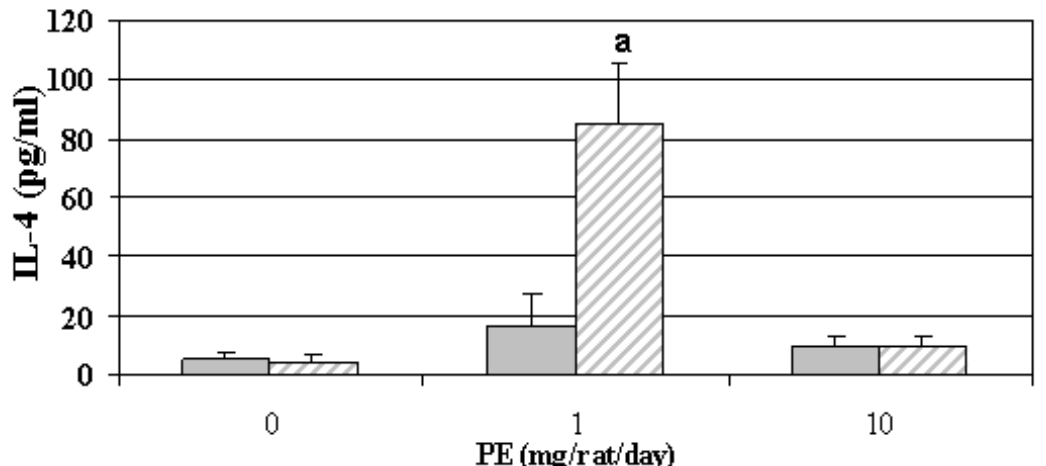

FIGURE 5. IL-4 levels in PE-restimulated spleen and MLN cells

Groups of female rats ( $n=8$ for each dosing regimen) received 0,1 or $10 \mathrm{mg} / \mathrm{rat} / \mathrm{d}$ of peanut extract (PE). Spleens and mesenteric lymph nodes (MLNs) were dissected at $d 49$ and their cells were incubated with $\mathrm{PE}(1 \mathrm{mg} / \mathrm{ml})$ in cell cultures $\left(4 \times 10^{5}\right.$ cells/culture). Data are displayed as IL-4 levels (average + S.E.M) in the supernatants of spleen (A) or MLN (B) cultures. Grey bars represent the non-treated groups and striped grey bars represent the Lactobacillus casei Shirota (LCS)-treated groups ( $1 * 10^{9} \mathrm{CFU}$ of LcS/rat/d).

LCS significantly increased the overall difference in IL-4 levels in the supernatants of spleen cells $(P=0.003)$ and of MLN cells $(P=0.006)$.

a effects of LCS on IL-4 levels were significant when separate allergen dose groups were analyzed: $P=0.010$ (spleen; $1 \mathrm{mg}$ PE + LcS compared to $1 \mathrm{mg} \mathrm{PE}$ ) and P=0.014 (MLN; $1 \mathrm{mg} \mathrm{PE}+\mathrm{LcS}$ compared to $1 \mathrm{mg} \mathrm{PE}$ ).

\section{DISCUSSION}

We investigated whether the probiotic strain Lactobacillus casei Shirota (LCS) could influence the food allergic response against peanut extract (PE) in a $\mathrm{BN}$ rat model for food allergy. The most pronounced effects of LCS were found on allergen-specific cytokine production. The Th2- related cytokine IL-4 was increased by LCS and this increase was found in the supernatants of both spleen and MLN cultures. IFN- $\gamma$ was 
also non-significantly increased in the supernatants of both spleen and MLN cultures of the control animals. This indicates that LCS had an effect on IFN- $\gamma$ that was independent of the PE-response, which has been described earlier (Ezendam and van Loveren 2008). The most pronounced effect of LCS noted in this study was on IL4 production in rats that were dosed with $1 \mathrm{mg} P \mathrm{PE}$. In contrast, in rats that received 1 or $10 \mathrm{mg}$ PE, IFN- $\gamma$ production was not affected by LCS. It is remarkable that the effect of LCS on IL-4 was only observed in the $1 \mathrm{mg}$ PE group. This is possibly due to the timing of the experiment: IL-4 was measured after 96 hours of culturing, which might be too late for the $10 \mathrm{mg} P E$ group.

Effects of LCS on PE-specific IgE levels were only observed after 14 days of exposure. In the $1 \mathrm{mg}$ PE group, LcS increased specific IgE levels further. In the $10 \mathrm{mg} P E$ group, however, two rats did not respond with specific IgE levels, whereas the mean values of the other six rats were increased compared to the rats that did not receive LCS. At day 42, the levels of IgE were similar in rats that did or did not not receive LCS. Taken together, our data do not show statistically decreased IgE titres as a result of LCS treatment. This is in contrast to what has been previously published (Matsuzaki and Chin 2000; Matsuzaki et al. 1998; Shida et al. 2002), but in accord to other studies that failed to demonstrate suppressive effects of LCS on specific IgE levels (Ezendam and van Loveren 2008). It should be noted that these latter observations were not done in oral sensitization models, but rather in intraperitoneal or respiratory sensitization models.

Both PE-specific IgG1 and IgG2a antibody titres were increased by LcS during the course of the experiment. This increase was directed more towards Th2, which is accordance with the observed effects on cytokine production. In contrast to what was hypothesized, based on the notion that if LCS would suppress allergic responses, LcS could also suppress the food allergic response, our results indicate that LcS increased the levels of PE-specific IgE, IgG1 and IgG2a, although IgE was only affected early after exposure to PE. Enhancement of the immune system by LcS was also illustrated by an increase of the number of basophils. LcS did not affect mast cell degranulation, as measured by the release of RCMP-II. This parameter is considered to be clinically relevant, since mediators released from mast cells cause clinical symptoms in allergic patients.

From our experimental data, we can conclude that LcS stimulates certain responses in this experimental model for peanut allergy, rather than suppressing the food allergic response. Our study does therefore not support the hypothesis that probiotics have a protective role in the prevention of allergic responses in our $\mathrm{BN}$ rat model for food allergy against peanut. It is important to note that effects of probiotics are highly dependent on the species and strain used, and further depend on viability, dose and time (Broekaert and Walker 2006; de Waard et al. 2003; Kalliomaki and Isolauri 2004). Hence, although our study does not demonstrate an inhibitory effect of LCS on the food allergic response, this does not necessarily imply that other pro- 
biotic strains would not have such effects. Furthermore, in other studies LcS has been shown to decrease IgE responses against OVA (Shida et al. 1998; Shida et al. 2002), which could imply that the effects of a probiotic strain are also dependent on the experimental model used.

At present, evidence for efficacy of probiotics on allergy prevention in humans is scarce. Although there are some promising results on prevention and alleviation of atopic eczema in infants (Kalliomaki et al. 2001; Kalliomaki et al. 2003; Rosenfeldt et al. 2003; Sistek et al. 2006; Viljanen et al. 2005), at the moment no effects on atopic manifestations that occur later in life, e.g. asthma, have been reported. More importantly, a recent study has demonstrated that $L$. plantarus enhanced sensitization to food and respiratory allergens in infants that received this probiotic in the first six months of their lives (Taylor et al. 2007). It is unknown if the observed increase in sensitization will also lead to an increased development of clinical effects in these infants. Additionally, a recent review, in which twelve randomized clinical trails were included, has demonstrated that probiotics significantly reduce infant eczema. However, when the analysis was restricted to studies on IgE-dependent atopic eczema the reduction in eczema was no longer significant. In addition, it was shown that no benefits were reported for any other allergic disease or hypersensitivity outcome (Osborn and Sinn 2007). Recently, it has been shown that probiotics might beneficially affect rhinitis induced by Japanese cedar pollen. In a randomized double-blind, placebo-controlled study LcS did not prevent allergic symptoms, but after subgroup analysis it was shown that in patients with moderate-to-severe nasal symptom scores, LcS delayed the occurrence of allergic symptoms (Tamura et al. 2007). Hence, currently there is insufficient evidence from human studies for the efficacy of probiotics in prevention of either allergic diseases or food hypersensitivity.

More research is needed to substantiate efficacy of probiotics in allergy prevention. Experimental animal models for allergy are useful to select probiotics which could be effective in allergy prevention and can provide more insight in the mechanisms involved. Efficacy and safety, however, should both be demonstrated in humans.

\section{ACKNOWLEDGEMENTS}

The author likes to thank the following people for their generous assistance: Jennie Odink, Arja de Klerk, Bert Verlaan, Eric R. Gremmer, Yvonne C. Wallbrink, and Liset J.J. de la Fonteyne. This study was financed by a grant from the Netherlands Food and Consumer Products Authority (VWA, Den Haag, the Netherlands). None of the authors had conflicts of interest. 


\section{REFERENCES}

Baken, K.A., Ezendam, J., Gremmer, E.R., de Klerk, A., Pennings, J.L., Matthee, B., Peijnenburg, A.A. and van Loveren, H., 2006. Evaluation of immunomodulation by Lactobacillus casei Shirota: Immune function, autoimmunity and gene expression. Int J Food Microbiol 112, 8-18.

de Waard, R., Garssen, J., Snel, J., Bokken, G.C., Sako, T., Veld, J.H. and Vos, J.G., 2001. Enhanced antigenspecific delayed-type hypersensitivity and immunoglobulin $\mathrm{G} 2 \mathrm{~b}$ responses after oral administration of viable Lactobacillus casei YIT9029 in Wistar and Brown Norway rats. Clin Diagn Lab Immunol 8, 762-767.

Ezendam, J. and van Loveren, H., 2008. Lactobacillus casei Shirota administered during lactation increased the duration of autoimmunity in rats and enhanced lung inflammation in mice. BrJ Nutr 99, 83-90.

Matsuzaki, T. and Chin, J., 2000. Modulating immune responses with probiotic bacteria. Immunol.Cell Biol. 78, 67-73.

Matsuzaki, T., Yamazaki, R., Hashimoto, S. and Yokokura, T., 1998. The effect of oral feeding of Lactobacillus casei strain Shirota on immunoglobulin E production in mice. J Dairy Sci. 81, 48-53.

Shida, K., Takahashi, R., Iwadate, E., Takamizawa, K., Yasui, H., Sato, T., Habu, S., Hachimura, S. and Kaminogawa, S., 2002. Lactobacillus casei strain Shirota suppresses serum immunoglobulin $E$ and immunoglobulin $\mathrm{G} 1$ responses and systemic anaphylaxis in a food allergy model. Clin Exp Allergy 32, 563-570.

Kato, I., Tanaka, K. and Yokokura, T., 1999. Lactic acid bacterium potently induces the production of interleukin-12 and interferon-gamma by mouse splenocytes. Int J Immunopharmacol 21, 121-131.

Prioult, G., Pecquet, S. and Fliss, I., 2004. Stimulation of interleukin-10 production by acidic betalactoglobulin-derived peptides hydrolyzed with Lactobacillus paracasei NCC2461 peptidases. Clin Diagn Lab Immunol 11, 266-271.

Rook, G.A., Adams, V., Hunt, J., Palmer, R., Martinelli, R. and Brunet, L.R., 2004. Mycobacteria and other environmental organisms as immunomodulators for immunoregulatory disorders. Springer Semin Immunopathol 25, 237-255.

Bongaerts, G.P. and Severijnen, R.S., 2005. Preventive and curative effects of probiotics in atopic patients. Med Hypotheses 64, 1089-1092.

Rosenfeldt, V., Benfeldt, E., Valerius, N.H., Paerregaard, A. and Michaelsen, K.F., 2004. Effect of probiotics on gastrointestinal symptoms and small intestinal permeability in children with atopic dermatitis. J Pediatr 145, 612-616.

Rosenfeldt, V., Benfeldt, E., Nielsen, S.D., Michaelsen, K.F., Jeppesen, D.L., Valerius, N.H. and Paerregaard, A., 2003. Effect of probiotic Lactobacillus strains in children with atopic dermatitis. J Allergy Clin Immunol 111, 389-395.

Sistek, D., Kelly, R., Wickens, K., Stanley, T., Fitzharris, P. and Crane, J., 2006. Is the effect of probiotics on atopic dermatitis confined to food sensitized children? Clin Exp Allergy 36, 629-633.

Viljanen, M., Savilahti, E., Haahtela, T., Juntunen-Backman, K., Korpela, R., Poussa, T., Tuure, T. and Kuitunen, M., 2005. Probiotics in the treatment of atopic eczema/dermatitis syndrome in infants: a double-blind placebo-controlled trial. Allergy 60, 494-500.

Kalliomaki, M., Salminen, S., Arvilommi, H., Kero, P., Koskinen, P. and Isolauri, E., 2001. Probiotics in primary prevention of atopic disease: a randomised placebo-controlled trial. Lancet 357, 1076-1079.

Kalliomaki, M., Salminen, S., Poussa, T., Arvilommi, H. and Isolauri, E., 2003. Probiotics and prevention of atopic disease: 4-year follow-up of a randomised placebo-controlled trial. Lancet 361, 1869-1871.

Brouwer, M.L., Wolt-Plompen, S.A., Dubois, A.E., van der Heide, S., Jansen, D.F., Hoijer, M.A., Kauffman, H.F. and Duiverman, E.J., 2006. No effects of probiotics on atopic dermatitis in infancy: a randomized placebo-controlled trial. Clin Exp Allergy 36, 899-906.

Gruber, C., Wendt, M., Sulser, C., Lau, S., Kulig, M., Wahn, U., Werfel, T. and Niggemann, B., 2007. Randomized, placebo-controlled trial of Lactobacillus rhamnosus GG as treatment of atopic dermatitis in infancy. Allergy 62, 1270-1276. 
Taylor, A.L., Dunstan, J.A. and Prescott, S.L., 2007. Probiotic supplementation for the first 6 months of life fails to reduce the risk of atopic dermatitis and increases the risk of allergen sensitization in high-risk children: A randomized controlled trial. J Allergy Clin Immunol 119, 184-191.

Beardslee, T.A., Zeece, M.G., Sarath, G. and Markwell, J.P., 2000. Soybean glycinin G1 acidic chain shares IgE epitopes with peanut allergen Ara h 3. Int Arch Allergy Immunol 123, 299-307.

de Jonge, J.D., Knippels, L., Ezendam, J., Odink, J., Penninks, A.H. and van Loveren, H., 2007. The importance of dietary control in the development of a peanut allergy model in Brown Norway rats. Methods 41, 99-111.

Eigenmann, P.A., Burks, A.W., Bannon, G.A. and Sampson, H.A., 1996. Identification of unique peanut and soy allergens in sera adsorbed with cross-reacting antibodies. J Allergy Clin Immunol 98, 969-978.

Koppelman, S.J., Knol, E.F., Vlooswijk, R.A., Wensing, M., Knulst, A.C., Hefle, S.L., Gruppen, H. and Piersma, S., 2003. Peanut allergen Ara h 3: isolation from peanuts and biochemical characterization. Allergy 58, 1144-1151.

Laemmli, U.K., 1970. Cleavage of structural proteins during the assembly of the head of bacteriophage T4. Nature 227, 680-685.

Broekaert, I.J. and Walker, W.A., 2006. Probiotics and chronic disease. J Clin Gastroenterol 40, 270-274.

de Waard, R., Claassen, E., Bokken, G.C., Buiting, B., Garssen, J. and Vos, J.G., 2003. Enhanced immunological memory responses to Listeria monocytogenes in rodents, as measured by delayed-type hypersensitivity (DTH), adoptive transfer of DTH, and protective immunity, following Lactobacillus casei Shirota ingestion. Clin Diagn Lab Immunol 10, 59-65.

Kalliomaki, M.A. and Isolauri, E., 2004. Probiotics and down-regulation of the allergic response. Immunol Allergy Clin North Am 24, 739-752, viii.

Shida, K., Makino, K., Morishita, A., Takamizawa, K., Hachimura, S., Ametani, A., Sato, T., Kumagai, Y., Habu, S. and Kaminogawa, S., 1998. Lactobacillus casei inhibits antigen-induced IgE secretion through regulation of cytokine production in murine splenocyte cultures. Int Arch Allergy Immunol. $115,278-287$.

Tamura, M., Shikina, T., Morihana, T., Hayama, M., Kajimoto, O., Sakamoto, A., Kajimoto, Y., Watanabe, O., Nonaka, C., Shida, K. and Nanno, M., 2007. Effects of probiotics on allergic rhinitis induced by Japanese cedar pollen: randomized double-blind, placebo-controlled clinical trial. Int Arch Allergy Immunol 143, 75-82.

Osborn, D.A. and Sinn, J.K., 2007. Probiotics in infants for prevention of allergic disease and food hypersensitivity. Cochrane Database Syst Rev, CD006475. 


\section{Chapter 5}

\section{Gene expression changes in the}

mesenteric lymph nodes of rats after oral peanut extract exposure

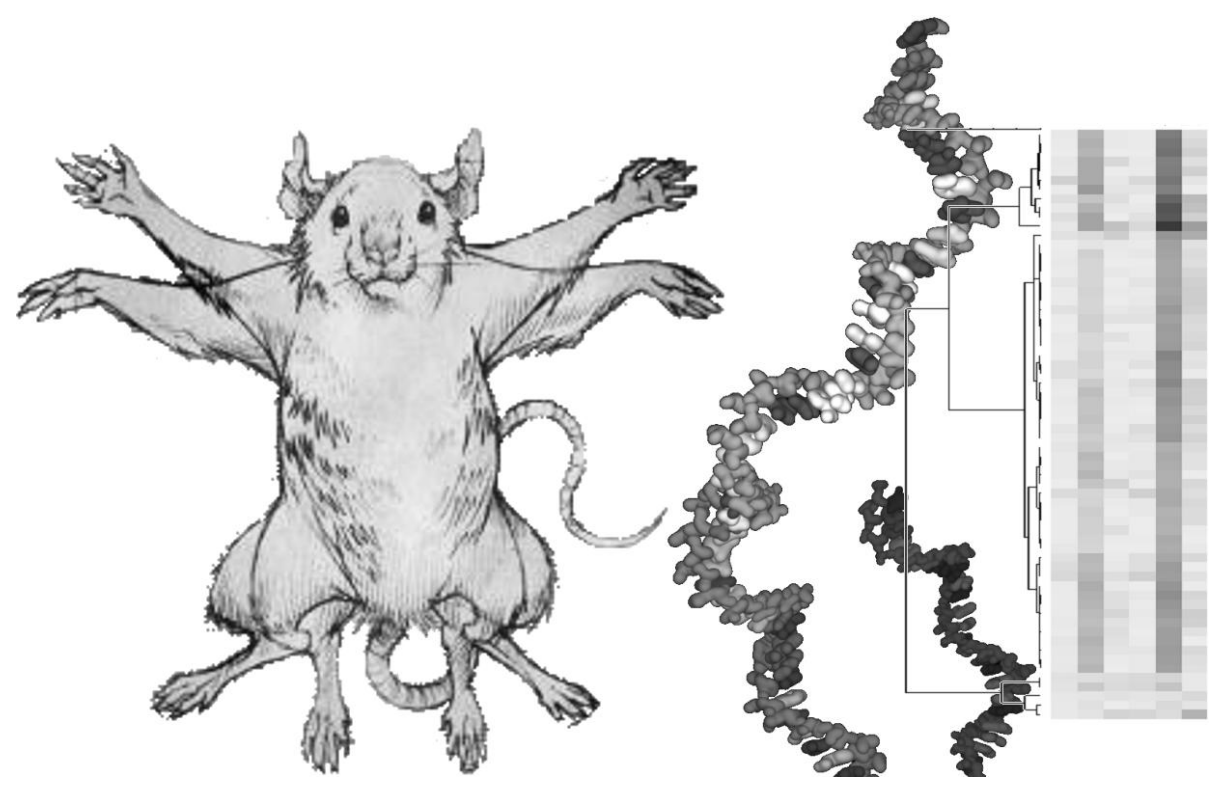

Published in J Immunotoxicol 5, 385-94 (2008). 


\section{ABSTRACT}

New techniques are needed to broaden the understanding of the food allergic response. The capacity of peanut extract to influence gene expression profiles was investigated in a Brown Norway rat model for food allergy.

Brown Norway rats were sensitized to peanut extract $(0,1$ and $10 \mathrm{mg} / \mathrm{rat} / \mathrm{d})$ by daily oral gavage and were dissected after 3, 7 or 14 days of exposure. RNA extracted from mesenteric lymph nodes of individual rats were hybridized against a common reference pool on Agilent whole rat genome $(4 * 44 \mathrm{k})$ arrays. The raw data were normalized and statistically analyzed using the statistical program R. A False Discovery Rate of $10 \%$ and a Fold Ratio of $-1.5 \leq$ Fold Ratio or Fold Ratio $\geq 1.5$ between the experimental groups and their respective control groups were applied. Differentially expressed genes were clustered into a heatmap. Functional annotation and GeneOntology term enrichment were examined. Furthermore, the involvement of the differentially expressed genes in specific cellular pathways was investigated with MetaCore.

Gene expression changes, which were both dose- and time-dependent, were detected after sensitization to peanut. A total of 64 genes were differentially expressed, of which 60 were up-regulated and four were down-regulated. These changes were related to the regulation of immunological processes, most notably increased cell division.

The findings indicate that responses to peanut include proliferation of immunologically relevant tissues, which can be identified by analysis of gene expression profiles. This may lay a basis for further research into possibilities for discrimination of allergenic from non-allergenic proteins.

\section{INTRODUCTION}

About $2 \%$ of the adult population and $6-8 \%$ of children below the age of 3 are affected by a food allergy (Burks and Ballmer-Weber 2006; Untersmayr and JensenJarolim 2006), which sometimes results in fatal reactions (anaphylactic shock) (Sicherer 2002). It is often difficult to predict whether foods that so far were not substantially consumed (novel foods) may be allergenic, and this problem may further increase due to the production of genetically modified food resulting in the introduction of new potentially allergenic proteins (Taylor 2006).

Animal models, although not yet validated, have been proposed for assessing the potential allergenicity of novel foods. In such models, specific IgE synthesis as well as other features such as mast cell mediator release, are indicators of allergenicity of the products to which the animals are exposed.

The publication of the sequence of the human genome has resulted in a dramatic increase in knowledge in the field of genomics (Gatzidou et al. 2007) and as a consequence, during the past two decades great advances have been achieved in mo- 
lecular biology. One of the most recent techniques accountable for these advances is the microarray technique. DNA microarrays permit the quantitative measurement of the expression levels of thousands of individual genes in different biological samples at the same time. Another benefit of this technique is that it allows for monitoring of early parameters of biological effects. Several studies have shown that it is possible to detect changes in the gene expression profile after exposure to immunomodulating agents, both in vivo (Ezendam et al. 2004) and in vitro (Schoeters et al. 2007). Schoeters et al. (Schoeters et al. 2007) compared the gene expression profiles of dendritic cells (DCs) exposed to contact allergens and irritants. They found 25 genes that were altered in response to contact allergens, but not to the irritants. Most of these genes could be linked to the immune response and/or to their expression in DCs. So far no studies have been performed that assessed the expression profile in food allergy. We aimed to test whether effects on the gene expression profile could be found in an in vivo setting of food allergy.

In the study described below, the effects of oral exposure to peanut extract (PE) on gene expression was investigated in a Brown Norway (BN) rat model for food allergy. $P E$ is known to produce food allergic reactions in humans and rats. $P E$ is the whole aqueous peanut extract and consists of several peanut allergens in the aqueous peanut matrix. Changes in expression of immunologically relevant and other genes that would be detected in this experimental setting could yield additional insight into the mechanisms of responses to proteins, including food allergens, and could eventually help to provide early markers of food allergy.

\section{METHODS}

\section{Animals}

PE sensitization was studied in young Brown Norway (BN) rats. In this study Brown Norway (BN Rij:Hsd) rats obtained from Harlan Netherlands B.V. (Horst, the Netherlands) were used. These rats were bred and raised on a peanut and soy protein-free diet (because soy and peanut are cross-reactive legumes) obtained from Harlan Netherlands B.V. (2016S Teklad Global 16\% Protein Rodent Diet) at our institute Female rats of the third generation (F3) and onwards were used and fed the peanut and soy protein-free diet during the experiment. At study initiation, the rats were 3 4 weeks old. The rats were housed in an animal room maintained at $23 \pm 3^{\circ} \mathrm{C}$, with a light/dark cycle of $14 \mathrm{~h} / 10 \mathrm{~h}$, and a relative humidity of 30-70\% during the experiment and for at least 7 days prior to study initiation. The animals were housed in stainless-steel wire (Macrolon III) cages in groups of two and had free access to food and tap-water. The guidelines described in the Dutch "Experiments on Animals" Act (1997), which can be found online (http://www.vet.uu.nl/nca/userfiles/other/The_Dutch_Experiments_on_Animals_A ct.pdf), were applied for the care and use of the animals. Approval from the Institu- 
tional Animal Ethics Committee was obtained for all experimental procedures involving animals.

\section{PE sensitization}

To ensure that animals were immunologically naive with respect to peanut, prestudy blood samples were always tested for allergen specific antibodies. Rats were randomly allocated to their dosing regimens ( $n=8$ per dosing regimen). Some reallocation was performed to ensure even starting weight distribution in all dosing regimens. Rats were exposed to $1 \mathrm{ml}$ of 0,1 or $10 \mathrm{mg} / \mathrm{ml}$ PE in PBS by daily po gavage, using a 18-gauge stainless steel animal feeding needle for the duration of 3, 7, or 14 days for the microarrays and 42 days followed by 7 days of rest (no PE sensitization) for the mesenteric lymph node (MLN) proliferation assay. After exposure the rats were sacrificed by exsanguination from the aorta under $\mathrm{CO}_{2} / \mathrm{O}_{2}$ anesthesia. The $\mathrm{MLNs}$ were removed aseptically and stored at $-80^{\circ} \mathrm{C}$ for RNA isolation. For the proliferation assay single cell suspensions were prepared from fresh MLNs for proliferation analysis of MLN cells after ex-vivo re-stimulation with PE.

\section{PE-specific IgE, IgG1 and IgG2a ELISAs}

$P E-s p e c i f i c$ IgE, IgG1, IgG2a levels were measured to examine whether the animals were adequately sensitized. PE-specific IgE, IgG1 and IgG2a Enzyme-Linked ImmunoSorbent Assay (ELISAs) were performed as described earlier (de Jonge et al. 2007b). Serum samples were collected at sacrifice at day 3, 7 and 14.

\section{Ex vivo stimulation of spleen cells: allergen-specific cell proliferation}

Assessment of PE-specific proliferation was done to assess if the rats animals were adequately sensitized. Single cell suspensions were prepared under aseptic conditions by pressing the MLN through a $70 \mu \mathrm{m}$ nylon cell strainer (Falcon, Franklin Lakes, USA). Cells were washed twice and resuspended in $5 \mathrm{~mL}$ standard medium (RPMI $1640+25$ mM Hepes + L-Glutamine) obtained from Gibco BRL (Breda, the Netherlands) supplemented with $10 \%$ heat inactivated fetal calf serum (FCS) obtained from Integro B.V. (Zaandam, The Netherlands) and $1 \%$ penicillinstreptomycin (Gibco) with $7.5 \times 10^{-5} \mathrm{M}$ 2-mercaptoethanol (2-ME) obtained from SERVA (Heidelberg, Germany). Cell number was determined with a Coulter Counter (Z2, Coulter Electronics, Mijdrecht, The Netherlands). Cell viability was determined by the Trypan blue cytotoxicity test. The concentration of the cell suspensions was adjusted to $1 \times 10^{6}$ viable cells $/ \mathrm{ml}$.

For cell proliferation, $100 \mu \mathrm{L}$ of the cell suspension was added per well in triplicate. Cells were incubated for $96 \mathrm{~h}$ with $2 \mathrm{mg} / \mathrm{ml} \mathrm{PE}$ and $\left[{ }^{3} \mathrm{H}\right]$-Thymidine was added for the last $18-20 \mathrm{~h}$. The optimal time point to assess lymphocyte proliferation was established in previously performed studies and 96 hours was the most optimal time point. 


\section{RNA isolation}

The RNA of the MLNs was isolated using the RNeasy Lipid Tissue midi kits (Qiagen, Maryland, USA) according to the manufacturers' instructions. To start the procedure, the frozen MLNs were first finely crushed using a pestle and mortar cooled with liquid nitrogen, after which the crushed tissue was transmitted into $5 \mathrm{~mL}$ Qiazol Lysis Reagent (Qiagen) and homogenized to allow immediate lysis after thawing. The quantity of RNA in each sample was determined spectrophotometrically (DU 800-spectrophotometer, Beckman Coulter, Fullerton, CA, USA) and RNA integrity was assessed using a Bioanalyzer 2100 (Agilent Technologies, Breda, the Netherlands). The RNA samples were stored at $-80 \circ \mathrm{C}$ until used. A common reference pool was prepared by mixing $0.33 \mu \mathrm{g}$ of RNA of all samples to be analyzed.

\section{RNA amplification and labeling}

First, $0.5 \mu \mathrm{g}$ total RNA (volume: $3.25 \mu \mathrm{L}$ ) of each sample and $1 \mu \mathrm{g}$ RNA (volume: 6.5 $\mu \mathrm{L}$ ) of the common reference pool was used for the labelling with Cyanine fluorophores (Cy3 and Cy5; Agilent Technologies) using the Low RNA Input Linear Amplification kit (Agilent Technologies) according to the manufacturers' instruction, with some adjustments. To the samples, $2.5 \mu \mathrm{L}$ T7-primer, $4.25 \mu \mathrm{L}$ cDNA mastermix and $15 \mu \mathrm{L}$ transcription mastermix were added per reaction; to the refence pool, $5 \mu \mathrm{L}$ T7-primer, $8.5 \mu \mathrm{L}$ cDNA mastermix and $30 \mu \mathrm{L}$ transcription mastermix were added per reaction. Briefly, the total RNA was reverse transcribed into cDNA using T7primers and MMLV reverse transcriptase. This CDNA was transcribed into CRNA, during which the fluorophores were incorporated into the RNA; Cy3 was incorporated into the common reference pool and Cy5 was incorporated into the samples. Next, the cDNA was purified using the RNeasy Mini kit (Qiagen) according to the manufacturer's instructions and the incorporation rate of the fluorophores into the cRNA was determined spectrophotometrically. Only samples with a dyeincorporation rate of $\geq 7 \mathrm{pmol} / \mu \mathrm{g}$ cRNA were considered suitable for further processing.

\section{Hybridization}

The labeled cRNA was prepared for hybridization using a Gene Expression Hybridization Kit (Agilent Technologies), according to manufactures' instructions. A mix of equal amounts of cRNA from the samples and the common reference pool was hybridized to slides from the Whole Rat Genome (4x44k) Oligo Microarray Kit (Agilent Technologies). This technique is also known as a two dye microarray; one dye for the individual samples and the other dye for the pooled reference sample, whereby the pooled reference sample allows for standardized comparison of individual samples. In total, 23 array slides with each four samples/ slide were generated. The arrays were hybridized for 17 hours at $65{ }^{\circ} \mathrm{C}$ in a hybridization oven (Agilent technologies). After washing the slides with the Gene Expression Wash 
Buffer kit (Agilent Technologies) according to the manufacturer's protocol, the slides were dipped in Stabilization and Drying Solution (Agilent) (2:1 diluted with acetonitrile) to protect the slides from environmental ozone and dried with $\mathrm{N}_{2}$.

\section{Scanning}

Immediately after washing, the arrays were scanned (GenePix 4000B) with a scan precision of $5 \mu \mathrm{m}$ which generated separate Cy3 and Cy5 images. The photomultiplier tube (PMT)-gain for Cy5 was set at $623 \mathrm{~nm}$ and the PMT-gain for Cy3 was set at $450 \mathrm{~nm}$. Imagene software was used to determine Cy3 and Cy5 signal intensities for each separate spot and the background noise. Quality control was performed on the raw data: first, the scans were visually inspected in Imagene followed by analyses of the raw data using a specifically designed Excel-file application. In this application the raw data were visualized as a scatter plot and an M/A-plot as well as a normal probability plot to assess signal distribution.

\section{Data analysis}

The raw data were normalized using the statistical program R (www.r-project.org), in three steps: (1) natural log-transformation, (2) quantile normalization of all scans and (3) correction of the sample spot signal for differences in the corresponding reference spot signal between arrays. For additional quality control, these normalized data were visualized by Principle Component Analysis (PCA). Next, statistical analysis of the data took place; in $\mathrm{R}$ significance of differences in gene expression between the experimental groups was calculated with one-way ANOVA. A False Discovery Rate (FDR) of $10 \%$ and a Fold Ratio (FR) of $-1.5 \leq F R$ or FR $\geq 1.5$ between the experimental groups and their respective control groups were applied.

Differentially expressed genes were clustered into a heatmap using GeneMaths (Applied Maths, St-Martens-Latem, Belgium). Functional annotation and GeneOntology (GO) term enrichment (www.geneontology.org) were examined with the DAVID/EASE program (david.abcc.ncifcrf.gov/). MetaCoreTM (GeneGo, San Diego, CA) was used to identify and visualize the involvement of the differentially expressed genes in specific cellular pathways, and this was related to the total amount of genes involved in the particular pathway and in all the available pathways combined.

\section{Statistics of ex vivo proliferation assay}

To determine if PE altered the ex vivo proliferation of MLNs within a dosing group of $\mathrm{PE}$ a one-way ANOVA with Bonferroni as post hoc test was done. Differences were considered significant if $p<0.05$ (two-sided). 


\section{RESULTS}

Antigen-specific antibodies

The animals were naïve at the level of antigen-specific antibodies before study initiation. At day 3 PE-specific IgE, IgG1 and IgG2a were not detectable in both dosing groups. At day 7, increased levels of PE-specific IgG2a and IgG1 levels were detected in the $10 \mathrm{mg}$ PE group. At this time-point PE-specific IgE levels were not detectable (data not shown). At day 14, PE-specific IgG1 (Fig. 1C) and IgG2a titres (Fig. 1B) are detectable in both dosing groups. PE-specific IgE titres are detectable in 4 of the 8 rats in the $1 \mathrm{mg} P E$ group and in 6 of the 8 rats in the $10 \mathrm{mg}$ PE group (fig. $1 \mathrm{~A}$ ).

\section{Figure 1A}

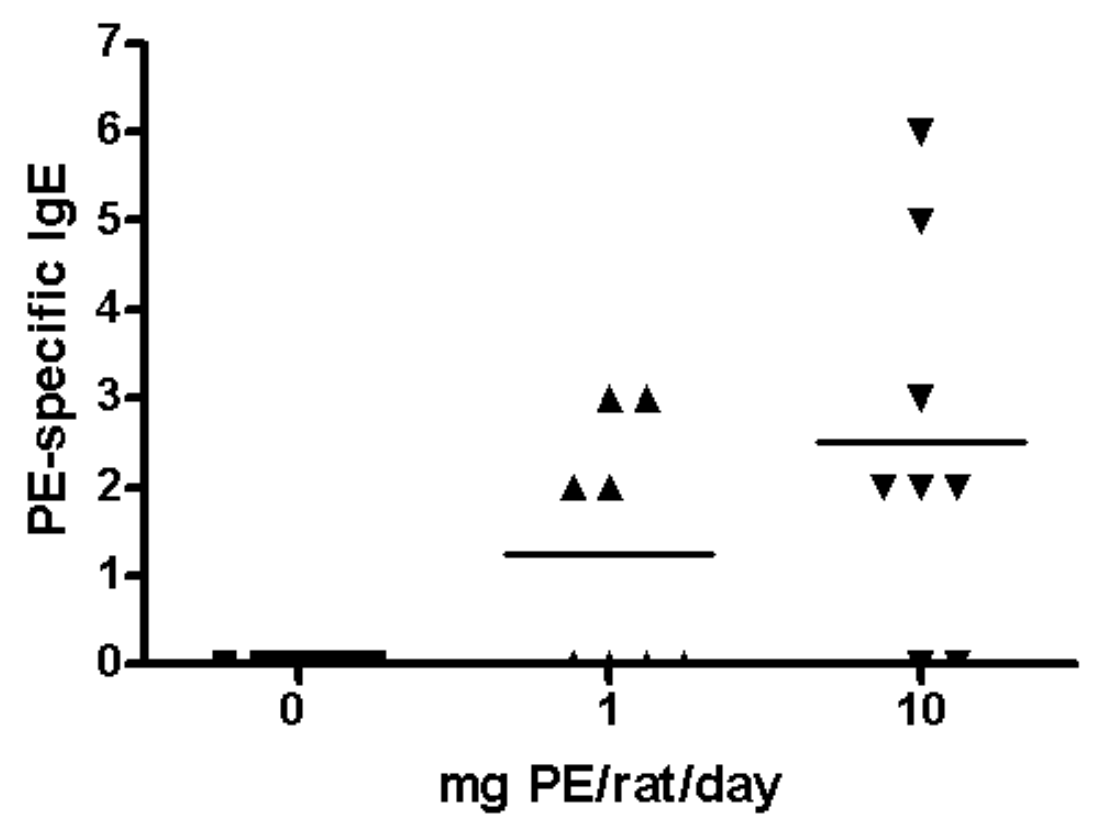




\section{Figure 1B}

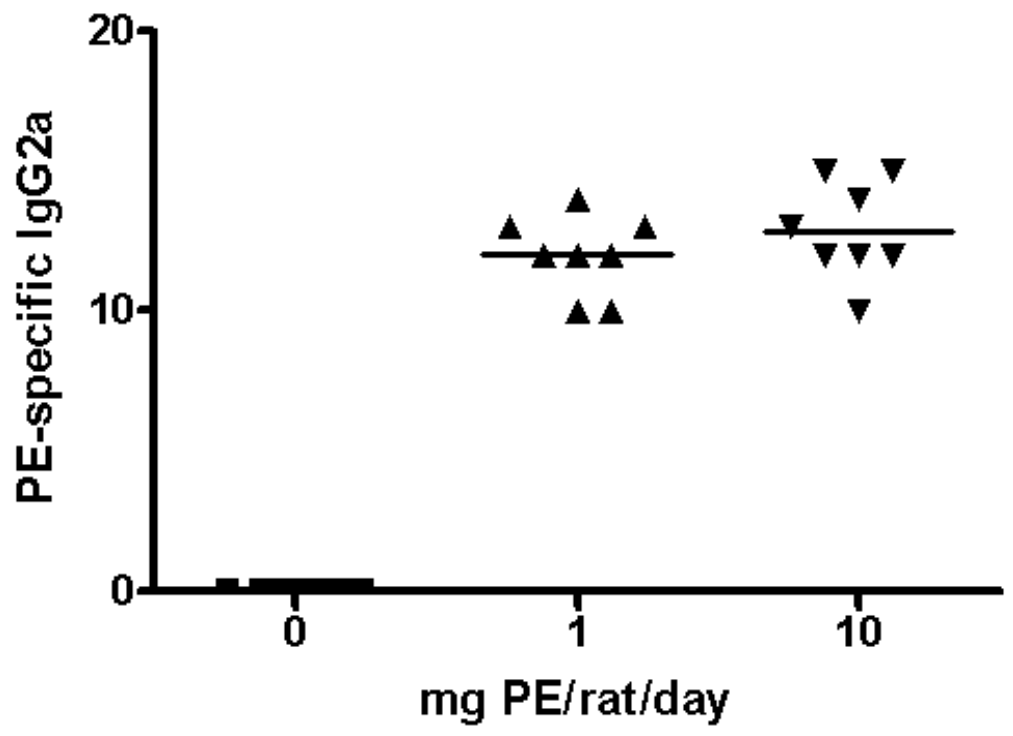

Figure 1C

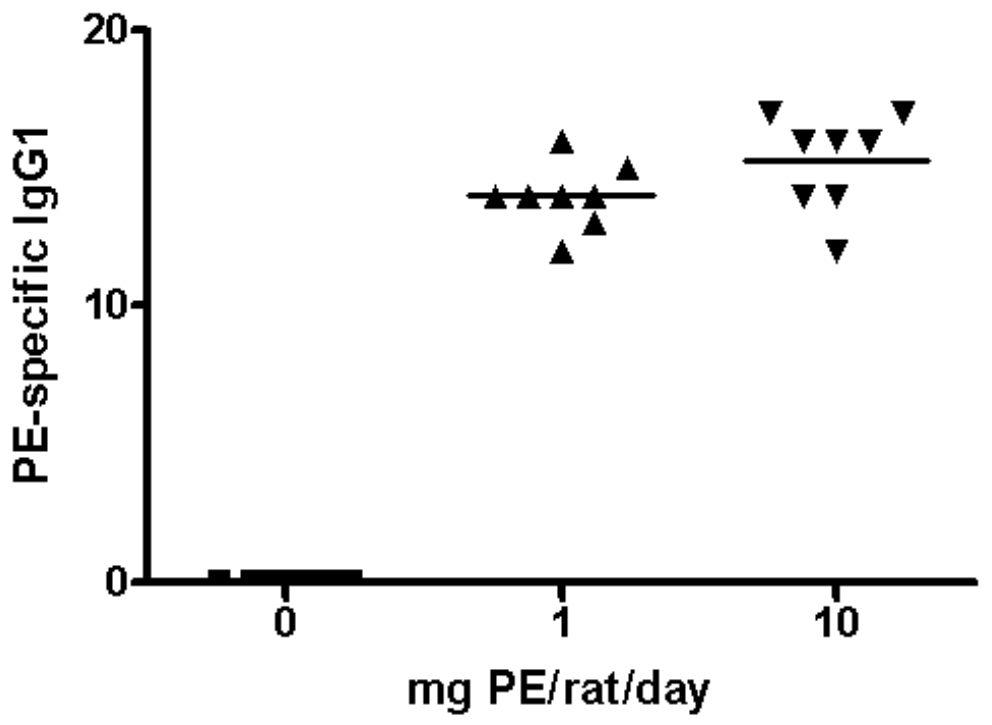

FIGURE 1. PE-specific IgE, IgG2a and IgG1 titers after 14 days of exposure to PE.

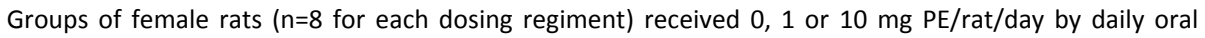
gavage. PE-specific Ig titers ( ${ }^{2} \log$ ) are shown at day 14: (A) displays PE-specific IgE titers, (B) displays PEspecific IgG2a titers and (C) displays PE-specific IgG1 titers. 


\section{PE-specific lymphocyte cell proliferation of MLN cells}

Figure 2 shows that in vivo dosing with $10 \mathrm{mg} P E / \mathrm{rat} /$ day group increased the PEspecific ex vivo proliferation, as compared to the $0 \mathrm{mg} \mathrm{PE} / \mathrm{rat} /$ day group of MLN cells. This change was not significant, due to variability especially in the $10 \mathrm{mg}$ peanut/rat/day group, but a strong dose-response correlation was found ( $R^{2}$ of 0.9999).

\section{Figure 2}

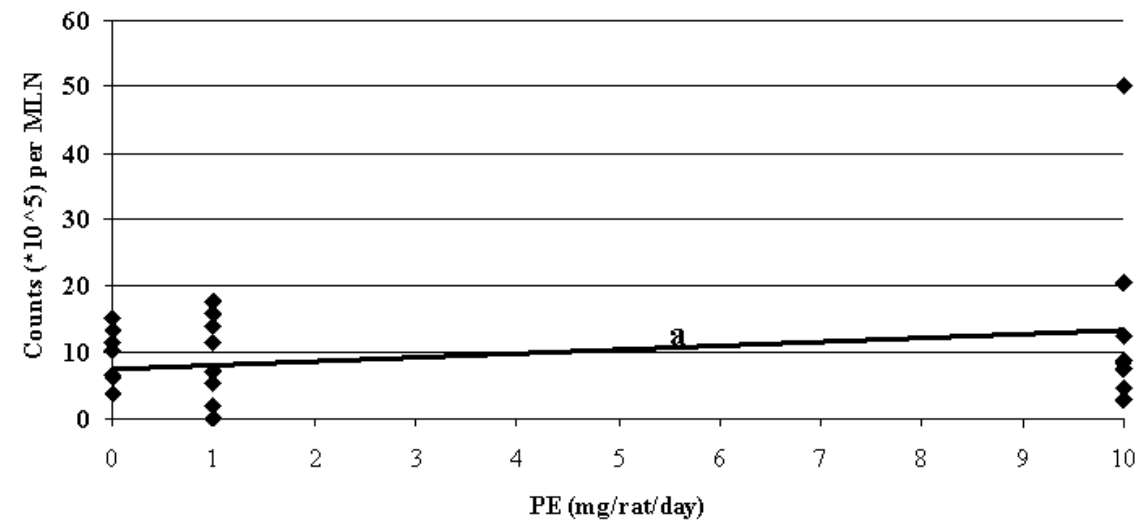

FIGURE 2. PE-specific proliferation of MLN cells

Groups of female rats ( $n=8$ for each dosing regiment) received 0,1 or $10 \mathrm{mg} P E / \mathrm{rat} /$ day by daily oral gavage. MLNs were dissected at day 49 , single cell suspensions were prepared and $1 \times 10^{5}$ cells/well were incubated with $1 \mathrm{mg} / \mathrm{ml} \mathrm{PE}$ for $96 \mathrm{~h}$. In earlier studies were we performed time series analysis we found $96 \mathrm{~h}$ of restimulation with $\mathrm{PE}$ to be the optimal time point for lymphocyte proliferation. Lymphocyte proliferation of MLN cells is expressed in $\mathrm{cpm}\left(* 10^{5}\right)$ per organ.

${ }^{a} y=0.5923 x+6.7682$ with $a R^{2}$ of 0.9999 define the trendline of the dose response between ex vivo PEspecific proliferation of MLN cells and in vivo PE-dosing.

\section{Gene expression profiles}

Gene expression data of the three groups exposed to $1 \mathrm{mg} \mathrm{PE} / \mathrm{rat} /$ day and the three groups exposed to $10 \mathrm{mg} \mathrm{PE} / \mathrm{rat} /$ day were compared to the data of their timematched controls by one-way ANOVA. An apparent time-effect was seen, as well as a clear dose-response relationship. Differential gene expression was most pronounced on day 7 for both the $1 \mathrm{mg}$ and the $10 \mathrm{mg} P E / \mathrm{rat} /$ day group. The groups exposed to $10 \mathrm{mg} \mathrm{PE} / \mathrm{rat} /$ day showed a stronger effect on all three days than the groups exposed to $1 \mathrm{mg} \mathrm{PE} / \mathrm{rat} /$ day. On day 7 in the $10 \mathrm{mg} \mathrm{PE} / \mathrm{rat} /$ day exposure group 60 genes were differentially expressed with a Fold Ratio of $>1.5$; on day 7 in the $1 \mathrm{mg} \mathrm{PE} / \mathrm{rat} /$ day exposure group 12 genes were differentially expressed with a Fold Ratio of $>1.5$. In total, 64 genes were differentially expressed with a Fold Ratio of $>1.5$ in one or more of the groups exposed to PE, of which there were 50 unique identifiable genes. 
Table I shows these genes with the FRs for the different exposure groups. In this table the genes are itemized into three groups: (Table I A) cell cycle genes, (Table I B) immunological genes and (Table I C) other genes. Figure 3 shows the clustering of these regulated genes. GO term enrichment analysis showed that cluster $A$, which consists of consistently up-regulated genes for both dosing regimens, was significantly enriched for cell cycle-related and immunological genes. In addition, MetaCore analysis of the differentially regulated genes resulted in the identification of several pathways in which the proteins coded by these genes were implicated. The six most regulated pathways identified by MetaCore were involved in cell cycle, confirming the GO-term enrichment analysis. These pathways were (number of genes regulated of the total genes included in this pathway during analysis are placed between brackets): role anaphase-promoting complex (APC) in cell cycle regulation (8 of 53), nucleocytoplasmic transport of cyclin-dependent kinase (CDK)/cyclins (4 of 22), cell cycle (generic schema; 4 of 26), the metaphase checkpoint (4 of 36), ataxia telangiectasia mutated (ATM)/ ataxia telangiectasia and RAD3-related (ATR) regulation of G2/M checkpoint (3 of 29) and chromosome condensation in prometaphase (3 of 33). Figure 4 shows the highest ranking pathway obtained by MetaCore analysis. It represents the role of the APC in cell cycle regulation and illustrates the expression changes for cell cycle related genes. The genes involved in the six most significant pathways were: Cdk1 (cyclin-dependent kinase; cdc2a: cell division cycle 2a), cyclin A, cyclin E and SPBC24 (Spbc24), which were upregulated at day 7 in $\mathrm{BN}$ rats exposed to $1 \mathrm{mg} \mathrm{PE} / \mathrm{rat} /$ day or $10 \mathrm{mg} \mathrm{PE} / \mathrm{rat} / \mathrm{day}$; and cyclin B1, MAD2 (mitotic arrest deficient; Mad2l1), Cks1 (Cdc kinase subunit 1; RGD1561797), geminin, BUB1 (budding uninhibited by benzimidazoles 1 homolog, beta; Bub1) and BUBR1 (Bub1b) which were up regulated at day 7 after exposure to $10 \mathrm{mg} \mathrm{PE} / \mathrm{rat} /$ day, but not after exposure to $1 \mathrm{mg} \mathrm{PE} / \mathrm{rat} /$ day. All these genes were proliferation related.

No immunological pathways based on sufficient numbers of regulated genes were found using MetaCore analysis, but several individual immunologically relevant genes were regulated by PE in the food allergy model: adenosine deaminase (ADA), immunoglobulin light chain variable region (Ig), IgG1, Igj, tumor necrosis factor receptor (TNFR) superfamily, member 17 (Tnfrsf17), Siva and tumor rejection antigen gp96 (Tra1). These genes were all up-regulated in the exposure group receiving 10 $\mathrm{mg} \mathrm{PE} / \mathrm{rat} /$ day at day 7 , Tra1 was also up-regulated in the $1 \mathrm{mg} \mathrm{PE} / \mathrm{rat} /$ day group at day 7. 
TABLE I: Individually regulated genes in a rat model for peanut allergy

A: Cell cycle genes

\begin{tabular}{|c|c|c|c|c|c|c|c|c|}
\hline \multirow{3}{*}{$\begin{array}{l}\text { Accession } \\
\text { number }\end{array}$} & \multirow[t]{3}{*}{ Symbol } & \multirow[t]{3}{*}{ Gene name } & \multicolumn{6}{|l|}{ FR } \\
\hline & & & \multicolumn{3}{|c|}{ 1mg PE/rat/day } & \multicolumn{3}{|c|}{ 10mg PE/rat/day } \\
\hline & & & $3 d$ & $7 d$ & $14 d$ & $3 d$ & $7 d$ & $14 d$ \\
\hline XM_215849 & $\begin{array}{l}\text { Bub1_predicte } \\
\text { d }\end{array}$ & $\begin{array}{l}\text { budding uninhibi- } \\
\text { ted by benzimida- } \\
\text { zoles } 1 \text { homolog (S. } \\
\text { cerevisiae) (pre- } \\
\text { dicted) }\end{array}$ & -1.03 & 1.49 & 1.07 & -1.03 & $2.07^{A}$ & 1.10 \\
\hline NM_053702 & Ccna2 & cyclin A2 & 1.13 & $1.51^{A}$ & 1.07 & 1.18 & $1.92^{A}$ & 1.05 \\
\hline NM_171991 & Ccnb1 & cyclin B1 & -1.10 & 1.49 & -1.01 & -1.06 & $1.85^{A}$ & 1.05 \\
\hline NM_019296 & Cdc2a & $\begin{array}{l}\text { cell division cycle } 2 \\
\text { homolog A (S. } \\
\text { pombe) }\end{array}$ & -1.10 & $1.69^{A}$ & 1.11 & -1.08 & $2.6^{A}$ & 1.07 \\
\hline XM_214152 & $\begin{array}{l}\text { Cdkn3_predict } \\
\text { ed }\end{array}$ & $\begin{array}{l}\text { cyclin-dependent } \\
\text { kinase inhibitor } 3 \\
\text { (predicted) }\end{array}$ & -1.07 & $1.69^{A}$ & 1.00 & -1.04 & $2.7^{A}$ & 1.19 \\
\hline XM_218601 & E2f8 & $\begin{array}{l}\text { E2F transcription } \\
\text { factor } 8\end{array}$ & 1.01 & 1.41 & 1.14 & -1.05 & $1.94^{A}$ & 1.21 \\
\hline XM_214477 & $\begin{array}{l}\text { Gmnn_predict } \\
\text { ed }\end{array}$ & $\begin{array}{l}\text { geminin (pre- } \\
\text { dicted) }\end{array}$ & -1.05 & 1.47 & -1.00 & -1.11 & $1.67^{A}$ & 1.05 \\
\hline XM_216161 & $\begin{array}{l}\text { Mad2|1_predic } \\
\text { ted }\end{array}$ & $\begin{array}{l}\text { MAD2 (mitotic } \\
\text { arrest deficient, } \\
\text { homolog)-like } 1 \\
\text { (yeast) (predicted) }\end{array}$ & -1.13 & 1.29 & 1.02 & -1.08 & $1.59^{A}$ & 1.10 \\
\hline NM_022381 & Pena & $\begin{array}{l}\text { proliferating cell } \\
\text { nuclear antigen }\end{array}$ & -1.05 & 1.48 & 1.02 & 1.05 & $1.6^{A}$ & -1.00 \\
\hline XM_236477 & Ttk_predicted & $\begin{array}{l}\text { Ttk protein kinase } \\
\text { (predicted) }\end{array}$ & -1.03 & 1.44 & 1.07 & -1.00 & $1.91^{A}$ & 1.06 \\
\hline XM_213891 & $\begin{array}{l}\text { Aspm_predicte } \\
\text { d }\end{array}$ & $\begin{array}{l}\text { asp (abnormal } \\
\text { spindle)-like, } \\
\text { microcephaly } \\
\text { associated (Droso- } \\
\text { phila) (predicted) }\end{array}$ & -1.08 & 1.42 & -1.04 & -1.08 & $1.89^{A}$ & 1.07 \\
\hline XM_342494 & Bub1b & $\begin{array}{l}\text { budding uninhibi- } \\
\text { ted by benzimida- } \\
\text { zoles } 1 \text { homolog, } \\
\text { beta (S. cerevisiae) }\end{array}$ & 1.00 & 1.33 & 1.16 & 1.01 & $1.59^{A}$ & 1.12 \\
\hline XM_001077331 & Cone1 & cyclin $\mathrm{E}$ & -1.03 & $1.54^{A}$ & 1.07 & 1.02 & $2.23^{A}$ & 1.13 \\
\hline XM_226624 & Ell2 & $\begin{array}{l}\text { elongation factor } \\
\text { RNA polymerase II } \\
2\end{array}$ & 1.06 & 1.14 & 1.02 & 1.04 & $2.02^{A}$ & 1.18 \\
\hline XM_226624 & Ell2 & $\begin{array}{l}\text { elongation factor } \\
\text { RNA polymerase II } \\
2\end{array}$ & 1.09 & 1.15 & -1.14 & 1.18 & $1.67^{A}$ & 1.08 \\
\hline
\end{tabular}




\begin{tabular}{|l|l|l|l|l|l|l|l|l|}
\hline XM_341592 & $\begin{array}{l}\text { Kif20a_predict } \\
\text { ed }\end{array}$ & $\begin{array}{l}\text { kinesin family } \\
\text { member 20A } \\
\text { (predicted) }\end{array}$ & -1.11 & 1.47 & 1.03 & -1.16 & $1.97^{A}$ & 1.12 \\
\hline NM_001025740 & Rrm2_mapped & $\begin{array}{l}\text { ribonucleotide } \\
\text { reductase M2 }\end{array}$ & 1.00 & $1.50^{A}$ & -1.01 & -1.01 & $2.93^{A}$ & 1.19 \\
\hline NM_001025740 & Rrm2_mapped & $\begin{array}{l}\text { ribonucleotide } \\
\text { reductase M2 }\end{array}$ & -1.03 & 1.40 & 1.01 & 1.03 & $2.06^{A}$ & 1.18 \\
\hline BG153336 & Smarcb1 & $\begin{array}{l}\text { SWl/SNF related, } \\
\text { matrix associated, } \\
\text { actin dependent } \\
\text { regulator of chro- } \\
\text { matin, subfamily b, } \\
\text { member 1 }\end{array}$ & -1.02 & 1.16 & 1.01 & -1.04 & $1.75^{A}$ & 1.21 \\
\hline XM_215471 & Solt_predicted & $\begin{array}{l}\text { SoxLZ/Sox6 leucine } \\
\text { zipper binding } \\
\text { protein in testis } \\
\text { (predicted) }\end{array}$ & 1.10 & 1.42 & 1.02 & 1.06 & $1.93^{A}$ & 1.00 \\
\hline XM_343359 & $\begin{array}{l}\text { Spbc24_predic } \\
\text { ted }\end{array}$ & $\begin{array}{l}\text { spindle pole body } \\
\text { component 24 } \\
\text { homolog (S. cere- } \\
\text { visiae) (predicted) }\end{array}$ & 1.01 & $1.62^{A}$ & 1.02 & -1.01 & $2.06^{A}$ & -1.04 \\
\hline
\end{tabular}

B: Immunological genes

\begin{tabular}{|c|c|c|c|c|c|c|c|c|}
\hline \multirow{3}{*}{$\begin{array}{l}\text { Accession } \\
\text { number }\end{array}$} & \multirow[t]{3}{*}{ Symbol } & \multirow[t]{3}{*}{ Gene name } & \multicolumn{6}{|l|}{ FR } \\
\hline & & & \multicolumn{3}{|c|}{$1 \mathrm{mg} P E /$ rat/day } & \multicolumn{3}{|c|}{ 10mg PE/rat/day } \\
\hline & & & $3 d$ & $7 d$ & 14d & $3 d$ & $7 d$ & $14 d$ \\
\hline \multicolumn{9}{|c|}{ Immunological genes } \\
\hline NM_130399 & Ada & $\begin{array}{l}\text { adenosine } \\
\text { deaminase }\end{array}$ & 1.00 & 1.18 & -1.01 & -1.02 & $1.95^{A}$ & 1.09 \\
\hline NM_130399 & Ada & $\begin{array}{l}\text { adenosine } \\
\text { deaminase }\end{array}$ & -1.00 & 1.33 & -1.02 & -1.04 & $1.99^{A}$ & 1.18 \\
\hline XM_344042 & $\lg$ & $\begin{array}{l}\text { similar to immu- } \\
\text { noglobulin light } \\
\text { chain variable } \\
\text { region (predicted) }\end{array}$ & 1.00 & 1.04 & -1.06 & -1.02 & $1.86^{A}$ & 1.05 \\
\hline XM_344042 & $\lg$ & $\begin{array}{l}\text { similar to immu- } \\
\text { noglobulin light } \\
\text { chain variable } \\
\text { region (predicted) }\end{array}$ & -1.02 & 1.13 & 1.00 & -1.05 & $1.87^{A}$ & 1.21 \\
\hline XM_573321 & LOC498113 & $\begin{array}{l}\text { similar to This CDS } \\
\text { feature is included } \\
\text { to show the trans- } \\
\text { lation of the corre- } \\
\text { sponding V_region. } \\
\text { Presently transla- } \\
\text { tion qualifiers on } \\
\text { V_region features } \\
\text { are illegal }\end{array}$ & 1.02 & $1.81^{A}$ & 1.36 & 1.11 & $5.21^{A}$ & $1.88^{A}$ \\
\hline TC548855 & $\lg \mathrm{Ig}$ & immunoglobulin G1 & 1.06 & 1.09 & 1.21 & -1.10 & $2.11^{A}$ & $1.64^{A}$ \\
\hline
\end{tabular}




\begin{tabular}{|c|c|c|c|c|c|c|c|c|}
\hline XM_341195 & Igj & $\begin{array}{l}\text { immunoglobulin } \\
\text { joining chain }\end{array}$ & -1.06 & 1.49 & -1.07 & -1.03 & $2.65^{A}$ & 1.07 \\
\hline S82585 & Igj & $\begin{array}{l}\text { immunoglobulin } \\
\text { joining chain }\end{array}$ & 1.01 & $1.58^{A}$ & -1.05 & -1.03 & $2.84^{A}$ & 1.12 \\
\hline XM_213211 & $\begin{array}{l}\text { Tnfrsf17_predi } \\
\text { cted }\end{array}$ & $\begin{array}{l}\text { tumor necrosis } \\
\text { factor receptor } \\
\text { superfamily, mem- } \\
\text { ber } 17 \text { (predicted) }\end{array}$ & 1.07 & $1.78^{A}$ & -1.01 & 1.06 & $3.79^{A}$ & 1.20 \\
\hline XM_343117 & Siva_predicted & Siva_predicted & -1.04 & 1.23 & 1.00 & 1.02 & $1.55^{A}$ & 1.10 \\
\hline NM_001012197 & Tra1_predicted & $\begin{array}{l}\text { tumor rejection } \\
\text { antigen gp96 } \\
\text { (predicted) }\end{array}$ & -1.02 & 1.17 & -1.09 & -1.10 & $2.46^{A}$ & 1.03 \\
\hline
\end{tabular}

\section{C: Other genes}

\begin{tabular}{|c|c|c|c|c|c|c|c|c|}
\hline \multirow{3}{*}{$\begin{array}{l}\text { Accession } \\
\text { number }\end{array}$} & \multirow[t]{3}{*}{ Symbol } & \multirow[t]{3}{*}{ Gene name } & \multicolumn{6}{|l|}{ FR } \\
\hline & & & \multicolumn{3}{|c|}{$1 \mathrm{mg} \mathrm{PE} / \mathrm{rat} / \mathrm{day}$} & \multicolumn{3}{|c|}{ 10mg PE/rat/day } \\
\hline & & & $3 d$ & $7 d$ & $14 d$ & $3 d$ & $7 d$ & $14 d$ \\
\hline XM_236614 & $\begin{array}{l}\text { Ar- } \\
\text { met_predicted }\end{array}$ & $\begin{array}{l}\text { arginine-rich, } \\
\text { mutated in early } \\
\text { stage tumors } \\
\text { (predicted) }\end{array}$ & -1.05 & 1.13 & 1.05 & -1.04 & $1.90^{A}$ & 1.13 \\
\hline XM_236614 & $\begin{array}{l}\text { Ar- } \\
\text { met_predicted }\end{array}$ & $\begin{array}{l}\text { arginine-rich, } \\
\text { mutated in early } \\
\text { stage tumors } \\
\text { (predicted) }\end{array}$ & -1.03 & 1.13 & \begin{tabular}{|l|}
1.01 \\
\end{tabular} & -1.02 & $1.94^{A}$ & 1.13 \\
\hline XM_343189 & $\begin{array}{l}\text { Ckap4_predicte } \\
\text { d }\end{array}$ & $\begin{array}{l}\text { cytoskeleton- } \\
\text { associated protein } \\
4 \text { (predicted) } \\
\end{array}$ & 1.08 & 1.16 & -1.04 & 1.06 & $2.31^{A}$ & 1.05 \\
\hline NM_053886 & Lman1 & $\begin{array}{l}\text { lectin, mannose- } \\
\text { binding, } 1\end{array}$ & 1.04 & 1.14 & -1.02 & 1.04 & $1.78^{A}$ & 1.19 \\
\hline NM_053886 & Lman1 & $\begin{array}{l}\text { lectin, mannose- } \\
\text { binding, } 1\end{array}$ & -1.07 & 1.17 & -1.02 & 1.02 & $1.67^{A}$ & 1.13 \\
\hline NM_153628 & Sec11/3 & $\begin{array}{l}\text { Sec11-like } 3 \text { (S. } \\
\text { cerevisiae) }\end{array}$ & -1.05 & 1.32 & -1.05 & -1.04 & $2.17^{A}$ & 1.20 \\
\hline NM_001008891 & Ssr1 & $\begin{array}{l}\text { signal sequence } \\
\text { receptor, alpha }\end{array}$ & -1.08 & 1.22 & -1.14 & 1.06 & $2.09^{A}$ & 1.16 \\
\hline NM_001008334 & Tmem97 & $\begin{array}{l}\text { transmembrane } \\
\text { protein } 97\end{array}$ & 1.08 & 1.31 & -1.37 & -1.00 & $3.24^{A}$ & 1.43 \\
\hline NM_181084 & Trp53inp1 & $\begin{array}{l}\text { transformation } \\
\text { related protein } 53 \\
\text { inducible nuclear } \\
\text { protein } 1\end{array}$ & -1.02 & 1.17 & -1.02 & -1.03 & $1.70^{A}$ & -1.01 \\
\hline XM_225257 & $\begin{array}{l}\text { Txndc5_predict } \\
\text { ed }\end{array}$ & $\begin{array}{l}\text { thioredoxin do- } \\
\text { main containing } 5 \\
\text { (predicted) }\end{array}$ & 1.04 & 1.28 & -1.04 & 1.11 & $2.02^{A}$ & 1.09 \\
\hline NM_001034952 & Pqlc3 & $\begin{array}{l}\text { PQ loop repeat } \\
\text { containing } 3\end{array}$ & -1.04 & 1.18 & 1.05 & 1.05 & $1.85^{A}$ & \begin{tabular}{|l|}
1.12 \\
\end{tabular} \\
\hline
\end{tabular}




\begin{tabular}{|c|c|c|c|c|c|c|c|c|}
\hline NM_053849 & Pdia4 & $\begin{array}{l}\text { protein disulfide } \\
\text { isomerase family } \\
\text { A, member } 4\end{array}$ & 1.07 & 1.13 & -1.05 & -1.00 & $2.21^{A}$ & 1.01 \\
\hline NM_001024240 & RGD1310251 & $\begin{array}{l}\text { similar to RIKEN } \\
\text { cDNA } \\
2010001 \mathrm{M} 09\end{array}$ & -1.06 & $1.55^{A}$ & 1.02 & -1.08 & $3.90^{A}$ & 1.33 \\
\hline XM_001058771 & LOC681870 & $\begin{array}{l}\text { hypothetical } \\
\text { protein } \\
\text { LOC681870 }\end{array}$ & -1.14 & $1.55^{A}$ & 1.05 & -1.03 & $1.88^{A}$ & -1.01 \\
\hline NM_001025683 & RGD1311946 & $\begin{array}{l}\text { similar to RIKEN } \\
\text { cDNA } \\
1810055 G 02\end{array}$ & -1.02 & 1.19 & -1.04 & -1.10 & $1.81^{A}$ & 1.10 \\
\hline XM_579997 & $\begin{array}{l}\text { RGD1561797_pr } \\
\text { edicted }\end{array}$ & $\begin{array}{l}\text { RGD1561797 } \\
\text { (predicted) }\end{array}$ & -1.08 & 1.37 & 1.05 & -1.04 & $1.77^{A}$ & 1.18 \\
\hline NM_001014041 & LOC310721 & $\begin{array}{l}\text { similar to } \\
\text { 4930431B09Rik } \\
\text { protein }\end{array}$ & -1.04 & 1.13 & -1.11 & 1.01 & $1.75^{A}$ & 1.14 \\
\hline XM_001058844 & LOC680782 & $\begin{array}{l}\text { similar to signal } \\
\text { peptidase com- } \\
\text { plex subunit } 3 \\
\text { homolog }\end{array}$ & -1.05 & 1.13 & -1.01 & -1.01 & $1.75^{A}$ & 1.06 \\
\hline AY310157 & RGD1311563 & $\begin{array}{l}\text { similar to Oligo- } \\
\text { saccharyl trans- } \\
\text { ferase } 3 \text { CG7748- } \\
\text { PA }\end{array}$ & 1.02 & 1.14 & -1.01 & -1.01 & 1.63 & -1.06 \\
\hline NM_198776 & MGC72973 & beta-glo & -1.22 & 1.24 & $1.55^{A}$ & $\begin{array}{l}- \\
1.78^{A}\end{array}$ & 1.32 & -1.07 \\
\hline NM_001013853 & LOC287167 & globin, alpha & -1.28 & 1.08 & $\begin{array}{l}- \\
1.51^{A}\end{array}$ & $\begin{array}{l}- \\
1.68^{A}\end{array}$ & 1.14 & -1.05 \\
\hline $\mathrm{x} 53003$ & Acaca & $\begin{array}{l}\text { acetyl-coenzyme } \\
\text { A carboxylase } \\
\text { alpha }\end{array}$ & 1.02 & -1.14 & \begin{tabular}{|l|}
-1.26 \\
\end{tabular} & 1.04 & -1.23 & $-1.63^{A}$ \\
\hline NM_012543 & Dbp & $\begin{array}{l}\text { D site albumin } \\
\text { promoter binding } \\
\text { protein }\end{array}$ & -1.07 & -1.22 & 1.15 & 1.14 & -1.48 & $1.54^{A}$ \\
\hline NM_017297 & Kcnj5 & $\begin{array}{l}\text { potassium in- } \\
\text { wardly-rectifying } \\
\text { channel, subfam- } \\
\text { ily J, member } 5\end{array}$ & -1.08 & -1.33 & 1.00 & -1.10 & $\begin{array}{l}- \\
1.64^{A}\end{array}$ & 1.03 \\
\hline
\end{tabular}

Gene expression data are displayed as the Fold Ratio (FR) of the individual genes at the three time points: days (d) 3, 7 or 14 .

${ }^{A}$ Differentially expressed genes 


\section{Figure 3}

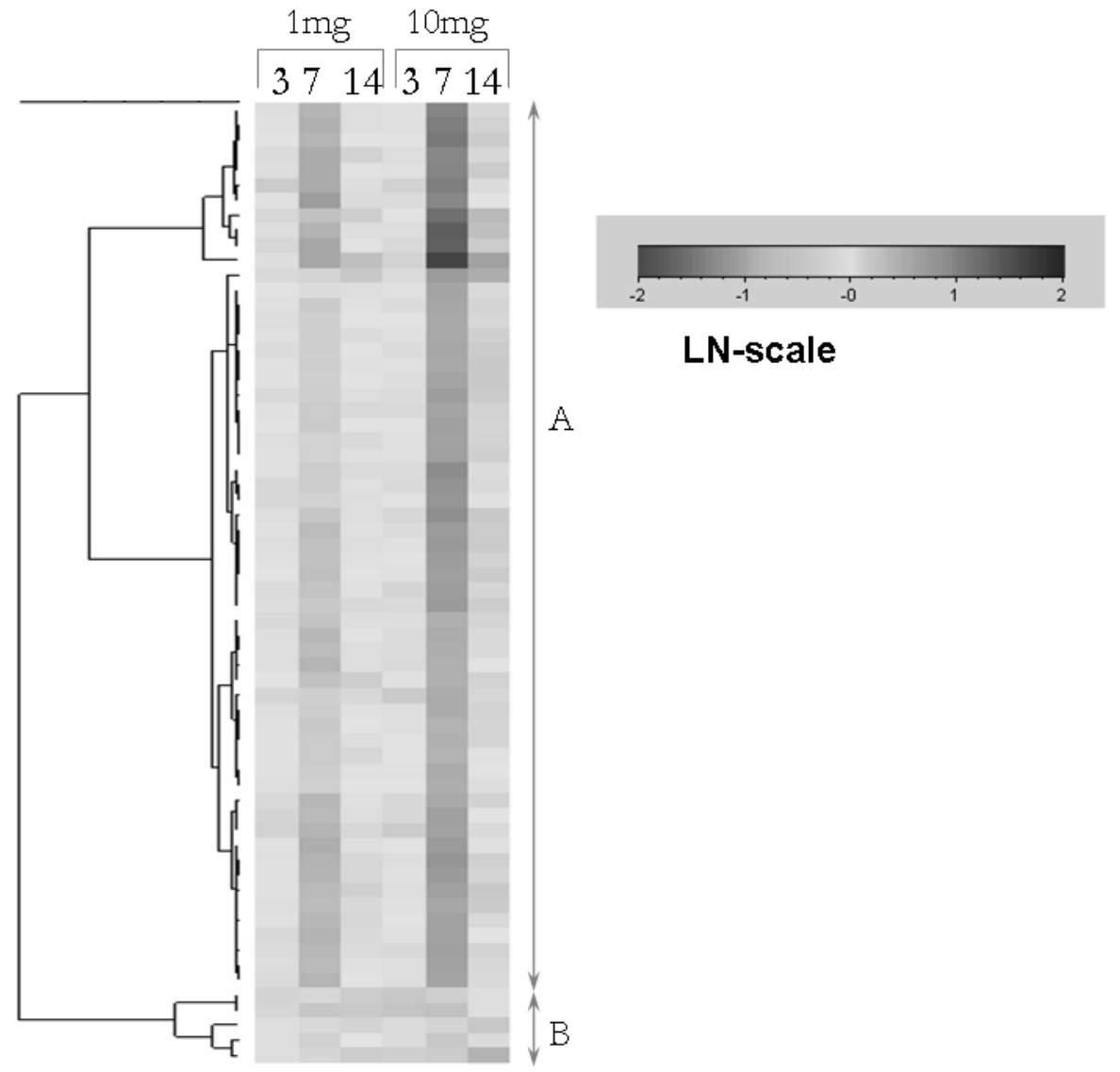

FIGURE 3. Hierarchial clustering of genes regulated by PE

Gene expression data are displayed as a clustered heat map (in LN-scale ranging from -2 to +2 ). The color bar and the corresponding Fold Ratio indicate gene expression: red represents up-regulation, green down-regulation and yellow no difference. Cluster A consists of consistently up-regulated genes for both dosing regimens and cluster $B$ consists of less consistent regulated genes.

ADA is an enzyme that catalyzes the deamination of adenosine and deoxyadenosine to inosine and deoxyinosine, respectively. ADA is required for the maturation and function of lymphocytes, especially $T$ lymphocytes in which its main biologic activity is detected (Mishra et al. 2005), and for the maturation of human blood monocytes to macrophages.

Tnfrsf17 is a member of the TNFR superfamily that is important for B cell development. It is preferentially expressed in mature B lymphocytes, especially that of $B$ memory cells (Treml et al. 2006), and autoimmune response. Several TNF ReceptorAssociated Factors are able to bind to Tnfrsf17 hereby transducing cell-signals for cell survival and proliferation (Hatzoglou et al. 2000). 


\section{Figure 4}

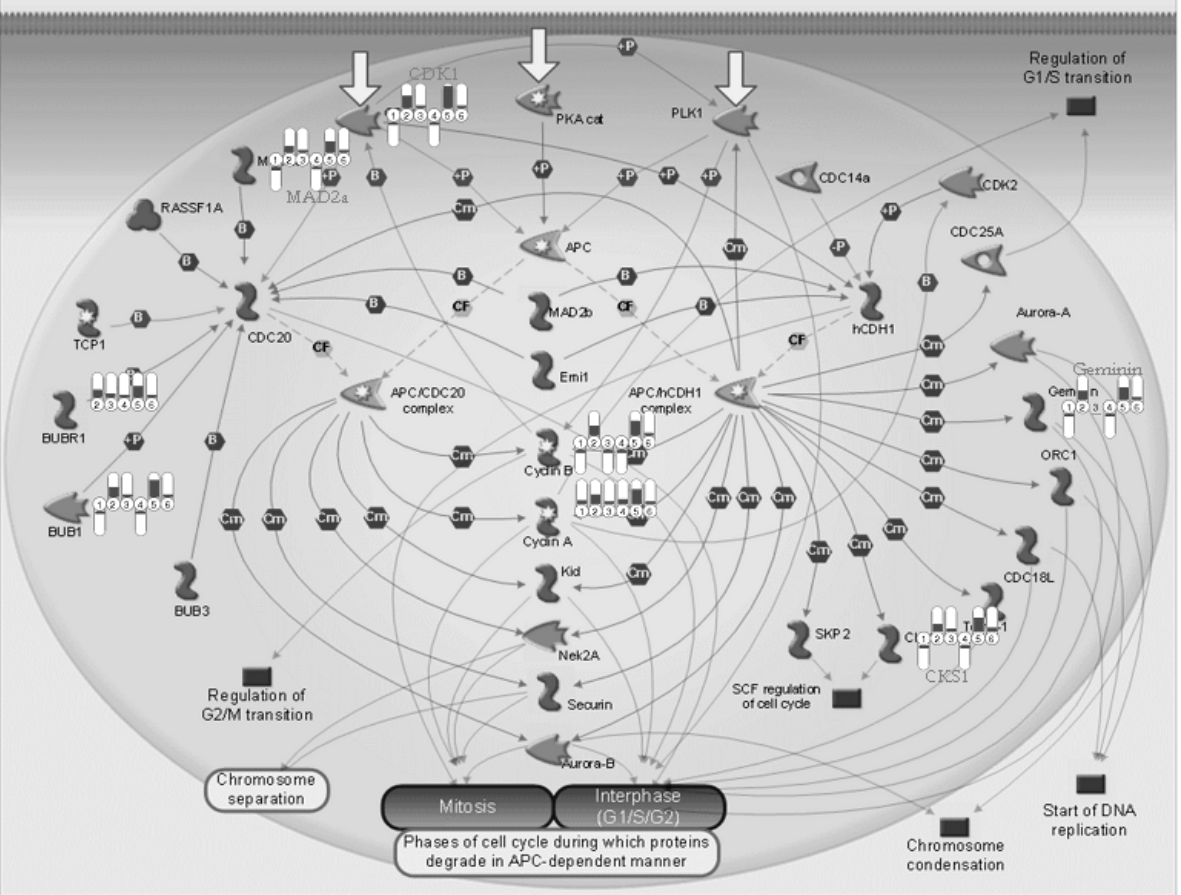

FIGURE 4. Effect of PE on role of anaphase-promoting complex (APC) in cell cycle regulation

Expression changes of several cell cycle-related genes are displayed in a pathway. The red (up-regulation) and green (down-regulation) bars represent the raw gene expression data. For each regulated gene, from left to right the first three bars and the last three bars represent days 3, 7 and 14 of the $1 \mathrm{mg} P E$ and the $10 \mathrm{mg}$ PE groups, respectively. A legend of symbols can be found online (http://www.genego.com/files/MC legend.pdf).

Siva (apoptosis-inducing factor) plays an important role in the apoptotic pathway of thymocytes. Association of Siva with members of the TNFR family, sends proapoptotic signals into the cell. It negatively regulates the nuclear factor-kappa B (NF$\mathrm{KB}$ ) activity, which has anti-apoptotic properties. Hereby, Siva promotes the activation-induced cell death, resulting in the down-regulation of immune responses, which is essential for T-cell homeostasis (Gudi et al. 2006).

Tra1, also known as heat shock protein gp96, has protective functions during cellular stress and plays an important role in the maintenance of protein homeostasis. Furthermore, gp96 exerts potent stimulatory activity on both innate and adaptive immunity. Gp96 is especially involved in the immune response to tumor antigens by chaperoning tumor antigen-derived immunogenic peptides and deliver them to antigen-presenting cells for specific T cell stimulation. Gp96 also mediates the matu- 
ration of DCs by up-regulating the expression of MHC class II and co-stimulatory molecules (Rivoltini et al. 2003; Zhang et al. 2006).

\section{DISCUSSION AND CONLUSIONS}

We investigated the immunologic response to PE at the level of gene expression in a $\mathrm{BN}$ rat model for food allergy. This peanut model has been tested for various conventional immune parameters (de Jonge et al. 2007a; de Jonge et al. 2007b). In an earlier study (de Jonge et al. 2007b) we used PE in combination with the adjuvant cholera toxin as a positive control, and found that careful breeding for multiple generations on feed that excluded the protein of interest (PE) and cross-reactive proteins (soy) resulted in strong allergic responses in non-adjuvated animals that were similar to animals that were adjuvated with cholera toxin. In the current article we repeat earlier results, indicating that oral exposure to PE leads to specific antibody responses and specific lymphocyte proliferative responses, and in addition that oral exposure to PE results in gene expression profiles in the MLN that were associated with cell division and immunological processes.

Gene expression profiles demonstrate a dose-response relationship, exposure to 10 $\mathrm{mg}$ PE induced a more pronounced differential expression than exposure to $1 \mathrm{mg}$ $P E$. In previous experiments it has been shown that PE-specific IgE levels (de Jonge et al. 2007a) and the number of eosinophilic and basophilic granulocytes (de Jonge et al. 2007b) were higher in the BN rats exposed to $10 \mathrm{mg}$ PE compared to those exposed to $1 \mathrm{mg} P E$. In addition, the ex vivo proliferation rates of the MLNs of BN rats exposed to $10 \mathrm{mg}$ PE were also higher than those of the $1 \mathrm{mg}$ PE group.

Besides a dose-dependent effect, a time-dependent effect was also demonstrated. In both the 1 and $10 \mathrm{mg}$ PE groups, the strongest differential gene expression was shown on day 7. This might be explained by the observation that the $T$ cell response after the encounter with an antigen peaks after seven days (Haring and Harty 2006). Furthermore, analysis of Ig levels by ELISA showed that the PE-specific ${ }^{2} \log \lg$ Iga and IgG1 titers after PE-sensitization were higher on day 14 than on day 7. It should be mentioned that days 3 and 7 are in fact too early to detect specific IgE responses, and even day 14 is not optimal (de Jonge et al. 2007b). The early response in the MLN can be explained by the fact that the MLN is an immunologic organ that is at the frontline of the gut-associated immune response, whereas the production of food allergenspecific antibodies by B-cells takes place at a later moment in the response. Furthermore, changes in gene expression precede biological changes. Lastly, some regulation or some degree of oral tolerance could have occured on day 14.

In the MLN, several genes involved in immunological processes were found to be upregulated. Increased expression of genes encoding for the immunoglobulin components Ig (the variable light region) and Igj (the joining segment) are in accordance with the observed increased levels of PE-specific IgG1 in serum. Also, recent studies 
indicate that free light chains, not assembled into an immunoglobulin, are involved in the pathogenesis of allergies (Redegeld et al. 2004). Several genes, ADA, Tnfrs17 and Siva, known to be involved in lymphocyte functioning (Mishra et al, 2005, Trem et al 2006, Hatzoglou et al 2000, Gudi et al, 2006) were found to be upregulated by PE. Gp96, is involved in innate and adaptive immune response (Rivoltinie et al 2003, Zhang et al 2006).

Besides genes directly involved in immunological processes, a large number of cell cycle-related genes was affected by PE and the most regulated pathways were all involved in cell proliferation. In accordance with this are the dose-dependent effects of PE on lymphocyte proliferation in the MLN. In this conventional assay high variability was observed. This might indicate a higher sensitivity of investigating numerous genes by the microarray technique as compared to conventional testing of cell proliferation.

The genes that we found stimulated in the current experiment could be involved in the allergic response against peanut, although it cannot be excluded that other antigen-specific immune responses, including oral tolerance, are also associated with regulation of these genes. That the genes found in this experiment are indicative of an immunological response of rats to an orally applied protein extract (in this case $\mathrm{PE}$ ) is supported by the fact that almost all regulated genes were involved in cell proliferation or general immunological processes, but these genes do not discriminate between different types of immunity, i.e. do not specifically indicate allergy. The only gene which was upregulated and which is strongly associated with allergy, was the gene encoding for IgG1 (Faquim-Mauro et al. 1999; Knippels et al. 1998). Further research is needed to determine whether the effect at the gene expression level found in our BN rat model was limited to an immunologic response, or could also be indicative of an allergic response. Subsequent studies should therefore include immunologically active, but non-allergenic proteins alongside known allergens such as peanut.

To date, no other studies have been conducted that determined the gene expression profiles in food allergy models. However, microarray data of respiratory allergy studies are available. Benson et al. (Benson et al. 2006) performed a network-based analysis of DNA microarray data from allergen-challenged CD4(+) T cells from patients with seasonal allergic rhinitis. They found a strong upregulation of expression of TNFRSF4, one of the genes of the TNF superfamily, which is involved in regulation of apoptosis and Th2 proliferation. Interestingly, in our study we found the TNFRSF17 gene of the same superfamily to be up-regulated most strongly of all immunologic genes (Table I). Although both studies differ: (a) one is a study into respiratory allergy, the other study is that of a food allergic model, (b) different species were studied and (c) Benson et al. (Benson et al. 2006) studied allergenspecific T cells, whereas we studied a pool of MLN cells. With both studies in mind one could further substantiate the claim that the proliferation of allergen- 
challenged Th2 cells is associated with an increase in TNFRSF-family signaling. However, an association of TNFRSF17 with Th2 responses has not been made to date. In addition, in a mouse model for experimental asthma, gene expression profiling of lung tissue was performed (Zimmermann et al. 2003). We compared the regulated genes of this study with the results of our study and found overlap, especially at the levels of immunological genes (11 overlapping genes) and cell cycle genes (19 overlapping genes). This corroborates that both immunological and cell cycle genes are involved in allergen response reactions.

Gene expression profiles assessed in this food allergy model were compared to previous immunotoxicogenomics studies in rodents performed at the National Institute of Public Health and the Environment results. For this, Numerical Overlap Analysis of GenericGene Groups (NOAGGG) analysis, developed in house, was used. It was demonstrated that exposure to both hexachlorobenzene (HCB) (Ezendam et al. 2004) and bis(tri-n-butyltin)oxide (TBTO) (Baken et al. 2007a) affected several genes implicated in the cell cycle and some of the genes induced by these compounds overlap with genes that were upregulated in the food allergy model. TBTO which is a known immunosuppressive chemical, downregulated genes involved in cell proliferation (Baken et al. 2007a), whereas HCB, a pollutant known to stimulate the immune system, upregulated cell cycle genes (Ezendam et al. 2004). Hence, when we compare gene expression profiles of known immunotoxic compounds with $\mathrm{PE}$, it appears that a common target of immunosuppressive as well as immunostimulatory compounds is the cell cycle.

In conclusion, gene expression changes related to the regulation of immunological processes, most notably increased cell division were detected after oral exposure to peanut. This finding confirms that in the response to a foreign protein proliferation of immunologically relevant tissues is of great importance, and that such effects can be detected by analysis of gene expression profiles. Further studies using other food

allergens, and proteins that are capable of inducing immune responses yet fail to induce food allergic sensitization, will likely shed more light on specific genes and pathways indicative of food allergens and might thus be of value for both the mechanistic insight in the food allergic process as well as potential predictive screening purposes for potential allergens.

\section{FUNDING}

The Dutch Food and Consumer Product Safety Authority (VWA, The Hague the Netherlands).

\section{ACKNOWLEDGEMENTS}

The authors like to thank Renske Annette Maria Krijgsman for her generous assistance. 


\section{REFERENCES}

Baken, K.A., Arkusz, J., Pennings, J.L., Vandebriel, R.J., and van Loveren, H. (2007a). "In vitro immunotoxicity of bis(tri-n-butyltin)oxide (TBTO) studied by toxicogenomics." Toxicology 237 (1-3): 35-48.

Baken, K.A., van Loveren, H., Pennings, J.L.A., de Vries, A., Breit, T.M., and van Steeg, H. (2006). "Gene Expression Profiling of Bis(tri-n-butyltin)oxide (TBTO)-Induced Immunotoxicity in Mice and Rats." Journal of Immunotoxicology 3 (4): 227-244.

Baken, K.A., Vandebriel, R.J., Pennings, J.L., Kleinjans, J.C., and van Loveren, H. (2007b). “Toxicogenomics in the assessment of immunotoxicity." Methods 41 (1): 132-141.

Benson, M., Carlsson, L., Guillot, G., Jernas, M., Langston, M.A., Rudemo, M., and Andersson, B. (2006). "A network-based analysis of allergen-challenged CD4+ T cells from patients with allergic rhinitis." Genes Immun 7 (6): 514-521.

Burks, W., and Ballmer-Weber, B.K. (2006). "Food allergy." Mol Nutr Food Res 50 (7): 595-603.

de Jonge, J.D., Ezendam, J., Knippels, L.M.J., Odink, J., Pourier, M.S., Penninks, A.H., Pieters, R., and van Loveren, H. (2007a). "Bis(tributyltin)oxide (TBTO) decreases the food allergic response against peanut and ovalbumin in Brown Norway rats." Toxicology 239 (1-2): 68-76.

de Jonge, J.D., Knippels, L., Ezendam, J., Odink, J., Penninks, A.H., and van Loveren, H. (2007b). "The importance of dietary control in the development of a peanut allergy model in Brown Norway rats." Methods 41 (1): 99-111.

Ezendam, J., Staedtler, F., Pennings, J., Vandebriel, R.J., Pieters, R., Harleman, J.H., and Vos, J.G. (2004). "Toxicogenomics of subchronic hexachlorobenzene exposure in Brown Norway rats." Environ Health Perspect 112 (7): 782-791.

Faquim-Mauro, E.L., Coffman, R.L., Abrahamsohn, I.A., and Macedo, M.S. (1999). “Cutting edge: mouse IgG1 antibodies comprise two functionally distinct types that are differentially regulated by IL-4 and IL-12." J Immunol 163 (7): 3572-3576.

Gatzidou, E.T., Zira, A.N., and Theocharis, S.E. (2007). "Toxicogenomics: a pivotal piece in the puzzle of toxicological research." J Appl Toxicol 27 (4): 302-309.

Gudi, R., Barkinge, J., Hawkins, S., Chu, F., Manicassamy, S., Sun, Z., Duke-Cohan, J.S., and Prasad, K.V. (2006). "Siva-1 negatively regulates NF-kappaB activity: effect on T-cell receptor-mediated activation-induced cell death (AICD)." Oncogene 25 (24): 3458-3462.

Haring, J.S., and Harty, J.T. (2006). "Aberrant contraction of antigen-specific CD4 T cells after infection in the absence of gamma interferon or its receptor." Infect Immun 74 (11): 6252-6263.

Hatzoglou, A., Roussel, J., Bourgeade, M.F., Rogier, E., Madry, C., Inoue, J., Devergne, O., and Tsapis, A. (2000). "TNF receptor family member BCMA (B cell maturation) associates with TNF receptorassociated factor (TRAF) 1, TRAF2, and TRAF3 and activates NF-kappa B, elk-1, c-Jun N-terminal kinase, and p38 mitogen-activated protein kinase." J Immunol 165 (3): 1322-1330.

Knippels, L.M., Penninks, A.H., Spanhaak, S., and Houben, G.F. (1998). "Oral sensitization to food proteins: a Brown Norway rat model." Clin. Exp. Allergy 28 (3): 368-375.

Mishra, O.P., Ghosh, J., Ali, Z., Sen, M., and Prasad, R. (2005). "Lymphocyte adenosine deaminase activity in children with idiopathic nephrotic syndrome." Pediatr Nephrol 20 (10): 1426-1429.

Redegeld, F.A., Van Der Heijden, M.W., Kool, M., Kraneveld, A.D., and Nijkamp, F.P. (2004). "Functional role for Ig free light chains in immediate and delayed hypersensitivity responses." Inflamm Res 53 Suppl 1 S6-8.

Rivoltini, L., Castelli, C., Carrabba, M., Mazzaferro, V., Pilla, L., Huber, V., Coppa, J., Gallino, G., Scheibenbogen, C., Squarcina, P., et al. (2003). "Human tumor-derived heat shock protein 96 mediates in vitro activation and in vivo expansion of melanoma- and colon carcinoma-specific T cells." J Immunol 171 (7): 3467-3474.

Schoeters, E., Verheyen, G.R., Nelissen, I., Van Rompay, A.R., Hooyberghs, J., Van Den Heuvel, R.L., Witters, H., Schoeters, G.E., Van Tendeloo, V.F., and Berneman, Z.N. (2007). "Microarray analyses in dendritic cells reveal potential biomarkers for chemical-induced skin sensitization." Mol Immunol.

Sicherer, S.H. (2002). "Food allergy." Lancet 360 (9334): 701-710. 
Taylor, S.L. (2006). "Review of the development of methodology for evaluating the human allergenic potential of novel proteins." Mol Nutr Food Res 50 (7): 604-609.

Treml, L.S., Crowley, J.E., and Cancro, M.P. (2006). "BLyS receptor signatures resolve homeostatically independent compartments among naive and antigen-experienced B cells." Semin Immunol 18 (5): 297-304.

Untersmayr, E., and Jensen-Jarolim, E. (2006). "Mechanisms of type I food allergy." Pharmacol Ther 112 (3): 787-798.

Zhang, Y., Zan, Y., Shan, M., Liu, C., Shi, M., Li, W., Zhang, Z., Liu, N., Wang, F., Zhong, W., et al. (2006). "Effects of heat shock protein gp96 on human dendritic cell maturation and CTL expansion." Biochem Biophys Res Commun 344 (2): 581-587.

Zimmermann, N., King, N.E., Laporte, J., Yang, M., Mishra, A., Pope, S.M., Muntel, E.E., Witte, D.P., Pegg, A.A., Foster, P.S., et al. (2003). "Dissection of experimental asthma with DNA microarray analysis identifies arginase in asthma pathogenesis." J Clin Invest 111 (12): 1863-1874. 



\section{Chapter 6}

Summary and general discussion

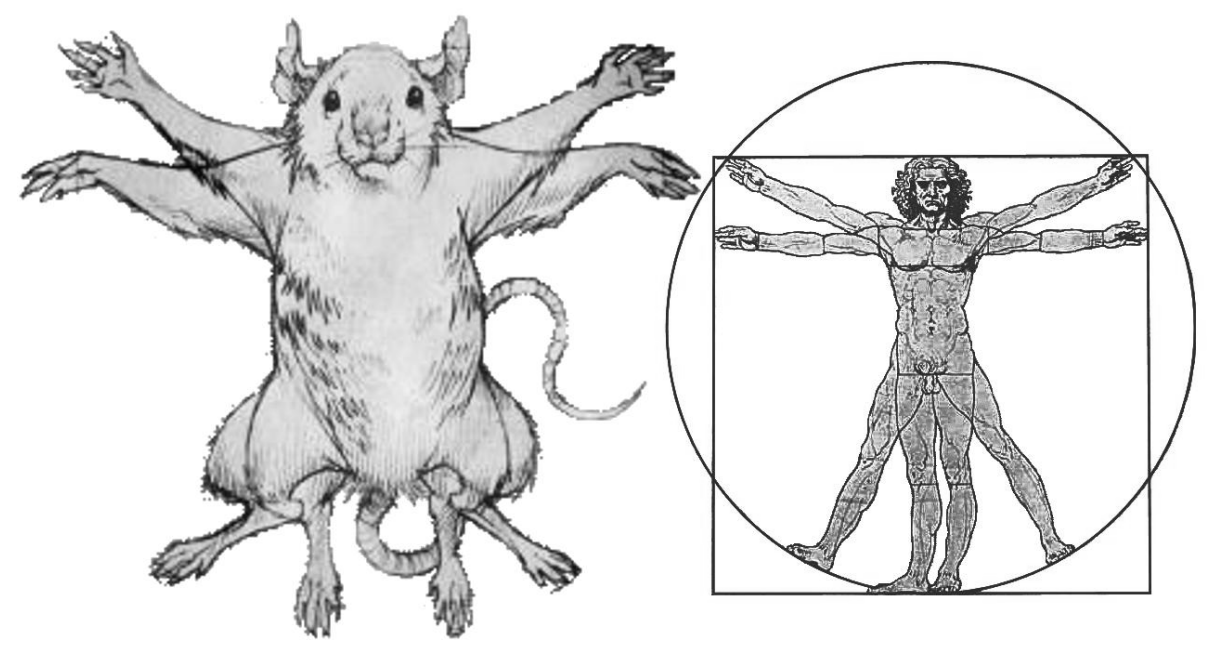




\section{MAIN FINDINGS}

Food allergy is a puzzling problem of our modern era due to its relatively high prevalence, its potentially fatal symptoms and its impact on social life. Furthermore, our continuously advancing food chain may be further supplemented by the rise of the use of genetically modified organisms, which may introduce new potentially allergenic proteins. Risk assessment of food allergens is still in its infancy mainly because of the fact that the most sensitive patients are not enrolled in challenge studies to assess threshold levels for elicitation. In addition, several factors have an effect on the prevalence of food allergy, and might thus be included in the risk assessment of food allergy, the most important being genetic factors and environmental factors. Currently no validated animal models to study food allergy are available. Not only may such animal models aid in helping understanding how environmental factors impact the expression of food allergy, they may also be of value for identification of novel food allergens. In this thesis the further development of an experimental rodent model for food allergy is described, and the model is applied to investigate effects of immunomodulatory compounds on food allergy. Furthermore, gene expression profiles as a novel tool to be applied in food allergy research were studied in this model. The main findings of this thesis can be summarized as:

- Brown Norway (BN) rats showed allergic sensitization to peanut allergens after ingestion via the oral route, but only when the rats were bred on a peanut- and soy-free diet (Chapter 2). Soy proteins and peanut proteins show crossreactivity, e.g. preexposure to soy influences the status of sensitization and/or lead to tolerance when subsequently exposed to peanut.

- The most renowned allergens contained in peanut are three sugar-protein molecules named 'Ara h1', 'Ara h2' and 'Ara h3'. Rats orally sensitized to peanut extract (PE) recognized all tested major peanut allergens; Ara h1-3 whereas intraperitoneally (i.p). sensitized rats only recognized Ara $h 1$ and Ara $h 2$ (Chapter 2). Indicating the importance of the route of exposure in allergen recognition. In contrast to i.p. dosing, oral dosing involves both oral mucosa and gut and the accompanying mucosal immune systems, which may lead to induction of IgE responses and/or oral tolerance to different allergens in orally compared to i.p. exposed rats.

- Cholera toxin (CT) enhanced allergic sensitization to a limited extent (Chapter 2).

- The immunosuppressant bis(tributyltin)oxide (TBTO) suppressed food allergy against both peanut and ovalbumin (an allergen present in hen's egg white) on multiple levels in the food allergic response (Chapter 3)

- The bacterial strain Lactobacillus casei Shirota (LCS), claimed to have an impact on food allergy, failed to suppress the food allergic response to peanut in our model. Moreover, LcS shifted the Th1/Th2 ratio towards Th2 dominance both at the level of cytokine production and immunoglobulin production (Chapter 4). 
- Chapter 5 described for the first time the effect of oral exposure to peanut on the level of gene expression and it was shown that gene expression changes were both dose- and time-dependent. The most important pathway (in this context a set of related responses within a specific process (e.g. cell proliferation)), that was regulated after oral administration, was that of cell division. In addition, immunological processes were activated.

\section{RODENT FOOD ALLERGY MODELS: ISSUES TO CONSIDER}

In order to successfully assess the effect of both allergens and (potential) immunomodulation by food constituents or food contaminants on the allergic response, we investigated a range of conventional parameters at multiple levels of the food allergic process. It was apparent from our studies that in our experimental model for food allergy, this range of parameters at multiple levels of the food allergic process helped in the interpretation of the effect of these interventions. Complimentary to these conventional parameters, this thesis also investigated other novel parameters that could potentially be used as biomarkers for food allergy. The application possibilities of animal models for food allergy may lie in investigations of effects of environmental factors and food components on food allergic processes, as well as in the identification of allergenic activities of a new food to which no a priori exposure in the population is apparent. In the development of animal models of food allergy several issues need to be considered:

\section{Species and strain}

Various animal models for food allergy are presently in use including models in mice, rats, dogs and swines (Dearman and Kimber, 2009). We will briefly discuss the two most popular species in this research: mice and rats.

The species most commonly favoured with respect to animal model development for food allergy is the mouse. This is largely driven by the availability of various immunological and molecular reagents, including transgenic animals in which particular genes of interest have been over expressed or deleted. A major advantage for studies involving IgE antibody responses is the availability of inbred and congenic high IgE responder mouse strains, such as the high IgE responder BALB/c strain (Dearman and Kimber, 2007; Mori et al., 1990; Yamanishi et al., 2003) and the $\mathrm{C} 3 \mathrm{H} / \mathrm{HeJ}$ strain (Li et al., 1999; van Wijk et al., 2004). As such, these strains have analogy with the susceptible (atopic) human phenotype that has a propensity to develop IgE-mediated disease, facilitating the identification of potentially allergenic proteins. Mice are most often dosed i.p. for sensitization to the allergen with or without the use of an adjuvant, an alternative that is also regularly applied are mice dosed orally for sensitization to the allergen in the presence of an adjuvant. 
Other rodent species, particularly the $\mathrm{BN}$ rat have been the experimental model of choice for many investigators (Akiyama et al., 2001; de Jonge et al., 2007; Jia et al., 2005; Knippels and Penninks, 2002; Knippels et al., 1998b; Pilegaard and Madsen, 2004). The BN rat is a high-immunoglobulin (particularly $\operatorname{IgE}$ ) responder rat strain that to a certain degree resembles atopic humans in their genetic predisposition to react with an overproduction of IgE to antigens. In addition, clinical reactions, including increased gut permeability and changes in blood pressure and respiratory function, were observed in BN rats after an oral challenge (Knippels et al., 1999b) and the profile of allergens recognized by the immune system of the $\mathrm{BN}$ rat appeared comparable with the profile of allergens recognized by allergic patients (Knippels and Penninks, 2003). One of the advantages of this model is that these rats can be sensitized orally in the absence of an adjuvant (Akiyama et al., 2001; de Jonge et al., 2007; Jia et al., 2005; Knippels and Penninks, 2002; Knippels et al., 1998b; Pilegaard and Madsen, 2004). Furthermore, this rat, due to its size, offers the possibility to monitor within individual animals the kinetics of specific serum antibody (IgE and IgG) responses. Moreover, rats, unlike mice, are routinely used in toxicity studies, which may also lead to an easier integration process of food allergy assessment studies in rat models into the current line of safety studies.

\section{Dietary exposure to the allergen or cross-reactive proteins}

An important aspect that should be considered with regard to the development of a food allergy model is uncontrolled dietary pre-exposure of the test animals and their parental generations to the allergen under investigation. Exposure of the parental generation to the antigen under investigation influences the outcome of oral sensitization studies with the offspring, at least two generations of animals should be bred on a diet free of the antigen under investigation. For instance: Knippels et al. (Knippels et al., 1998a) described that soy-specific IgG antibodies could not be detected after two generations bred on soy-free diet. Animal feed may contain proteins that are identical to the proteins that will be tested, or may share cross reactivity with these proteins. It is evident that previous exposure of the test animals to proteins that will be the focus of the investigation will have an impact on the status of sensitization and/or lead to tolerance. This thesis shows that exclusion of such proteins in the diet of the test animals for a number of generations is a prerequisite for a proper function of the model (Chapter 2 ). This underlines the importance of diet restrictions in oral models for food allergy as has been shown previously (Knippels et al, 1998a, Brix et al. 2005, Christensen et al 2003, 2004).

\section{Route of exposure}

Exposure to food allergens in humans is predominantly by oral consumption of allergens present in food. After oral exposure, proteins can be digested in the gastrointestinal tract, which may subsequently lead to presentation of different anti- 
genic structures to the mucosal immune system. Some models involve i.p. sensitization, but as oral administration represents the most appropriate route of exposure for a method designed to identify potential food allergens, oral models for food allergy are preferred. This rationale is supported by experimental data. Chapter $\mathbf{2}$ showed that although the responses of animals that were either i.p. or orally sensitized to peanut to one of the three tested purified peanut allergens (Ara h1) were comparable, the responses differed for the remaining two purified allergens (Ara $h 2$ and $\operatorname{Ara}$ h3). The specific IgG2a response (Th2-mediated in rat) against Ara h2 in i.p. sensitized animals was twice that of orally sensitized animals. Moreover, the specific IgG2a response against Ara $h 3$ was not found in the i.p. sensitized group but was found in $50 \%$ of the orally sensitized group. After oral exposure, proteins can be digested in the gastrointestinal tract, which may lead to presentation of different antigenic structures compared to i.p. exposure, without digestion. In contrast to i.p. dosing, oral dosing involves both oral mucosa and gut (Madsen and Pilegaard, 2003) and the accompanying mucosal immune systems, which may lead to induction of IgE responses to different allergens in orally compared to i.p. exposed rats. The data as presented in Chapter $\mathbf{2}$ indicate that oral sensitization in comparison to i.p. sensitization of $\mathrm{BN}$ rats better reflects the responses as observed in peanut allergic patients where specific IgE responses against Ara h1-3 are observed (Koppelman et al., 2004).

\section{Adjuvation}

Most animal models used in food allergy research, both pertaining to i.p. and oral models, incorporate the use of an adjuvant for successful sensitization to the protein under investigation. Adjuvant is applied to boost the allergic responses to allergens that may have a low intrinsic allergenic potential. Drawbacks might be that such adjuvants may add to the complexity of the model, and renders the mode of sensitization probably different from how humans are sensitized. Inclusion of an adjuvant may increase sensitivity, but this may go at the cost of selectivity. The BN rat model is one of the few experimental models for food allergy that allows for oral sensitization, without the use of an adjuvant. Furthermore, BN rats can discriminate between strong- (ovalbumin), weak- (bovine serum albumin) and non-allergenic (potato acid phosphatase) proteins after oral exposure without the use of any adjuvants (Jia et al., 2005). Moreover, the orally sensitized BN rat as a model for food allergy can result in $100 \%$ IgE-responders, even without the use of an adjuvant, if preconditions such as allergen free diets are carefully met (Chapter $\mathbf{2}$ ).

\section{Other factors}

Other factors, including gender and age of animals, are also known to contribute to the sensitivity of oral allergy induction. Pilegaard and Madsen (Pilegaard and 
Madsen, 2004) demonstrated that sensitization of female BN rats to egg allergens offered a higher amount of IgE-responders (38-75\%) than did males (13-38\%). With age the immune system matures which makes sensitization more difficult. BN rats become less Th2-prone with age (Ide et al., 1999; van der Meide et al., 1995) and consequently less apt to sensitization (Ide et al., 1999; Pauwels et al., 1979). For this reasons we used female rats that were 3-4 weeks of age at study initiation.

Finally, the matrix in which the protein is presented is of importance for determining the allergenicity of the protein in an experimental model for food allergy (van Wijk et al., 2005), since some food constituents have the potential to modulate allergic responses to allergens.

Ideally, test animals should, next to sensitization as measured by allergen-specific IgE responses, show clinical reactions with respect to organ sensitivities that reflect responses seen in humans upon a challenge with the allergen. The model should be relatively easy to conduct and reproducible in time and different laboratories (Penninks and Knippels, 2001). Although all these criteria (i.e. oral exposure, no requirement for the use of an adjuvant, clinical manifestations, reproducibility and ease to perform) are difficult to attain in one model, the oral food allergy model developed in $\mathrm{BN}$ rats and presented in this thesis might provide a suitable model to study the allergenicity of food proteins in humans. This notion is also supported in publications describing studies in BN rats (Atkinson et al., 1996; Atkinson and Miller, 1994; Jia et al., 2004; Jia et al., 2005; Knippels et al., 1999a; Knippels and Penninks, 2002; Knippels et al., 1999b; Knippels et al., 1998b; Knippels et al., 1999c; Knippels et al., 2000; Ogawa et al., 2003; Pilegaard and Madsen, 2004).

\section{LIMITATIONS OF THE BROWN NORWAY RAT AS AN EXPERIMENTAL MODEL FOR FOOD ALLERGY}

Although our BN rat food allergy model has many advantages as an experimental model, it also has some drawbacks.

These drawbacks for the assessment of risks include:

1. the BN rat is an inbred strain of rats: although the high Coefficient of Inbreeding increases the likeliness that one BN rat's immune reaction resembles that of another (and thus decreases the number of animals needed in each group), the drawback is that as a model it has not the wide genetic diversion as seen in atopic humans;

2. absence of anaphylactic reactions: the absence of anaphylactic reactions in BN rats differs with the strong anaphylactic reactions that occur in humans. This difference between $\mathrm{BN}$ rats and atopic patients is of special relevance since anaphylaxis is both life-threatening and greatly contributing to the suffering of food allergic patients; 
3. single gender: the use of female $\mathrm{BN}$ rats as applied in our further development of the $\mathrm{BN}$ rat food allergy model, increased the sensitivity to the antigens of interest (and thus decreases the number of animals needed in each group), but also does not resemble the human situation in which atopic patients are represented by both genders; and

4. possible underestimation of the effect of immunostimulants: Chapter 2 described that the adjuvant CT was not capable of substantially increasing the severity of the allergic response to peanut proteins, this could imply that this model might be suboptimal to address the effect of immunostimulants on the food allergic response.

\section{UTILITY OF A FOOD ALLERGY MODEL IN BN RATS}

The first rule of toxicology is that all substances produce an effect, but it is the dose that decides whether the effects are adverse or beneficial (Paracelcus (1493-1541); "Dosis sola facit veneum" (only the dose determines whether something is poisonous)). As indicated above, besides the dose, also other factors, including environmental factors or other components in the food than the allergens themselves, determine the outcome of the food allergy. There is a difference between hazards (the potential to cause adverse effects) and risks (the actual risk that these adverse effects do occur). In food allergy validated animal models for food allergy could be used, besides for hazard identification, also for risk assessment, especially to probe factors influencing risk, such as environmental factors or food components other than the allergen itself.

\section{Immunodulatory effects investigated with the BN rat food allergy model}

The effects of three different immunomodulators were studied in this thesis. In Chapter 2 effects of the mucosal adjuvant CT was studied. For this purpose BN rats were sensitized to peanut by daily oral gavage and the CT-groups were simultaneously with the peanut dosing also exposed to a daily oral dosing of CT. The adjuvant CT had only limited effects in this model. Adjuvation with CT enhanced the magnitude of IgE and to a lesser extent IgG1 but not of IgG2a, rat mast cell protease 2 (RMCPII) levels, numbers of granulocytes and cytokine levels. This indicates that in rats bred on a soy- and peanut-free diet, oral sensitization may already have been nearly optimal and CT could not greatly increase the sensitivity of the model.

Chapter 3 described the influence of the immunosuppressive compound TBTO, present in the food chain, on the development of food allergy to peanut or ovalbumin in BN rats. To study these effects $B N$ rats were sensitized to either peanut or ovalbumin by daily oral gavage and the TBTO-groups were fed a diet containing TBTO. Co-exposure to TBTO not only resulted in decreased general immunologic 
parameters, but also had a suppressing effect on allergic parameters. TBTO decreased allergen-specific Th2 cytokine production by spleen cells, allergen-specific IgE, number of eosinophilic and basophilic granulocytes in the blood and production of mast cell protease II after oral food challenge.

After investigating such different immunomodulating effects on the food allergic response in our model, i.e. the effects of the immunosuppressant (TBTO) and those of the immunostimulant (CT), we tested the effect of Lactobacillus casei Shirota (LCS) on the food allergic process against peanut (Chapter 4). Figure 1 gives a simplified overview of the interactions of the immunomodulators CT and TBTO with the immune system, and also depicts where Lactobacillus casei Shirota (LcS) has an impact. We hypothesized an immunosuppressive effect of this bacterial strain that is proposed to have probiotic (probiotica - literally "for life") activity. Unexpectedly, we did not find LCS to suppress the food allergic response against peanut. Moreover, in our peanut allergy model (Chapter 4) it was found that LCS shifted the Th1/Th2 ratio towards Th2 dominance on both the level of cytokine production and immunoglobulin production. The most pronounced effect of LCS noted in this study was on IL-4 production by spleen and mesenteric lymph node (MLN) cells. LcS was also capable of stimulating early peanut extract (PE)-specific IgE-levels and PEspecific IgG levels. This is in contrast to three studies on food allergy in rodents that describe decreased IgE levels (Matsuzaki and Chin, 2000; Matsuzaki et al., 1998; Shida et al., 2002), LCS has also been described to decrease IgE levels produced by in vitro restimulated splenocytes from OVA-primed mice (Shida et al., 1998). In a respiratory allergy model LCS did not reduce IgE levels (Ezendam and van Loveren, 2008).

What does this mean for the situation in humans? First, it should be noted that effects of probiotics depend on viability, dose, time, length of treatment, mode of treatment, prenatal exposure and strain (Broekaert and Walker, 2006; de Waard et al., 2003; Kalliomaki and Isolauri, 2004; Prescott et al., 2005; Savilahti et al., 2008). Furthermore, it has been shown that the effects of bacterial strains on the immune system depend on the immunological state of an individual (Pelto et al., 1998; Roessler et al., 2007). Pelto et al. (Pelto et al., 1998) have shown that Lactobacillus GG (LGG)-supplementation resulted in an increased expression of phagocytosis receptors in healthy subjects, whereas LGG-supplementation resulted in suppressed expression of these receptors in milk-hypersensitive subjects. Roessler et al. (Roessler et al., 2007) claimed to have shown that probiotic activity differently modulates peripheral immune parameters, in healthy volunteers and adults with atopic dermatitis. Probably, the underlying mechanism is partly associated with the existing differences in the composition and stability of the microbiota. Hence, different environmental conditions influence the host-bacterial crosstalk by competing for epithelial attachment sites. Possibly, different pathways of bacterialenterocyte crosstalk may induce different immune responses in healthy subjects 
and allergic patients (Christensen et al., 2002; Perdigon et al., 2000; Roessler et al., 2007).

Studies in humans (Abrahamsson et al., 2007; Brouwer et al., 2006; Gruber et al., 2007; Kalliomaki et al., 2001; Kalliomaki et al., 2003; Osborn and Sinn, 2007; Rosenfeldt et al., 2003; Savilahti et al., 2008; Sistek et al., 2006; Taylor et al., 2007; Viljanen et al., 2005) demonstrate that bacterial strains can have beneficial effects on allergies and may be considered probiotic, but that some probiotics can also induce unintended immunostimulation (Taylor et al., 2007).

It is evident that more research is needed to substantiate efficacy of bacterial strains meant as probiotics in allergy prevention. It could very well be that certain bacterial strains can be beneficial for human health in some disorders, while having adverse effects in others. Therefore the search for specific bacterial strains that decrease the onset and/or severity of food allergic responses remains crucial since not all probiotic strains exhibit the same properties and might even increase the onset and/or severity of food allergic responses.

Experimental animal models for allergy are useful as a first selection tool in order to select bacterial strains which could be effective in allergy prevention and can also provide more insight in the mechanisms involved. Subsequently, both efficacy and safety of these selected bacterial strains should be demonstrated in humans.

\section{Novel biomarkers: gene expression profiles}

A validated animal model could be important for identification of potential allergenic proteins in foods to which no prior exposure is apparent (hazard identification). In addition to classical measures of allergic sensitization, novel markers such as food allergy specific genes, for example, could in the future be of potential use as additional tools to screen for potential allergens in novel foods (Chapter 5). There is an ongoing discussion concerning the ethical use of experimental animal models and a need for alternatives for animal models is eminent. In the search for alternatives to experimental animal models three categories (three $\mathrm{R}^{\prime} \mathrm{s}$ ) are considered: Reduction, Refinement and Replacement (Russell and Burch, 1959). Reduction refers to methods to reduce or minimize the number of animals used in experiments to acquire necessary information. Refinement refers to improved experimental techniques that eliminate or reduce animal stress and discomfort. Replacement refers to methods that allow a research goal to be achieved without conducting experiments on animals. In the context of this thesis, investigating gene expression profiles may especially be seen as a further refinement within the current model, by providing additional information on effects that may help to characterize allergic responses. All chapters of this thesis clearly indicate that in our experimental models for food allergy it is a necessity to investigate parameters at multiple levels of the food allergic process (some of these parameters are included in Figure 1). 
In Chapter 5 of this thesis the effects of oral administration of peanut on gene expression profiles in the mesenteric lymph nodes (MLNs) was investigated, with the aim to potentially find new biomarkers that could be of use to better predict allergenicity of food allergens (hazard identification). A second aim is obviously to broaden our knowledge base of the food allergic response (mechanistic research). Gene expression profiles were altered after three days of exposure to peanut, which was the earliest time-point included in these experiments. Furthermore, optimal regulation of gene expression was found after seven days of daily dosing with peanut, and this regulatory effect on gene expression was greatly diminished after 14 days of dosing to peanut. It is noteworthy that conventional parameters are often only (strongly) regulated at relatively late time-points: PE-specific IgE was optimal after 42 days of oral dosing with PE.

Peanut induced regulation of genes that were involved in cell proliferation or general immunological processes. However, the genes involved in immunological proceses were not specific to the degree that they allowed us to discriminate between different types of immunity, i.e. these genes did not specifically indicate allergy. Further studies that strengthen this initial concept are needed to determine whether the effect at the gene expression level found in our BN rat model was limited to an immunologic response, or could also be indicative of an allergic response. Subsequent studies should therefore include immunologically active, but nonallergenic proteins alongside known allergens such as peanut. Such additional research will likely shed more light on specific genes and pathways indicative of food allergens and might thus be of value for both the mechanistic insight in the food allergic process as well as potential predictive screening purposes for potential allergens.

Further anticipating on the future possibilities, gene expression profiles could in a later phase be a very interesting tool to help elucidating the driving forces behind the phenomenon that some animals and humans do develop allergy after exposure to an allergen while some animals and humans do not. We expect that assessing the discrepancy in the involvement of genes and pathways between these two immunological outcomes could play a key role in answering this question and thereby greatly increasing our knowledge on this topic. This knowledge in turn could help in the prevention and treatment of food allergy and could also supply us with some directions for different outcomes after exposure to allergens in other types of allergy/ allergy in general. 


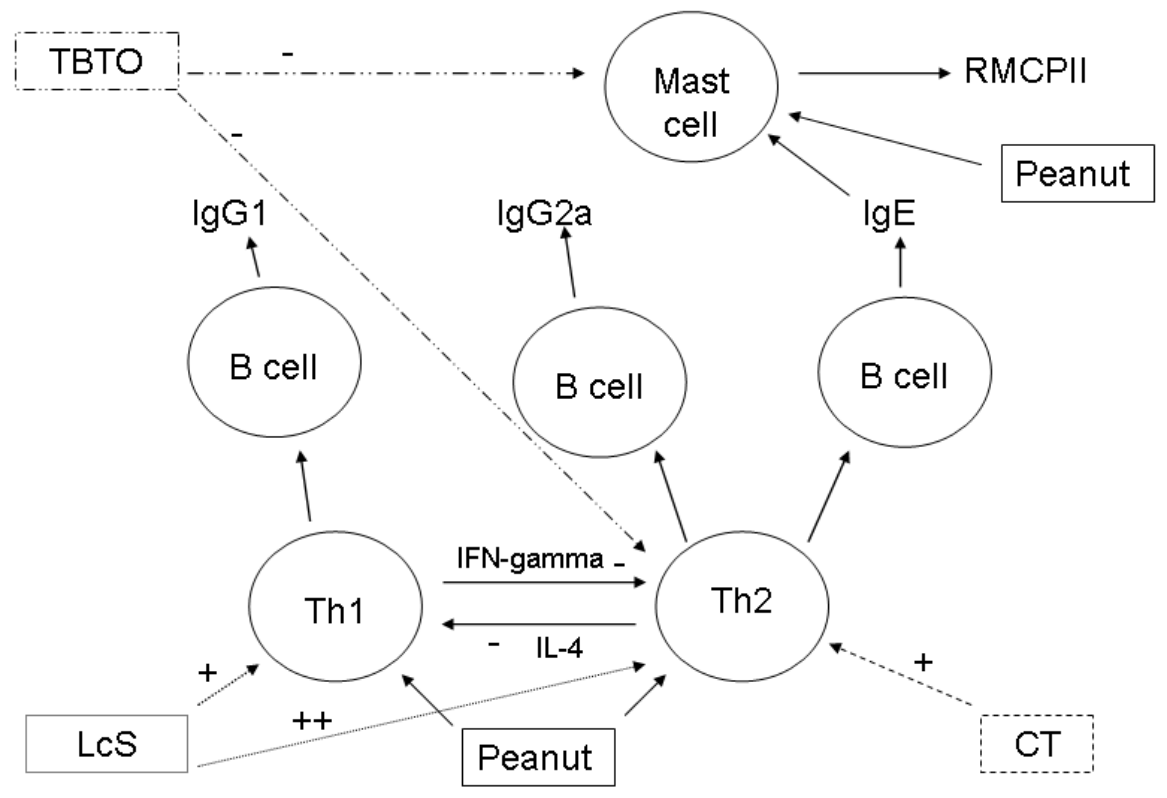

FIGURE 1. The effect of the (potential) immunomodulators: cholera toxin (CT), bis(tributyltin)oxide (TBTO) and Lactobacillus casei Shirota (LCS) on parameters at various levels of the food allergic response to peanut.

Each immunomodulator's effect are displayed by arrows that indicate at which level they potentially modulate the food allergic response. Moreover, the direction of the effect at the aforementioned levels in the food allergic response are indicated by ' - ' (inhibition), ' + ' (stimulation) or ' ++ ' (very strong stimulation).

RMCPII is the abbreviation of "rat mast cell protease 2 ", which is a mast cell release product that can be released by degranulation after repeated exposure to the sensitized allergen. 


\section{REFERENCES}

Abrahamsson, T.R., Jakobsson, T., Bottcher, M.F., Fredrikson, M., Jenmalm, M.C., Bjorksten, B., Oldaeus, G., 2007, Probiotics in prevention of IgE-associated eczema: a double-blind, randomized, placebocontrolled trial. J Allergy Clin Immunol 119, 1174-1180.

Akiyama, H., Teshima, R., Sakushima, J.I., Okunuki, H., Goda, Y., Sawada, J.I., Toyoda, M., 2001, Examination of oral sensitization with ovalbumin in Brown Norway rats and three strains of mice. Immunol Lett. 78, 1-5.

Atkinson, H.A., Johnson, I.T., Gee, J.M., Grigoriadou, F., Miller, K., 1996, Brown Norway rat model of food allergy: effect of plant components on the development of oral sensitization. Food Chem.Toxicol. 34, 27-32.

Atkinson, H.A., Miller, K., 1994, Assessment of the brown Norway rat as a suitable model for the investigation of food allergy. Toxicology 91, 281-288.

Broekaert, I.J., Walker, W.A., 2006, Probiotics and chronic disease. J Clin Gastroenterol 40, 270-274.

Brouwer, M.L., Wolt-Plompen, S.A., Dubois, A.E., van der Heide, S., Jansen, D.F., Hoijer, M.A., Kauffman, H.F., Duiverman, E.J., 2006, No effects of probiotics on atopic dermatitis in infancy: a randomized placebo-controlled trial. Clin Exp Allergy 36, 899-906.

Christensen, H.R., Frokiaer, H., Pestka, J.J., 2002, Lactobacilli differentially modulate expression of cytokines and maturation surface markers in murine dendritic cells. J Immunol 168, 171-178.

de Jonge, J.D., Knippels, L., Ezendam, J., Odink, J., Penninks, A.H., van Loveren, H., 2007, The importance of dietary control in the development of a peanut allergy model in Brown Norway rats. Methods 41, 99-111.

de Waard, R., Claassen, E., Bokken, G.C., Buiting, B., Garssen, J., Vos, J.G., 2003, Enhanced immunological memory responses to Listeria monocytogenes in rodents, as measured by delayed-type hypersensitivity (DTH), adoptive transfer of DTH, and protective immunity, following Lactobacillus casei Shirota ingestion. Clin Diagn Lab Immunol 10, 59-65.

Dearman, R.J., Kimber, I., 2007, A mouse model for food allergy using intraperitoneal sensitization. Methods 41, 91-98.

Dearman, R.J., Kimber, I., 2009, Animal models of protein allergenicity: potential benefits, pitfalls and challenges. Clin Exp Allergy 39, 458-468.

Ezendam, J., van Loveren, H., 2008, Lactobacillus casei Shirota administered during lactation increased the duration of autoimmunity in rats and enhanced lung inflammation in mice. BrJ Nutr 99, 83-90.

Gruber, C., Wendt, M., Sulser, C., Lau, S., Kulig, M., Wahn, U., Werfel, T., Niggemann, B., 2007, Randomized, placebo-controlled trial of Lactobacillus rhamnosus GG as treatment of atopic dermatitis in infancy. Allergy 62, 1270-1276.

Ide, K., Hayakawa, H., Yagi, T., Sato, A., Koide, Y., Yoshida, A., Uchijima, M., Suda, T., Chida, K., Nakamura, H., 1999, Decreased expression of Th2 type cytokine mRNA contributes to the lack of allergic bronchial inflammation in aged rats. J Immunol 163, 396-402.

Jia, X., N., L., Wang, W., Wu, Y., 2004, [Determination of protein allergenicity--BN rat model] [Article in Chinese]. Wei Sheng Yan Jiu 33, 63-65.

Jia, X.D., Li, N., Wu, Y.N., Yang, X.G., 2005, Studies on BN rats model to determine the potential allergenicity of proteins from genetically modified foods. World J Gastroenterol 11, 5381-5384.

Kalliomaki, M., Salminen, S., Arvilommi, H., Kero, P., Koskinen, P., Isolauri, E., 2001, Probiotics in primary prevention of atopic disease: a randomised placebo-controlled trial. Lancet 357, 1076-1079.

Kalliomaki, M., Salminen, S., Poussa, T., Arvilommi, H., Isolauri, E., 2003, Probiotics and prevention of atopic disease: 4-year follow-up of a randomised placebo-controlled trial. Lancet 361, 1869-1871.

Kalliomaki, M.A., Isolauri, E., 2004, Probiotics and down-regulation of the allergic response. Immunol Allergy Clin North Am 24, 739-752, viii.

Knippels, L.M., Houben, G.F., Spanhaak, S., Penninks, A.H., 1999a, An oral sensitization model in Brown Norway rats to screen for potential allergenicity of food proteins. Methods 19, 78-82.

Knippels, L.M., Penninks, A.H., 2002, Assessment of protein allergenicity: studies in brown norway rats. Ann.N.Y.Acad.Sci. 964, 151-161. 
Knippels, L.M., Penninks, A.H., 2003, Assessment of the allergic potential of food protein extracts and proteins on oral application using the brown Norway rat model. Environ. Health Perspect. 111, 233238.

Knippels, L.M., Penninks, A.H., Houben, G.F., 1998a, Continued expression of anti-soy protein antibodies in rats bred on a soy protein-free diet for one generation: the importance of dietary control in oral sensitization research. J. Allergy Clin. Immunol. 101, 815-820.

Knippels, L.M., Penninks, A.H., Smit, J.J., Houben, G.F., 1999b, Immune-mediated effects upon oral challenge of ovalbumin-sensitized Brown Norway rats: further characterization of a rat food allergy model. Toxicol. Appl. Pharmacol. 156, 161-169.

Knippels, L.M., Penninks, A.H., Spanhaak, S., Houben, G.F., 1998b, Oral sensitization to food proteins: a Brown Norway rat model. Clin. Exp. Allergy 28, 368-375.

Knippels, L.M., Penninks, A.H., van Meeteren, M., Houben, G.F., 1999c, Humoral and cellular immune responses in different rat strains on oral exposure to ovalbumin. Food Chem. Toxicol. 37, 881-888.

Knippels, L.M., van der Kleij, H.P., Koppelman, S.J., Houben, G.F., Penninks, A.H., 2000, Comparison of antibody responses to hen's egg and cow's milk proteins in orally sensitized rats and food-allergic patients. Allergy 55, 251-258.

Koppelman, S.J., Wensing, M., Ertmann, M., Knulst, A.C., Knol, E.F., 2004, Relevance of Ara h1, Ara h2 and Ara h3 in peanut-allergic patients, as determined by immunoglobulin E Western blotting, basophilhistamine release and intracutaneous testing: Ara h2 is the most important peanut allergen. Clin Exp Allergy 34, 583-590.

Li, X.M., Schofield, B.H., Huang, C.K., Kleiner, G.I., Sampson, H.A., 1999, A murine model of IgE-mediated cow's milk hypersensitivity. J Allergy Clin Immunol 103, 206-214.

Madsen, C., Pilegaard, K., 2003, No priming of the immune response in newborn brown norway rats dosed with ovalbumin in the mouth. Int.Arch.Allergy Immunol. 130, 66-72.

Matsuzaki, T., Chin, J., 2000, Modulating immune responses with probiotic bacteria. Immunol.Cell Biol. 78, 67-73.

Matsuzaki, T., Yamazaki, R., Hashimoto, S., Yokokura, T., 1998, The effect of oral feeding of Lactobacillus casei strain Shirota on immunoglobulin E production in mice. J Dairy Sci. 81, 48-53.

Mori, A., Yamamoto, K., Suko, M., Watanabe, N., Ito, M., Miyamoto, T., Okudaira, H., 1990, Interleukin-4 gene expression in high and low IgE responder mice. Int Arch Allergy Appl Immunol 92, 100-102.

Ogawa, T., Miura, S., Tsuzuki, Y., Ogino, T., Teramoto, K., Inamura, T., Watanabe, C., Hokari, R., Nagata, H., Ishii, H., 2003, Chronic allergy to dietary ovalbumin induces lymphocyte migration to rat small intestinal mucosa that is inhibited by MAdCAM-1. AJP - Gastrointestinal and Liver Physiology, 00183.

Osborn, D.A., Sinn, J.K., 2007, Probiotics in infants for prevention of allergic disease and food hypersensitivity. Cochrane Database Syst Rev, CD006475.

Pauwels, R., Bazin, H., Platteau, B., van der Straeten, M., 1979, The effect of age on IgE production in rats. Immunology 36, 145-149.

Pelto, L., Isolauri, E., Lilius, E.M., Nuutila, J., Salminen, S., 1998, Probiotic bacteria down-regulate the milkinduced inflammatory response in milk-hypersensitive subjects but have an immunostimulatory effect in healthy subjects. Clin Exp Allergy 28, 1474-1479.

Penninks, A.H., Knippels, L.M., 2001, Determination of protein allergenicity: studies in rats. Toxicol.Lett. 120, 171-180.

Perdigon, G., Medina, M., Vintini, E., Valdez, J.C., 2000, Intestinal pathway of internalisation of lactic acid bacteria and gut mucosal immunostimulation. Int J Immunopathol Pharmacol 13, 141-150.

Pilegaard, K., Madsen, C., 2004, An oral Brown Norway rat model for food allergy: comparison of age, sex, dosing volume, and allergen preparation. Toxicology 196, 247-257.

Prescott, S.L., Dunstan, J.A., Hale, J., Breckler, L., Lehmann, H., Weston, S., Richmond, P., 2005, Clinical effects of probiotics are associated with increased interferon-gamma responses in very young children with atopic dermatitis. Clin Exp Allergy 35, 1557-1564. 
Roessler, A., Friedrich, U., Vogelsang, H., Bauer, A., Kaatz, M., Hipler, U.C., Schmidt, I., Jahreis, G., 2007, The immune system in healthy adults and patients with atopic dermatitis seems to be affected differently by a probiotic intervention. Clin Exp Allergy.

Rosenfeldt, V., Benfeldt, E., Nielsen, S.D., Michaelsen, K.F., Jeppesen, D.L., Valerius, N.H., Paerregaard, A., 2003, Effect of probiotic Lactobacillus strains in children with atopic dermatitis. J Allergy Clin Immunol 111, 389-395.

Russell, W.M.S.I., Burch, R.L., 1959, The Principles of Humane Experimental Technique. Universities Federation for Animal Welfare Wheathampstead, England (reprinted in 1992).

Savilahti, E., Kuitunen, M., Vaarala, O., 2008, Pre and probiotics in the prevention and treatment of food allergy. Curr Opin Allergy Clin Immunol 8, 243-248.

Shida, K., Makino, K., Morishita, A., Takamizawa, K., Hachimura, S., Ametani, A., Sato, T., Kumagai, Y., Habu, S., Kaminogawa, S., 1998, Lactobacillus casei inhibits antigen-induced IgE secretion through regulation of cytokine production in murine splenocyte cultures. Int Arch Allergy Immunol. 115, 278287.

Shida, K., Takahashi, R., Iwadate, E., Takamizawa, K., Yasui, H., Sato, T., Habu, S., Hachimura, S., Kaminogawa, S., 2002, Lactobacillus casei strain Shirota suppresses serum immunoglobulin E and immunoglobulin G1 responses and systemic anaphylaxis in a food allergy model. Clin Exp Allergy 32, 563570.

Sistek, D., Kelly, R., Wickens, K., Stanley, T., Fitzharris, P., Crane, J., 2006, Is the effect of probiotics on atopic dermatitis confined to food sensitized children? Clin Exp Allergy 36, 629-633.

Taylor, A.L., Dunstan, J.A., Prescott, S.L., 2007, Probiotic supplementation for the first 6 months of life fails to reduce the risk of atopic dermatitis and increases the risk of allergen sensitization in high-risk children: A randomized controlled trial. J Allergy Clin Immunol 119, 184-191.

van der Meide, P.H., Groenestein, R.J., de Labie, M.C., Aten, J., Weening, J.J., 1995, Susceptibility to mercuric chloride-induced glomerulonephritis is age-dependent: study of the role of IFN-gamma. Cell Immunol 162, 131-137.

van Wijk, F., Hartgring, S., Koppelman, S.J., Pieters, R., Knippels, L.M., 2004, Mixed antibody and T cell responses to peanut and the peanut allergens Ara h 1, Ara h 2, Ara h 3 and Ara h 6 in an oral sensitization model. Clin Exp Allergy 34, 1422-1428.

van Wijk, F., Nierkens, S., Hassing, I., Feijen, M., Koppelman, S.J., de Jong, G.A., Pieters, R., Knippels, L.M., 2005 , The effect of the food matrix on in vivo immune responses to purified peanut allergens. Toxicol Sci 86, 333-341.

Viljanen, M., Savilahti, E., Haahtela, T., Juntunen-Backman, K., Korpela, R., Poussa, T., Tuure, T., Kuitunen, M., 2005, Probiotics in the treatment of atopic eczema/dermatitis syndrome in infants: a doubleblind placebo-controlled trial. Allergy 60, 494-500.

Yamanishi, R., Yusa, I., Bando, N., Terao, J., 2003, Adjuvant activity of alum in inducing antigen specific IgE antibodies in BALB/c mice: a reevaluation. Biosci Biotechnol Biochem 67, 166-169. 


\section{Chapter 7}

Samenvatting en algemene discussie

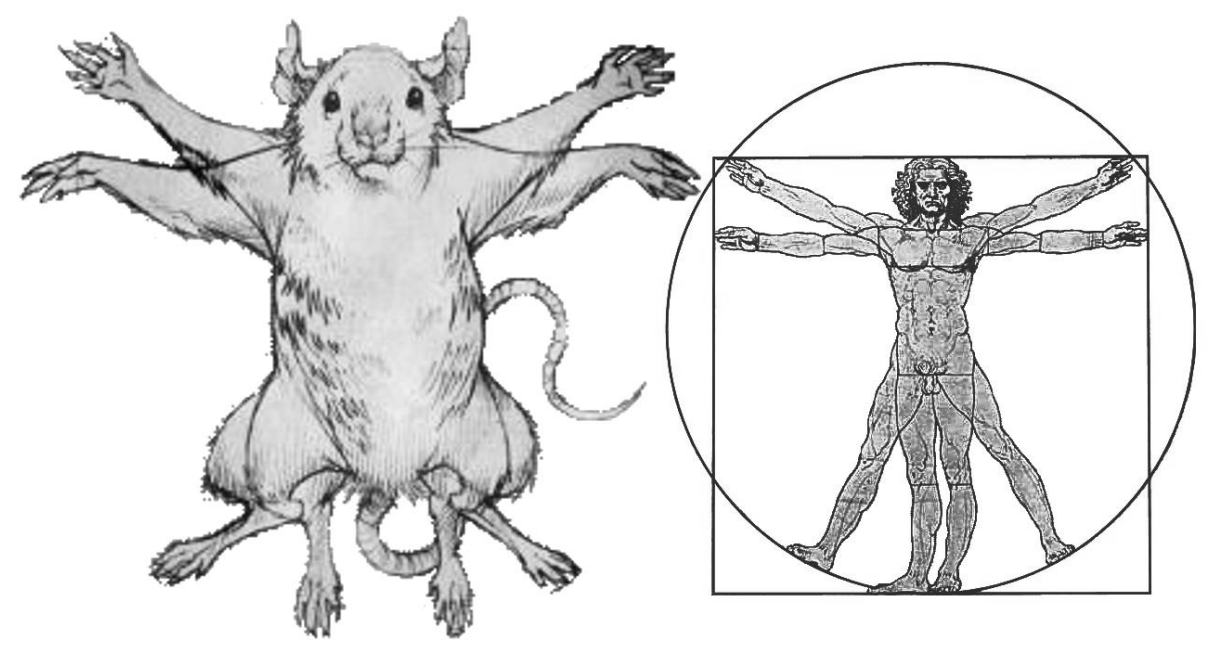




\section{HOOFDBEVINDINGEN}

Voedselallergie is een probleem in de samenleving vanwege haar relatief hoge prevalentie, haar potentieel fatale symptomen en haar impact op het sociale leven. In het ontstaan van voedselallergie spelen verschillende factoren een rol, waarvan de meest belangrijke genetische en omgevingsfactoren zijn. Daarnaast is het mogelijk dat consumenten blootgesteld worden aan nieuwe allergenen, die aan de voedselketen kunnen worden toegevoegd door ontwikkelingen op het gebied van de voeding, zoals genetisch gemodificeerde voeding. Op dit moment is de risico-evaluatie op dit gebied nog in ontwikkeling en zijn er nog geen gevalideerde diermodellen voorhanden om voedselallergie te bestuderen. Dergelijke diermodellen helpen niet alleen om de invloed van externe factoren op de ontwikkeling van voedselallergie beter te begrijpen, maar kunnen ook van nut zijn bij de identificatie van nieuwe voedselallergenen in bijvoorbeeld genetisch gemodificeerde voeding.

In dit proefschrift wordt de verdere ontwikkeling van een experimenteel diermodel voor voedselallergie beschreven. Dit model werd gebruikt om de effecten van immunomodulerende bestanddelen zoals aanwezig kunnen zijn in voeding op de voedselallergische respons te bepalen. Tevens is dit model toegepast om vast te stellen of door middel van het bepalen van genexpressie profielen nieuwe biomarkers konden worden gedetecteerd.

De hoofdbevindingen van dit proefschrift kunnen worden samengevat als:

- Na orale inname van pinda extract (PE) waren Brown Norway (BN) ratten allergisch gesensibiliseerd, mits de ratten 3 generaties gevoed werden op een pindaen soja-vrij dieet (Hoofdstuk 2). Soja eiwitten en pinda eiwitten vertonen kruisreactiviteit, en blootstelling aan soja kan tolerantie veroorzaken tegen zowel soja als pinda en als zodanig pinda sensibilisatie beïnvloeden.

- De meest notoire allergenen die in pinda's voorkomen zijn drie suikereiwit moleculen genaamd 'Ara h1', 'Ara h2' en 'Ara h3'. Ratten die oraal gesensibiliseerd werden met PE herkenden de belangrijke pinda allergenen: Ara h1-3, terwijl intraperitoneaal (i.p.) gesensibiliseerde ratten alleen Ara h1 en Ara h2 herkenden (Hoofdstuk 2). Deze vinding onderstreept het belang van de blootstellingsroute in de herkenning van allergenen. In tegenstelling tot i.p. dosering, leidt orale dosering tot blootstelling van zowel de orale mucosa als de darm mucosa inclusief de bijbehorende immuunsystemen, wat mogelijk in de inductie van IgE responsen en/of orale tolerantie tegen verschillende eiwitten resulteert in oraal blootgestelde ratten ten opzichte van ratten die i.p. blootgesteld zijn.

- Cholera toxine (CT) versterkte de allergische sensibilisatie slechts in beperkte mate.

- De immunosuppressieve stof bis(tributyltin)oxide (TВTO) onderdrukte voedselallergie gericht tegen zowel pinda als ovalbumine (een allergeen aanwezig in 
kippeneiwit) en deed dit op meerdere niveaus van de voedselallergische respons (Hoofdstuk 3)

- De bacteriële stam Lactobacillus casei Shirota (LCS), waarvan geclaimd wordt dat deze een effect op allergie heeft, had geen effect op de allergische respons geïnduceerd door pinda. De hypothese was dat LcS de Th1/Th2 balans richting Th1 dominantie zou schuiven en zo de Th2-gemedieerde allergische respons zou dempen. Echter, LcS induceerde een Th2 dominantie, zowel op het niveau van cytokine productie als op het niveau van immunoglobuline productie (Hoofdstuk 4).

- Hoofdstuk 5 beschrijft de effecten van orale blootstelling aan PE op genexpressie profielen. Na inname van PE werden tijds- en dosisafhankelijke veranderingen in genexpressie gevonden. De belangrijkste gereguleerde "pathway" (in deze context een verzameling van aan elkaar gelieerde responsen binnen een bepaald proces) was die van de celdeling. Daarnaast werden ook immunologische processen geactiveerd.

\section{KNAAGDIERMODELLEN VOOR VOEDSELALLERGIE: RELEVANTE FACTOREN}

De effecten van (potentiële) immunomodulerende bestanddelen van en contaminanten uit voeding op de pinda-allergische respons zijn onderzocht door middel van bepaling van een spectrum aan conventionele parameters in het BN model. De resultaten van deze studies tonen aan dat het bepalen van meerdere parameters op verschillende niveaus van de voedselallergische respons waarde toevoegt aan de interpretatie van het effect. Diermodellen voor voedselallergie kunnen gebruikt worden in onderzoek naar de effecten van immuunmodulerende verbindingen, bij het bestuderen van mechanismen en voor het identificeren van potentiële allergenen in bijvoorbeeld genetisch gemodificeerde voeding.

\section{Keuze van het diermodel: species en stam}

Verschillende diermodellen voor voedselallergie zijn op dit moment in gebruik, inclusief modellen in muizen, ratten, honden en zwijnen (Dearman and Kimber, 2009). We bespreken hier kort de twee meest populaire diersoorten die in deze onderzoekstak worden gebruikt: knaagdiermodellen in de muis en in de rat.

De muis is de diersoort, die op dit moment het meest wordt toegepast met betrekking tot de ontwikkeling van een diermodel voor voedselallergie. Deze voorkeur wordt voornamelijk gevoed door de beschikbaarheid van verscheidene immunologische en moleculaire reagentia, inclusief transgene dieren waarin bepaalde interessante genen tot overexpressie gebracht zijn, danwel buiten werking zijn gesteld. Een belangrijk voordeel in studies naar IgE-antilichaam responsen is de beschikbaarheid van inteelt en congene hoge IgE reagerende muizenstammen, zoals de hoge IgE reagerende BALB/c stam (Dearman and Kimber, 2007; Mori et al., 1990; Yamanishi 
et al., 2003) en de C3H/HeJ strain (Li et al., 1999; van Wijk et al., 2004). Als zodanig hebben deze stammen analogie met het ontvankelijke (atopische) menselijke fenotype dat de inclinatie heeft om IgE-gemedieerde ziekte te ontwikkelen, en faciliteren zodoende de identificatie van potentiële allergene eiwitten. Om muizen te sensibiliseren wordt over het algemeen i.p. dosering toegepast, al dan niet in de aanwezigheid van een adjuvant. Een andere methode die veel wordt toegepast is oraal doseren met het allergeen en een adjuvant.

Naast muizen worden ook ratten gebruikt als experimenteel model en dat vooral de BN rat (Akiyama et al., 2001; de Jonge et al., 2007; Jia et al., 2005; Knippels and Penninks, 2002; Knippels et al., 1998b; Pilegaard and Madsen, 2004). De BN rat heeft als specifieke eigenschap dat Th2 responsen makkelijk op te wekken zijn en dat hij grote hoeveelheden antilichamen, vooral IgE, kan aanmaken. Na het oraal toedienen van voedselallergenen worden reacties waargenomen, zoals toename in de darmpermeabiliteit en veranderingen in bloeddruk en respiratoire functie (Knippels et al., 1999b), die ook humaan klinisch relevant zijn. Het profiel aan allergenen dat herkend wordt door BN ratten lijkt vergelijkbaar met het profiel dat door allergische patiënten wordt herkend (Knippels and Penninks, 2003). BN ratten kunnen oraal worden gesensibiliseerd zonder gebruik te maken van adjuvantia (Akiyama et al., 2001; de Jonge et al., 2007; Jia et al., 2005; Knippels and Penninks, 2002; Knippels et al., 1998b; Pilegaard and Madsen, 2004). Een bijkomend voordeel is dat ratten door hun grootte makkelijk te gebruiken zijn voor kinetiekstudies, zoals het monitoren van antilichaamresponsen over de tijd. Belangrijk is tevens dat ratten, in tegenstelling tot muizen, routinematig in toxiciteitstudies gebruikt worden, waardoor een dergelijk model ook makkelijker hierin geïntegreerd zou kunnen worden.

\section{Blootstelling aan het allergeen of kruisreactieve eiwitten via het dieet}

Een belangrijk aspect om te beschouwen bij het ontwikkelen van een model voor voedselallergie is onbedoelde voorblootstelling (de reeds opgetrede blootstelling voorafgaande aan de daadwerkelijke proef), middels het dieet, van de proefdieren en de voorouders daarvan aan het allergeen van interesse. Blootstelling van de ouderdieren aan het te testen antigeen beïnvloedt de uitkomst van orale sensibilisatie, om dit te voorkomen dienen studies met het nageslacht worden voorafgegaan door ten minste twee generaties gefokt op een diet dat vrij is van het te onderzoeken antigeen. Zo beschreven Knippels et al. (Knippels et al., 1998a) bijvoorbeeld dat sojaspecifieke IgG antilichamen niet meer gedetecteerd konden worden indien twee generaties lang op soja-vrij dieet werd gefokt. Diëten voor knaagdieren kunnen eiwitten bevatten die ofwel identiek zijn aan de te onderzoeken eiwitten, danwel kruisreactiviteit vertonen met de te onderzoeken eiwitten. Het is duidelijk dat voorblootstelling van de proefdieren aan de te onderzoeken eiwitten invloed uitoefent op de status van sensibilisatie en/of tot orale tolerantie leidt. Dit proefschrift toont aan dat exclusie van dergelijke eiwitten in het dieet van de proefdieren gedurende 
een aantal opeenvolgende generaties een vereiste is voor het juist functioneren van het model (Hoofdstuk 2). Deze resultaten bevestigen het belang van dieetcontrole, zoals eerder is aangetoond (Knippels et al, 1998a, Brix et al. 2005, Christensen et al 2003, 2004).

\section{Blootstellingsroute}

Mensen worden voornamelijk via het dieet blootgesteld aan voedselallergenen. Eenmaal in de darmen aangekomen worden de eiwitten verteerd door het spijsverteringskanaal, waarbij verschillende antigene structuren ontstaan. Deze worden gepresenteerd aan het immuunsysteem van de darmen. Een andere blootstellingsroute zal ook kunnen leiden tot een andere presentatie van de antigene structuren aan het immuunsysteem. Er zijn diermodellen beschreven die gebruik maken van i.p. sensibilisatie. Het is mogelijk om op deze manier allergische responsen te induceren. In Hoofdstuk 2 wordt aangetoond dat na zowel i.p. als orale blootstelling allergische responsen worden geïnduceerd. Echter, de allergenen die herkend worden verschillen. Het allergeen Ara $h 1$ werd in beide modellen herkend, maar voor Ara $h 2$ en Ara $h 3$ werden verschillen gevonden. De specifieke IgG2a respons gericht tegen Ara $h 2$ in ratten die i.p. blootgesteld waren was twee keer zo hoog als in de oraal blootgestelde ratten. Een specifieke IgG2a respons tegen Ara h3 werd geheel niet gevonden in i.p. behandelde dieren, maar werd in $50 \%$ van de oraal behandelde ratten wel aangetoond. Na orale blootstelling, kunnen eiwitten in het maagdarmkanaal verteerd worden, wat vervolgens weer kan leiden tot de presentatie van andere antigene structuren in vergelijking tot de situatie na i.p. blootstelling waarbij de verteringsstap ontbreekt. In tegenstelling tot i.p. dosering, zijn bij orale dosering zowel de orale slijmvliezen als de darmen betrokken (Madsen and Pilegaard, 2003), inclusief de bijbehorende immuunsystemen, wat vervolgens mogelijk kan leiden tot de inductie van IgE responsen tegen andere allergenen dan bij i.p. blootgestelde ratten het geval zou zijn.

De data zoals gepresenteerd in Hoofdstuk 2 attenderen ons erop dat de orale sensibilisatie ten opzichte van de i.p. sensibilisatie van $\mathrm{BN}$ ratten, een nauwkeurigere reflectie oplevert van de responsen in patiënten met pinda-allergie, waar specifieke IgE responsen tegen Ara h1-3 worden waargenomen (Koppelman et al., 2004).

\section{Gebruik van adjuvantia}

In het merendeel van de diermodellen, zowel i.p. als oraal blootgesteld, worden adjuvantia toegepast om ervoor te zorgen dat de dieren succesvol gesensibiliseerd kunnen worden tegen het gewenste eiwit. Het adjuvant heeft als doel om de allergische respons te versterken. Mogelijke nadelen hiervan zijn dat dergelijke adjuvantia de complexiteit van het model kunnen verhogen en dat de manier van sensibilisatie mogelijk verschilt van de normale humane situatie. Hoewel het gebruik van een adjuvant de sensitiviteit kan verhogen, kan dit ten koste gaan van de selectiviteit. In 
BN ratten kan zonder gebruik van adjuvantia een voedselallergische respons geïnduceerd worden na orale blootstelling. In dit BN rat model kan bovendien onderscheid worden gemaakt tussen sterke allergenen (ovalbumine), zwakke allergenen (serum albumine afkomstig van een rund) en eiwitten die niet allergeen zijn (aardappel zure fosfatase) (Jia et al., 2005). Zelfs zonder gebruik van een adjuvant kan orale blootstelling resulteren in $100 \%$ IgE-responders, als zorgvuldig aan randvoorwaarden zoals het gebruik van allergeen vrije diëten wordt voldaan (Hoofdstuk 2).

\section{Andere factoren}

Naast bovengenoemde, spelen andere factoren ook een rol in dit model. Pilegaard en Madsen (Pilegaard and Madsen, 2004) demonstreerden dat vrouwelijke BN ratten gevoeliger waren voor kippeneiwit allergenen dan mannelijke exemplaren. $\mathrm{Na}$ orale blootstelling waren er meer vrouwelijke ratten met een positieve IgE respons (38-75\%) dan bij mannelijke BN ratten (13-38\%) het geval was. Veroudering leidt bij BN ratten tot verminderde Th2-dominantie (Ide et al., 1999; van der Meide et al., 1995), waardoor het moeilijk wordt om een allergische respons te induceren (Ide et al., 1999; Pauwels et al., 1979). Om deze redenen hebben wij jonge (3-4 wk oude) vrouwelijke ratten gebruikt in onze studies.

De voeding zelf kan ook van invloed zijn, omdat sommige voedselbestanddelen in potentie de voedselallergische respons kunnen veranderen. De matrix waarin het eiwit in contact komt met het immuunsysteem is van belang om de allergeniciteit van het eiwit in het experimentele model voor voedselallergie te kunnen bepalen (van Wijk et al., 2005).

In het ideale model vertonen de proefdieren, naast sensibilisatie zoals gemeten door allergeenspecifieke IgE responsen, reacties die overeenkomen met menselijke reacties na een acute blootstelling aan (een hoge dosering van) het allergeen. Verder moet het proefdiermodel relatief makkelijk uitvoerbaar en reproduceerbaar zijn (Penninks and Knippels, 2001). Hoewel al deze factoren moeilijk te vatten zijn in één enkel model, lijkt het orale voedselallergiemodel in BN ratten mogelijk zoals gepresenteerd in deze thesis een geschikt model om de allergeniciteit van voedselallergenen in mensen te bestuderen. Dit gedachtengoed vind ook steun middels eerdere publicaties betreffende studies in BN ratten (Atkinson et al., 1996; Atkinson and Miller, 1994; Jia et al., 2004; Jia et al., 2005; Knippels et al., 1999a; Knippels and Penninks, 2002; Knippels et al., 1999b; Knippels et al., 1998b; Knippels et al., 1999c; Knippels et al., 2000; Ogawa et al., 2003; Pilegaard and Madsen, 2004).

\section{BEPERKINGEN VAN DE BN RAT ALS EEN EXPERIMENTEEL MODEL VOOR VOEDSEL- ALLERGIE}

Hoewel ons BN rat model voor voedselallergie vele voordelen kent voor gebruik als een experimenteel model, heeft ook dit model nadelen voor risico-inschatting: 
1. de BN rat is een inteeltstam: alhoewel de hoge inteeltcoëfficiënt de waarschijnlijkheid verhoogt dat de immuunreactie van een BN rat overeenkomt met die van een andere $\mathrm{BN}$ rat (en als gevolg daarvan het benodigde aantal dieren in elke blootstellinggroep helpt verminderen), is de keerzijde van dit effect dat de $\mathrm{BN}$ rat als een model niet de brede genetische variatie heeft die wel in atopische mensen voorkomt;

2. afwezigheid van anafylactische reacties: dit verschilt met de sterke anafylactische reacties die in menselijke patiënten voorkomen. Dit verschil tussen BN ratten en atopische patiënten is van speciaal belang aangezien anafylaxis zowel levensbedreigend is als een grote impact heeft op het leven van voedselallergische patiënten in algemenere zin;

3. beperking tot één geslacht: het gebruik van vrouwelijke BN ratten, zoals toegepast in de door ons uitgevoerde verdere doorontwikkeling van de $\mathrm{BN}$ rat als model voor voedselallergie, verhoogt weliswaar de sensitiviteit tegen de te onderzoeken antigenen (en als gevolg daarvan een vermindering in het benodigde aantal dieren in elke blootstellinggroep), maar vertegenwoordigt aan de andere kant niet de humane situatie waarbij atopische patiënten beide geslachten omvatten; en

4. mogelijke onderschatting van het effect van immunostimulatoren: in Hoofdstuk $\mathbf{2}$ werd beschreven dat het adjuvant CT niet in staat was om de kracht van de allergische reactie tegen pinda eiwitten substantieel te verhogen, dit kan betekenen dat in het hier gebruikte experimentele model al optimaal immuunreacties worden geïnduceerd, en het model daardoor suboptimaal is om het effect van dergelijke immunostimulatoren op de voedselallergische respons te bestuderen.

\section{GEBRUIK VAN EEN BN RAT MODEL VOOR VOEDSELALLERGIE}

De eerste regel van de toxicologie is dat alle stoffen een effect hebben, maar dat de dosering bepaalt of het effect wenselijk of onwenselijk is (Paracelcus (1493-1541); "Dosis sola facit veneum" (alleen de dosis bepaalt of iets een vergif is)). Zoals eerder aangegeven, spelen naast de dosis ook andere factoren, inclusief omgevingsfactoren en andere voedselcomponenten in het voedsel buiten het allergeen zelf, een rol in de het uiteindelijke effect op (het onstaan van) voedselallergie. Er is een verschil tussen "hazards" (het potentieel om een negatief effect te veroorzaken) en risico's (het negatieve potentieel gekoppeld aan de kans dat deze effecten ook daadwerkelijk optreden). Binnen voedselallergie kunnen gevalideerde diermodellen voor voedselallergie naast hun toepassing voor "hazard" identificatie, ook gebruikt worden voor de inschatting van risico's en dan met name om risicobeïnvloedende factoren, zoals omgevingsfactoren of voedselcomponenten in het voedsel buiten het allergeen zelf, op te pikken. 


\section{Immunodulerende effecten onderzocht met het $B N$ rat model voor voedselallergie}

De effecten van drie verschillende immunomodulatoren werden voor dit proefschrift bestudeerd. Hoofdstuk 2 beschrijft het effect van het mucosale adjuvant CT. Het adjuvant CT was in dit model slechts in beperkte mate effectief in het versterken van de voedselallergische respons. CT adjuvatie verhoogde wel de kracht van de IgE respons en in mindere mate die van de IgG1 respons, maar niet die van de IgG2a respons, niet de hoogte van de rat mest cel protease 2 (RMCPII) concentraties, en ook niet de hoeveelheid granulocyten of het niveau van de cytokines. Deze resultaten impliceren dat in ratten die gefokt zijn op een soja- en pinda-vrij dieet, orale sensibilisatie mogelijk reeds dicht tegen een optimaal resultaat aan zit en dat CT daarom de sensitiviteit van het model niet aanzienlijk kon verhogen.

Hoofdstuk 3 beschrijft de invloed van de in de voedselketen voorkomende contaminant, de immunosuppressieve verbinding TBTO, op de ontwikkeling van voedselallergie tegen pinda of ovalbumine in BN ratten. Blootstelling aan TBTO resulteerde niet alleen in afgenomen algemene immunologische parameters, maar had tevens een onderdrukkend effect op allergische parameters. TBTO verminderde de productie van allergeenspecifieke Th2 cytokines door miltcellen, de allergeenspecifieke IgE niveaus, de hoeveelheden eosinofiele en basofiele granulocyten in het bloed en de productie van mest cel protease II na een orale acute hoge dosering van het allergeen.

$\mathrm{Na}$ het onderzoeken van de effecten van de immunosuppressieve verbinding (TBTO) en de immunostimulerende verbinding (CT), werd het effect van Lactobacillus casei Shirota (LCS) op de voedselallergische respons tegen pinda onderzocht (Hoofdstuk 4). Figuur 1 toont een versimpeld overzicht van de interacties van de immunomodulatoren CT en TBTO met het immuunsysteem, en toont ook waar Lactobacillus casei Shirota (LCS) invloed uitoefent. We veronderstelden een remmend effect van deze bacteriële stam, vanwege haar effect op Th1 immuniteit. LcS verminderde de voedselallergische respons tegen pinda niet. Integendeel, in ons allergiemodel tegen pinda (Hoofdstuk 4) verschoof LcS de Th1/Th2 balans in de richting van Th2 dominantie op zowel het niveau van de productie van cytokines als op het niveau van de productie van de antilichamen IgG1 en IgG2a. Het meest uitgesproken effect van LcS dat in deze studie werd gevonden was haar effect op de productie van IL-4 door milt- dan wel mesenterische lymfeklier (MLK) cellen. LcS was tevens in staat om vroege pinda extract (PE)-specifieke IgE niveaus en PE-specifieke IgG niveaus te stimuleren. De resultaten van onze studie staan in contrast met de resultaten uit drie dierstudies met knaagdieren die een afname van IgE beschrijven (Matsuzaki and Chin, 2000; Matsuzaki et al., 1998; Shida et al., 2002). In een respiratoir allergie model had LCS geen effect op IgE (Ezendam and van Loveren, 2008). LcS verminderde ook de in vitro IgE productie in miltcellen van aan OVA blootgestelde muizen (Shida et al., 1998). 
Wat betekenen deze resultaten voor de menselijke situatie? Allereerst dient de kanttekening gemaakt te worden dat de effecten van probiotica afhangen van stam, viabiliteit, dosering, duur en wijze van de behandeling, en tijdstip van (prenatale) blootstelling (Broekaert and Walker, 2006; de Waard et al., 2003; Kalliomaki and Isolauri, 2004; Prescott et al., 2005; Savilahti et al., 2008). Daarnaast is aangetoond dat de effecten die bacteriële stammen op het immuunsysteem kunnen uitoefenen afhangen van de individuele immunologische status (Pelto et al., 1998; Roessler et al., 2007). Pelto et al. (Pelto et al., 1998) lieten zien dat inname van Lactobacillus GG (LGG) resulteerde in een toegenomen expressie van fagocytose receptoren in gezonde personen, terwijl LGG-supplementatie in personen die overgevoelig zijn tegen melk een onderdrukte expressie van deze receptoren veroorzaakte. Roessler et al. (Roessler et al., 2007) claimen dat perifere parameters verschillend beïnvloed worden door probiotica in gezonde volwassen vrijwilligers ten opzichte van volwassenen met atopische dermatitis. Waarschijnlijk is het onderliggende mechanisme gedeeltelijk geassocieerd met het bestaande verschil in de competitie en de stabiliteit van microbiota. De gastheer lijkt van invloed te zijn op de effecten van bacteriën, bijvoorbeeld door competitie voor epitheliale bindingsplekken. Mogelijk spelen in gezonde personen ten opzichte van allergische patiënten andere factoren een rol die van invloed zijn op de effecten van probiotica (Christensen et al., 2002; Perdigon et al., 2000; Roessler et al., 2007).

Onderzoek in proefpersonen (Abrahamsson et al., 2007; Brouwer et al., 2006; Gruber et al., 2007; Kalliomaki et al., 2001; Kalliomaki et al., 2003; Osborn and Sinn, 2007; Rosenfeldt et al., 2003; Savilahti et al., 2008; Sistek et al., 2006; Taylor et al., 2007; Viljanen et al., 2005) toont aan dat bacteriële stammen verschillende effecten kunnen uitoefenen op allergieën en zodoende probiotisch werken, terwijl sommige probiotica ook ongewenste immunostimulatie kunnen veroorzaken (Taylor et al., 2007).

Het is evident dat meer onderzoek nodig is om de preventieve effecten van probiotica op allergieën te onderbouwen. Het lijkt waarschijnlijk dat bepaalde bacteriestammen een gunstige uitwerking kunnen hebben op de gezondheid van patiënten met bepaalde aandoeningen, terwijl deze zelfde stammen mogelijk negatieve effecten kunnen hebben bij patiënten met andere ziektebeelden. Het blijft daarom van belang om de zoektocht te vervolgen naar specifieke bacteriestammen die het ontwikkelen en/of de hevigheid van voedselallergische responsen kunnen verminderen, temeer daar niet alle probiotische stammen dezelfde eigenschappen vertonen en zelfs de ontwikkeling en/of de hevigheid van voedselallergische responsen kunnen verhogen.

Experimentele diermodellen voor allergie zijn bruikbaar als een eerste screening om bacteriestammen te selecteren die potentieel effectieve probiotica kunnen zijn in preventie of behandeling van allergie. In deze diermodellen kunnen ook onderliggende mechanismen bestudeerd worden. Vervolgens zullen werkzaamheid en veiligheid in humane studies moeten worden vastgesteld. 


\section{Nieuwe biomarkers: genexpressie profielen}

Een gevalideerd diermodel kan van belang zijn voor de identificatie van eiwitten die in potentie allergenen kunnen zijn in voedsel waaraan nog geen eerdere blootstelling heeft opgetreden ("hazard" identificatie). Ter aanvulling van de klassieke metingen van allergische sensibilisatie, zou in de toekomst een potentiële rol weggelegd kunnen zijn voor nieuwe markers, zoals bijvoorbeeld allergiespecifieke genen (Hoofdstuk 5). Er vindt een doorlopende discussie plaats aangaande het ethisch verantwoord gebruik van proefdiermodellen en er is een behoefte aan alternatieven voor proefdiermodellen. In de zoektocht naar alternatieven voor diermodellen worden drie categorieën (de $3 \mathrm{~V}$ 's) in beschouwing genomen, te weten: Vermindering, Verfijning en Vervanging (Russell and Burch, 1959). Vermindering refereert aan methoden om het aantal dieren dat in deze experimenten noodzakelijk is te verminderen of minimaliseren. Verfijning refereert aan verbeterde experimentele technieken die stress en ongemak in proefdieren elimineren of verminderen. Vervanging refereert aan methoden, die onderzoekers in staat stellen een onderzoeksdoel te realiseren zonder gebruik te hoeven maken van proefdierexperimenten. In de context van dit proefschrift, kan onderzoek van het gebruik van genexpressie profielen vooral gezien worden als een verdere verfijning binnen het huidige model. Alle hoofdstukken van dit proefschrift tonen duidelijk aan dat in ons experimenteel model voor voedselallergie, de noodzaak bestaat om parameters op verschillende niveaus van het voedselallergische proces te onderzoeken (enkele van deze parameters zijn verwerkt in Figuur 1).

In Hoofdstuk 5 van dit proefschrift worden de effecten van orale toediening van pinda op genexpressie profielen van MLK beschreven. Na drie dagen blootstelling aan pinda werden al veranderde genexpressie profielen waargenomen, dit is het eerste tijdspunt dat was meegenomen. Optimale regulatie op het niveau van genexpressie werd gevonden na zeven dagen blootstelling en deze effecten waren na 14 dagen sterk verminderd. In deze context is het vermeldenswaardig dat conventionele parameters slechts (sterk) gereguleerd zijn op relatief late tijdstippen: zo was $\mathrm{PE}$-specifieke IgE optimaal na 42 dagen van orale dosering met PE.

Blootstelling aan pinda induceerde regulatie van genen die betrokken waren bij celdeling of bij algemene immunologische processen. Daarnaast werden ook immunologische processen geactiveerd. De genen die betrokken waren bij immunologische processen waren niet specifiek indicatief voor allergie. Aanvullende studies om deze eerste resultaten te versterken zijn nodig om te bepalen of het effect op het niveau van genexpressie zoals in ons BN rat model werd gevonden, beperkt was tot een immunologische respons of tevens indicatief kan zijn voor een allergische respons. Vervolgstudies moeten daarom immunologisch actieve, maar niet-allergene eiwitten naast bekende allergenen zoals pinda meenemen. Dergelijk additioneel onderzoek zal waarschijnlijk meer informatie kunnen verschaffen over de specifieke genen en "pathways" (in dit geval in genen met onderlinge afhankelijkheid), die indicatief zijn voor voedsel- 
allergenen en als zodanig van waarde kunnen zijn voor het mechanistisch inzicht in het voedselallergische proces, en heeft daarnaast een mogelijke toepassing in het voorspellend onderzoek om potentiële allergenen door te lichten.

Verder anticiperend op toekomstige mogelijkheden, kunnen genexpressie profielen in een later stadium mogelijk een erg interessant gereedschap zijn om vast te stellen waarom sommige dieren en mensen wel een allergie ontwikkelen na blootstelling aan een allergeen terwijl andere dieren en mensen na blootgesteld te zijn aan hetzelfde allergeen geen allergie ontwikkelen. We verwachten dat het inschatten van de discrepantie op het niveau van betrokken genen en "pathways" tussen deze twee immunologische uitkomsten een sleutelrol in het beantwoorden van deze vraag kan spelen en daarmee onze kennis op dit onderwerp aanzienlijk kan vergroten. Deze kennis kan vervolgens weer een hulp zijn in de preventie en behandeling van voedselallergie en ons ook van wat aanwijzingen voorzien voor verschillende immunologische uitkomsten na blootstelling aan allergenen in andere soorten van allergie/ allergie in het algemeen.

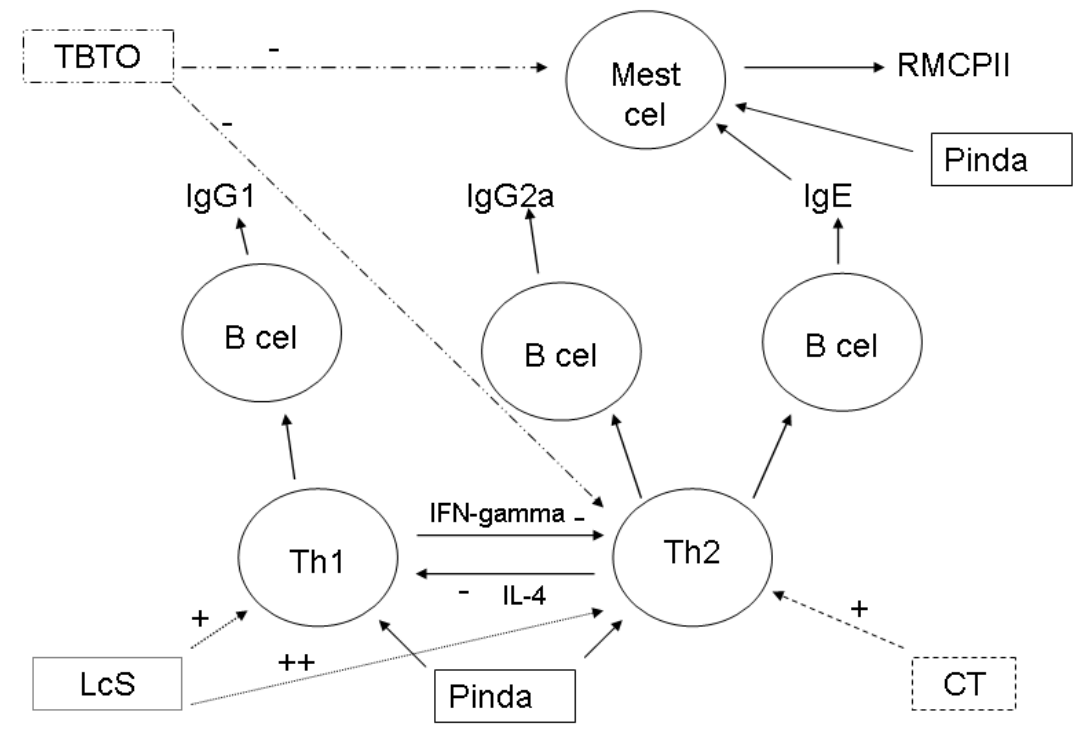

FIGURE 1. Het effect van de immunomodulatoren: cholera toxine (CT), bis(tributyltin)oxide (TBTO) en Lactobacillus casei Shirota (LCS) op parameters op verschillende niveaus binnen de voedselallergische respons tegen pinda.

Het potentiële effect dat elke immunomodulator uitoefent staat afgebeeld door middel van pijlen, die het niveau aangeven waarop de modulatie van de voedselallergische respons geschiedt. De richting van het effect op de voedselallergische respons is aangegeven door '-' (inhibitie), ' + ' (stimulatie) of '++' (erg sterke stimulatie).

RMCPII is de afkorting voor "rat mest cel protease 2", een mest cel product dat vrijkomt tijdens het degranulatieproces na herhaalde blootstelling aan het allergeen waartegen sensibilisatie heeft plaatsgevonden. 


\section{REFERENTIES}

Abrahamsson, T.R., Jakobsson, T., Bottcher, M.F., Fredrikson, M., Jenmalm, M.C., Bjorksten, B., Oldaeus, G., 2007, Probiotics in prevention of IgE-associated eczema: a double-blind, randomized, placebocontrolled trial. J Allergy Clin Immunol 119, 1174-1180.

Akiyama, H., Teshima, R., Sakushima, J.I., Okunuki, H., Goda, Y., Sawada, J.I., Toyoda, M., 2001, Examination of oral sensitization with ovalbumin in Brown Norway rats and three strains of mice. Immunol Lett. 78, 1-5.

Atkinson, H.A., Johnson, I.T., Gee, J.M., Grigoriadou, F., Miller, K., 1996, Brown Norway rat model of food allergy: effect of plant components on the development of oral sensitization. Food Chem.Toxicol. 34, 27-32.

Atkinson, H.A., Miller, K., 1994, Assessment of the brown Norway rat as a suitable model for the investigation of food allergy. Toxicology 91, 281-288.

Brix, S., Christensen, H.R., Barkholt, V., Frokiaer, H., 2005, Effect of maternal dietary cow's milk on the immune response to beta-lactoglobulin in the offspring: a four-generation study in mice. Int Arch Allergy Immunol 136, 250-257.

Broekaert, I.J., Walker, W.A., 2006, Probiotics and chronic disease. J Clin Gastroenterol 40, 270-274.

Brouwer, M.L., Wolt-Plompen, S.A., Dubois, A.E., van der Heide, S., Jansen, D.F., Hoijer, M.A., Kauffman, H.F., Duiverman, E.J., 2006, No effects of probiotics on atopic dermatitis in infancy: a randomized placebo-controlled trial. Clin Exp Allergy 36, 899-906.

Christensen, H.R., Frokiaer, H., Pestka, J.J., 2002, Lactobacilli differentially modulate expression of cytokines and maturation surface markers in murine dendritic cells. J Immunol 168, 171-178.

Christensen, H.R., Brix, S., Frokiaer, H., 2004, Immune response in mice to ingested soya protein: antibody production, oral tolerance and maternal transfer. Br J Nutr 91, 725-732.

Christensen, H.R., Kjaer, T.M., Frokiaer, H., 2003, Low-dose oral tolerance due to antigen in the diet suppresses differentially the cholera toxin-adjuvantized IgE, IgA and IgG response. Int Arch Allergy Immunol 132, 248-257.

de Jonge, J.D., Knippels, L., Ezendam, J., Odink, J., Penninks, A.H., van Loveren, H., 2007, The importance of dietary control in the development of a peanut allergy model in Brown Norway rats. Methods 41, 99-111.

de Waard, R., Claassen, E., Bokken, G.C., Buiting, B., Garssen, J., Vos, J.G., 2003, Enhanced immunological memory responses to Listeria monocytogenes in rodents, as measured by delayed-type hypersensitivity (DTH), adoptive transfer of DTH, and protective immunity, following Lactobacillus casei Shirota ingestion. Clin Diagn Lab Immunol 10, 59-65.

Dearman, R.J., Kimber, I., 2007, A mouse model for food allergy using intraperitoneal sensitization. Methods 41, 91-98.

Dearman, R.J., Kimber, I., 2009, Animal models of protein allergenicity: potential benefits, pitfalls and challenges. Clin Exp Allergy 39, 458-468.

Ezendam, J., van Loveren, H., 2008, Lactobacillus casei Shirota administered during lactation increased the duration of autoimmunity in rats and enhanced lung inflammation in mice. BrJ Nutr 99, 83-90.

Gruber, C., Wendt, M., Sulser, C., Lau, S., Kulig, M., Wahn, U., Werfel, T., Niggemann, B., 2007, Randomized, placebo-controlled trial of Lactobacillus rhamnosus GG as treatment of atopic dermatitis in infancy. Allergy 62, 1270-1276.

Ide, K., Hayakawa, H., Yagi, T., Sato, A., Koide, Y., Yoshida, A., Uchijima, M., Suda, T., Chida, K., Nakamura, H., 1999, Decreased expression of Th2 type cytokine mRNA contributes to the lack of allergic bronchial inflammation in aged rats. J Immunol 163, 396-402.

Jia, X., N., L., Wang, W., Wu, Y., 2004, [Determination of protein allergenicity--BN rat model] [Article in Chinese]. Wei Sheng Yan Jiu 33, 63-65.

Jia, X.D., Li, N., Wu, Y.N., Yang, X.G., 2005, Studies on BN rats model to determine the potential allergenicity of proteins from genetically modified foods. World J Gastroenterol 11, 5381-5384.

Kalliomaki, M., Salminen, S., Arvilommi, H., Kero, P., Koskinen, P., Isolauri, E., 2001, Probiotics in primary prevention of atopic disease: a randomised placebo-controlled trial. Lancet 357, 1076-1079. 
Kalliomaki, M., Salminen, S., Poussa, T., Arvilommi, H., Isolauri, E., 2003, Probiotics and prevention of atopic disease: 4-year follow-up of a randomised placebo-controlled trial. Lancet 361, 1869-1871.

Kalliomaki, M.A., Isolauri, E., 2004, Probiotics and down-regulation of the allergic response. Immunol Allergy Clin North Am 24, 739-752, viii.

Kimber, I., Stone, S., Dearman, R.J., 2003, Assessment of the inherent allergenic potential of proteins in mice. Environ. Health Perspect. 111, 227-231.

Knippels, L.M., Houben, G.F., Spanhaak, S., Penninks, A.H., 1999a, An oral sensitization model in Brown Norway rats to screen for potential allergenicity of food proteins. Methods 19, 78-82.

Knippels, L.M., Penninks, A.H., 2002, Assessment of protein allergenicity: studies in brown norway rats. Ann.N.Y.Acad.Sci. 964, 151-161.

Knippels, L.M., Penninks, A.H., 2003, Assessment of the allergic potential of food protein extracts and proteins on oral application using the brown Norway rat model. Environ. Health Perspect. 111, 233238.

Knippels, L.M., Penninks, A.H., Houben, G.F., 1998a, Continued expression of anti-soy protein antibodies in rats bred on a soy protein-free diet for one generation: the importance of dietary control in oral sensitization research. J. Allergy Clin. Immunol. 101, 815-820.

Knippels, L.M., Penninks, A.H., Smit, J.J., Houben, G.F., 1999b, Immune-mediated effects upon oral challenge of ovalbumin-sensitized Brown Norway rats: further characterization of a rat food allergy model. Toxicol. Appl. Pharmacol. 156, 161-169.

Knippels, L.M., Penninks, A.H., Spanhaak, S., Houben, G.F., 1998b, Oral sensitization to food proteins: a Brown Norway rat model. Clin. Exp. Allergy 28, 368-375.

Knippels, L.M., Penninks, A.H., van Meeteren, M., Houben, G.F., 1999c, Humoral and cellular immune responses in different rat strains on oral exposure to ovalbumin. Food Chem. Toxicol. 37, 881-888.

Knippels, L.M., van der Kleij, H.P., Koppelman, S.J., Houben, G.F., Penninks, A.H., 2000, Comparison of antibody responses to hen's egg and cow's milk proteins in orally sensitized rats and food-allergic patients. Allergy 55, 251-258.

Koppelman, S.J., Wensing, M., Ertmann, M., Knulst, A.C., Knol, E.F., 2004, Relevance of Ara h1, Ara h2 and Ara h3 in peanut-allergic patients, as determined by immunoglobulin E Western blotting, basophilhistamine release and intracutaneous testing: Ara h2 is the most important peanut allergen. Clin Exp Allergy 34, 583-590.

Li, X.M., Kleiner, G., Huang, C.K., Lee, S.Y., Schofield, B., Soter, N.A., Sampson, H.A., 2001, Murine model of atopic dermatitis associated with food hypersensitivity. J Allergy Clin Immunol 107, 693-702.

Li, X.M., Schofield, B.H., Huang, C.K., Kleiner, G.I., Sampson, H.A., 1999, A murine model of IgE-mediated cow's milk hypersensitivity. J Allergy Clin Immunol 103, 206-214.

Li, X.M., Serebrisky, D., Lee, S.Y., Huang, C.K., Bardina, L., Schofield, B.H., Stanley, J.S., Burks, A.W., Bannon, G.A., Sampson, H.A., 2000, A murine model of peanut anaphylaxis: T- and B-cell responses to a major peanut allergen mimic human responses. J Allergy Clin Immunol 106, 150-158.

Madsen, C., Pilegaard, K., 2003, No priming of the immune response in newborn brown norway rats dosed with ovalbumin in the mouth. Int.Arch.Allergy Immunol. 130, 66-72.

Matsuzaki, T., Chin, J., 2000, Modulating immune responses with probiotic bacteria. Immunol.Cell Biol. 78, 67-73.

Matsuzaki, T., Yamazaki, R., Hashimoto, S., Yokokura, T., 1998, The effect of oral feeding of Lactobacillus casei strain Shirota on immunoglobulin E production in mice. J Dairy Sci. 81, 48-53.

Mori, A., Yamamoto, K., Suko, M., Watanabe, N., Ito, M., Miyamoto, T., Okudaira, H., 1990, Interleukin-4 gene expression in high and low IgE responder mice. Int Arch Allergy Appl Immunol 92, 100-102.

Ogawa, T., Miura, S., Tsuzuki, Y., Ogino, T., Teramoto, K., Inamura, T., Watanabe, C., Hokari, R., Nagata, H., Ishii, H., 2003, Chronic allergy to dietary ovalbumin induces lymphocyte migration to rat small intestinal mucosa that is inhibited by MAdCAM-1. AJP - Gastrointestinal and Liver Physiology, 00183.

Osborn, D.A., Sinn, J.K., 2007, Probiotics in infants for prevention of allergic disease and food hypersensitivity. Cochrane Database Syst Rev, CD006475. 
Pauwels, R., Bazin, H., Platteau, B., van der Straeten, M., 1979, The effect of age on IgE production in rats. Immunology 36, 145-149.

Pelto, L., Isolauri, E., Lilius, E.M., Nuutila, J., Salminen, S., 1998, Probiotic bacteria down-regulate the milkinduced inflammatory response in milk-hypersensitive subjects but have an immunostimulatory effect in healthy subjects. Clin Exp Allergy 28, 1474-1479.

Penninks, A.H., Knippels, L.M., 2001, Determination of protein allergenicity: studies in rats. Toxicol.Lett. 120, 171-180.

Perdigon, G., Medina, M., Vintini, E., Valdez, J.C., 2000, Intestinal pathway of internalisation of lactic acid bacteria and gut mucosal immunostimulation. Int J Immunopathol Pharmacol 13, 141-150.

Pilegaard, K., Madsen, C., 2004, An oral Brown Norway rat model for food allergy: comparison of age, sex, dosing volume, and allergen preparation. Toxicology 196, 247-257.

Prescott, S.L., Dunstan, J.A., Hale, J., Breckler, L., Lehmann, H., Weston, S., Richmond, P., 2005, Clinical effects of probiotics are associated with increased interferon-gamma responses in very young children with atopic dermatitis. Clin Exp Allergy 35, 1557-1564.

Roessler, A., Friedrich, U., Vogelsang, H., Bauer, A., Kaatz, M., Hipler, U.C., Schmidt, I., Jahreis, G., 2007, The immune system in healthy adults and patients with atopic dermatitis seems to be affected differently by a probiotic intervention. Clin Exp Allergy.

Rosenfeldt, V., Benfeldt, E., Nielsen, S.D., Michaelsen, K.F., Jeppesen, D.L., Valerius, N.H., Paerregaard, A., 2003, Effect of probiotic Lactobacillus strains in children with atopic dermatitis. J Allergy Clin Immunol 111, 389-395.

Russell, W.M.S.I., Burch, R.L., 1959, The Principles of Humane Experimental Technique. Universities Federation for Animal Welfare Wheathampstead, England (reprinted in 1992).

Savilahti, E., Kuitunen, M., Vaarala, O., 2008, Pre and probiotics in the prevention and treatment of food allergy. Curr Opin Allergy Clin Immunol 8, 243-248.

Shida, K., Makino, K., Morishita, A., Takamizawa, K., Hachimura, S., Ametani, A., Sato, T., Kumagai, Y., Habu, S., Kaminogawa, S., 1998, Lactobacillus casei inhibits antigen-induced IgE secretion through regulation of cytokine production in murine splenocyte cultures. Int Arch Allergy Immunol. 115, 278287.

Shida, K., Takahashi, R., Iwadate, E., Takamizawa, K., Yasui, H., Sato, T., Habu, S., Hachimura, S., Kaminogawa, S., 2002, Lactobacillus casei strain Shirota suppresses serum immunoglobulin $E$ and immunoglobulin G1 responses and systemic anaphylaxis in a food allergy model. Clin Exp Allergy 32, 563570.

Sistek, D., Kelly, R., Wickens, K., Stanley, T., Fitzharris, P., Crane, J., 2006, Is the effect of probiotics on atopic dermatitis confined to food sensitized children? Clin Exp Allergy 36, 629-633.

Taylor, A.L., Dunstan, J.A., Prescott, S.L., 2007, Probiotic supplementation for the first 6 months of life fails to reduce the risk of atopic dermatitis and increases the risk of allergen sensitization in high-risk children: A randomized controlled trial. J Allergy Clin Immunol 119, 184-191.

van der Meide, P.H., Groenestein, R.J., de Labie, M.C., Aten, J., Weening, J.J., 1995, Susceptibility to mercuric chloride-induced glomerulonephritis is age-dependent: study of the role of IFN-gamma. Cell Immunol 162, 131-137.

van Wijk, F., Hartgring, S., Koppelman, S.J., Pieters, R., Knippels, L.M., 2004, Mixed antibody and T cell responses to peanut and the peanut allergens Ara h 1, Ara h 2, Ara h 3 and Ara h 6 in an oral sensitization model. Clin Exp Allergy 34, 1422-1428.

van Wijk, F., Nierkens, S., Hassing, I., Feijen, M., Koppelman, S.J., de Jong, G.A., Pieters, R., Knippels, L.M., 2005 , The effect of the food matrix on in vivo immune responses to purified peanut allergens. Toxicol Sci 86, 333-341.

Viljanen, M., Savilahti, E., Haahtela, T., Juntunen-Backman, K., Korpela, R., Poussa, T., Tuure, T., Kuitunen, M., 2005, Probiotics in the treatment of atopic eczema/dermatitis syndrome in infants: a doubleblind placebo-controlled trial. Allergy 60, 494-500.

Yamanishi, R., Yusa, I., Bando, N., Terao, J., 2003, Adjuvant activity of alum in inducing antigen specific IgE antibodies in BALB/c mice: a reevaluation. Biosci Biotechnol Biochem 67, 166-169. 


\section{Dankwoord}

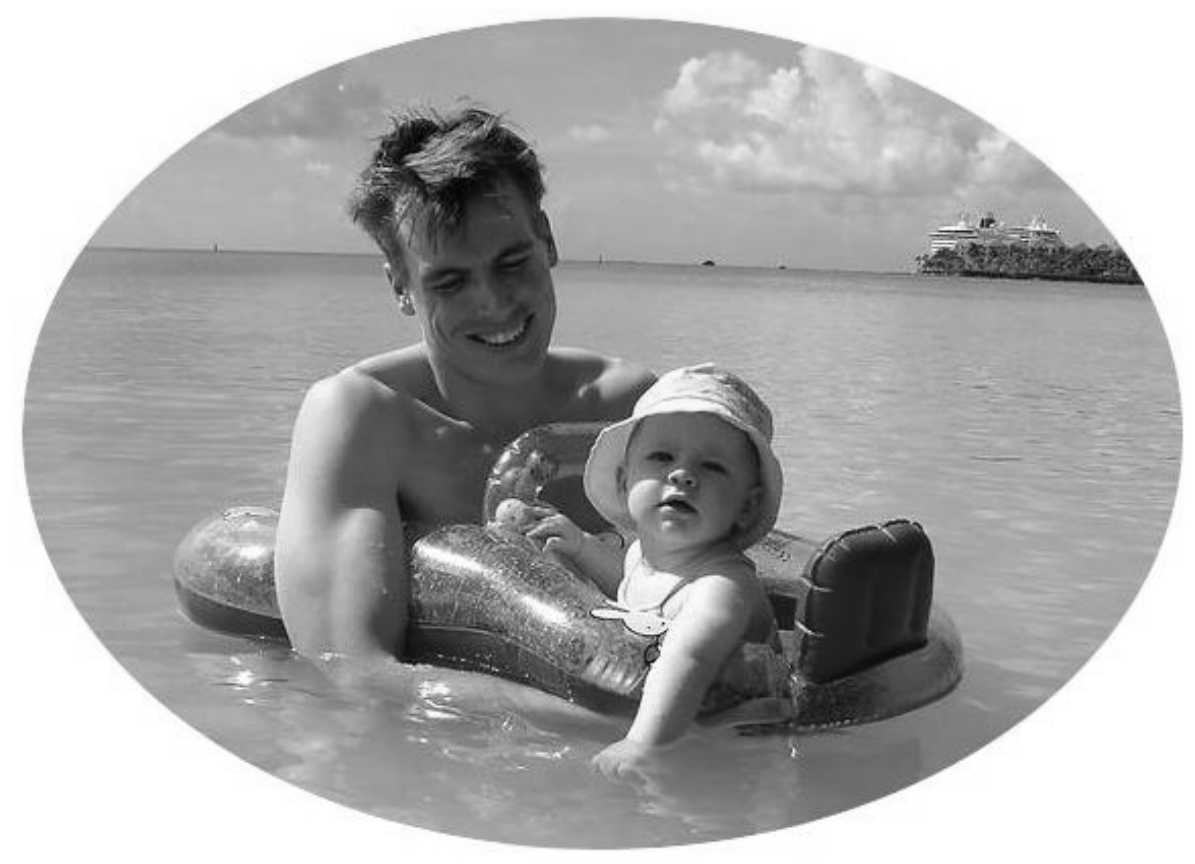


Na ruim vier jaar onderzoek, fifty fifty verdeeld over twee onderzoeksinstituten, en er meer dan $250.000 \mathrm{~km}$ voor afgelegd te hebben ligt hier dan het proefschrift waar het allemaal om ging. Dit proefschrift is niet alleen het eindpunt van mijn promotie traject, maar ook de afsluiting van een leerzame, leuke, van tijd tot tijd hectische, maar bovenal uitdagende periode. Terugblikkend ben ik een groot aantal mensen dank verschuldigd.

Allereerst mijn promotor Henk: voor het schrijven en begeleiden van dit promotieonderzoek. Ondanks je drukke schema en de tussenliggende afstand tijdens mijn periode in Maastricht was het altijd fijn om te weten dat ik indien nodig altijd over jouw kennis en kunde kon beschikken. Ik heb veel bewondering voor je wijze waarop jij zo goed het overzicht kon houden en de rode lijn kon bewaken, hier heb ik veel van geleerd. Bedankt voor het vertrouwen en je wijze woorden!

Janine, ook aan jou heb ik enorm veel te danken, je was net als Henk bij alle publicaties betrokken. Ondanks dat je in korte tijd voor de tweede keer moeder werd, heb ik zelfs tijdens de laatste schrijffase veel aan je gehad. Een welverdiende plaats als copromotor dus!

Léon, dank voor de kans om uit jouw kennis van het Brown Norway model voor voedselallergie te kunnen putten en ook jouw als copromotor te mogen verwelkomen.

Raymond, jouw kritische noot en stimulerende interactie hield mij scherp en heeft de artikelen gepolijst.

André, dank voor jouw commentaar op de stukken, ondanks je verantwoordelijkheden.

Jeroen, voor het microarray artikel heb ik enorm veel te danken aan jou, want zonder jouw hulp, je schat aan bioinformatica kennis en de supersnelle analyses had ik de microarray data nooit zo snel kunnen uitwerken en publiceren.

Kirsten, bedankt voor je kritische blik over het microarray artikel en het doorgeven van je handige verzendlijst voor de distributie van het proefschrift, succes met je carrièreswitch van onderzoekster naar lerares.

Ex-collega's. Eerst bij de afdeling TOX op het RIVM en later bij de afdeling GRAT op de Universiteit Maastricht was de hulpvaardigheid en collegialiteit van iedereen steeds een enorme steun in de rug. TOX - Met name Arja: enorm betrokken bij zowel het lab werk als op persoonlijk vlak. Dankjewel! Eric en Bert waren naast een 
steun bij de grootschalige experimenten ook een bron van humor en plezier. Dat doorbrak de sleur! Moeder Selva, voor korte tijd mijn kamergenootje op het RIVM, helaas van korte duur maar nu kom ik je in het Mestreechse toch weer tegen tijdens het doen van de boodschappen. Maar ook Henny, Liset en Yvonne: bedankt voor jullie hulp waar nodig. Verder veel dank aan het duo Hans en Piet, afgewisseld met Christine, voor de hulp bij de secties en Ruud voor zijn rol in de huisvesting en fok van de ratten. Geen lab zoals het GRAT-lab: met name de hulp van Marcel als assistent gedurende de secties en zowel Marcel als Ralph voor de introductie in de wereld van de microarrays. Onze super secretaresse Marie-Claire, bedankt voor je warme betrokkenheid en het assisteren of uitvoeren van allerlei hand en spandiensten.

Een warm gevoel houd ik ook over aan mijn ex-kamergenootjes Pim, Joep en later Kevin. Jullie hebben veel bijgedragen aan de gezelligheid van de laatste twee jaar van mijn project. Bedankt voor de inhoudelijke conversaties en de lol, binnen en buiten werktijden, een welkome afwisseling tijdens het onderzoek en het typen. Ook dank aan alle anderen die op GRAT aan de uitstekende sfeer bijdroegen, en de enorm gezellige "Mestreechse" PhD-groep. Jullie zijn geweldig!

Daarnaast wil ik zeker ook mijn collega's van BioMedbooster (Jasper, Inge, Erik, Hera, Lia; maar zeker ook Rene, Paul en Winand) bedanken voor de stimulerende, enorm leuke, interactieve werksfeer, gezelligheid, teamspirit en de belangstelling voor en de ondersteuning van mijn promotie.

Applaus ook voor mijn studenten die stuk voor stuk een belangrijke bijdrage hebben geleverd: Jennie (alle begin is moeilijk, maar een goed begin is het halve werk!), Milanthy (salsa-dansende dokter-wannabe), Renske (project-hopper) en Joke (ingetogen potentieel). Bedankt voor de gezellige tijd, het was een genoegen om jullie te begeleiden! En in het geval van Joke: veel succes met het traject naar je eigen PhD.

De docenten en de medestudenten tijdens de opleiding tot toxicoloog boden een welkome verdiepingsslag door het combineren van kennisuitwisseling met netwerken.

Vanzelfsprekend wil ik ook de Voedsel en Waren autoriteit bedanken voor het financieel faciliteren van dit project. Ook de leden van the Immunotoxicology and Chemical Allergy Speciality Section en the Centre of Food Allergy ben ik dank verontschuldigd voor stimulerende discussies en het inhoudelijke commentaar op mijn presentaties. 
Nu ook een woord van dank aan al mijn vrienden, bekenden en familieleden die de afgelopen jaren met me mee hebben geleefd. Enkelen zal ik specifiek noemen.

Germaïn, Nataly en de kleine Trixton: vrienden door dik en dun. Al zitten jullie nu in Aruba, in mijn hart en tijdens mijn vakantie(s?) zijn jullie altijd dichtbij!

Dave en Milevis: bedankt voor het altijd meedenken, de gezelligheid en de relativerende gesprekken.

Robbert, ik ken je nu al 17 jaar, wat vliegt de tijd!: gezellige lunches en medeliefhebber van het wat rapper vervoer.

Damiën, studiegenootje, vriend, medepromovendus en nu paranimf naast mij. Ook voor jou ligt binnen no-time een prachtige promotie in het verschiet.

'Ome' Ron en 'tante' Rita, bedankt voor het hele jaar dat ik doordeweeks op jullie riante zolderkamer mocht verblijven om het eerste jaar van dit project onderzoek te verrichten!

Jeroen S., spraakwaterval, beste vriend van Don, maar ook ik geniet van onze vriendschap.

Chris, ken jou nog niet zo lang als de rest maar wel direct een leuke "click", "No man can be condemned for owning a dog. As long as he has a dog, he has a friend; and the poorer he gets, the better friend he has".

Ten slotte wil ik de mensen bedanken die er echt altijd voor mij zijn.

Mijn broer Donovan, van jongs af aan al de beste maatjes. Fijn om iemand te hebben die je door en door kent en waarmee het uitstekend relativeren, vernieuwen en lol beleven is. Het is ook niet voor niets dat ik jou als paranimf op het erepodium naast mij wil. Geen betere kandidaat om mijn rug te dekken, en vice versa. Op naar vele nieuwe avonturen: "The world is ours!".

Zoveel warmte en liefde in een gezinnetje, altijd en voor iedereen gezellig, een thuishaven van rust in alle hectiek, zoveel steun en vertrouwen: Lieve Dick en Hilly, jullie zijn geweldig! Lieve mam, regelaar van alles, spil van la familia, zo zie je maar wat er van dat straatschoffie is geworden. Pap, jouw humor, creatieve "drive", onvoorwaardelijke steun en heerlijk nuchtere relativering zijn doorgekomen, reken maar. Beiden, nogmaals bedankt voor de genoten opvoeding, de oneindige steun en het heerlijke familiegevoel, dat nu alweer de volgende generatie ingaat met jullie als opa en oma.

Ook mijn schoonouders, Wim en Annie, en mijn schoonbroer Shane, jullie hebben een en ander ook van zeer dichtbij mogen meemaken. Vooral tijdens de tijd dat wij noodgedwongen bij jullie terecht konden voor een tijdelijk adres zodat Arlene kon blijven werken in Rotterdam en ik in Bilthoven. Ik heb het gevoel dat ik een tweede 
gezin erbij heb gekregen. En dat voor maar drie (pluche) kamelen . . . . . . Over valorisatie gesproken. :)

Save the best for last: mijn lieve vrouw Arlene, mijn allergrootste steun en toeverlaat. Idioot hoeveel er alleen al in deze promotieperiode met ons (inmiddels gezinnetje) is gebeurd: getrouwd, tweemaal verhuist, tweemaal zwanger, nu al een prachtig dochtertje en een zoontje op komst! Veel van mijn tijd en energie zijn de laatste jaren in de aanloop van het nu voor je liggende boekje gaan zitten, de hoogste tijd dus om vanaf nu een en ander in te gaan halen. "Buckle up!, and enjoy the ride".

J. \& A.?, JA!

En als aller-allerlaatste jullie: Nikita en Anakin, heerlijke rolmopsjes, kleine J. \& A. recombinanten, jullie atopische predispositie hebben jullie van beide ouders meegekregen, toch zal het nog wel heel wat tijd vergen voordat zelfs jullie wijsneusjes dit kunnen begrijpen. Maar aan de andere kant, de vooruitgang van de wetenschap gaat zo snel, wie weet? Aan jullie draag ik dit proefschrift dan ook op.

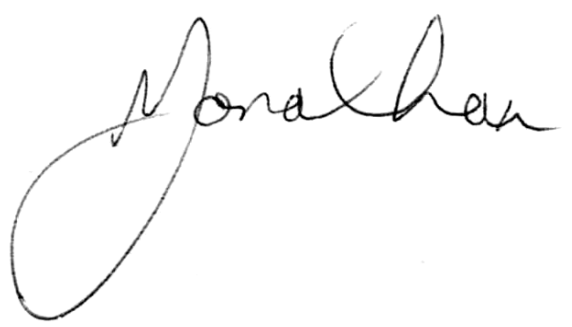



Curriculum vitae 
Jonathan Dennis de Jonge werd op 27 februari 1979 geboren te Rotterdam. In 1997 behaalde hij het Atheneum aan de Serviam scholengemeenschap (tegenwoordig de Trevianum scholengroep) te Sittard. Aansluitend studeerde hij Gezondheidswetenschappen aan de Universiteit Maastricht, met als afstudeerrichting Milieugezondheidkunde. Zijn afstudeerstage vond plaats bij de afdeling Gezondheidsrisico Analyse en Toxicologie (GRAT) van de Universiteit Maastricht, waarna in 2002 het doctorale diploma werd behaald. Aansluitend was Jonathan aangesteld als junior onderzoeker op verscheidene projecten bij de afdeling GRAT, totdat hij van december 2003 tot december 2007 werd aangesteld als promovendus bij deze afdeling. Zijn promotieonderzoek, dat is beschreven in dit proefschrift, betrof een samenwerking met de afdeling Toxicologie, Pathologie en Genetica (TOX) van het Rijksinstituut voor Volksgezondheid en Milieu (RIVM) te Bilthoven, alwaar de eerste twee jaar van het onderzoek zijn uitgevoerd. Tijdens deze aanstelling werden de certificaten 'Stralingshygiëne, deskundigheidsniveau $5 b$ ' en 'Proefdierkunde op grond van artikel 9 van de Wet op de Dierproeven' behaald, en werd de Postdoctorale Opleiding Toxicologie (POT) gevolgd ten behoeve van registratie als toxicoloog bij de Nederlandse Vereniging voor Toxicologie (NVT). Sinds mei 2008 is Jonathan werkzaam als Manager Technology Transfer bij BioMedbooster en houdt zich in deze hoedanigheid bezig in het commercialiseren van nieuwe kennis door middel van licentie transacties of middels het opstarten van nieuwe bedrijven. Vanaf mei 2009 is Jonathan begonnen aan een door de Nederlandse Biotechnologie Associatie (NIABA) en De Baak Management Centrum VNO verzorgde postdoctorale Masterclass opleiding in BioBusiness.

Jonathan Dennis de Jonge was born on February $27^{\text {th }}$ in Rotterdam. He graduated from his secondary education at the Serviam College in Sittard in 1997. In the same year he started studying Health Sciences at Maastricht University, with a specialization in Environmental Health Sciences. After an internship at the department of Health Risk Analysis and Toxicology (GRAT) of the University Maastricht, he received his master degree in 2002. After which Jonathan was a junior researcher on various projects at the department of GRAT, until he was appointed as a PhD student at this department from December 2003 until December 2007. The research, conducted in these years and presented in this thesis, occurred within a cooperation framework with the Laboratory for Toxicology, Pathology and Genetics (TOX) at the National Institute for Public Health and the Environment (RIVM) in Bilthoven, at which the first two years of the research took place. During this research period, Jonathan obtained licenses for working with laboratory animals (according to article 9 of the Dutch law on experimental animals) and with radioactive material (competence level $5 b$, as accredited by the Dutch government). In addition, a Postgraduate Education in Toxicology (PET) was completed resulting in the registration as a toxicologist by the Netherlands Society of Toxicology (NVT). As of May 2008, Jonathan has been working as a Manager Technology Transfer at BioMedbooster, in this function he commercializes new ideas through either licensing deals or new start-up ventures. As of May 2009 Jonathan has started his post-graduate degree Masterclass program in BioBusiness, as presented by the Netherlands Biotechnology Association (NIABA) and De Baak Management Centrum VNO. 


\section{LIST OF PUBLICATIONS}

\section{PEER-REVIEWED FULL PAPERS}

1. de Jonge, J. D., L. Knippels, J. Ezendam, J. Odink, A. H. Penninks, and H. van Loveren. 2007. The importance of dietary control in the development of a peanut allergy model in Brown Norway rats. Methods 41:99.

2. de Jonge, J. D., J. Ezendam, L. M. J. Knippels, J. Odink, M. S. Pourier, A. H. Penninks, R. Pieters, and H. van Loveren. 2007. Bis(tributyltin)oxide (TBTO) decreases the food allergic response against peanut and ovalbumin in Brown Norway rats. Toxicology 239:68.

3. de Jonge, J. D., J. Ezendam, L. M. J. Knippels, A. H. Penninks, R. Pieters, and H. Van Loveren. 2008. Lactobacillus casei Shirota does not decrease the food allergic response to peanut extract in Brown Norway rats. Toxicology 249:140.

4. de Jonge, J. D., J. L. A. Pennings, K. A. Baken, J. Konings, J. Ezendam, and H. Van Loveren. 2008. Gene expression changes in the mesenteric lymph nodes of rats after oral peanut extract exposure. J Immunotoxicol 5:385.

\section{CONTIBUTION TO BOOKS}

1. de Jonge, J. D., Ezendam, J., and Van Loveren, H. (2009). Chapter 21: Food Allergy. In: Advanced Food Toxicology (Wageningen, The Netherlands, Wageningen Academic Publishers). 


\section{PRESENTATIONS}

1. De Jonge, J.D., van Loveren, H. The influence of immunomodulating food constituents on food allergic processes. Current Research 2005; the $5^{\text {th }}$ presentation of ongoing research work by the Graduate School VLAG.

2. De Jonge, J.D., Knippels, L.M.J., Penninks, A.H., Pieters, R., Ezendam, J, van Loveren, $\mathrm{H}$. The influence of immunomodulating food constituents on food allergic processes: focusing on Lactobacillus casei Shirota. Annual PhD student meeting of the Netherlands Society of Toxicology (NVT), Wageningen, The Netherlands, June 2006.

3. De Jonge, J.D., van Loveren, H. The influence of immunomodulating compounds on the food allergic process. $3^{\text {rd }}$ Research in Progress Meeting of the EUROTOX Immunotoxicology and Chemical Allergy Speciality Section (ITCASS), Lodi, Italy, September 2006.

4. De Jonge, J.D., Knippels, L.M.J., Penninks, A.H., Pieters, R., Ezendam, J, van Loveren, $\mathrm{H}$. The influence of immunomodulating food constituents on food allergic processes. Utrecht Center for Food Allergy (CFA), Soesterberg, The Netherlands, November 2006.

5. De Jonge, J.D., Knippels, L.M.J., Penninks, A.H., Pieters, R., Ezendam, J, van Loveren, $\mathrm{H}$. The influence of immunomodulating food constituents on allergic sensitization in Brown Norway rats. Utrecht Center for Food Allergy (CFA), Soesterberg, The Netherlands, November 2006.

6. De Jonge, J.D., Ezendam, J, Knippels, L.M.J., Penninks, A.H., Pieters, R., van Loveren, $\mathrm{H}$. The influence of immunomodulating food constituents on foodallergic processes. $2^{\text {nd }}$ International Symposium on Molecular Allergology (ISMA); allergens: from identification to therapy, Rome, Italy, April 2007.

7. De Jonge, J.D., Pennings, J.L.A., Ezendam, J, Baken, K.A., van Loveren, H. Preliminary communication: gene expression profiles as early markers for allergic sensitization. $4^{\text {th }}$ Work in Progress Meeting of the Netherlands Toxicogenomics Centre (NTC), Wageningen, The Netherlands, June 2007.

8. De Jonge, J.D., Ezendam, J, Pennings, J.L.A., Knippels, L.M.J., Penninks, A.H., Pieters, R., van Loveren, H. A BN rat model for food allergy: the influence of route of exposure, diet and immuno-modulating food constituents on food allergic processes. \& Preliminary communication: Gene expression profiles as early markers for food allergic sensitization. Utrecht Center for Food Allergy (CFA), Utrecht, The Netherlands, October 2007. 